3814

\title{
The Use of \\ Compensatory Strategies \\ by Dutch Learners of \\ of English
}

Nanda Poulisse 

The Use of Compensatory Strategies by Dutch Learners of English 
(c) 1989 by the author

All rights reserved. No part of this publication may be reproduced or transmitted in any form or by any means, electronic or mechanical, including photocopy, recording, or any information storage and retrieval system, without written permission from the author.

ISBN 90-9002869-2

Typographical layout by Wolter Jansen, K.U. Nijmegen

Printed in The Netherlands by Sneldruk, Enschede 


\section{The Use of Compensatory Strategies by Dutch Learners of English}

een wetenschappelijke proeve op het gebied van de Letteren

\section{Proefschrift}

ter verkrijging van de graad van doctor aan

de Katholieke Universiteit te Nijmegen, volgens besluit van het college van decanen in het openbaar te verdedigen op

dinsdag 27 juni 1989

des namiddags te 1.30 uur precies

$$
\text { door }
$$

Wijnanda Maria Poulisse

geboren op 11 augustus 1958 te Kerkdriel 
Promotores: Prof. Dr T.J.M. van Els

Prof. Dr F.G.A.M. Aarts

Co-referenten: Dr Th.C.G. Bongaerts

Dr E. Kellerman 


\section{Contents}

Preface

ix

1 Introduction 1

1.1 Research on second language acquisition 2

1.2 Two fundamental issues 6

1.2.1 Language use and language leaming 7

1.2.2 Communication strategies in the $\mathrm{L} 1$ and the $\mathrm{L} 2$

$\begin{array}{lr}1.3 \text { The Nijmegen project } & 10\end{array}$

1.4 The contents of this thesis 13

2 A Survey of the Literature: Definitions and Taxonomies 16

$\begin{array}{ll}2.1 \text { Definitions } & 16\end{array}$

2.2 Taxonomies 22

2.2.1 Tarone (1977) 22

2.2.2 Færch \& Kasper (1980) 23

2.2.3 Practical problems related to traditional taxonomies 25

2.2.4 Theoretical problems related to traditional taxonomies 28

$\begin{array}{lll}2.3 \text { Conclusion } & 30\end{array}$

3 A Survey of the Literature: Empirical Research 33

3.1 Empirical research on communication strategies to date 33

3.2 Referential communication studies 42

3.3 Conclusion 50

4 Compensatory Strategies and Communication 53

4.1 A model of communication 53

4.2 Communication and compensatory strategies 57

4.3 A taxonomy of compensatory strategy use 58

4.3.1 'Conceptual Strategies' 58

4.3.2 'Linguistic Strategies' 60

4.3.3 Interaction of 'Conceptual' and 'Linguistic Strategies' 61

4.4 'Conceptual' and 'Linguistic Strategies' in terms of Levelt's model 61

4.5 Communication: general principles and constraints 64

4.5.1 The cooperative principle 64

4.5.2 The role of mutual knowledge 66

4.5.3 Constraints on communication 68

$\begin{array}{ll}4.6 \text { Conclusion } & 69\end{array}$ 
5.2.1 Years of tuition in English

5.2.2 School-report marks and exam marks $\quad 74$

$\begin{array}{ll}\text { 5.2.3 Teacher judgements } & 74\end{array}$

5.2.4 Scores on a gencral language proficiency test 75

5.3 Tasks used in the experiment 77

5.3.1 The concrete picture description task (task I) 78

$\begin{array}{ll}\text { 5.3.2 The oral interview (task IV) } & 79\end{array}$

5.3.3 The story retell task (task III) $\quad 80$

5.3.4 The abstract picture description task (task II) 82

$\begin{array}{lll}5.4 & \text { Retrospective tasks } & 83\end{array}$

5.5 The experimentation $\quad 84$

5.6 Processing of the data $\quad 86$

6 The Identification of Compensatory Strategies 88

6.1 The criteria and the identification procedure adopted in the 88

Nijmegen project

6.2 Identification on the basis of problem indicators in the data 90

6.2.1 The use of problem indicators 90

$\begin{array}{ll}\text { 6.2.2 Instructions } & 92\end{array}$

6.2.3 The correspondence between the two judges 93

6.3 Identification on the basis of retrospective comments 94

6.3.1 The reliability of retrospective data 94

6.3.2 The influence of "researcher bias" 95

6.3.3 The usefulness of retrospective data 98

6.4 A quantitative comparison of two methods of identification 101

$\begin{array}{ll}6.5 \text { Conclusion } & 104\end{array}$

7 The Classification of Compensatory Strategies 107

$\begin{array}{lll}7.1 & \text { The coding system } & 107\end{array}$

$\begin{array}{ll}7.2 & \text { The applicability of the coding system } 110\end{array}$

$\begin{array}{lll}7.3 \text { Conclusion } & 112\end{array}$

8 The Use of Compensatory Strategies in Tasks I, III and IV 114

8.1 A quantitative analysis of the data 114

8.1.1 The number of compensatory strategies used 115

8.1.2 Analysis of compensatory strategy types: frequencies 117

8.1.3 Analysis of compensatory strategy types in terms of ANOVA

8.1.4 A visualization of the results: correspondence analysis 122

8.2 A qualitative analysis of the data 
8.2.1 The use of compensatory strategies in the picture description task (task I)

8.2.2 The use of compensatory strategies in the story retell task (task III)

8.2.3 The use of compensatory strategies in the interview (task IV)

8.2.4 Individual differences

8.3 Discussion

8.3.1 Proficiency-level effects

8.3.2 Task effects

8.3.3 Differences between super- and subordinate compensatory strategies

8.3.4 Individual differences

8.4 Conclusion

9 A Comparison of Referential Strategies in L1 and L2 153

9.1 Method

9.2 Hypotheses 154

9.3 Some procedural information $\quad 157$

$\begin{array}{lll}9.4 \text { Results } & 159\end{array}$

9.4.1 A general overview of strategy use in Dutch and English 160

9.4.2 Identical strategies versus shifts 161

9.4.3 Time and number of words 165

$\begin{array}{lll}9.5 & \text { Discussion and conclusion } & 166\end{array}$

10 The Effectiveness of Compensatory Strategies 170

10.1 Research to date $\quad 170$

10.2 Some pilot studies $\quad 172$

10.3 The York study of effectiveness 176

$\begin{array}{ll}\text { 10.3.1 Method } & 176\end{array}$

10.3.2 Subjects $\quad 176$

10.3.3 Results of the guessing task and the pseudo-cloze task 177

10.3.4 Two experimental tasks compared 179

10.4 Conclusion $\quad 181$

11 Conclusion 183

11.1 Evaluation of the experimental design 183

$\begin{array}{ll}11.2 \text { Some theoretical considerations } & 185\end{array}$

11.3 General discussion of the results 188

11.4 Implications of the Nijmegen project 190

$\begin{array}{ll}\text { 11.4.1 Second language use } & 190\end{array}$

11.4.2 Foreign language pedagogy $\quad 190$

11.5 Suggestions for further research 193 
Appendices $\quad 206$

Appendix I The abstract figures used in task II (from Krauss \& 206 Weinheimer, 1964)

Appendix II Instructions to tasks I, II, III and IV 207

Appendix III The stories and the pictures used in task III 209

Appendix IV Method of transcription $\quad 212$

Appendix $\mathrm{V}$ The relative use of each $\mathrm{CpS}$ type per task and per group 214

Appendix VI The York experiments (instructions, samples of the tasks, list of compensatory strategies) 216

Summaries

222

Curriculum Vitae

228 


\section{Preface}

This thesis reports the results of a four-year research project on the use of compensatory strategies by Dutch learners of English. The project was financed by the Research Pool of the University of Nijmegen (u.o.p. project L5/83) and was carried out at the Department of Applied Linguistics. It was run from November 1983 until November 1987.

I would like to thank all those who have helped me with the project and while writing this thesis: Wolter Jansen for his expert assistance with the layout; Eugene van Lccuwen and his colleagues from the Elshof College in Nijmegen for their help in the selection of VWO pupils; Adri Elsen, Ema van Hest, Mart van der Poel, Pieter Reintjes and Rijk Willemsen for their contributions to the project as student assistants; Geraldine Hargrave for conducting the interviews; Rob Schreuder, Director of the Interfaculty Research Unit for Language and Speech (IWTS), for his advice on psycholinguistic matters; Prof. Dr. W. Levelt and Herbert Schriefers, both of the Max Planck Institut für Psycholinguistik, for their comments on chapter 4; and Erik Schils for his invaluable assistance with the statistical analyses.

Many people at many conferences have, probably unknowingly, kept my spirits up. I am particularly grateful to the late Claus Farch and to Gabi Kasper (University of Hawaii), whose interest in the project from an early stage onwards has not only been beneficial to the project, but also very encouraging to me personally. As far as encouragement goes, I also owe a great deal to the staff of the Department of Applied Linguistics, who provided me with a most peaceful room in their stimulating Department for more than a year after the project had been finished, and to Adriènne Poulisse and Thea Steeghs, who lent moral support when it was needed most.

Unfortunately, the two people who have contributed most to this thesis cannot be mentioned here because of our University's regulations. I thank them most heartily anyway! 



\section{Introduction}

When second and foreign language learners (henceforth $\mathrm{L} 2$ learners) attempt to communicate in the $\mathrm{L} 2$, they are often confronted with linguistic problems resulting from an inadequate command of that language. Although this occasionally leads to a breakdown in communication, L2 learners generally manage to overcome their problems by employing what are known as Communication Strategies (CmS). It seems that two basic options present themselves to L2 learners in this situation. Either they dispense with the original communicative goal, or they try and reach it via altemative plans, making use of the limited linguistic means they have at their disposal. In the following two extracts both approaches are illustrated. ${ }^{1}$

1) I: ... you you fry the cabbages and carrots or what do you do?

S: no you just erm, cook them, but they have to erm, uh they have not, they they just uh, I'm sorry, uh you cook them, and then erm, you just serve them on a plate, and that's it (crisp; 113t4)

2) I: $\mathrm{mm}$, where were you last summer?

S: erm 1 in erm 2 Oostenrijk (=Austria) <laughs>, erm, a country uh, near uh Switzerland 1 with uh mountains, too

I: $\mathbf{m m}$

S: with snow (Austria; 303t4)

The L2 leamer in the first extract tries to tell the interlocutor (a native spcaker of English) that the vegetables have to be crisp, but she ${ }^{2}$ gives up after three unsuccessful attempts and continues with the conversation. Conversely, the L2 learner in the second extract holds on to his original communicative goal. He first tries to reach it by using the Dutch word 'Oostenrijk', and then by giving a description of the country. In the literature on $\mathrm{CmS}$, the strategies employed by the leamers in extracts 1 and 2 have been referred to as Reduction Strategies and Compensatory Strategies respectively (Færch \& Kasper, 1980; 1983b; 1984; cf. also Tarone, 1977 and Corder, 1978 for similar distinctions).

Both 'Reduction Strategies' and 'Compensatory Strategies' (CpS) are aimed at maintaining communication (hence the term 'Communication Strategies'), but whereas one could say that with 'Reduction Strategies' the solution is based on omission, with 'Compensatory Strategies' the solution is clearly based on commission.

Since $1973 \mathrm{CmS}$ have been the focus of increasing interest (see the collection of articles in Færch \& Kasper, 1983a; and the overview given in chapters 2 and

$3)^{3}$ Most of the initial studies were directed at defining $\mathrm{CmS}$ and developing taxonomies that could be used to classify them (see e.g. Tarone, Cohen \& Dumas, 1976; Tarone, 1977; Corder, 1978; Fxrch \& Kasper, 1980). The data 
presented in these studies were generally used to illustrate the definitions of different $\mathrm{CmS}$ types, but there were hardly any attempts at analysing them systematically.

Later, a number of empirical studies were conducted in which answers were sought to questions conceming the relationship between $\mathrm{CmS}$ use and learner characteristics such as L2 proficiency level, L1 background and personality (see e.g. Tarone, 1977; Palmberg, 1979; Bialystok \& Fröhlich, 1980; Haastrup $\&$ Phillipson, 1983). Besides, there were some attempts to establish the comprehensibility and the effectiveness of L2 leamers' CmS (see Ervin, 1979; Bialystok \& Froblich, 1980; Bialystok, 1983). The majority of these studies, however, were exploratory and fairly small-scale. They did not allow quantitative analyses of $\mathrm{CmS}$ use, so that the conclusions that could be drawn from them were necessarily tentative.

The present thesis reports the results of a four-year project on the use of $\mathrm{CpS}$ that does allow quantitative analyses. To make this possible a 110,000 word corpus of leamer language data was compiled, after which the $\mathrm{CpS}$ in this corpus were investigated. The subjects who participated in the project were 45 Dutch learners of English at three different proficiency levels. They performed four different tasks, so that the corpus is not only large, but also sufficiently varied to warrant generalizable conclusions.

Towards the end of the present chapter the project (from now on 'the Nijmegen project') will be described in more detail (see also chapter 5). First, however, some general background information will need to be given. To begin with it will be shown how the study of $\mathrm{CmS}$ was promoted by certain developments in second language acquisition research and foreign language pedagogy (section 1.1). Subsequently, in section 1.2, there will be a discussion of two issues which are fundamental to the study reported here: (1) the distinction between studies of second language acquisition and studies of second language use - it will be argued that the study of $\mathrm{CmS}$ belongs primarily to the latter category - and (2) the fact that CmS use is not specific to L2 communication - it will be contended that the ability to use $\mathrm{CmS}$ constitutes part of both L1 and L2 speakers' communicative competence, and hence that $\mathrm{CmS}$ are used in L1 and L2 speech alike. It will appear that our position with respect to these issues has had certain implications for the theoretical framework in which the present study of $\mathrm{CpS}$ is embedded. At the very end of this chapter, after the outline of the Nijmegen project (section 1.3), there will be a description of the organization of this thesis (section 1.4).

\subsection{Research on second language acquisition}

When Corder (1967) pointed out the significance of learners' errors, he set the stage for a new direction in second language acquisition (SLA) research Until 
then the Contrastive Analysis Hypothesis (CAH) had dominated the field. This hypothesis was firmly rooted in behaviourism, which viewed language leaming as a series of habits to be developed through practice and reinforcement. Since it was assumed that the old habits of the L1 would get in the way of the new habits of the L2, differences between languages were expected to lead to problems (and hence errors). Ultimately, the aim of protagonists of the CAH was to provide teachers with materials that would enable them to prevent and eradicate their leamers' errors. For this reason the identification of problem areas was of primary importance, which explains why CA research focussed on the description of linguistic differences between languages (see the overview in Van Els, Bongaerts, Extra, Van Os \& Janssen-Van Dieten, 1984:45). The leamer himself played no role in this research: the $L 1$ was regarded as the sole source of all errors.

Towards the end of the 1960s CA started losing ground (cf. the contributions in Alatis, 1968). One of the major reasons for this decline was empirical. Research had raised serious doubts concerning the influence of the L1 on the L2 learning process, and hence concerning the ability of CA to predict errors. Analyses of $\mathrm{L} 2$ learners' errors indicated that $\mathrm{L} 1$ interference was by no means the only cause of errors (e.g. Richards, 1971; George, 1972; Dulay \& Burt 1972; 1973; 1974a). As Dulay \& Burt (1973) pointed out, a large proportion of L2 leamers' errors could be explained as developmental errors, that is, they were similar to errors made by children acquiring the language in question as L1. Other errors were shown to be 'unique' and appeared to be neither developmental nor the result of $\mathrm{L} 1$ interference.

In addition, the results of the 'morpheme' studies suggested that leamers from different $L 1$ backgrounds went through similar developmental processes. There were hardly any differences in the order in which they acquired (or rather, accurately used) various morphosyntactic elements. This appeared to be so both for children (Dulay \& Burt, 1973; 1974b) and adults learning the L2 (Bailey, Madden \& Krashen, 1974).

The predominance of developmental errors and the similarities across leamers from different language backgrounds led to the view that $\mathrm{L} 2$ leaming takes place in much the same way as L1 acquisition. Since this view of L2 learning precludes the influence of the L1, contrastive studies of the L1 and the L2 were no longer considered useful. ${ }^{4}$

The second reason for the decline of CA is theoretical. Chomsky (1959) had attacked behaviourist theories of language learning. He rejected the concept of 'imitation' because it cannot account for the creativity of language: human beings produce and understand sentences they have never heard before. He also rejected the concept of 'reinforcement' on the ground that parents seldom correct their children's formal errors or reward correct utterances. Instead, Chomsky (1965) proposed a mentalist theory of leaming in which the child itself plays a central role. He assumed that children are born with a language 
faculty, or Language Acquisition Device, that enables them to formulate hypotheses about the language to be acquired, provided they are exposed to a sufficient amount of linguistic input. Essential in this theory is the assumption made by Chomsky that all languages are structured according to a set of universal principles. It is the child's innate knowledge of these principles which constrains the hypotheses it comes up with, and thus enables it to acquire the language fast and easily.

Chomsky's theory of language learning was developed with respect to L1 acquisition and Chomsky himself never extended it to L2 leaming. Even so, it has had its effect on L2 learning theories (for a recent discussion see Cook, $1985 ; 1988)$. One of the points that drew the attention in the 1960 s was that language learning could not be explained in terms of habit-formation. This meant that the then current behaviouristic view that $L 1$ habits interfere with the new habits of the $\mathrm{L} 2$ became untenable. Consequently, differences between languages were no longer considered relevant to the learning of an $\mathbf{L} 2$.

It was at this time, when the utility of CA was challenged, that Corder published his seminal article on the significance of leamers' errors (Corder, 1967). It brought about a considerable change in SLA research, mainly because it changed the prevalent attitude towards errors. Whereas they had hitherto been considered as something negative, to be avoided at all cost, there was now an increasing tendency to view them as a necessary part of language learning, resulting from the learners' need to test their hypotheses about the language. Moreover, there was a growing awareness among researchers that systematic errors could provide important information about the leamers' transitional competence (Corder's term) as well as the L2 leaming process.

As a result, research on SLA became more process-oriented. This approach is best illustrated by Selinker (1972), who discussed five processes that in his opinion were central to second language learning. They were language transfer, transfer of training, strategies of $L 2$ learning, strategies of $L 2$ communication and overgeneralization of target language linguistic material. Each of these processes was held responsible for certain errors that characterize the leamers' linguistic system, or interlanguage (IL) as Selinker calls it (see also Selinker, 1969, for the introduction of this term).

The interest in the language leaming process that developed as a result of Corder's (1967) article assigned a new role to studies of Error Analysis (EA). Until the carly 1970s EA had been descriptive in nature. It mostly consisted in listing common errors which were then classified according to linguistic regularities. As with CA, the goals of this traditional kind of EA were primarily pedagogical. After Corder's article, however, the explanation of errors became much more important than their description. Studies which illustrate this development can be found in Richards (1974). 
Van Els et al. (1984) point out that this kind of explanatory EA also had its limitations. Their most fundamental criticism concems the fact that it provides an incomplete picture of the language leaming process. One reason for this is that EA exclusively deals with errors and neglects non-erroneous language learning phenomena such as avoidance. A second reason is that generally only one stage of the learning process is captured, so that it is impossible to deal with developmental aspects. ${ }^{5}$ These limitations, Van Els et al. note, caused a shift of interest from EA to Performance Analysis (PA).

Unlike EA, PA considers all of the leamer's performance as relevant data; that is, both correct and erroneous utterances are taken into account. By adopting either a longitudinal or a quasi-longitudinal design (i.e. a cross-sectional design containing subjects of different proficiency levels), researchers managed to include developmental aspects of language learning in their studies. The reader compiled by Hatch (1978) contains many examples of PA studies. Other PA studies are discussed in Van Els et al. (1984: chapter 5).

An important development to be noted here is that performance features such as slips of the tongue or pen, self-corrections, and, in oral language production, intonation and temporal variables like speed and pauses, are now beginning to be included in such analyses (cf. Dechert \& Raupach, 1980; Dechert, Möhle \& Raupach, 1984). As Færch \& Kasper (1987b: 8) have noted, these features may be indicative of underlying processing mechanisms and can therefore yield valuable information about the organization and processing of linguistic knowledge.

A second point worth mentioning with respect to PA is the shift from the study of isolated words or utterances to that of words and utterances in context. This approach, which is fundamentally discourse analytical, makes it possible to deal with aspects of communication that go beyond sentence level. Examples are the studies of speech acts and conversational rules discussed in Hatch \& Long (1980) and Brown (1987). For a good discussion of discourse in SLA research see Hatch (1983).

The description of SLA research given above is necessarily sketchy (for extensive overviews see e.g. Van Els et al., 1984; Ellis, 1985; McLaughlin, 1987). Still, it brings out certain developments that may account for the present interest in CmS.

Firstly, as behaviourist theories of language leaming gave way to mentalist theories, more emphasis was given to the mental processes at work in the language leamer. As a result, the notion of strategies, to relate input to existing knowledge (Leaming Strategies) and to relate existing knowledge to output (Communication Strategies) (cf. Ellis, 1985: 71) became a relevant research object. 
Secondly, the changed view of errors - from a negative by-product of L2 learning to an important source of information conceming the language learning process - directed the researchers' attention to the processes responsible for these errors. Since CmS had been mentioned by Selinker (1972) as one of five processes central to second language leaming, it is not surprising that this process was one of the research subjects taken up almost immediately afterwards (cf. Váradi, 1973).

Thirdly, it is now commonly accepted that the study of L2 learner language should comprise non-erroneous as well as erroneous data. In most studies of $\mathrm{CmS}$, except some of the very first (e.g. Tarone et al., 1976), the use of $\mathrm{CmS}$ is treated as a characteristic aspect of L2 performance that may result in erroneous, but also in correct language use. Thus, the interest in $\mathrm{CmS}$ reflects the current interest in performance studies as a whole. ${ }^{6}$

Finally, it should be noted that the current tendency to study language in context, although not initiating $\mathrm{CmS}$ research, is apparent in this field too. As Ellis states, researchers have recognized "the importance of using continuous stretches of discourse in order to identify how the leamer negotiates meaning in collaboration with his or her interlocutor" (Ellis, 1985:14).

Theoretical developments in SLA research were not the only reason for the increasing interest in $\mathrm{CmS}$. Research on $\mathrm{CmS}$ has also been stimulated by the rise of communicative approaches to foreign language teaching in the mid 1970s (see e.g. Wilkins, 1975; 1976; Shaw, 1977; Munby, 1978; Widdowson, 1978; Brumfit \& Johnson, 1979). One of the effects of the increased emphasis on communication in the classroom was that grammatical correctness was no longer considered an end in itself and was frequently sacrificed to communicative effectiveness. A more positive attitude towards the use of $\mathrm{CmS}$ was the result. Particularly since teachers have come to realize that leamers cannot possibly be provided with all the linguistic means they may need for future communication, they have begun to encourage learners to use $\mathrm{CmS}$ both inside and outside the foreign language classroom (Littlewood, 1984; Færch \& Kasper, 1986; Willems, 1987). This development has undoubtedly promoted the study of $\mathrm{CmS}$ too, if only because it has made this research topic into one that is "socially relevant".

\subsection{Two fundamental issues}

There are two issues relating to the study of $\mathrm{CmS}$ that need to be discussed at the outset of this thesis, because the position one takes in them has wide-ranging implications for the theoretical framework of a study like the present one. The first of these issues concerns the distinction between studies of L2 leaming and 
L2 use. The second relates to the current practice of treating $\mathrm{CmS}$ use as an L2-specific phenomenon.

\subsection{Language use and language learning}

From the preceding section it will be clear that the study of $\mathrm{CmS}$ emerged from certain developments in SLA research, and was further promoted as a result of the increased emphasis on the development of communicative skills in forcign language pedagogy. This background explains why $\mathrm{CmS}$ have predominantly been studied in connection with $\mathrm{L} 2$ learners. It should be noted, however, that the study of $\mathrm{CmS}$ is primarily a study of language use, not learning. Consider the following characterization of $\mathrm{CmS}$ given by Canale \& Swain (1980:25):

“... strategies that speakers employ to handle breakdowns in communication: for example, how to deal with false starts, hesitations, and other performance factors, how to avoid grammatical forms that have not been mastered fully, how to address strangers when unaware of their social status - in short, how to cope in an authentic communicative situation and how to keep the communicative channel open."

Canale \& Swain regard strategic competence as one of three components constituting communicative competence, the two other components being grammatical competence and sociolinguistic competence. From their description of $\mathrm{CmS}$ it will be clear that the strategic component plays an important role in matters of language use. Of course, this does not mean that developmental aspects of $\mathrm{CmS}$ use cannot be studied at the same time, just as it is possible to study to what extent $\mathrm{CmS}$ use promotes language learning. In the present project, however, the focus will be on people's use of $\mathrm{CmS}$ when dealing with problematic communicative situations. We will, in other words, deal with $\mathrm{CmS}$ as an aspect of communication. Issues conceming the leaming of $\mathrm{CmS}$ will receive much less attention. They will only be dealt with in the sense that the use of $\mathrm{CmS}$ will be studied at different stages of L2 leaming.

At this point it is worth noting that many researchers have considered it important to distinguish between 'Communication Strategies' and 'Leaming Strategies'. Particularly in the early papers on CmS use, this distinction gave rise to considerable confusion. Corder (1978) suggests that this is because in both cases the relevant data are $\mathbb{I L}$ utterances. As he points out, it is not always possible to decide whether an utterance is the result of a 'Learning' or a 'Communication Strategy'. For instance, if an utterance is traceable to the leamer's $L 1$, the learner may have transferred an $L 1$ item, because, on the basis of similarities between the L1 and the L2, he generated the hypothesis that the L1 item might also be part of the L2. In this case he uses the item to test his hypothesis, which makes the utterance the result of a 'Learning Strategy'. However, the same utterance may also be borrowed from the L1 for 
communicative purposes, without any intention on the part of the leamer to incorporate it into his IL system. In that case, Corder says, the utterance is the result of a $\mathrm{CmS}$.

The confusion was further increased by the fact that $\mathrm{CmS}$ may lead to learning. For instance, if the utterance borrowed from the $\mathrm{L} 1$ for communicative purposes proves to be successful, the learner may decide to retain it so that he can use it again when necessary. In that case, one could say, he has learnt this particular utterance. The reverse is also possible. One may learn certain utterances for the sole purpose of communication, e.g. when one memorizes the phrase needed to buy a theatre ticket (Sharwood Smith, 1981). In this case again, it is not clear whether a leaming or a communication strategy ${ }^{7}$ has been used.

In general, researchers have been aware of this interaction and distinguished between the two kinds of strategy on the basis of their function (cf. Corder, 1978; 1981; Tarone, 1981; Palmberg, 1983; Færch \& Kasper, 1983b). To illustrate, Corder defines 'Leaming Strategies' as "the mental processes whereby a leamer creates for himself or discovers a language system underlying the data he is exposed to" and CmS as "the devices whereby he exploits whatever linguistic knowledge he possesses to achieve his communicative ends" (Corder,1981:89). It should be noted that in practice the controversy need not cause problems. When conducting a study of $\mathrm{CmS}$ it is irrelevant whether or not the use of a particular CmS happens to have an additional leaming effect.

\subsubsection{Communication Strategies in the $L 1$ and the $L 2$}

In most of the studies to date $\mathrm{CmS}$ were treated as an L2-specific phenomenon. This is not very surprising, of course, considering that the study of $\mathrm{CmS}$ originated in SLA research. Besides, CmS are much more frequent and therefore more obvious in L2 speech, which makes it easier and more rewarding to study them in this context.

Nevertheless, many researchers have pointed out in passing that $\mathrm{CmS}$ are also used by L1 speakers (e.g. Tarone, 1977; 1981; Trosborg, 1982; Farch \& Kasper, 1983b). Wagner (1983:167) formulated the point quite explicitly:

"... we want to insist on the interrelationship of all communicative behaviour and emphasize the similarity, but also the difference, between the communication of native speakers and that of $\mathbb{L}$ users. The similarity is caused by the fact that all speakers employ strategies when communicating: native speakers also have gaps in their linguistic repertoires, and consequently there are no strategies which are specific for IL users. Normally, however, IL users have to improvise much more than native speakers and create solutions in their verbal plans in an ad hoc manner. This is particularly so in the area of vocabulary." 
A similar point is made by Kellerman, Bongaerts \& Poulisse (1987), who suggest that L2 leamers have the same compensatory capability as native speakers, although they may have additional encoding problems as a result of their reduced linguistic competence (cf. also Bialystok \& Kellerman, 1987). To support their point that native speakers and L2 speakers take recourse to similar strategies Kellerman et al. (1987) draw attention to the following situations:

1. Teachers explaining words and expressions to children (or non-native learners);

2. Experts explaining technical terms to laymen;

3. Native speakers temporarily unable to retrieve a word;

4. Native speakers having to describe some referent for which they do not have a name (perhaps because there does not happen to be one);

5. Native speakers taking part in T.V. quizzes where the object is to enable their partners to guess the word on a card without using the word under severe time constraints;

6. Aphasics compensating for anomia. ${ }^{8}$

In all these situations, they say, as in the case of $\mathrm{L} 2 \mathrm{CmS}$ use, "a name for a particular referent cannot be retrieved, or must be withheld, or is not understood by the listener so that the referent must be labelled, relabelled or described in such a way that it can be recognized by the listener" (p.101).

Parallels can also be drawn between the use of $\mathrm{CpS}$ by $\mathrm{L} 2$ leamers and the construction of lexical innuvations by children faced with lexical gaps, or the mechanisms developed in pidgins to extend a highly restricted lexical inventory. E. Clark (1983a) notes that children who are acquiring their $L 1$ have three options to fill their lexical gaps. They can use Overextensions, such as "ball" for 'doorknob', General Purpose Words, like "that" or "thing", and Word Coinages, such as "to needle" for 'mend', "a fixer" for 'tool' and "a plantman" for 'gardener' (see also E. Clark, 1981; 1983b). With respect to pidgins, Mühlhäusler (1986:171ff.) discusses mechanisms of lexical expansion such as the use of syntactic paraphrases and circumlocutions (e.g. "lahi gabua gauna", which is Hiri Motu for 'match', literally: fire bum thing); and the use of a general verb such as 'to make' in combination with a noun (e.g. Tok Pisin "mekin hos", literally: to make horse, meaning 'to saddle'). In both cases the strategies which are used to overcome lexical shortcomings are very similar to the $\mathrm{CmS}$ used by $\mathrm{L} 2$ leamers.

In addition to child language, pidgins, and adult native speakers addressing children or foreigners, Blum-Kulka \& Levenston (1983) mention two other linguistic contexts in which people have to make do with an impoverished vocabulary. They are simplified reading texts prepared by native speakers for the use of $\mathrm{L} 2$ learners, and translations. To illustrate the similarity between the 
lexical simplification strategies used in these situations, Blum-Kulka \& Levenston quote numerous examples of Overgeneralization, Circumlocution, Paraphrase, Language Switch, Appeal to Authority, Change of Topic and Semantic Avoidance. These strategy types have all been treated as CmS elsewhere in the literature.

Blum-Kulka \& Levenston argue that the similarity between the strategies used in the situations mentioned above is due to the fact that in all cases the need for lexical simplification is constant and derives from the limited vocabulary at the disposal of the speaker. In this respect, they say, it is irrelevant whether these limits are due to the speaker's own lack of knowledge, the listener's linguistic immaturity, or - in the case of pidgins - features of the language itself. Secondly, they claim that the strategies are similar because they are based on certain aspects of semantic competence shared by all speakers. In chapter 4 it will be seen that these two arguments apply to CpS use as well.

Researchers, then, agree that $\mathrm{CmS}$ are used by $\mathrm{L} 1$ as well as $\mathrm{L} 2$ speakers. It therefore makes sense to remove the study of $\mathrm{CmS}$ from the isolated position it has hitherto taken, and to adopt a more general approach that brings out the commonalities in L1 and L2 speakers' use of CmS. As a first step in this approach it seems useful to compare the use of $\mathrm{CmS}$ by $\mathrm{L} 1$ and $\mathrm{L} 2$ speakers. A comparative study of this kind will be reported in chapter 9 .

The second step is to account for both $\mathrm{L} 1$ and $\mathrm{L} 2$ strategic behaviour by means of one common theoretical framework. In the previous section it has already been pointed out that the Nijmegen project deals with $\mathrm{CmS}$ as an aspect of communication. For this reason the framework adopted for the present study will include a model of communication as one of its main bases. It will be presented in chapter 4 .

\subsection{The Nijmegen project}

In the introduction to this chapter it was indicated that the data base compiled as part of the Nijmegen project was sufficiently large to allow quantitative analyses of CpS use. Such a data base will, of course, also permit qualitative analyses, and these should definitely not be neglected. Still, it is the comprehensiveness of the data base, both in terms of the amount of data and in terms of the variety of data collected, that lends the Nijmegen project its uniqueness.

More specifically, the project aimed at answering the following three research questions:

1. What is the relationship between the subjects' $L 2$ proficiency level and their use of $\mathrm{CpS}$ ? 
2. What is the relationship between CpS use in $\mathrm{L} 1$ and L2?

3. What is the relative effectiveness of different $\mathrm{CpS}$ types?

The first of these research questions reflects the focus on L2 learners that characterized much of the research on CmS until 1983. The choice of $L 2$ proficiency level as an independent factor was based on the results of previous studies (cf. chapter 3).

The second research question arose from the awareness that $\mathrm{CmS}$ use is not L2-specific. The existence of similar strategies in the L1 called for a comparison of L1 and L2 strategic behaviour, so that eventually the relationship between L1 and L2 CpS use might be described and a common explanation found.

The third research question, finally, was motivated by current pedagogical interests. In 1983, when the project was started, there had been little research into the effectiveness of $\mathrm{CmS}$ types, while the results of such research were expected to have important implications for foreign language teaching practices.

With respect to the first two research questions a number of specific hypotheses can be formulated. This will be done in chapter 3 , since they are based on the studies that will be discussed there. Research on the effectiveness of CmS types is too scanty to permit the formulation of reasoned hypotheses. Therefore, this part of the project should be considered as hypothesis-raising, rather than hypothesis-testing.

The Nijmegen project involved three groups of Dutch leamers of English at three different proficiency levels. The subjects could be characterized as advanced, intermediate and beginning leamers. The advanced leamers were 15 second-year university students of English. They had studied English for at least 7 years. The intermediate leamers were 155 -VWO pupils (secondary education, cf. chapter 5, note 1) who had studied English for 4 or 5 years. The beginners were $153-V W O$ pupils. They had been learning English for just over 2 years.

Since previous research (cf. chapter 3 ) had indicated that $\mathrm{CmS}$ choice might be task-specific, the subjects were asked to carry out four different tasks, viz.

I. to name or describe in English 20 concrete objects for which they were unlikely to know the conventional English names;

II. to describe 12 novel graphic designs both in Dutch and in English;

III. to retell in English four one-minute stories told to the subjects in Dutch;

IV. to have a fifteen-minute interview on everyday topics with a native speaker of English.

Each subject's performance on these four tasks was video-recorded and subsequently transcribed. To answer research question 1 , the number of times 
each subject used a particular type of $\mathrm{CpS}$ in tasks I, III and IV was counted and compared across tasks and proficiency levels. With respect to research question 2, the strategies used in the Dutch version of task II were compared to those used in the English version.

Separate experiments were carried out to answer research question 3. Stories containing a number of the $\mathrm{CpS}$ used in task III were presented to four groups of 25 to 35 native speakers of English. The informants were asked first to guess the words which the CpS were meant to convey, and then to indicate on a seven-point scale how comprehensible they considered these $\mathrm{CpS}$ to be.

There are a number of areas in which the Nijmegen project has been restricted. Firstly, the investigation covers the use of CpS only, and neglects the subjects' use of 'Reduction Strategies'. There were two reasons for this. One was that $\mathrm{CpS}$ constitute the most interesting group of $\mathrm{CmS}$ from a pedagogical viewpoint, since they require the $\mathrm{L} 2$ leamer to solve his linguistic problems. This makes his role in the $\mathrm{L} 2$ communication situation a much more active one. The second reason is practical. Avoidance phenomena are difficult to demonstrate in a language corpus (see Van Els et al., 1984:63 ff.), which would have made it extremely difficult to study 'Reduction Strategies' reliably. Even so, it should be noted that the distinction between $\mathrm{CpS}$ and 'Reduction Strategies' is not always very clear. Some $\mathrm{CpS}$ involve reduction of the original speech plan, while not all 'Reduction Strategies' are equally reductive (cf. Færch \& Kasper, 1980:91; see also section 2.2.2).

Secondly, the notion of $\mathrm{CpS}$ was confined to those strategies which were used to solve lexical problems. This decision was primarily motivated by the fact that we wanted our research to be comparable to other research on CmS, which had focussed on lexical aspects. A second reason was that lexis plays a central role in communication. This is illustrated by the fact that without knowledge of (at least a few of) the words of a language it is impossible to communicate in it, however large one's knowledge of the grammar of that language may be. The third reason, finally, was that in our pretests people tended to be aware of, and therefore pointed out, lexical problems when they were asked to comment on communication tasks they had performed earlier, while syntactic, morphological and phonological problems were seldom reported. Consequently, lexical $\mathrm{CpS}$ are by far the easiest to study.

And thirdly, the Nijmegen project was restricted to an investigation of CpS used in the oral production of language. Again, the reason was mainly practical: spoken data are typically more spontaneous than written data and therefore contain problem markers like pauses and repetitions which are not found in written data. These can be used for the identification of $\mathrm{CpS}$ (Færch \& Kasper, 1983c; Raupach, 1983). Moreover, performance phenomena like the ones mentioned above can shed light on the planning process that underlies speech production (cf. e.g. Goldman- Eisler, 1968; and the contributions to Dechert \& 
Raupach, 1980). This implies that spoken data allow one to adopt a process-oriented approach to the study of $\mathrm{CpS}$ use, an approach which is much to be preferred to one that is exclusively product-oriented (see chapter 2 ).

\subsection{The contents of this thesis}

This thesis can be divided into three parts. The first part is largely theoretical. Apart from this first chapter in which the study of CmS has been placed within the context of SLA research and current pedagogical insights, it will consist of three more chapters. In chapters 2 and 3 a survey will be given of the relevant research to date. Chapter 2 comprises a summary of the discussion on definitions and deals with a number of practical and theoretical problems related to existing taxonomies of $\mathrm{CmS}$ use. Chapter 3 contains a description of empirical studies of $\mathrm{CmS}$ and a discussion of some studies on $\mathrm{L} 1$ referential communication in which strategies similar in nature to $\mathrm{CmS}$ have been used by native speakers of a language. Both chapters end with brief discussions of their implications for the Nijmegen project.

Chapter 4 presents a theoretical framework which should account for the use of $\mathrm{CpS}$ in the L1 as well as the L2. The chapter will start with a brief discussion of a recent model of communication (Levelt, 1989). Subsequently, the use of $\mathrm{CpS}$ and other $\mathrm{CmS}$ will be integrated into this model, after which a new process-oriented taxonomy of $\mathrm{CpS}$ will be presented. Finally, some of the factors that constrain the communication process will be discussed, because they are expected to constrain $\mathrm{CpS}$ use as well.

The second part of this thesis could be characterized as 'procedural'. It consists of chapters 5, 6 and 7. Chapter 5 contains a motivation of the choice of the three proficiency levels. It also describes the procedure used to select the subjects and presents a detailed discussion of the four tasks that were used. In addition, this chapter will contain a description of the two experimental sessions.

In chapter 6 the procedure will be described that was followed to identify the CpS in tasks I, III and IV. It begins with a discussion of some of the research on performance characteristics, such as pauses, repetitions, slips of the tongue and laughs, that may be indicative of $\mathrm{CpS}$ use. Subsequently, the use of retrospective data for the identification of $\mathrm{CpS}$ in tasks III and IV will be motivated. It will be argued that retrospective data can be a useful source of information provided they are collected in conformity with certain requirements.

Chapter 7 deals with certain more practical aspects of classification that were left out of account in chapter 4 . The coding system that was actually used was more detailed than the taxonomy described in chapter 4 . Since this may seem to go against the theoretical standpoint taken before, it will be explained 
why this more detailed system was decmed preferable. The second part of chapter 7 describes the coding procedure and reports on its reliability and its applicability to the data.

The last part of this thesis consists of the results, to be reported in chapters 8,9 and 10 , and a discussion of their implications in chapter 11. Chapter 8 deals with the data of tasks I, III and IV in view of the question conceming the relationship between $\mathrm{L} 2$ proficiency level and $\mathrm{CpS}$ use. Both quantitative and qualitative analyses will be reported. Apart from proficiency-related differences, task-related and individual differences will be discussed.

Chapter 9 deals with the relationship between CpS use in L1 and L2. The Dutch and English versions of task II are compared and the findings related to those of earlier studies involving comparable tasks.

Chapter 10 focusses on the effectiveness of $\mathrm{CpS}$ types. Two studies in which this topic was investigated are discussed in some detail (Ervin, 1979; Bialystok \& Fröhlich, 1980). Subsequently, various pilot studies conducted by students at Nijmegen university will be described. They are followed by a description of the York study of effectiveness which was carried out as part of the Nijmegen project, and a presentation of its results.

The concluding chapter, chapter 11 , contains an evaluation of the project and a general discussion of the results reported in chapters 8,9 and 10. The implications of the Nijmegen project for studies of L2 use and for foreign language pedagogy will be discussed, after which the chapter will finish with some suggestions for further research.

\section{Notes to chapter 1}

1. Examples taken from the Nijmegen corpus will be followed by the target word and a code indicating which subject produced it and in which task. Thus, $303 \mathrm{t} 4$ indicates that this extract was produced by subject 303 in task IV. The first digit indicates the subject's proficiency level, 101 referring to a second-year student of English, 201 to a 5-VWO pupil, and 301 to a 3-VWO pupil. Detailed information about the subjects, their proficiency levels and the tasks in which they participated is given in chapter 5 .

In all examples S stands for 'subject', while I stands for 'interviewer'. The numbers in the data indicate the length of pauses in seconds. Pauses shorter than one second are marked by a comma. Rising intonation is marked by a question mark. Relevant information on the subjects' and the interviewer's behaviour is given between angular brackets, e.g. <laughs>. Translations of Dutch words that are crucial to a proper understanding of the examples are added in brackets, e.g. (= Austria).

2. Throughout this book he, his and him will be used as neutral pronouns referring to both male and female learners, subjects, teachers and so on. Whenever she and her are used, reference is made to a specific female person.

3. Since most previous research relates to both 'Reduction Strategies' and 'Compensatory Strategies', the term 'Communication Strategies' $(\mathrm{CmS})$ will be used in this thesis when 
previous research is discussed. In connection with the Nijmegen project, however, the more specific term 'Compensatory Strategies' (CpS) will be used, since 'Reduction Strategies' were not included in this project.

4. Both Ellis (1985:58) and McLaughlin (1987:67-69) note that the conclusions drawn on the basis of the morpherne studies did not stand up to scrutiny. Several longitudinal studies yielded acquisition orders different from the accuracy orders reported in the morpheme studies (Hakuta, 1974; Rosansky, 1976). Besides, different accuracy orders were found when elicitation methods other than the Bilingual Syntax Measure, which was used by Dulay \& Burt, were adopted (Larsen Freeman, 1975; see also Rosansky, 1976, for a detailed discussion of this and other methodological problems).

5. Naturally, this problem is not intrinsic to studies of EA. If longimdinal designs had been adopted, EA could easily have dealt with developmental aspects.

6. Note that the increasing use of performance features for the identification of $\mathrm{CmS}$ also reflects this interest (cf. e.g. Dechert, 1983; Farch \& Kasper, 1983c; and for a more balanced approach, including the additional use of introspective data, Raupach, 1983).

7. To distinguish types of strategies from tokens, types are capitalized and marked by '...' as in 'The distinction between 'Learning' and 'Communication Strategies' is not clear". Tokens are not distinguished from ordinary running text (e.g. "He used 7 communication strategies").

8. Kellerman (1988) mentions two additional situations in which native speakers adopt strategies similar to $\mathrm{CpS}$ : a) dictionary makers defining words and expressions and b) people selecting trade names that are often highly descriptive of the products they designate. 


\section{A Survey of the Literature: Definitions and Taxonomies}

This is the first of two chapters surveying the literature on $\mathrm{CmS}$. It deals with two issues: definitions and taxonomies. Obviously, both issues are essential to the study of $\mathrm{CmS}$ and for this reason they have received a great deal of attention in the literature, particularly in the early articles on $\mathrm{CmS}$.

The question of definitions will be taken up in the first part of this chapter (section 2.1). After a brief discussion of some of the initial definitions, the section will go into the criteria of $\mathrm{CmS}$ use, as they have been proposed by Færch \& Kasper (1980; 1983b; 1984; Færch, 1984) and Bialystok (1984). The (working) definition of $\mathrm{CpS}$ which has been employed in the Nijmegen project will be presented at the end of the first section.

The second part of this chapter contains a review of the two best-known "traditional" taxonomies, viz. those presented by Tarone (1977) and Farch \& Kasper (1980). Some practical problems related to these and similar taxonomies will be discussed, but, more importantly, it will be argued that the criteria which have been chosen to distinguish between various types of $\mathrm{CmS}$ are ill-founded. They are largely product-oriented and therefore lack psychological plausibility.

The taxonomy which has been employed in the Nijmegen project meets both the practical and the theoretical problems raised here. It will be presented in chapter 4.

\subsection{Definitions}

One of the first definitions of $\mathrm{CmS}$ is given by Tarone, Cohen \& Dumas (1976), ${ }^{1}$ who refer to $\mathrm{CmS}$ as "a systematic attempt by the leamer to express or decode meaning in the target language, in situations where the appropriate systematic target language rules have not been formed" (p.5). In this definition the use of $\mathrm{CmS}$ is restricted to (second) language learners, which reflects Tarone et al.'s view of $\mathrm{CmS}$ as a central component of interlanguage. Very soon afterwards, however, Tarone notes that communicative problems "may occur when one speaks in one's first language, as well as when one attempts to communicate in an interlanguage" (Tarone, 1977:195). Hence she then gives the following definition: "conscious communication strategies are used by an individual to overcome the crisis which occurs when language structures are inadequate to convey the individual's thought" (p.195, emphasis mine). The same point is also made by Corder (1978), who consequently defines $\mathrm{CmS}$ as "a systematic technique employed by a speaker to express his meaning when faced with some difficulty" (p.16, emphasis mine). 
In 1980 Tarone revises her definition again to include the role played by the listener. A CmS, she writes, is "a mutual attempt of two interlocutors to agree on a meaning in situations where requisite meaning structures do not seem to be shared" (p.419; see also Tarone, 1981:288). This time she adds a list of criteria on the basis of which she distinguishes between $\mathrm{CmS}$, Production Strategies and Learning Strategies. The following are necessary criteria for CmS:

1. A speaker desires to communicate a meaning $x$ to a listener,

2. The speaker believes the linguistic or sociolinguistic structure desired to communicate meaning $\mathrm{x}$ is unavailable or is not shared with the listener;

3. The speaker chooses to:

a) avoid - not attempt to communicate meaning $x$ or

b) attempt altemate means to communicate meaning $x$. The speaker stops trying alternatives when it seems clear to the speaker that there is shared meaning (Tarone, 1980:419).

In the case of 'Production Strategies', which she defines as "an attempt to use one's linguistic system efficiently and clearly with a minimum of effort" (p.419), criterion (3b) is absent since there is no use of altemative means with which to negotiate meaning. ${ }^{2}$ 'Leaming Strategies', according to Tarone, do not require criterion (1), since their basic motivation is not to communicate but to learn (cf. also the discussion in chapter 1).

So far, the definitions mentioned here mainly served to distinguish $\mathrm{CmS}$ from other classes of strategies such as 'Leaming Strategies' and 'Production Strategies'. Other definitions were set up in an attempt to distinguish strategies from processes, procedures, plans, tactics and so on. The best-known example of this approach can be found in Færch \& Kasper's work. Starting from the assumption that it is possible to make a meaningful distinction between strategic and non-strategic language use, they define $\mathrm{CmS}$ as "potentially conscious plans for solving what to an individual presents itself as a problem in reaching a particular communicative goal" (Færch \& Kasper, 1980:81; 1983b:36). In this definition problem-orientedness is adopted as a primary and potential consciousness as a secondary defining criterion.

The use of 'problem-orientedness' as a defining criterion of strategies is not unprecedented (cf. the definitions in Clark \& Clark, 1977:567; Jordens, 1977:14; Kellerman, 1977:93). 'Problem' is an ambiguous notion though: in both Jordens' and Kellerman's definitions it is used in its everyday sense of 'difficulty'. In Clark \& Clark's definition, however, it seems to have the more technical meaning 'task', which is common in the field of cognitive psychology. ${ }^{3}$ To prevent potential misinterpretations, Færch \& Kasper (1983b) explicitly point out that in their definition 'problem' is used as a synonym of 'difficulty'. Thus, they use 'problem-orientedness' to distinguish between 
plans which relate to non-strategic communicative goals, i.e. goals that can be reached without difficulty, and plans which relate to strategic goals, i.e. goals which present themselves to the individual as problems (p.32). Only plans of the latter type are considered 'strategies'.

Færch \& Kasper point out that the goals to which 'strategies' relate may be problematic for various reasons. Usually, in the case of L2 learners, the problem is due to the speaker himself having insufficient linguistic knowledge. In the case of $\mathrm{L} 1$ speakers conversing with $\mathrm{L} 2$ leamers, however, the problem may also be due to insufficient linguistic knowledge on the part of the listener. Thus, Færch \& Kasper too make it quite clear that the use of $\mathrm{CmS}$ is not restricted to L2 leamers.

'Consciousness' is adopted as a secondary criterion because it is derived from the criterion of problem-orientedness. "If the individual experiences a problem in reaching a goal, this implies that he is conscious about there being a difficulty" (Færch \& Kasper, 1983b:34). Unfortunately, Færch \& Kasper's discussion of the criterion of consciousness is somewhat confusing. It is not clear whether they mean to say that the individual is conscious of having a problem, or that he consciously uses certain plans to solve this problem. At first, they seem to mean the former, since they point out several problems related to a definition of $\mathrm{CmS}$ as consciously employed plans. They note that consciousness is a graded notion and that, rather than saying that strategies are conscious or not conscious, one should say they are more or less conscious. Moreover, they observe that consciousness is subject to change. Plans that were consciously employed at first may become automatized later on.

Later, however, Færch \& Kasper suggest that a classification of $\mathrm{CmS}$ into plans which are always, never, or in some situations consciously employed would be interesting both from a pedagogical point of view (L2 leamers can be made more conscious of $\mathrm{CmS}$ ) and from a researcher's point of view ("it delimits the subgroup of plans which can be characterized by means of introspective techniques from other types of plans", p.36). For these reasons Færch \& Kasper finally decide to define strategies as potentially conscious plans.

It should be noted here that Færch \& Kasper do not consider 'problemorientedness' and 'potential consciousness' to be the defining criteria of CmS. As they are careful to point out, strategies do not constitute a class of phenomena given a priori: there is no compelling reason imposed by reality why $\mathrm{CmS}$ (or strategic plans) should be distinguished from non- strategic plans. Consequenuly, the definition of $\mathrm{CmS}$ is not bound to any naturally determined criteria. Rather, the criteria will have to be based on the researcher's "Erkenntnisinteresse", i.e. on what he considers appropriate or useful. Farch $\&$ Kasper have taken the foreign language teacher's perspective, and choose to focus on the devices which leamers can consciously employ when they are faced with communicative problems. 
Færch \& Kasper (1984) contrast their psychological definition with the interactional definition given by Tarone $(1980 ; 1981)$. Tarone's definition, it will be recalled, emphasizes the importance of the interlocutor. Both the speaker and the interlocutor are supposed to actively contribute to the negotiation of meaning. This definition is criticized on a number of grounds. Firstly, Færch \& Kasper point out that Tarone does not make clear what it is that makes a CmS interactional. It could be either the interlocutor's reaction to the speaker's strategy (weak interactional claim) or the fact that both interlocutors contribute actively to the solution of each communicative problem that presents itself (strong interactional claim). A problem with the weak claim is that it does not distinguish properly between the use of $\mathrm{CmS}$ and other situations in which the speaker gives feedback. Besides, it does not account for the use of $\mathrm{CmS}$ in situations in which there is no or delayed feedback, as e.g. in lectures. This last problem also goes for the strong claim. Cases in which the speaker manages (or wants) to solve the problem by himself are not covered by a definition in which 'interactiveness' is adopted as a defining criterion. This makes such a definition insufficiently comprehensive.

Although Færch \& Kasper's definition of $\mathrm{CmS}$, with 'problemorientedness' and 'potential consciousness' as its defining criteria, is now widely used, it is certainly not the only possible view of $\mathrm{CmS} .{ }^{4}$ Bialystok (1984) suggests a more general approach, in which she seeks to develop a theoretical framework that accounts for the use of both leaming and communication strategies by L1 and L2 speakers, including both children and adults.

In her analysis of preceding work, Bialystok identifies three features, or criteria, that have consistently been used - either implicitly or explicitly - to define strategies. They are problematicity, consciousness and intentionality. ${ }^{5}$ These criteria, she claims, have led to an interpretation of strategies which may be useful from an applied linguistic or a pedagogical perspective, but "obscures their similarity with the conception and functioning of strategies in other domains" (p.40), notably, that of child language development. To illustrate this point Bialystok points out the similarity between the strategies used by children acquiring the $\mathrm{L} 1$ and adults leaming the $\mathrm{L} 2$. Both are known to make use of the context, to overgeneralize word meanings, and to use formulaic expressions. Subsequently, she argues that since the criteria of 'consciousness', 'problematicity' and 'intentionality' all involve metacognitive skills, they cannot be used to define the strategies used by pre-metacognitive children learning their L1. To use them to define L2 strategies all the same would be highly unreasonable, she says, since this would mean that different criteria are employed to define two phenomena that are obviously similar in many respects.

Part of the controversy conceming the definition of strategies seems to arise from the fact that Færch \& Kasper's notion of CmS covers only a subset of 
what Bialystok considers to be CmS. Whereas Færch \& Kasper explicitly restrict the use of the term $\mathrm{CmS}$ to cases in which the speaker (either native or non-native) attempts to overcome linguistic difficulty, Bialystok's definition covers all attempts to reach a communicative goal, whether this goal confronts the speaker with difficulty or not. It has already been discussed why Færch \& Kasper chose to confine themselves to what they have called strategic language use (as opposed to non-strategic language use). It is this choice, and the consequent need to distinguish between the two kinds of language use, that requires them to adopt a criterion like 'problematicity'. Clearly, there is no need for Bialystok to adopt this criterion, since she does not distinguish between strategic and non-strategic language use. ${ }^{6}$ Consequently, 'consciousness', which according to Færch \& Kasper is implied by 'problematicity', is of no use to Bialystok either.

As an alternative Bialystok presents a cognitive framework that may account for both L1 and L2 acquisition and use (see also Bialystok \& Ryan, 1985; Bialystok \& Sharwood Smith, 1985). It is based on two cognitive skills: analysis of knowledge and cognitive control. The first of these refers to the leamer's ability "to represent the structure of knowledge along with its content". The second refers to his ability "to deliberately focus on relevant aspects of a problem and not be misled by distracting alternatives" (Bialystok, 1984:45/46). The framework permits a distinction between two types of strategies: Knowledge-based Strategies and Control-based Strategies. Basically, the former exploit the relationships that the leamer knows exist in the code, i.e. they manipulate analysed knowledge, while the latter relate to the use of the system rather than to the knowledge of it.

Bialystok argues that her approach is process-oriented rather than product-oriented and that the classification of a strategy as knowledge-based or control-based depends on its source and function in language production. To illustrate this she quotes an example from Færch \& Kasper (1983c), who distinguished between two types of transfer from the L1 to the L2: (1) unconscious transfer resulting from the interference of L1 habits; and (2) conscious use of $\mathrm{Ll}$ knowledge to solve a lexical problem. In spite of their apparent similarities these strategies would be coded differently in Bialystok's framework: (1) would be a control-based strategy, while (2) would be knowledge-based.

It is worth noting here that according to Færch \& Kasper's definition only (2) should be considered an instance of $\mathrm{CmS}$ use. This suggests that what Færch \& Kasper have defined as CmS will (generally) be classified as knowledge-based stratcgies by Bialystok. ${ }^{7}$

Bialystok's paper is extremely interesting from a theoretical point of view. By pointing out the similarities between $\mathrm{L} 1$ and L2 speakers' leaming and communication strategies she draws attention to relationships that had until 
then remained largely unnoticed. As has been indicated in chapter 1, one of these relationships, viz. that between $\mathrm{L} 1$ and $\mathrm{L} 2$ speakers' use of $\mathrm{CmS}$, will be further investigated in the Nijmegen project (cf. chapter 9). Moreover, the framework to be presented in chapter 4 of this thesis reflects Bialystok's views to some extent in that it aims at a more encompassing explanation of $\mathrm{CmS}$ use than has been common in this field of research.

From a practical - identification - point of view, however, Færch \& Kasper's more restricted definition seemed more useful, in particular since our major interests, like theirs, initially lay with L2 learners' abilities to deal with lexical problems. It is for this reason that the working definition of CpS which was used for the Nijmegen project was based on Færch \& Kasper's definition of $\mathrm{CmS}$. It reads as follows:

Compensatory strategies are strategies which a language user employs in order to achieve his intended meaning on becoming aware of problems arising during the planning phase of an utterance due to his own linguistic shortcomings.

Like Færch \& Kasper's definition this working definition uses 'problematicity' (in its informal sense of 'difficulty') as a primary defining criterion, or rather, perhaps, as a primary heuristic for locating strategy use. We hesitated to adopt 'consciousness' as a secondary criterion though, since it did not seem possible to reliably distinguish conscious from unconscious mental activity (cf. Poulisse et al., 1984). For this reason we preferred the term awareness which should be interpreted in a much more restricted way than 'consciousness' in Færch \& Kasper's definition. It refers to the language user being aware of having a problem, and not to his being conscious of the decision to use a particular type of $\mathrm{CpS}$. In this respect it is important to note that it is the speaker who must be aware of the problem rather than the researcher. Or, as Kelleman (1977) would put it, CpS use follows from ignoranceby-self-evaluation rather than ignorance-by-observation.

There are two other points which are of crucial importance to this definition. One is that the problem must be linguistic in nature. Although this point may seem to be somewhat trivial right now, it is definitely relevant to the identification of $\mathrm{CpS}$ (see chapter 6). The other point is that the language user must aim at the solution of this linguistic problem, that is to say, he must attempt to achieve his originally intended meaning. It is this point which distinguishes CpS from 'Reduction Strategies', which, as we have seen in chapter 1, constitute another subset of CmS.

It will be noted that the working definition specifies that the problems arise "during the planning phase of an utterance". This phrase was included because the Nijmegen project was not intended to investigate strategies used to solve pronunciation problems, which, it was thought, occur in the execution phase of the speech process. Similarly, the reference to "his own linguistic 
shortcomings" was included to indicate that strategies used to compensate for someone else's problems (as might occur in the simplified language spoken to foreigners, cf. Blum-Kulka \& Levenston, 1983) were not studied either.

Although the working definition can undoubtedly be improved (see chapter 11), if only because it is general in some respects (language user, linguistic shortcomings) and specific in others (problems arising during the planning phase, due to the language user's own linguistic shortcomings), it has served its purpose in the identification stage of the Nijmegen project. 'Problematicity', and more particularly 'awareness of problems', proved to be useful heuristics for the location of $\mathrm{CpS}$, because information on these points could be obtained by means of retrospective techniques. In chapter 6 it will be shown that this facilitated the identification procedure considerably.

\subsection{Taxonomies 9}

Taxonomies played a large role in most of the early studies of $\mathrm{CmS}$ (cf. e.g. Váradi, 1973; Tarone et al., 1976; Tarone, 1977; 1980; 1981; Galvắn \& Campbell, 1979; Bialystok \& Frohlich, 1980; Færch \& Kasper, 1980; 1983b). Of these taxonomies the ones presented in Tarone (1977) and Færch \& Kasper (1980) are amongst the most frequently cited. Both are concerned with $\mathrm{CmS}$ and hence include both 'Reduction Strategies' and CpS (see chapter 1 for the distinction between these two types of strategies). It should be noted that only $\mathrm{CpS}$ are relevant to the present study. Still, for the sake of completeness, the two taxonomies will be discussed in full.

\subsubsection{Tarone (1977)}

Tarone (1977) is a revision of the taxonomy in Tarone et al. (1976). In the (1977) taxonomy five main categories are distinguished: Avoidance, Paraphrase, Conscious Transfer, Appeal for Assistance and Mime.

1. Avoidance. Two types of 'Avoidance' are distinguished. The first, Topic Avoidance, occurs "when the leamer simply does not talk about concepts for which the vocabulary is not known" (p.198). The second, Message Abandonment, occurs "when the leamer begins to talk about a concept, but is unable to continue and begins a new sentence" (p.198).

2. Paraphrase. 'Paraphrase' is defined as "the rewording of a message in an altemate, acceptable target language construction, in situations where the appropriate form or construction is not known or not yet stable" (p.198). Three types of 'Paraphrase' are defined:

a. Approximation is "the use of a single target language vocabulary item or structure which the learner knows is not correct, but which shares 
enough of the semantic features in common with the desired item to satisfy the leamer" (p.198). Examples are high-coverage words such as "worm" for 'silkworm' and "pipe" for 'waterpipe', and low-coverage words such as "labor" for 'work".

b. Word Coinage occurs "when the learner makes up a new word to communicate a desired concept" (p.198), e.g. "airball" for 'balloon" (from: Váradi, 1973) and "person worm" or "jugworm" for 'caterpillar'.

c. Circumlocution is "a wordly (sic) extended process in which the leamer describes the characteristics or elements of the object or action instead of using the appropriate target language structure ... e.g. in describing a waterpipe, a subject said: 'She is uh, Persian, and we use in Turkey a lot of"' (p.198).

3. Conscious Transfer may take the form of Literal Translation or Language Switch.

a. 'Literal Translation' occurs when the leamer translates word for word from the native language, e.g. when a Mandarin speaker describes two persons toasting one another by translating the equivalent Mandarin expression as: "He invites him to drink".

b. 'Language Switch' is the use of a native language term without the leamer bothcring to translate, e.g. the use of Turkish "balon" for English 'balloon', or Turkish "tirtil" for English 'caterpillar'.

4. Appeal for Assistance occurs "when the leamer asks for the correct term: asks the experimenter, any native speaker, or even refers to a dictionary" (p.199), e.g. when a subject says: "What is this? What called?".

5. Mime "refers to the use of non-verbal $\mathrm{CmS}$ by a second language learner" (p.199), e.g. clapping one's hands to illustrate applause.

\subsubsection{Farch \& Kasper (1980)}

Compared to Tarone's (1977) taxonomy Færch \& Kasper's (1980) is more detailed. They start with the distinction between Reduction Strategies and Achievement Strategies. In the case of Formal Reduction the leamer communicates by means of a system that has been phonologically, morphologically, syntactically or lexically reduced, while in the case of Functional Reduction the communicative goal is reduced. The subtypes of 'Functional Reduction Strategies' are 'Topic Avoidance', 'Message Abandonment' and Meaning Replacement. ${ }^{10}$ The first two types are familiar from Tarone (1977). In the case of 'Meaning Replacement' "the learner preserves the 'topic' but refers to this by means of a more general expression, the result of which is a certain amount of vagueness" (p.91).

Færch \& Kasper note that the distinction between 'Topic Avoidance' and 'Meaning Replacement' is rather arbitrary. They suggest that the 'Functional Reduction Strategies' (apart from 'Message Abandonment') should be seen as 
"forming a continuum. At the one end, the leamer says 'almost' what she wants to say about a given topic (= 'Meaning Replacement'), at the other end she says nothing at all about this (= 'Topic Avoidance')" (p.91). This characterization, it will be noted, reveals how difficult it is to draw the line between 'Reduction Strategies' and CpS. After all, "saying almost what one wants to say about a given topic" in effect boils down to using a $\mathrm{CpS}$.

The 'Achievement Strategies', here referred to as CpS, are "subclassified according to what resources the learner draws on in trying to solve her planning problems: a different code ('Code Switching' and 'Interlingual Transfer'), a different code and the IL code simultaneously ('Inter-/Intralingual Transfer'), the IL code exclusively ('Generalization', 'Paraphrase', etc.), discourse phenomena (e.g. 'Appeals for Assistance'), and non-linguistic communication ('Mime', etc.)" (p.92).

1. Code Switching is what Tarone (1977) referred to as 'Language Switch'. When 'Code Switching' affects single words only, as in "do you want to have some ah - Zinsen ( $\mathrm{Ll}=$ German) or do you want to have some more ....", Færch \& Kasper refer to it as Borrowing (cf. also Corder, 1978).

2. The second 'Achievement Strategy' is Interlingual Transfer, which combines linguistic features from the $\mathrm{IL}$ and the $\mathrm{L} 1$ (or any other language different from L2). If 'Interlingual Transfer' takes place at the phonological or morphological level, it is referred to as Foreignizing, e.g. Danish 'knallert' pronounced as ('knælø) for English 'moped'. If it involves the lexical level of the $\mathbb{I}$ system it is called Literal Translation, e.g. 'greens things', a literal translation of Danish 'grontsager', for 'vegetables' (cf. also Tarone, 1977).

3. Strategies of Inter-/Intralingual Transfer may be applied if the language distance between L1 and L2 is considered to be small. The result is "a generalization of an IL rule, but the generalization is influenced by the properties of the corresponding L1 structures" (p.94), e.g. Danish 'sv $\phi m m e$ - svфmmede' (regular past tense) may result in English 'swim - swimmed' instead of 'swim - swam'.

4. Interlanguage-based Strategies fall into four subtypes:

a. Generalization. Leamers fill "the 'gaps' in their plans with IL items which they would not normally use in such contexts" on the assumption that "the generalized item can convey the appropriate meaning in the given situation/context" (p.94). An example is the use of the superordinate term "animals" to refer to 'rabbits'.

b. Paraphrase is defined as the use of a well-formed IL construction. It is said that '“Paraphrases' can have the form of Descriptions or Circumlocutions (Varadi, 1973; Tarone, 1977), the leamer focussing on characteristic properties or functions of the intended referent" (p.96). Thus, 'interest' is described as "have some more money". 
Exemplification, i.e. the use of a hyponymic expression, is considered a special case of 'Paraphrase'. Færch \& Kasper mention the use of "Puch" for 'moped' as an example.

c. Word Coinage is defined as "the creative construction of a new IL word", e.g. "we were sitting in the rounding of the stadion" for 'the curve of the stadium' ( $\mathrm{L} 1$ = German).

d. Restructuring. When the original speech plan fails, the leamer can use a 'Restructuring Strategy' in an attempt to reach his goal via alternative ways. An example would be ".... my parents has - I have er four elder sisters ..." used by a Danish leamer who tried to get around the word 'daughter' (from: Albrechtsen, Henriksen \& Færch, 1980).

Two final subclassifications that Færch \& Kasper make are Cooperative Strategies (including 'Appeals for Assistance') and Non-linguistic Strategies such as "mime, gesture and sound imitation" (p.98). ${ }^{11}$

Færch \& Kasper also mention six Retrieval Strategies (cf. Glahn, 1980), which the leamer may adopt when he has difficulties in retrieving specific $\mathbb{L}$ items. The use of such strategies concems words which the speaker knows, although their use may not yet have become automatized, and it is only when retrieval fails that a CpS will have to be used. Thus, 'Retrieval Strategies' precede CpS and cannot be equivalent to them. Therefore, they will not be discussed here.

\subsubsection{Practical problems related to traditional taxonomies}

When Tarone presented her taxonomy she pointed out two problems. One was that "any ... attempt to establish an enlightening typology of clear-cut mutually exclusive communication strategies is bound to run into trouble as soon as we begin to deal with real data." (Tarone, 1977:197). The other was that her taxonomy seemed to be a system that would "provide the best tool to make sense of the behavior of my subjects in this communication situation" (Tarone, 1977:197, emphasis mine). Clearly, this implies that for someone else's data, a different taxonomy may be better.

The first problem is a coding problem. It applies to most traditional taxonomies, and it is possible to point out various factors which may have contributed to it. Firstly, some of the criteria used to distinguish the different $\mathrm{CmS}$ types are not defined explicitly enough. Both Tarone (1977) and Færch \& Kasper (1980) use words like 'acceptable', 'appropriate' and 'well-formed' without indicating whether these should be interpreted from the leamer's or the obscrver's point of view. Nor do they specify who determines whether "the appropriate form or construction is not known or not yet stable" (cf. Tarone's definition of 'Paraphrase') or whether leamers use "IL items which they would not normally use in such contexts" (cf. Færch \& Kasper's definition of 'Generalization'). 
Secondly, some of the criteria are not very well chosen. Defining 'Word Coinage' as "the construction of a new (IL) word" excludes all those words as word coinages which were creatively constructed by the learners, but which happened to exist already. Similarly, defining 'Paraphrase' as an "acceptable target language construction" (cf. Tarone, 1977) excludes all ungrammatical utterances as such, and demanding of 'Circumlocutions' that they are "wordly extended" (cf. Tarone, 1977) leaves one with a number of unclassifiable short utterances, like "without hair" for 'bald'. Rather than saying that 'newness', 'acceptability' and 'length of utterance' are defining criteria, we would consider them as characteristics which go for most word coinages, paraphrases and circumlocutions, but which are fairly useless when it comes to defining these categories.

Thirdly, some of the distinctions seem to be non-existent or arbitrary. Færch \& Kasper (1980:91) defined 'Meaning Replacement' as a case where the learner "preserves the 'topic' but refers to this by means of a more general expression", the result of which is "a certain amount of vagueness". It is not clear in what way this differs from 'Generalization'. Even though their definition of the latter $\mathrm{CpS}$ does not explicitly refer to the use of 'a general expression', the example ("animals" for 'rabbits') implies that this kind of general expression is included. Since the two strategies capture the same phenomena there seems to be no need to distinguish them.

In the same way, it is not clear why Færch \& Kasper have a separate heading for 'Generalization' (i.e. the use of superordinate terms), but group 'Exemplification' (i.e. the use of hyponymic terms) together with 'Description' as subcategories of 'Paraphrase'. Surely, 'Generalization' and 'Exemplification' are more alike than 'Description' and 'Exemplification'. Note, by the way, that Færch \& Kasper's taxonomy does not list 'Approximation', which could have served as a suitable category grouping superordinate (e.g. 'animal' - 'rabbit'), co-ordinate (e.g. 'hare' - 'rabbit') and hyponymic terms ('rose' - 'flower') together.

The second problem pointed out by Tarone (1977) has to do with a lack of generality. Tarone's taxonomy was set up to deal with her data (elicited in a cartoon-story telling task) and most of the CpS used by her subjects concemed concrete items. Consequently, researchers who had different data had tremendous problems in applying Tarone's taxonomy. Paribakht (1982), who used a task which required subjects to compensate for concrete and abstract items (like 'hope', 'faith' and 'justice'), reports: "On the basis of the data collected in this study certain major modifications were made in the existing taxonomies. That is, due to the nature of this study, in terms of the variety of item types (concrete nouns and abstract nouns) and variety of subject groups (lcamer groups at two different developmental stages of their IL and a group of NS (native speakers) of the TL (target language)), a number of new CmS were elicitcd" (p.43). To this she adds: "The proposed classification of CmS 
elicited in this study, does not preclude the possibility of alternative classifications, or the discovery of other CmS" (p.44). Paribakht's taxonomy does indeed contain a number of subclassifications which are highly task-specific. CpS like Antonymy, Use of TL Idioms and Proverbs and Metonymy were shown to occur only with abstract concepts, while CpS like Physical and Functional Descriptions, and Descriptions of Locational and Historical Properties were reported to be specific to concrete concepts.

There is yet another way in which the traditional taxonomies lack generality. They are characterized by a tendency to describe everything in detail. For this reason any utterance that differed slightly from the utterances covered by existing CpS types seemed to call for the creation of a new type of CpS, or a further subdivision of the original type. Thus, Galván \& Campbell (1979) added the strategies Requests for Confirmation and Requests for Repetition to the existing (direct and indirect) Requests for Form, while Færch \& Kasper (1980) distinguished between 'Code Switching' and 'Borrowing' on the basis of the number of words transferred from the L1 to the L2. Even if it is easy to make such distinctions consistently, it is doubtful whether they will add much to one's understanding of CPS use. Too many (sub)categories, with only few instances of each of them, will make it difficult to see the wood for the trees. For this reason related subcategories will need to be collapsed again into more comprehensive categories to draw general conclusions. This makes it superfluous to have made such minute distinctions in the first place.

In this respect it is also telling to consider Bialystok \& Fröhlich's (1980) subcategorization of 'Description' into Description of General Physical Properties (specifying the target item's colour, size, material and spatial dimension), Description of Specific Features (usually marked by 'it has'), and Description of Interactional/Functional Characteristics (indicating what one can do with the target item). Of course, once one starts making subdivisions like these, there is no end to it, as can be concluded from Paribakht's (1982) addition of 'Locational' and 'Historical Properties' as two further subcategories of 'Description' to refer to the place and the time where the item is/was used. No doubt, it is possible to think of other features. Example (1) illustrates this.

(1) a toy $\mathrm{f}$ for $\mathrm{k}$ uh for small ch children when they push on it 1 uh, the body starts, circling round very fast and is going to make music 1 or all kinds of noises 1 $<$ coughs> from within (humming-top; 111t1)

This utterance would require a 'Description of User' to denote the person(s) who typically use(s) the object, and a 'Description of Operation' to indicate how the item works, since "circling round" can hardly be considered a humming-top's function. It might even be necessary to have a $\mathrm{CpS}$ called 'Description of Sound' if one wishes to avoid putting the "music" and/or 
"noises" into one of the ragbags of 'Specific' or 'Other Features' (cf. Paribakht, $1982 ; 1985$, for the latter category).

The inconclusiveness of the definitions and the open-endedness of the taxonomies have led to numerous changes, additions and further subclassifications. As a result, there now exists a rather confusing multiplicity of taxonomies with little agreement on the terminology. This has made it rather difficult to interpret and compare empirical results.

\subsubsection{Theoretical problems related to traditional taxonomies}

Besides the two practical problems discussed above, there is also a more theoretical problem to be dealt with. This relates to the taxonomies' lack of psychological plausibility, as reflected by the criteria which have been chosen to distinguish between various subtypes of $\mathrm{CpS}$. Some of these criteria are largely product-oriented, and it can be demonstrated that this has concealed some obvious generalizations to be made with respect to the cognitive processes underlying $\mathrm{CpS}$ use. Others relate to the final (encoding) stage of the speech production process only, and this, it can be shown, tends to obscure what happened at earlier stages.

Firstly, consider utterances (2) to (5):

(2) hair-cutters (hairdressers; 204t3)

(3) hairgrowers (hair-restorers; 102t3)

(4) ones, who, who erm, could cut people's hair (hairdressers; 215t3)

(5) something to let 1 uh hairs grow (hair-restorer, 307t3)

Traditional taxonomies would distinguish between these utterances on the basis of their linguistic forms. They would classify (2) and (3) as 'Word Coinage' and (4) and (5) as 'Circumlocution', in spite of the fact that (2) and (4) and (3) and (5) refer to identical attributes of 'hairdressers' and 'hair-restorers' respectively. By focussing on the differences in form the similarity between the utterances in terms of propositional content is concealed, and the generalization which could have been made with respect to the analytic process underlying these utterances remains unnoticed.

The distinction of 'Mime' as a separate category to distinguish non-verbal from verbal encoding has a similar effect. It would lead to different classifications of utterances realized by words and utterances realized by gestures. In fact, however, the learner who distinguished a 'flute' from a 'recorder' by moving his fingers sideways first, and then in front of his mouth, would not have employed a different strategy, but a different encoding system, if he had said: "this is a thing which you play sideways, and this is one which you play in front of you". In both cases he considers the position of the hands 
when playing to be the distinctive attribute. Whether he encodes this information verbally or by means of gestures is irrelevant to the preceding analytic process.

Now consider the category of 'Circumlocution'. In many taxonomies this category (also referred to as 'Description') has been conscientiously subdivided according to the properties mentioned in the description. Hence (6) would be classified as containing two strategies, a description of general physical properties followed by a description of locational properties, while (7) would be considered a description of interactional/functional characteristics.

(6) an uh animal in the form of a star and uh you find it uh at the sea (starfish; 114t1)

(7) something to, to kill fly flies with (flyswat; 113t1)

However, in both (6) and (7) the criterial properties of the referents are mentioned. In the case of 'starfish' these happen to be form and place, in the case of 'flyswat' it happens to be function. That different properties are mentioned does not mean though that the $\mathrm{CpS}$ employed are different. It only means that 'starfish' and 'flyswats' are different. Clearly, a classification according to the properties mentioned in the description confuses differences in referents with differences in CpS. It is not surprising then that studies which have predominantly used concrete objects to elicit $\mathrm{CpS}$ report the use of a large number of descriptions of function (e.g. Bialystok \& Froblich, 1980). This is a direct result of the fact that concrete objects can usually be distinguished by their functions. A study involving abstract notions would very likely show a completely different picture, because in the case of abstract notions other properties are criterial. If, however, in both kinds of study (i.e. one involving concrete objects and the other one involving abstract concepts) the subjects compensated for unknown words by mentioning the referents' criterial properties, the conclusion should be that the subjects used the same $\mathrm{CpS}$ in both studies. Again then, this is an important generalization that will be missed if product-related criteria are employed to distinguish between $\mathrm{CpS}$ types.

Finally, some of the major distinctions made in traditional taxonomies may lead the researcher to underinterpret the leamer's behaviour. It will be recalled that many taxonomies have distinguished between strategies encoded in the $\mathrm{L} 1$ and strategies encoded in the L2 (or Ln). This distinction would make it natural to classify an utterance like "bore" (for 'hammer drill') as L1-based, because Dutch has a word 'boor' meaning 'drill'. This interpretation need not correctly represent the actual problem solving process though, since it is quite possible that preceding the L1-based strategy for 'drill', an approximation (viz. drill) was used to refer to 'hammer drill'. Clearly then, the process can be much more 
complicated than the surface form of the utterance suggests, and what we have here in terms of a traditional taxonomy is most probably not an L1-based strategy, but an approximation encoded in the L1.

Similarly, the classification of "nep-hair" as 'L1-based' (Dutch 'nep' = English 'fake') would miss the point that the speaker must have analyzed the concept 'wig' into its component features, namely that it is made of hair and that this hair is not real, before he decided to partly encode it in the L1.

The above examples go to show that quite a few of the distinctions made in traditional taxonomies tend to obscure rather than clarify our insights into the processes underlying $\mathrm{CpS}$ use. And since these need to be understood before one can ever attempt to explain and predict $\mathrm{CpS}$ choice, it must be concluded that a good taxonomy of CpS, besides being well-defined and sufficiently general, should be psychologically plausible. In other words, the distinctions that are made should reflect real differences in the processes underlying $\mathrm{CpS}$ use.

\subsection{Conclusion}

In the first part of this chapter several definitions of $\mathrm{CmS}$ were discussed. It was shown that much of the controversy concerning the usefulness of criteria like 'problematicity' and 'consciousness' was due to the fact that Bialystok's notion of $\mathrm{CmS}$ (Bialystok, 1984) is much more comprehensive than Færch \& Kasper's (e.g. Færch \& Kasper, 1983b). Since the Nijmegen project exclusively dealt with CpS used to overcome lexical difficulty, Færch \& Kasper's definition was adopted as the basis for a working definition. Thus, 'problematicity' and 'awareness of problems' will be used as heuristics for locating CpS use.

The discussion of traditional taxonomies brought up a number of practical and theoretical problems. It appeared that the definitions of the CpS types were too vague to allow consistent classification. Moreover, the taxonomies were too specific, both in the sense that they were developed to be used in particular tasks only, and in the sense that they were meant to capture too many minute details. As a result, many changes and additions were called for. The most serious drawback of traditional taxonomies was their lack of psychological plausibility. The criteria which were adopted to distinguish between various subtypes of CpS were not explicitly related to processes underlying CpS use. As a consequence, generalizations to be made with respect to these processes were missed out in many of the earlier studies on $\mathrm{CmS}$.

In view of these problems it was decided to set up a new taxonomy to classify the $\mathrm{CpS}$ in the Nijmegen project. Since we claim that this taxonomy is process-oriented, it will be presented in chapter 4 , where it will be integrated in a discussion of the communication process. 
1. Váradi (1973) defined $\mathrm{CmS}$ as "a conscious attempt to communicate the leamer's thought when the interlanguage structures are inadequate to convey that thought" (quoted by Tarone, 1977:195), but left this definition out in the published version of his paper (Váradi, 1980).

2. The notion of 'Production Strategies', as has repeatedly been noted (Paribakht, 1982:14-15; Færch \& Kasper, 1984:52), is not entirely clear. One wonders, for instance, why CmS are not considered a subset of 'Production Strategies'.

3. Note that Clark \& Clark (1977:225) conceive of communication as problem solving, irrespective of whether it is perceived as difficult or not.

4. An example of a completely different approach, inspired by Vygotskyan theory, is given in Lantolf \& Frawley (1985). In their opinion a strategy is to be defined in terms of the speaker's aims in a communicative act. These aims, they say, are not to transfer meaning, but to regulate oneself as an individual and to gain control over one's environment.

Lantolf \& Frawley's approach is reflected by their taxonomy of $\mathrm{CmS}$ which distinguishes between object-regulated, other-regulated and self-regulated $\mathrm{CmS}$. Basically, $\mathrm{CmS}$ are said to be object-regulated when the learner's interlanguage as an object regulates his choice of strategy (i.e. when his L2 knowledge is so limited that it allows only certain $\mathrm{CmS}$ to be used). They are other-regulated when the presence of another person or other persons in the communicative act regulates the choice of strategy (i.e. when the speaker's choice of a $\mathrm{CmS}$ is determined by the knowledge he assumes his interlocutor(s) to have). Finally. $\mathrm{CmS}$ are self-regulated when maintaining one's self in the communicative act regulates the choice of strategy. An example of self-regulated $\mathrm{CmS}$ is the use of private speech, often in the form of an appeal for assistance or language switch, which serves to gain self-regulation in a difficult task.

5. 'Intentionality' is defined as "the learner's control over those strategies so that particular ones may be selected from a range of options and deliberately applied to achieve certain effects" (Bialystok, 1984:40). This suggests that the strategies are selected and applied consciously, which makes it hard to see what distinguishes the criterion of consciousness from the criterion of intentionality. Færch (1984) mentions goal-relatedness as a third criterion of strategies and equates this with Bialystok's 'intentionality'. It is doubtful, however, whether the two criteria are the same, since Bialystok explicitly points out that "the criterion of intentionality needs to be examined in terms of the deliberative selective control adult L2 leamers display when using these strategies" (Bialystok, 1984:44). The only time she mentions 'goal- relatedness' is in connection with her discussion of the criterion of 'problematicity'. She claims that in the case of native speakers communication is only problematic in the sense that it is goal-oriented, and for this reason rejects 'problematicity' as a defining criterion of $\mathrm{CmS}$ use.

6. The same point is made more explicily by Bialystok \& Sharwood Smith (1985), who maintain that "Even if it is necessary to describe separately the processes responsible for language use under conditions of difficulty (i.e. problem in communication) differently from the processes responsible when no such problems are perceived (i.e. ordinary communication), it is unlikely that the two processes are different" (p.113). 
7. This statement is irreversible. It is not the case that all knowledge-based strategies are used to solve difficulties in communication. For instance, the strategy of selecting the most appropriate lexical itern from a number of available alternatives is also considered to be knowledge-based (cf. Bialystok \& Sharwood Smith, 1985:114).

8. This definition was first presented in Poulisse, Bongaerts \& Kellerman (1984:72).

9. Much of the discussion of traditional taxonomies is adopted from Poulisse et al. (1984). The remainder of this section is largely based on Kellerman, Bongaerts \& Poulisse (1987) and Poulisse (1987).

10. These three subtypes constitute 'Functional Reduction Strategies' of the propositional content. Two other elements of the communicative goal which, according to Farch \& Kasper, may be affected by functional reduction are the actional and madal elements, which relate to problems in performing specific speech acts and/or marking utterances appropriately for politeness/social distance (speech act modality, Færch \& Kasper, 1980:90).

11. In Færch \& Kasper (1984) 'Cooperative Strategies' and 'Non-cooperative Strategies' are distinguished as the two main types of 'Achievement Strategies'. 'Non-linguistic Strategies' in the same article are considered as a subtype of 'Non-cooperative Strategies', on a par with 'L1/L3 Strategies' and 'II Strategies'. 


\section{A Survey of the Literature: Empirical Research}

This chapter will present an overview of the relevant empirical studies to date. In the first place these are empirical studies of $\mathrm{CmS}$. Many of these, it will be seen, are exploratory and fairly small-scale, while some are notably weak from a methodological point of view. Consequently, the conclusions to be drawn from these studies are necessarily tentative. Still, the studies were important to the Nijmegen project for two reasons: first, they provided the basis for the hypotheses relating to research question 1 , concerning the relationship between the subjects' $L 2$ proficiency level and their use of $\mathrm{CpS}$; and second, they yielded certain practical insights which have affected the design of the project.

Besides the empirical studies of CmS a number of studies on L1 referential communication will be discussed. This will be done in section 3.2. It is assumed that research on referential communication will be relevant to the study of $\mathrm{CpS}$, since $\mathrm{CpS}$ generally have a referential function. Moreover, the task which has been used in some of this research proved to be most suitable for a comparison of L1 and L2 strategic behaviour. Two studies in which L1 and L2 speakers' performances on such a referential communication task were compared will be discussed at the end of section 3.2. They constituted the basis for the hypotheses to be formulated with respect to research question 2 , conceming the relationship between $\mathrm{CpS}$ use in $\mathrm{L} 1$ and $\mathbf{L} 2$.

\subsection{Empirical research on communication strategies to date $^{1}$}

The overview to be given in this section will be restricted to those studies in which $\mathrm{CmS}$ use is specifically related to gaps in the speaker's linguistic repertoire. As will have become clear from the discussion of Bialystok's work in chapter 2, it is also possible to adopt a more comprehensive view of $\mathrm{CmS}$ which captures all plans and/or processes that lead to the achievement of communicative goals. Other researchers besides Bialystok whose work relates to a broader concept of CmS are Klosek (1982), Dechert (1983), Raupach (1983), Wagner (1983) and Lê \& McCausland (1986). Their notion of CmS includes the use of repair strategies (Klosek, 1982), the use of 'islands of reliability', i.e. formulaic phrases which allow the speaker to plan the next utterance (Dechert, 1983), the use of drawls, filled pauses and repetitions as time gaining strategies (Raupach, 1983), the use of interactional strategies such as 'handing over the conversation to the more competent participant' (Wagner, 1983), and the use of praising, threatening, disarming or defensive strategies 
to obtain certain privileges (Lê \& McCausland, 1986). ${ }^{2}$ Interesting though their work is, it had to be excluded from the present overview for reasons of space.

The very first study on the use of $\mathrm{CmS}$ was a pilot study conducted by Varadi (1973). The elicitation method that was used in this study was a picture story description task, which has subsequently been adopted in one version or other by many other researchers of CmS. Váradi's study involved 19 adult Hungarian learners of English at an intermediate level (they had studied English for between 6 to 9 months, 16 hours per week). The learners were divided into two groups. Group 1 was asked to write down a description of a picture story in English and subsequently in Hungarian. They were allowed 45 minutes for the English version and 30 minutes for the Hungarian version. Group 2 was set the same task in reverse order, that is, they were asked to produce the Hungarian version before the English one. Some days later all subjects were asked to translate the Hungarian versions into English and the English versions into Hungarian. They were not allowed to leave blanks, but it was suggested they paraphrase unknown lexical items, reproducing as much of the original story as possible.

The advantage of Varadi's design is that a comparison of the Hungarian and the English versions made it possible to determine the leamer's optimal meaning (as, supposedly, expressed in Hungarian). The translations were meant to reveal whether differences between the two language versions were the result of conscious adjustments or unconscious mistakes. The disadvantage of this study is that the data are written, so that there is little or no information (in the form of pauses, repetitions, false starts and the like) about the process underlying language production. Váradi tentatively concludes from this study that the $L 2$ versions, particularly when produced before the $L 1$ versions, tended to be much more reduced. They are characterized by extreme stylistic economy and simplicity, while many situations, events and people are simply left out. Key concepts, however, seldom remained unmentioned, but were communicated by various kinds of $\mathrm{CmS}$.

Tarone (1977) used a spoken version of an otherwise similar picture story task. Her study involved 9 adult leamers of English as a second language (ESL students) of different language backgrounds, namely Spanish, Turkish and Mandarin. All learners were at an "intermediate level", although there was a good deal of variance within that proficiency level. Again, the pictures were described by the subjects in both their native language and in English, which made it easier to identify where $\mathrm{CmS}$ had been used. For this same purpose of $\mathrm{CmS}$ identification Tarone reviewed the task with each subject after she had recorded it. In these retrospective sessions she asked the subjects whether they knew particular forms in English, or why they had used one form rather than another. With the help of this kind of information she was better able to determine where problems had been experienced. 
Tarone's conclusions, which were based on the subjects' performance on 7 of the most difficult target items, were necessarily tentative because of the limited number of subjects in the study. She suggests that there is no relation between $\mathrm{L} 1$ background and $\mathrm{CmS}$ performance, but that both personality and L2 proficiency level may correlate highly with $\mathrm{CmS}$ preference.

Picture story tasks were also used by Palmberg (1979) and Ervin (1979). Palmberg's subjects were 24 Finns, 19 Finland-Swedes and 36 Swedes. They were given a series of pictures and were asked to tell the story it comprised, first in English (L2) and then in the L1. To make sure the subjects knew what the pictures were intended to express, and to enhance comparability between the subjects' stories Palmberg added to the picture story a brief summary in the subjects' L1.

Palmberg restricts his discussion of the results to the 6 most frequently occurring target items in the story. On the basis of the $\mathrm{CmS}$ used for these items by the three groups of subjects he hypothesizes, like Tarone (1977), that "strategy preference is primarily a question of proficiency level and personality, irrespective of learner L1" (p.73). Moreover, he points out that strategy preference may also be task- and/or item-specific. This suggests that a large variety of items in different tasks are needed to obtain valid results.

Ervin (1979) was not only interested in the type of $\mathrm{CmS}$ used by foreign language learners, but also in the comprehensibility of these $\mathrm{CmS}$. His study involved 14 American students of Russian, again at an intermediate level, who provided English and Russian narrations of three picture stories. The subjects proved to make extensive use of $\mathrm{CmS}$, especially 'Topic Avoidance' (36\% of the CmS used), 'Approximation' (25\%), and 'Description' (16\%). To establish the comprehensibility of $\mathrm{CmS}$ the students' renditions of 32 specific story items were presented to a panel of 12 judges who were asked to evaluate them. This part of Ervin's study will be discussed in more detail in section 10.1, which surveys research on the effectiveness of $\mathrm{CmS}$.

Although the picture story description task which was used in the four studies described above has certain practical advantages (e.g. with respect to the identification of $\mathrm{CmS}$ ), it has the disadvantage of being fairly unnatural. In particular the absence of an interlocutor was considered problematic by many researchers. They felt that the lack of feedback might affect the subjects' use of $\mathrm{CmS}$ and for this reason started experimenting with tasks that more closely resemble real communication.

A good example of this new approach is the study by Galvan \& Campbell (1979). They investigated the use of $\mathrm{CmS}$ by two Anglophone children (11 and 12 years old) who had been involved in a Spanish immersion programme since kindergarten. The children were asked to act as interpreters for their school secretary, a monolingual English speaker, who was filling in a form for a "monolingual Spanish mother". Since the children did not know they were 
being recorded this task can be considered as one which elicits natural communication.

The data revealed that certain types of $\mathrm{CmS}$ were indeed dependent on the nature of the task. It appeared that the more a situation approached a natural setting, the less a subject would opt for an 'Avoidance Strategy' and the more he would opt for CmS such as 'Appeal for Assistance' and 'Approximation', which maintain communication. The conclusion which Galván \& Campbell draw from this finding is that studies of $\mathrm{CmS}$ should comprise more than one experimental task. As we have seen, this point could also be made on the basis of the study reported by Palmberg (1979).

It has already been noted that both Tarone (1977) and Palmberg (1979) suggested that the subjects' proficiency levels and/or their personalities might affect their use of $\mathrm{CmS}$. In neither of these studies, however, had these factors been included as explicit objects of research. True, there were some global indications of the subjects' proficiency levels, but no attempts had been made to formally establish them, so that the relationship between $\mathrm{L} 2$ proficiency level and $\mathrm{CmS}$ use could not be reliably determined. As to the subjects' personalities, no information whatsoever was available on this point, so that the effect of this factor on CmS use could not be determined either. Clearly then, the hypotheses put forward by Tarone (1977) and Palmberg (1979) were still in need of testing.

A first attempt in this direction was made by Bialystok \& Froblich (1980), who investigated the relationship between a) the learner's inferencing ability and his use of $\mathrm{CmS}$; and b) the learner's L2 proficiency level and his use of $\mathrm{CmS}$. In addition, they studied c) the relationship between the task and the learner's use of $\mathrm{CmS}$, including both the effect of the target items and the effect of the communicative situation; and d) which $\mathrm{CmS}$ were most effective in communicating the subjects' intended meanings.

The subjects were three groups of English students of French at three different proficiency levels. The most proficient group consisted of 14 adults. The two other groups consisted of 12 and 18 17-year-olds, respectively. The subjects' proficiency level had been pretested by means of a cloze test. To determine their inferencing ability a Danish sentence translation task had been used.

Two tasks were used to elicit CmS: a picture reconstruction task and a picture description task. In the picture reconstruction task the subjects were asked to describe a picture of a young girl standing on a stool to hang a Christmas stocking on the mantlepiece so that a native speaker of French could reconstruct this scene on a flannel board. The subjects could see the flannel board and were thus provided with feedback, albeit non-verbal. This task was assumed to be communicative, difficult enough to elicit $\mathrm{CmS}$, and it enabled the experimenter to easily identify the $\mathrm{CmS}$ that were used. In the picture description task the same picture had to be described, but this time no feedback whatsoever was provided. 
The subjects were randomly assigned to one of the two tasks. Bialystok \& Froblich found that on the whole the three groups did not differ in the number or the type of $\mathrm{CmS}$ they used. The only exception to this finding was that the advanced student group used fewer L1-based strategies. Within the groups, however, there were more proficiency-related differences. Here too the most striking difference was that the less proficient subjects tended to use more L1-based strategies. Inferencing proved to have a positive effect on $\mathrm{CmS}$ use. Subjects with high scores on the Danish test were able to generate $\mathrm{CmS}$ that were "effective but within their limits of proficiency" (p.16). Task effects were considered both in relation to the task's items and in relation to the nature of the task. Items proved to have a clear effect on the choice of $\mathrm{CmS}$, which confirms Palmberg's (1979) suggestion that CmS use is item-specific. The two tasks differed in that in the picture description task the subjects were less motivated to produce language and to use $\mathrm{CmS}$ to communicate target items for which they did not know the French names. Bialystok \& Fröhlich ascribe this to the lack of feedback. ${ }^{3}$

The effectiveness of $\mathrm{CmS}$ was measured by a combination of two judgement tasks. In one, $\mathrm{CmS}$ had to be rank-ordered by 17 native speakers of French in terms of their effectiveness in conveying the meaning of the particular item. In the other, two native speakers of French were to score the comprehensibility of $\mathrm{CmS}$ on a six-point scale (0-5). The results of these judgement tasks suggest that 'Functional Description' is most and 'Language Switch' is least effective. In addition, Bialystok \& Fröhlich conclude that a learner has to have a certain proficiency level in order to be able to apply $\mathrm{CmS}$ effectively. A more detailed discussion of the effectiveness tests and their results will be given in section 10.1 .

The question of personality was taken up by Haastrup \& Phillipson (1983), whose subjects (8 Danish leamers of English, all of whom had had five years of English as part of their compulsory schooling) were chosen from three different types of school on the assumption that in this way one might get hold of different learner types, hence different personalities. No personality tests were administered, however. The data examined by Haastrup \& Phillipson consisted of 8 video-taped, 20 minute, dyadic, face-to-face conversations on everyday topics between the subjects and a native speaker of English. They are clearly communicative in nature and thus reflect the growing tendency to study $\mathrm{CmS}$ in spontaneous language use.

On the basis of the data a profile was set up for each learner. This involved a general characterization of the conversation in terms of fluency, the pattem of communication disruptions and the number and types of 'Achievement Strategy' used in it. It proved impossible, though, to relate the identified strategy styles to the leamers' school background. Rather, it seemed that each learner had his own strategy style, which was supposed to be determined by his particular personality. 
Haastrup \& Phillipson also investigated whether some CpS types are more successful than others, in the sense that they cause fewer communication disruptions. Their conclusions in this respect support those of Bialystok \& Frohlich (1980). 'L1-based Strategies' seemed to be least successful, while 'Interlanguage-based Strategies' (particularly 'Paraphrase') were most likely to lead to understanding.

While Galván \& Campbell (1979), Bialystok \& Fröhlich (1980) and Haastrup \& Phillipson (1983) chose to study $\mathrm{CmS}$ in a setting that was more natural than that of a picture story description task, other researchers chose more strictly controlled experimental set-ups. Two examples are the studies by Elsen, de Kleine, de Vries \& Weijnen (1982) and Paribakht $(1982 ; 1985)$.

Elsen et al. (1982) were interested in the L2 proficiency factor. To examine its effect on L2 learners' use of CmS they presented their subjects (16 Dutch learners of English at two different proficiency levels) with a series of 44 photographs, each picturing one concrete object, which the subjects were asked to name or describe. A pretest had established that the names of 21 of these objects were unlikely to be known to the subjects. The other 23 test items were expected to be known and had been included for encouragement. The experimenters did not give any feedback. No time limit was imposed.

In their analyses, Elsen et al. made a distinction between superordinate and subordinate (or embedded) strategies (see chapter 4). It appeared that the differences in the total number of $\mathrm{CmS}$ used were relatively small (students: 312 vs pupils: 371 ). The two groups did differ considerably, however, in the number of L1-based strategies they used (students: 17 vs pupils: 96 ). This confirms the findings of Bialystok \& Froblich (1980). Interestingly, Elsen et al. found a striking difference between super- and subordinate strategies. While most of the superordinate strategies were L2-based (L2-based: 465 vs L1-based: 36), many of the subordinate strategies were L1-based (L1-based: 77 vs L2-based: 105), particularly in the case of the pupils (pupils L1-based: 67 vs pupils L2-based: 30 ).

The task used by Elsen et al. has a number of advantages: 1) the effect of feedback can be controlled for; 2) the nature of the task is such that all problems have to be tackled; 3) given 2) $\mathrm{CmS}$ are comparatively easy to identify and 4) the task can easily be reproduced, which enhances comparability. The disadvantages are that the data are not very natural. Therefore, a task like this is best supplemented by other, less controlled, tasks.

Paribakht $(1982 ; 1985)$ used a similar controlled task both to establish the effect of the L2 leamers' proficiency level on their use of $\mathrm{CmS}$ and to compare native speakers' $\mathrm{CmS}$ use to that of non-native speakers. In her study the subjects had to refer to (one of) two sets of concrete items and one set of abstract items. Each set contained 10 concepts, which were expected to be known to the subjects, but which were at the same time sufficiently difficult - from a 
linguistic point of view - to constitute a genuine communicative problem for them. The abstract items were expected to place an even heavier linguistic burden on the subjects and consequently to reveal more clearly the disparity in communicative ability among the subject groups.

There were two groups of 20 Persian ESL students at different proficiency levels (G1 and G2). Their grammatical proficiency level had been measured by two tests: the 'Michigan Test of English Language Proficiency' (written) and the 'International Educational Achievement Test of Proficiency in English as a Foreign Language' (oral). In addition, there was a control group of 20 native speakers of English (G3). G1 and G2 were presented with pictures of the first set of concrete items and were asked to convey the concepts to their interlocutor, who had to identify them. In an attempt to make this highly controlled task somewhat more communicative, each subject had a different interlocutor, who was, in all cases, a native speaker of English. The native speaker group (G3) was asked to do the task with both sets of concrete items, but without using the names if they knew them. The procedure for the set of abstract items, which were written on cards in the subjects' mother tongues, was essentially the same.

On the basis of this study Paribakht concludes that the differences between the types of $\mathrm{CmS}$ used by the three groups are minimal. The groups did differ, however, in the relative frequency with which they used a number of $\mathrm{CmS}$ types. Initial leamers drew more often on their other knowledge sources, such as world and paralinguistic knowledge, in order to compensate for the limitations of their target language knowledge than more advanced learners and native speakers. This leads Paribakht to conclude that in general $\mathrm{CmS}$ use and L2 proficiency level are related.

It should be noted that Paribakht's design is somewhat problematic from a methodological point of view. The L1 and L2 data were elicited from two different groups of subjects. For this reason one can never be sure that the few differences that were found between native and non-native speaker subjects should be attributed to their native- or non-nativeness. They may also have been the result of e.g. cultural differences and/or differences in the subjects' educational backgrounds.

The same methodological problem featured in a study by Tarone \& Yule (1983), who compared the use of $\mathrm{CmS}$ in interactive tasks involving either two non-native speakers of English (of two different language backgrounds) or two native speakers of English. Tarone \& Yule's subjects were 12 Spanish speakers interacting with one of 15 Asian language speakers (Japanese, Korean or Chinese), and 9 native speakers of English interacting with each other. The speakers' tasks constituted a good mixture of controlled and more natural language activities. They were (1) to describe four objects, (2) to provide instructions for a series of actions, and (3) to narrate a series of events. The listener had to identify the object or event described (from a series of 
photographs) or to follow the instructions. After a speaker had performed all tasks, the listener and the speaker changed places. ${ }^{4}$ The only feedback that was allowed was non-verbal.

Tarone \& Yule report that the native and non-native speakers of English in this study largely used the same CmS. Differences between the two groups of subjects mostly related to the number of repetitions and the degree of explicitness. Non-native speakers interacting with other non-native speakers not only used more repetitions than native speakers, but also used them differently, for instance as a means of buying time and to provide the non-native listener with another chance to hear and process the information. Another point made by Tarone \& Yule is that non-native speakers only used culturally-based information which their listeners were likely to be familiar with. Clearly, this finding is in accordance with general principles of communication (see chapter 4) and it would in fact have been most surprising if the subjects had not taken their interlocutors' knowledge into account.

The problem with Tarone \& Yule's study, as with Paribakht's study, is that it cannot be determined whether the differences between the L1 and L2 data should be attributed to the speakers' native- or non-nativeness or to other differences, e.g. in their educational or cultural backgrounds. The only way to overcome this problem is to elicit both L1 and L2 data from one group of subjects (Raupach, 1983). Another problem, specific to the study by Tarone \& Yule, is the lack of data from non-native speakers interacting with native speakers and, conversely, of native speakers interacting with non-native speakers. As it is, the design that was used does not allow one to determine whether it is the non-nativeness of the speaker or the listener that caused the observed effects.

Since 1983, when all seminal papers on $\mathrm{CmS}$ were published in a very useful anthology (Færch \& Kasper, 1983a), there has been surprisingly little innovative empirical research on $\mathrm{CmS}$. There have been only few attempts at answering new research questions, the exceptions being Fakhri (1984), Irujo (1985) and Labarca \& Khanji (1986). Fakhri (1984) studied the use of CmS in different parts of narrative discourse. The conclusion drawn from this case study is that $\mathrm{CmS}$ use is constrained by the urgency to convey meaning in different parts of the narrative. The impact of this conclusion is severely limited though, since only 45 instances of $\mathrm{CmS}$ use were collected.

Irujo (1985) compared the use of $\mathrm{CmS}$ by second and foreign language learners in written dialogue joumals and observed that the former used fewer L1-related strategies than the latter. This is explained as a result of the fact that the foreign language leamers were native speakers of Spanish who knew that their L1-related strategies would be understood by their teacher. The second language leamers, however, spoke L1's which the teacher did not know. Hence, for them the use of L1-related strategies was not a real option. 
Finally, Labarca \& Khanji (1986) investigated the effect of different methods of instruction on $\mathrm{CmS}$ use and found that subjects instructed through the Strategic Interactive Method (Di Pietro, 1979; 1982) used fewer CmS to get their meaning across than subjects instructed through the Total Physical Response Method (Asher, 1969). Unfortunately, however, this study was not free from methodological problems either. The two subject groups not only differed in the method of instruction they received, but also in proficiency level. Consequently, it is not clear to which of these factors the observed difference in the number of $\mathrm{CmS}$ used had to be ascribed.

Most other studies of CmS largely resembled those conducted before 1983. They addressed the same research questions by means of the same research methods (see e.g. Jarujumpol, 1983; Allen, 1984; Corrales, 1985; Glahn, 1985; and Nayar, 1987: all on the influence of the learners' L2 proficiency level; and Trosborg, 1982; and Ellis, 1984: on the use of CmS by L1 and L2 speakers).

There have been only two large-scale studies (besides the one conducted in Nijmegen) in which a variety of different elicitation methods was used. One is an ongoing project by Stedje (1985) about the use of $\mathrm{CmS}$ by 40 Swedish leamers of German and an unreported number of anomic aphasics. The tasks are 1) the retelling of a well-known story, read by the experimenter, 2) a picture description task and 3) a picture story task. Unfortunately, however, the results of this project have not yet been published.

The other study was a longitudinal study by De Keijser (1986). This study involved two groups of American leamers of Spanish. Group 1 consisted of 7 students who were observed during a one-year stay in Spain. The observations included both formal (classroom) and informal (kitchen, bar) situations. In addition, the subjects were tested three times, with three-weekly intervals, on picture description tasks and oral interviews. Group 2 consisted of 5 American learners of Spanish who were planning to go abroad for a year. They were observed in the classroom and took the same two tests. De Keijser reports that few differences were found between the two groups' use of CmS. Rather, it appeared that $\mathrm{CmS}$ use differed in relation to task. Thus, this study confirms the predictions made in earlier research that the use of $\mathrm{CmS}$ is task-specific.

At this place it seems appropriate to summarize the studies discussed so far and to see in what ways they have contributed to the Nijmegen project.

Firstly, it has been shown that there has been considerable development in the elicitation methods used. Whereas initially picture story description tasks were the most popular, a wide variety of elicitation methods, including both more and less natural tasks, have been used later on. The experiences gained in the use of these elicitation methods greatly facilitated the selection of suitable tasks for the Nijmegen project. More important still was the point made by Palmberg (1979), Galván \& Campbell (1979) and Bialystok \& Fröhlich (1980) that $\mathrm{CmS}$ use is likely to be task- and item-specific. This convinced us that to 
obtain an overall picture of $\mathrm{CpS}$ use it is necessary to collect data on a variety of tasks. ${ }^{5}$ To ensure the validity of the results it was decided that at least one of the tasks should put the subjects in a 'natural' situation, that would give us data comparable to normal, spontaneous speech.

Secondly, it can be concluded that $\mathrm{CmS}$ research has mostly been directed at the relationship between $L 2$ leamers' proficiency levels and their use of $\mathrm{CmS}$. In chapter 1 it was mentioned that this research question will also be addressed in the present study. On the basis of the studies discussed in this chapter two hypotheses can be formulated:

1) learners at a lower $\mathrm{L} 2$ proficiency level will use more $\mathrm{CmS}$ than learners at a higher L2 proficiency level; and

2) learners at a lower L2 proficiency level will use (proportionally) more strategies which are based on their mother tongue than leamers at a higher L2 proficiency level.

These hypotheses will be tested in chapter 8 .

Other research questions addressed in the studies discussed here concerned the relationship between $\mathrm{CmS}$ use and the learner's L1 background or personality, the effectiveness of various $\mathrm{CmS}$ types, and the use of $\mathrm{CmS}$ by native and non-native speakers of a language. The learner's L1 background proved to have little influence on his use of $\mathrm{CmS}$, while the effect of personality could not be established because the researchers were unable to assign their subjects to different personality groups.

Studies of the effectiveness of CmS suggested that 'Descriptions' are most and 'L1-based Strategies' are least effective. It has already been indicated in chapter 1 that the question of effectiveness was included in the Nijmegen project too. The reason for this, it will be recalled, was that the answers to this research question were expected to have important pedagogical implications.

Finally, it was revealed that there were only a few differences between native speakers' and non-native speakers' use of $\mathrm{CmS}$. The findings of these comparative studies should be regarded with some suspicion though, since in all cases the L1 and L2 data were elicited from different groups of speakers, which implies that they were not really comparable. In the Nijmegen project this methodological problem was solved by using an elicitation method that allows one to collect both $L 1$ and $L 2$ data from the same speakers (see section 3.2).

\subsection{Referential communication studies}

In most of the studies described above $\mathrm{CmS}$ were used to establish reference to some object, person, state or event. This is, of course, most obvious in the 
case of picture description tasks, which typically require subjects to refer to specific objects so that (potential) listeners can recognize the picture which is being described. However, in ordinary conversations too $\mathrm{CmS}$ are to a large extent referential in nature, a point that will be most evident if one considers that reference is generally taken to be "one of the most basic of communicative functions" (Glucksberg, Krauss \& Higgins, 1975:305/306).

In view of the referential character of many $\mathrm{CmS}$ it seems appropriate to pay some attention to research on referential communication. After all, it is not unlikely that the factors which influence referential communication also play a role in the use of $\mathrm{CmS}$. A second reason for discussing referential communication here is a practical one. The task used in some of this research proved to be eminently suitable for comparing L1 and L2 speakers' strategic behaviour in the case of lexical gaps and was, for this reason, adopted in the Nijmegen project to answer research question 2 conceming the relationship between CpS use in L1 and L2. ${ }^{6}$

Referential communication takes place when one participant in a conversation constructs a message that enables someone else to select or identify a target stimulus (the referent) from among a set of implicit or explicit altematives (Glucksberg et al., 1975; Lyons, 1977). This job is not as simple as it appears at first sight. It is severely complicated by the fact that in ordinary language there is no one-to-one correspondence between the referent and its reference. As R. Brown (1958) pointed out, a particular person can be referred to as 'Daddy', 'a policeman' or 'Mr Jones', depending on who is speaking in which situation. It is up to the speaker to decide which of these references is most appropriate at a particular place and time. Conversely, one and the same reference, e.g. 'animal', may refer to many different referents including such diverse creatures as mice, cats, lions and elephants. Whether it can be used to refer to a particular mouse or cat depends on the presence of other animals from which this particular one needs to be distinguished. It is the speaker's job to solve such referential problems by encoding his references in such a way that they enable the listener to infer what the intended referent is.

Glucksberg \& Krauss (1967) maintain that the encoding of a referent by an adult speaker is affected by "his goals; the immediate social, physical and linguistic context; his perception of the listener, and the set of non-referents from which the referent is to be distinguished" (p.310). This position is further developed in Krauss \& Glucksberg (1969), where it is said that referential communication involves two analyses to be performed by the speaker. The first of these is an analysis of the stimulus array. This is needed to make sure that the reference distinguishes the referent from other non-referents. Obviously, different attributes of the referent will need to be mentioned depending on the number of altemative referents in the array (Olson, 1970) and their similarity to the intended referent (Krauss \& Weinheimer, 1967). The second analysis 
concerns the listener. The speaker will need to estimate the listener's knowledge and capabilities so that he can make use of shared knowledge and rely on the listener's inferencing skills when constructing a reference (cf. Ratner \& Rice, 1963).

In a later article, Glucksberg et al. (1975) present a two-stage model of referential communication. In the first stage, the speaker constructs a reference phrase on the basis of the attributes of the referent. In the second stage, the comparison stage, he compares the attributes of the referent to those of the non-referents and checks whether the reference phrase he constructed is sufficiently distinctive. If it is, the reference phrase will be emitted. If not, it will be stored in a buffer from which it will only be retrieved if a more suitable alternative cannot be constructed. ${ }^{7}$

Glucksberg et al.'s model of referential communication was the result of a long series of studies, the most important of which will be discussed below. All studies involved a referential task which required the speaker to refer to a number of novel graphic designs (see appendix I) in such a way that the listener, who could not see the speaker or the speaker's task materials, could identify them. The figures to be referred to were specifically designed for the experiment and therefore unknown to the subjects. They did not have conventional names, but rather tended to elicit a wide range of verbal labels. Depending on the participants of the study (adults or children) the figures were printed on cards or stuck to the four vertical sides of blocks that could be stacked on a peg. The task to be performed was a matching task. The speaker had to name or describe the figures in a particular order predetermined by the experimenter and the listener was to arrange his cards or blocks in exactly the same order. In most studies the listener was actually present, but separated from the speaker by means of an opaque screen so that non-verbal encoding, e.g. by pointing at the intended figure, was ruled out In some of the studies, however, the listener was put in a different room or was asked to respond to the speakers' references at a later time.

In the first study of this kind, Krauss \& Weinheimer (1964) showed that speakers tended to start with fairly lengthy references when first referring to a particular figure, but that after one or more trials the subjects generally agreed upon a name. These names were shortened as a function of the frequency with which they were used. To illustrate this Krauss \& Weinheimer cite a pair of subjects who "referred to a figure on the first mention as an upside down martini glass in a wire stand, then as an inverted martini glass, then as a martini glass, and then, after some time, simply as martini" (p.114). These examples suggest that the speaker took the listener's knowledge into account. Because they had gone through the trials together, the speaker could safely assume that "martini" would be interpreted by the listener as an abbreviation of "upside down martini glass in a wire stand". Hence, it would have been over-specific and thus a waste of effort if he had kept repeating this lengthy reference in every trial. 
In a follow-up study, Krauss \& Weinheimer (1966) investigated the effect of feedback on the speakers' references. They distinguished two kinds of feedback. One is the use of phrases like 'huh' and 'okay' on the part of the listener to inform the speaker of the effect his message is having. This they refer to as concurrent feedback since it occurs along with the speaker's message. The second kind of feedback is called confirmation. It can be derived from the listener's behaviour after the message has been completed. If, for instance, the listener selects the picture the speaker just described, the speaker can infer from this that his message was sufficiently clear.

In the experiment half of the subjects received concurrent feedback (CF) from the experimenter-listener who was in a different room, while the other half received no concurrent feedback (NCF). Moreover, half of the subjects in the CF and half of those in the NCF conditions received confirmation that the listener had correctly responded to their message after all trials ( $100 \%$ confirmation). The other subjects received such confimation after $50 \%$ of the trials only.

The experiment led Krauss \& Weinheimer to the conclusion that the length of reference phrases is affected by feedback. Both when CF was withheld and when confirmation was given after only $50 \%$ of the trials the subjects' reference phrases contained more words. Again, this study indicates that the speaker takes his listener into account and adapts the specificity of his references to the listener's needs (as indicated by positive or negative feedback).

At the same time Glucksberg, Krauss \& Weisberg (1966) conducted a study in which they compared adults' references to those produced by young children (nursery-age). It appeared that the children's references were much shorter than the adults'. Moreover, they proved to be highly idiosyncratic. They were virtually incomprehensible to other listeners, who were often unable to identify the referents they designated, but they were meaningful to the children themselves, who were able to select the right figures when their own descriptions were read to them.

On the basis of this study, Glucksberg \& Krauss (1967) hypothesized that children's speech is non-social. Children, they say, do not evaluate the informative value of their messages, nor do they adapt their messages when the listener's feedback indicates that the informative value was (too) low. To test this hypothesis they studied whether feedback had a differential effect on the reference phrases produced by children and adults. This proved to be the case. Whereas adults adjusted their references in accordance with the feedback given to them by the experimenter, young children did not. Even when they were explicitly asked to give more information children tended to stick to their initial descriptions.

In a later paper, however, Krauss \& Glucksberg (1977) explain the children's apparent non-social behaviour in the 1967 study as an artificial result of the cognitive difficulty of the figures to be described. They note that in similar tasks with simpler referents the children did take the listeners' 
perspectives into account and managed to produce socially acceptable messages.

Children's communication abilities were further studied by Krauss \& Rotter (1968) and Krauss \& Glucksberg (1969). Krauss \& Rotter's study indicated that a child's performance in the matching task, either as speaker or listener, was affected by his age ( 7 or 12) as well as his social status (middle or lower class). The same age effect was also found by Krauss \& Glucksberg (1969), who tested the intelligibility of children's references to Krauss \& Weinheimer's novel graphic designs.

The effect of social status was further examined by Alkire, Collum, Kaswan \& Love (1968, sorority members vs sorority pledges), Heider (1971, middle class white vs lower class white vs lower class black: ten year olds), Willich, Fischer \& Schwanenberg (1972, students vs firemen), Kăhler (1975, lower class vs middle class) and Johnston \& Singleton (1977, middle class vs working class: five year olds). In all these studies higher status subjects were found to be superior to lower status subjects in either encoding or decoding novel graphic designs or both.

Another interesting result obtained in these studies relates to the coding styles preferred by the subject groups. Lower status subjects tended to adopt what Heider (1971) refers to as a whole-inferential coding style. This means that they generally referred to the figure as a whole by means of a metaphor that the figure suggested to them, as in "it looks like a spaceship". Conversely, higher status subjects made more use of a part-descriptive encoding style (again Heider's terminology), often in combination with whole-inferential encoding. Thus, these subjects' whole-inferential encodings were often followed and/or preceded by a description of the component parts of the figure in terms of its physical properties. An example of a part-descriptive encoding is "it's got a line sticking out on the bottom".

It tumed out that whole-inferential encodings were easier to decode than part-descriptive encodings (Heider, 1971; Kăhler, 1975). This seems to contradict the finding that lower status subjects are less efficient encoders than higher status subjects. Heider (1971), however, reports that composite encodings, which consisted of a combination of whole-inferential and part-descriptive encodings, were decoded best. Since these were used frequently by middle class subjects (84\%) and very infrequently by lower class subjects $(21 \%)$, this explains the apparent contradiction in the results.

Finally, it is worth discussing a recent study by Clark \& Wilkes-Gibbs (1986) which is essentially a replication of Krauss \& Weinheimer (1964), except for the fact that tangram figures were used instead of the original Krauss \& Weinheimer figures. The main purpose of this study was to investigate how speakers and listeners try to reach agreement on a reference.

Clark \& Wilkes-Gibbs analysed their data in terms of the perspectives adopted by the speakers when describing the figures. They distinguished 
between two main global perspectives: a holistic one, "in which the object is conceived of as a wholc", and a segmental one, "in which the object is conceived of as segments that happen to be juxtaposed" (p.30-31). 'Holistic' perspectives tended to be analogical, that is, they tended to relate the figures to natural objects. 'Segmental' perspectives tended to be literal, meaning that they focussed on the geometrical parts of the figures and their relations. Clearly, this distinction is very similar to the distinction between whole-inferential and part-descriptive encodings made by Heider (1971).

Clark \& Wilkes-Gibbs report that in Trial One the subjects would generally start their references with an analogy (i.e. from a 'holistic' perspective) to which they added a description from a 'segmental' perspective. In subsequent trials the segmental part of the references would gradually be reduced until all that remained was the analogy. They then argue that the preference for 'holistic' perspectives is in accordance with their assumption that speech partners will try to minimize collaborative effort (see also chapter 4 ). They take it that "accepting a perspective on the whole establishes perspectives on each part, but not vice versa" (p.31).

So far, all of the studies discussed here were concerned with referential communication in the $\mathrm{L} 1$. It should be noted though that the matching task devised by Krauss \& Weinheimer can also be used with $\mathrm{L} 2$ speakers and thus to compare L1 and L2 speakers' referential strategies. The reason for this, of course, is that the novel graphic designs that were used do not have conventional names so that they pose similar referential problems to $\mathrm{L} 1$ and L2 speakers. In the last part of this section two studies will be discussed in which $L 2$ referential communication is compared with $\mathrm{L} 1$ referential communication. These studies formed the basis for that part of the Nijmegen project that concerns the relationship between $\mathrm{CpS}$ use in $\mathrm{L} 1$ and $\mathrm{L} 2$.

Bongaerts, Kellerman \& Bentlage $(1987)^{8}$ replicated Krauss \& Weinheimer's (1964) study with four groups of Dutch leamers of English. Each group consisted of 6 pairs of subjects who had been leaming English for approximately one, three, five and seven years, respectively. These four proficiency groups are referred to as P1, P2, P3 and P4. The matching task to be performed by each pair of subjects required the directors to refer to 12 of the original Krauss \& Weinheimer figures in such a way that the matchers, who were given these figures on separate cards, could arrange them in the order mentioned by the directors. This task was carried out six times by each of the dyads. Since only 6 of the 12 figures occurred in each trial, the analyses were restricted to the subjects' references to these 6 figures.

When the L2 speakers' referential behaviour was compared to that of the L1 speakers in Krauss \& Weinheimer (1964) and Clark \& Wilkes-Gibbs (1986), there appeared to be many resemblances. Firstly, the L2 learners and the native speakers of English followed an essentially similar pattern 
in reducing the complexity of their references over a number of trials. Secondly, the $\mathrm{L} 2$ leamers described the figures from the same perspectives as the native speakers in Clark \& Wilkes-Gibbs' study; that is, they adopted either a 'holistic' or a 'segmental' perspective (or both). And thirdly, the L2 leamers, like the native speakers in Krauss \& Weinheimer (1964) and Clark $\&$ Wilkes-Gibbs (1986), exhibited a preference for descriptions from a 'holistic' rather than a 'segmental' perspective. There was one exception to this: for no apparent reason the P3 group preferred descriptions from a 'segmental' perspective.

In other ways the leamers did not behave like American native speakers. They needed more words (in all six trials) and their final referential labels were structurally more complex than those in Krauss \& Weinheimer's (1964) study (cf. Carroll, 1980). Bongaerts et al. note, however, that this difference need not be a difference between native and non-native referential behaviour. In part it can be ascribed to the fact that Krauss \& Weinheimer's task was somewhat simpler (fewer figures were used, and they were presented in a fixed array) and consisted of 16 rather than 6 trials. It is also possible though that the difference may "boil down to a difference in behavior between the Dutch and American experimental populations" (p.189). To support this interpretation Bongaerts et al. refer to the results of an unpublished study in which the same task was carried out by native speakers of Dutch (Tielen \& Witteveen, 1987). In this study the final references were as complex as in Bongaerts et al.'s own study.

The study by Bongaerts et al. (1987) gœes to show that L1 and L2 referential behaviour are similar in many respects. In particular, the choice of referential strategies was much the same for L1 and L2 speakers. Unfortunately, however, an interactive task such as the one used by Bongaerts et al., and particularly one that involves a series of trials, requires that $\mathrm{L} 1$ and $\mathrm{L} 2$ data be collected from two different groups of subjects. The reason for this is that pairs of subjects who have performed this task in their $\mathrm{L} 1$ will naturally continue to use the established referential phrases in the L2 version of the task. And obviously, if in the $L 1$ version they managed to reduce their references successfully over a number of trials, they will attempt to use such reduced references in the L2 version from Trial One onwards. Thus, the $L 1$ version would have a distinct learning effect on the L2 version. As Bongaerts et al.'s study made clear, the impossibility of collecting $\mathrm{L} 1$ and $\mathrm{L} 2$ data from the same subjects poses a serious problem since it means that differences between $L 1$ and $L 2$ data cannot always be ascribed to the subjects' native- or non-nativeness.

To avoid methodological problems like this a comparative study of $\mathrm{L} 1$ and L2 referential behaviour should relate to data collected from one and the same group of subjects. Only in this case can the $\mathrm{L} 1$ data be considered as appropriate base-line data and can differences between the $\mathrm{L} 1$ and $\mathrm{L} 2$ data unequivocally be interpreted as the result of a language difference. 9 
Kellerman, Ammerlaan, Bongaerts \& Poulisse (in press) ${ }^{10}$ report on a study which meets the demand for strictly comparable $\mathrm{L} 1$ base-line data. The subjects in this study were 17 first-year university students of English. They were asked to describe 11 abstract figures, first in Dutch and a week later in English. Like the Krauss \& Weinheimer figures they did not have conventional names, but they were more difficult in that their structure was more complex and in that they could not be related to natural objects so easily.

Kellerman et al. found that the subjects adopted three general perspectives to describe the figures. The first of these, which like Clark \& Wilkes-Gibbs they refer to as holistic, results in an attempt to label the entire figure by associating it to a 'real-world' object or to a conventional geometric shape. The second general perspective is called partitive and conceives of the figure as if it consists of a number of smaller and often simpler shapes. The third general perspective, which was termed linear, leads the subject to break the figure up into its ultimate components (lines, angles, dimensions, spatial relations) and to describe it in terms of route directions. In Clark \& Wilkes-Gibbs' terms 'partitive' and 'linear' perspectives would both be 'segmental'.

Kellerman et al. report that the subjects generally adopted the same perspectives in Dutch and in English (164 times out of 183 pairs of descriptions). The great majority of these were 'holistic'. In those cases where lexical problems seemed to prevent the subjects from giving a description from the same (obviously preferred) perspective again, they tended to replace it with a description from either a 'partitive' or a 'linear' perspective. Since there is only one case where a 'linear' perspective is replaced with a 'partitive' one (and none where the original perspective is replaced with a 'holistic' one), it is suggested that the three perspectives are hierarchically arranged with respect to each other, such that both within and across languages descriptions from a 'holistic' perspective are preferred to descriptions from a 'partitive' perspective, which in turn are preferred to descriptions from a 'linear' perspective. It will be noted that this hierarchy is consistent with the findings of Krauss \& Weinheimer (1964) and Clark \& Wilkes-Gibbs (1986), as well as with Bongaerts et al.'s (1987) findings.

The study by Kellerman et al. (in press) again suggests that there are many similarities between the use of referential strategies in L1 and L2. Still, it was felt that more evidence was needed in this respect. In particular, it seemed essential to conduct a study which would also include learners at a lower L2 proficiency level, since in their case the use of particular strategies might be constrained by the limitations of their L2 vocabulary. A follow-up study like this will be reported on in chapter 9. In it Kellerman et al.'s figures will be replaced with those commonly used in L1 referential communication research. This should improve the comparability of this study to typical L1 studies. 
The referential communication studies discussed in this section have contributed to the Nijmegen project in two ways:

Firstly, they provided us with an experimental task which is extremely suitable for addressing research question 2, concerning the relationship between $\mathrm{CpS}$ use in $\mathrm{L} 1$ and $\mathrm{L} 2$. As we have seen, the figures used in the matching task devised by Krauss \& Weinheimer pose referential problems to both $\mathrm{L} 1$ and $\mathrm{L} 2$ speakers and therefore allow one to collect comparable $\mathrm{L} 1$ and L2 data from one and the same group of speakers. Yet another advantage related to the use of this task is that the figures present the subjects with referential problems similar to those experienced by the subjects in typical studies of $\mathrm{CmS}$. This suggests that the results of a study in which this task is used will also shed light on the more specific notion of CmS.

Secondly, the studies discussed in this section have made it possible to formulate three hypotheses with respect to the use of referential strategies in L1 and L2:

1. Subjects referring to abstract figures will adopt the same referential strategies in L1 and L2, unless limited knowledge of the L2 makes it impossible for them to do so.

2. Subjects referring to abstract figures will prefer descriptions from a 'holistic' perspective to descriptions from a 'partitive' or 'linear' perspective.

3. Subjects who are unable to describe abstract figures from their preferred perspectives because of lexical difficulties will replace 'holistic' perspectives with 'partitive' or 'linear' perspectives and 'partitive' perspectives with 'linear' ones, but not vice versa.

These are the three most important hypotheses to be tested in chapter 9 .

\subsection{Conclusion}

The discussion of empirical research first of all revealed that there is a lack of large-scale studies of $\mathrm{CmS}$ use. The comprehensiveness of the present study should make up for this deficiency. Of all research questions addressed in the studies to date the one dealing with the relationship between $\mathrm{CmS}$ use and the subject's L2 proficiency level was selected for further investigation in the Nijmegen project. Several studies suggested that L.2 proficiency level was an influential factor (cf. Tarone, 1977; Palmberg, 1979; Bialystok \& Fröhlich, 1980; Paribakht, 1982; 1985; Elsen et al., 1982). On the basis of some of these studies it could be hypothesized that beginning leamers will inevitably use more $\mathrm{CpS}$ than advanced learners, and that they will use more $\mathrm{CpS}$ which are based on the $\mathrm{L} 1$. 
The results of the $\mathrm{L} 1$ referential communication studies made clear that speakers' referential phrases are influenced by the (non-) availability of concurrent feedback, the speakers' ages and their social statuses. It was also shown that short references are preferred to longer ones. Krauss \& Weinheimer (1964) demonstrated that speech partners tend to agree on a name after a number of trials, and in various other studies it was reported that holistic encodings were used more often than analytic ones (cf. Clark \& Wilkes-Gibbs, 1986; Bongaerts et al., 1987; Kellerman et al., in press; as well as Krauss \& Weinheimer, 1964).

Few differences were observed between the use of referential strategies by L1 and L2 speakers. This suggests that there are no intrinsic differences between $\mathrm{L} 1$ and $\mathrm{L} 2 \mathrm{CpS}$ use, a hypothesis that will be further tested in the Nijmegen project. To do this, a modified version of Krauss \& Weinheimer's referential task will be used, since this allows one to collect comparable $\mathrm{L} 1$ and L2 data from one group of subjects.

\section{Notes to chapter 3}

1. Pert of this section is based on the overview of empirical research in Poulisse, Bongaerts \& Kellerman (1984).

2. Lê \& McCausland's (1986) study deals with the communicative strategies employed by children to obtain certain privileges. They observe that children, once they start taking the other person's feelings into account, become increasingly better at using such strategies, as is illustrated by the following examples:

A four-year-old: "Take me to Vicki's or I'll chop your head off"

A six-ycar-old: "You're the best Dad we ever had" preceding his request.

Their best example comes from a six-year-old who is obviously ahead of his age in this respect. He wanted two of his classmates to spend the weekend at his home, but his father had told him on Thursday that only one could come. The following conversation takes place on Friday:

Paul: Dad, do you think we should always keep our promises?

Father: (seriously) Yes Paul, we must. If you promise someone something, you must keep it.

Paul: (still smiling innocently) But Dad, I promised Tony and Adam that they could spend the weekend with us.

3. This explanation is in contrast with the findings reported by Krauss \& Weinheimer (1966), who observed that feedback reduced the length of native speakers' reference phrases (see later in this chapler). As will appear in chapter 8, it is also in contrast with the results of the Nijmegen project.

4. Tarone \& Yule (1983) note that those speakers who took the listener role first, may have benefited from a "listener effect". Unfortunately, however, no attempt was made to establish whether or not such an effect could indeed be detected. 
5. This point has also been made by De Villiers \& De Villiers (1981) in a paper on studies of child language acquisition. They note that the task requirement may influence the linguistic behaviour that is studied and suggest "to utilize diverse methodology in attacking any problem area, and to allow the task results to complement one another. By comparing results across tasks it is then possible to highlight constraints on strategies made available by any single task" (p.50)

6. For an extensive overview of studies on referential communication, including studies in which other tasks were used, see Dickson (1982).

7. Glucksberg et al.'s (1975) model closely resembles a model by Glucksberg \& Cohen (1968) discussed in the same article. Both models refer to associations which are to be selected in stage one and subsequently evaluated in stage two. Although 'associations' clearly play a large role in the referential tasks conducted by Krauss and his associates (see later in section 3.2), the term 'reference phrase' seems more appropriate in a general model of referential communication.

8. This study is based on Bentlage's M.A. thesis, written at the Department of English, Nijmegen University, 1985.

9. This point has also been made by Mohle (1984), who says that a comparison of L1 and L2 productions by the same speakers is absolutely necessary to determine "whether particular traits noticed in individual speakers or groups of speakers are L.2-specific or not" (p.28).

10. This study is based on Ammerlaan's M.A. thesis, written at the Department of English, Nijmegen University, 1984. 


\section{Compensatory Strategies and Communication}

In chapter 1 it was argued that $\mathrm{CpS}$ are strategies of language use, and that therefore the study of $\mathrm{CpS}$ should be embedded within the study of communication. This is the goal of the present chapter. It will be approached in three ways.

Firstly, in section 4.1, a model of verbal communication will be discussed (Levelt, 1989; see also Levelt \& Schriefers, 1987), after which it will be shown how the use of $\mathrm{CpS}$ can be integrated into such a model (section 4.2). Secondly, there will be a proposal for a new taxonomy of CpS (section 4.3). This taxonomy distinguishes between two basic $\mathrm{CpS}$ types only and these can be directly related to the conceptual and linguistic processes underlying $\mathrm{CpS}$ use (section 4.4). Thus it is not only more parsimonious, but also more psychologically plausible than the early taxonomies discussed in chapter 2. Finally, there will be a discussion of some principles and constraints that determine communication in general (section 4.5). It is assumed that these factors also influence the subjects' use of $\mathrm{CpS}$.

\subsection{A model of communication}

In one of the best known models of communication, based on Shannon \& Weaver (1949), communication is represented as the transfer of messages from the addressor (the speaker or writer) to the addressee (the listener or reader). Put simply, it is assumed that the addressor encodes the message into a signal (either verbal or non-verbal) which is to be decoded by the addressee at the other end of the communicative channel (see e.g. Jakobson, 1960; Lyons, 1977). This model has been referred to as the code model (Sperber \& Wilson, 1986:2).

The code model can be criticized for two reasons. Firstly, it represents communication as if it is a uni-directional process. ${ }^{1}$ The role of the addressee is completely ignored, as is the role of many other factors that may affect both the encoding and the decoding stages of communication (Reddy, 1979; Sperber \& Wilson, 1986). A second point of criticism, which is obviously related to the first one, is that the model lacks a monitoring device. This makes it impossible for the addressor to repair the communication process when he realizes that his message has not been or is unlikely to be properly decoded and interpreted by the addressee.

Recently, Levelt (1989) has presented a model of speech production which meets these two points of criticism. It acknowledges that the generation of messages is subject to contextual factors, such as the current state of the discourse and the interlocutors' knowledge of the situation and the world, and 
it includes a monitor that evaluates the comprehensibility of messages at various stages of the speech production process (see figure 4.1). In the present study, Levelt's model will be adopted to clarify the relationship between CpS use and communication. This implies that Levelt's model will be treated as a model of communication, even though, strictly speaking, it is a model of speech production which deals with speech reception only insofar as the speaker's internal speech comprchension system is concemed (cf. figure 4.1). Still, it was felt that Levelt's theory of speech production was sufficiently comprehensive to be used as a theory of communication, since it explicitly deals with issues such as conversational rules (including tum-taking rules and Grice's (1975) cooperative principle) and discourse models (i.e. "a speaker's record of what he believes to be shared knowledge about the content of the discourse as it evolved", p.114). Moreover, our project was restricted to the use of CpS in speech production, which means that of any model of communication to be used the speech production part would be the most relevant one in any case.

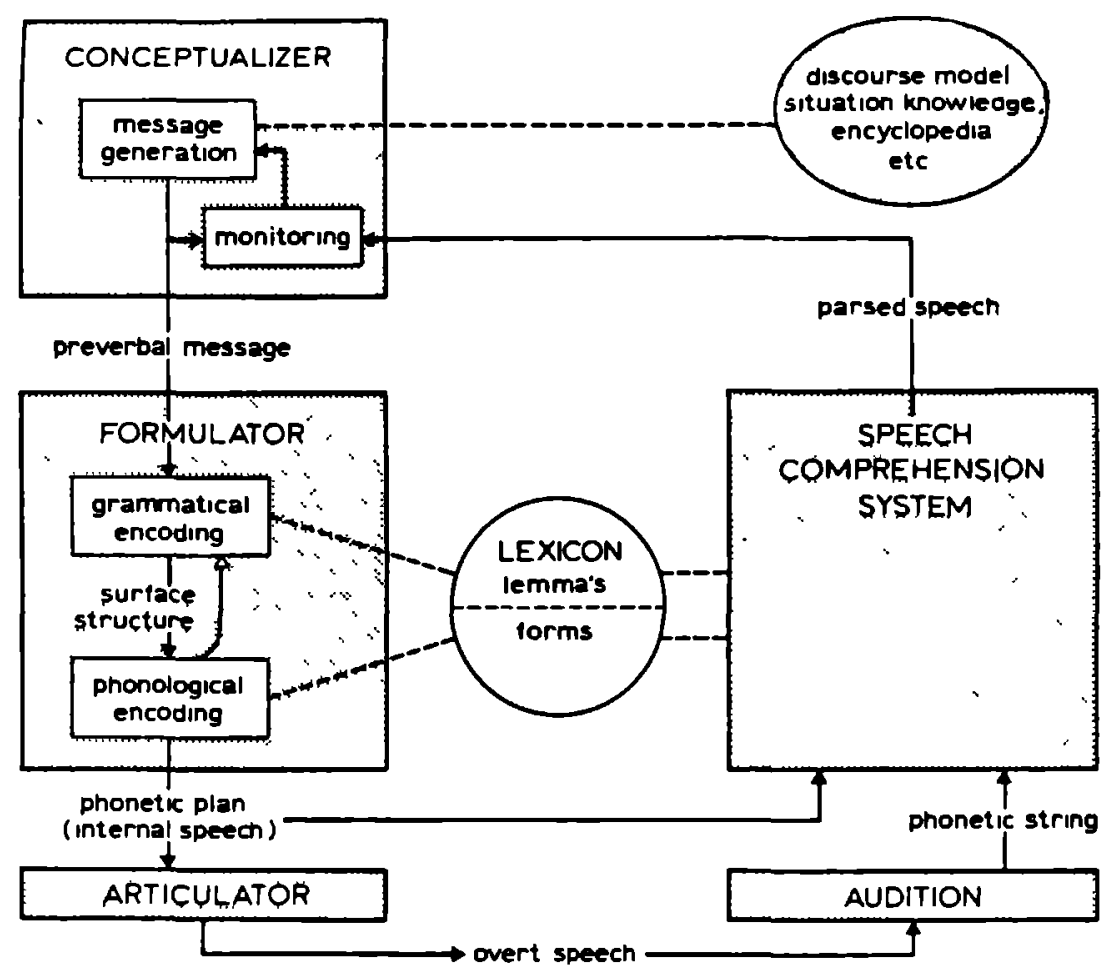

Figure 4.1. A model of speech production (from Levelt, 1989:9) 
Speech production, according to Levelt, consists of four steps: message generation, grammatical encoding, phonological encoding, and articulation. In figure 4.1 it can be seen that these steps are covered by three processing components (represented as square boxes). The first of these processing components is called the conceptualizer. It is here that messages are generated. Apart from the conception of a communicative intention, this involves planning the contents as well as the form of the message. Planning the contents is called macroplanning. It involves "selecting the information whose expression may realize the communicative goals" (p.5). Planning the form of the message is referred to as microplanning. Among other things it includes deciding on an appropriate speech act (e.g. an assertion, a question or a promise), marking referents as 'given' or 'new', and assigning topic and focus.

The generation of messages is influenced by a) the speaker's knowledge of what has been said before in the conversation ('discourse model'), b) his knowledge of the spatio-temporal environment ('situation (sic) knowledge') and c) his knowledge of the world ('encyclopedia'). These factors are represented in figure 4.1 as a circle which feeds into the conceptualizer. They will be dealt with in more detail in section 4.5 . Finally, it will be noted that the conceptualizer contains a monitor. This makes it possible to repair the conceptualization process.

The output of the conceptualizer is a preverbal message. It consists of a conceptual structure which can be accepted as input by the formulator.

The formulator is the second processing component in Levelt's model of speech production. It covers two steps of the speech production process: grammatical encoding and phonological encoding. The grammatical encoder translates the preverbal message into a surface structure, while the phonological encoder translates the surface structure into a phonetic plan. For this process to take place the formulator has to have access to the mental lexicon which Levelt describes as 'the store of information about the words in one's language" (p.6). The lexical items in the mental lexicon not only specify the words' meanings, but also contain syntactic, morphological and phonological information about them. In Levelt's model semantic (or conceptual) and syntactic information constitute the lemma of a lexical item, while morphological and phonological information constitute its form. The exact relationship between the lemma and the form component of a lexical item is not entirely clear (see e.g. Dell, 1986). One possible way of representing it has been depicted in figure 4.2, where the lemma 'points' to its corresponding form.

When a message is being formulated the conceptual information in the preverbal message triggers the appropriate lexical items into activity. This enables the grammatical encoder to access the syntactic information needed to map conceptual information onto grammatical functions. Similarly, the morphological and phonological properties of the activated lexical items trigger the phonological encoder which, on the basis of this information, produces a phonetic plan. 


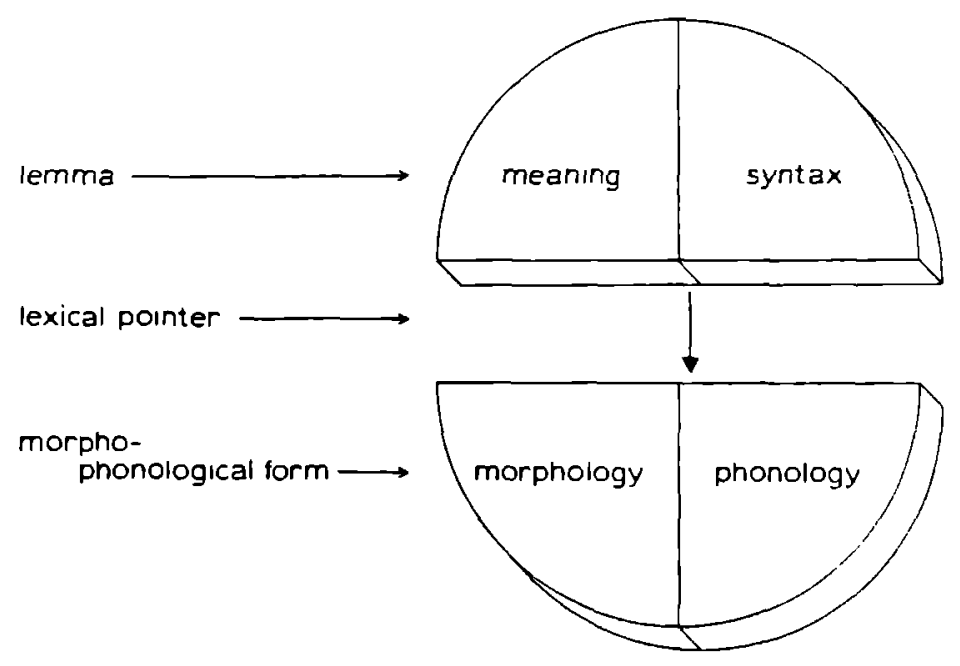

Figure 4.2 A representation of a lexical item (from Levelt,1989:188)

The phonetic plan, in its tum, serves as input to the articulator, which is the third processing component in Levelt's model. The articulator executes the phonetic plan bit by bit. The result is overt speech.

Although overt speech forms the input to the first step of the listener's speech reception process, this does not mean that the speech production process finishes here. After all, the speaker himself is endowed with a speech comprehension system too, and he uses it to parse both intemal and overt speech. Since the outcome of the speech comprehension process is fed into the monitoring device located in the conceptualizer this provides the speaker with another chance to evaluate his message. As Levelt points out, in this way speakers manage to avoid some speech errors and to repair others.

Two other points need to be made here with respect to Levelt's model. Firstly, most of the speech production process is largely automatic. This goes for grammatical encoding, phonological encoding and articulating. ${ }^{2}$ The only activities that require the speaker's continual attention are message generation and monitoring. Hence these activities are described as controlled.

Secondly, it should be noted that the speech production process described here operates incrementally, that is to say, it combines serial and parallel processing. Each fragment of the message goes through each of the processing components in the same order (as described above). As soon as it comes out of one component, the next one starts operating on it. Thus, the components work in parallel on different fragments of the message. This makes the speech production process one that is highly efficient. 


\subsection{Communication and compensatory strategies}

Levelt's model of communication was designed as an L1 model and some adaptations are needed to make it applicable to L2 communication. Most importantly, it should account for the fact that speakers may know more than one language. Among other things this means that the mental lexicon must not only contain lexical items for $\mathrm{L} 1$ words, but also for $\mathrm{L} 2$ and possibly $\mathrm{Ln}$ words. Whether these lexical items are related to each other within one lexicon, or whether they are stored in separate language-specific lexicons, is a moot point which need not concem us here (but see e.g. the overviews in Kerkman, 1982; and Appel \& Muysken, 1987). Important, however, is that the concepts included in the speaker's preverbal message can activate L1 as well as L2 (and Ln) lexical items.

How the choice between L1, L2 and Ln lexical items is made is not clear. Presumably, preverbal messages produced by multilingual speakers specify in one way or other whether L1, L2 or Ln items have to be activated for their encoding.

Let us now see how $\mathrm{CpS}$ can be integrated into the communication process. It will be remembered from the previous section that normally, i.e. when there are no lexical problems, the preverbal message triggers the appropriate lexical items into activity, which causes the activated items' syntactic, morphological and phonological information to trigger the grammatical and phonological encoding procedures. In the case of lexical problems, there either is no lexical item at all (e.g. when the intended concept has not been lexicalized in the target language or when the appropriate L1 or L2 word is not known) or it cannot be accessed (when the word has been forgotten). In either case the preverbal message cannot be encoded and the communication process threatens to break down. Speakers who do not want to let this happen can do three things:

(1) They can give up or revise their original communicative intention, and set up a new preverbal message. In terms of $\mathrm{CmS}$ this behaviour involves the use of 'Avoidance' or 'Reduction Strategies'. It implies a complete re-iteration of the speech production process.

(2) They can either implicitly or explicitly appeal to their interlocutors to provide the missing words. In the case of these Interactional Strategies, the speaker's language production process is cut short, and it is the interlocutor who has to solve the lexical problem.

(3) They can attempt to find alternative ways of encoding their original messages. It is the processes which lead to these altemative encodings which are referred to as $\mathrm{CpS}$ in this thesis. 


\subsection{A taxonomy of compensatory strategy use ${ }^{5}$}

The speaker who opts for the use of $\mathrm{CpS}$ has two knowledge sources at his disposal. One of these knowledge sources is conceptual and (presumably) constitutes part of the encyclopedia. It contains information about a concept's properties and its relations to other concepts. It is this information which enables speakers to analyse concepts into their component properties and allows them to exploit the fact that some concepts share a number of these properties and are therefore similar in meaning.

The other knowledge source is linguistic. Apart from morpho-phonological information about the L1, the L2 and possibly Ln lexical items associated with a particular concept, it contains knowledge of the syntactic, morphological and phonological rules of L1, L2 and Ln and the correspondences which may exist between these rules. It is not quite clear how linguistic knowledge is represented. It may be stored in a general linguistic knowledge base which contains all the linguistic rules a speaker has ever leamt, but in part it may also be derivable from other lexical items by analogy. However, this is a problem that need not be solved here.

Depending on whether the speaker predominantly exploits the conceptual knowledge source or the linguistic knowledge source for the construction of particular CpS these can be classified as conceptual or linguistic. In what follows the distinction between 'Conceptual' and 'Linguistic Strategies' will be illustrated with examples from the Nijmegen project. Moreover, it will be shown that each of these two "archistrategies" can be subdivided into two CpS types. Together, these four $\mathrm{CpS}$ types will constitute the taxonomy to be used for the classification of our data.

\subsection{1 'Conceptual Strategies'}

The speaker who uses a conceptual strategy may refer to the intended concept by listing (some of) its properties or by substituting the word for a related concept which shares some of the criterial properties. We have referred to these strategies as Analytic and Holistic Conceptual Strategies respectively.

The assumption which underlies the use of analytic strategies is that the listener will be able to infer the intended concept from the properties which have been mentioned. The following are two examples from situations with and without an interlocutor:

(1) S: ja, it's green and uh, you usually uh, eat it with uh potatoes

I: $\mathrm{mm}$

S: erm 2

I: that is a vegetable? 
S: yes, uh ja erm, Popeye uh eats it uh

I: <laughs> oh ja

S: erm

I: ja, I know what you mean now, spinach ja

S: oh ja, spinach ja (spinach; 303t4)

(2) this you use for a baby so uh, that it can't uh, make uh, his clothes em 3 uh dirty (bib; 114t1)

The speaker who adopts a holistic strategy refers to a concept by using the word for a related concept. The related concept can be superordinate or subordinate to the intended referent, as in examples (3) and (4), but it can also be at the same hierarchical level, as is illustrated in (5):

(3) erm, potatoes with erm, ja I don't know, some uh, ja uh vegetables something (peas; 30114)

(4) his neighbour made erm, made things like a hammer and that sort (tools; 215t3)

(5) S: it's (= his room) is uh quite big, and uh, with uh 1 uh a table

I: ja

S: and uh, a chair and uh, a bed (desk; 303t4)

Very often the speaker will wam the interlocutor that the word he uses does not fully express his intended meaning by using a hedge like "it's a sort of", or "it's like a".

It is possible for the 'Holistic' and the 'Analytic Conceptual Strategies' to be combined, in which case the speaker refers to a related concept and then specifies in what way this differs from the target concept. Examples of such combinations of strategies are:

(6) big uh 1 big uh, cars, they're not uh really cars but big and high cars (trucks; 304t4)

(7) he did on 1 uh, some hair 1 and he kon, could put, off it (wig; 310t3).

(8) large shoes (boots; 315t4)

It should be noted that the distinction between 'Holistic' and 'Analytic Conceptual Strategies' is very similar to the distinction between 'holistic' (or 'whole-inferential') and 'segmental' (or 'part-descriptive') perspectives and encoding styles proposed by Clark \& Wilkes-Gibbs (1986) and Heider (1971) to categorize references to novel graphic designs. An L2 leamer who does not know the appropriate L2 word for a certain concept and chooses to adopt a 'Conceptual Strategy' has the same choice as an Ll speaker who needs to refer to a figure that has not been lexicalized in his language. He can relate the concept to one which is similar to it or reminiscent of it, or he can analyse it into its component properties or parts and mention (some of) these. Yet a third alternative is to combine these two approaches. 
The speaker who uses a linguistic strategy manipulates his linguistic knowledge. In the case of an $\mathrm{L} 2$ learner this will be knowledge of the syntactic, morphological and phonological rules that apply in the L1, some knowledge of these rules in the L2 (and possibly Ln's), and knowledge of similarities and dissimilarities between the $\mathrm{L} 1$ and the L2 (and Ln).

One can distinguish two subtypes of the 'Linguistic Strategy'. One is the use of L2 rules of morphological derivation to create (what the subject assumes to be) comprehensible L2 lexis. We have referred to this strategy as Morphological Creativity. The morphological "creations" which result from this type of CpS usually consist of existing L2 words to which L2 morphemes have been added. The following examples illustrate this:
(9) representator (representative; $214 \mathrm{t} 3$ )
(10) shamely (shameful; 303t3)
(11) appliances (letters of application; 105t3)
(12) back-ups (favourable circumstances; 101t4)
(13) ironize (to iron; 209t3)
(14) dirty (dirt; 302/314t1)

The other 'Linguistic Strategy' exploits the similarities between languages. If, for instance, two languages are closely related, words or phrases may be transferred from one language to the other (cf. Kellerman, 1977). Sometimes, the utterances resulting from this Strategy of Transfer are phonologically and/or morphologically adapted to the L2 (cf. examples (15) to (18)), but this need not be the case (cf. (19) and (20)):

(15) $\Gamma$ i:t əla $3 /$ (shop-window, Du: etalage; $207 \mathrm{t} 3$ )

(16) middle (waist, Du: middel; 309tl)

(17) I will go by uh, tennisclub (join the tennisclub, Du: bij tennis gaan; 206t4)

(18) a cuffer (hairdresser, French: coiffeur; 314t3)

(19) paprika (green pepper, Du: paprika; 20144)

(20) uh, we say, voorwoord (preface, Du: voorwoord; 201t4).

It should be noted that both 'Morphological Creativity' and 'Transfer' may result in L2 words that actually exist, as is the case in (11), (14), (16) and (19). However, since we operate from the leamer's point of view, and not from the researcher's, this is irrelevant to the identification of these utterances as CpS and to their classification. 
Although we have distinguished 'Conceptual' and 'Linguistic Strategies' as the two basic approaches towards the solution of lexical problems, this does not necessarily imply that all utterances can be classified as exemplifying either purely conceptual or purely linguistic strategies. For instance, in the case of (21) and (22) it is possible that the two strategies interacted:

(21) clothes-maker (tailor, 2113)

(22) underarm (wrist; 204t1)

The fact that the Dutch words 'kleermaker' and 'onderarm' are transparent (their meanings can be inferred from the two component parts) may have contributed to their being literally translated into English. It is possible that a similar interaction led to (23):

(23) flowerist (florist; 107ß)

The existence of a Dutch word 'bloemist' may have triggered the semantic analysis of the intended concept as 'a person having to do with flowers' and the subsequent combination of 'flower' and '-ist' on the assumption that '-ist' is a morpheme denoting 'person' (cf. 'novelist', 'typist'). Although this interpretation of (21) to (23) is not necessarily the only correct one retrospective data proved similar cases to be the result of 'Transfer' - it is important to realize that interaction of the 'Conceptual' and 'Linguistic Strategies' may occur.

\section{4 'Conceptual' and 'Linguistic Strategies' in terms of Levelt's model}

At this stage it will be useful to briefly return to Levelt's model to show how 'Conceptual' and 'Linguistic Strategies' can be integrated into the speech production process. As we have seen, $\mathrm{CpS}$ are called into use when a concept included in the preverbal message fails to activate the lexical item needed for its encoding. The result is an incomplete phonetic plan which, when fed back to the monitor via the speech comprehension system, is likely to be rejected there. Consequently, it will be assumed that the processes underlying the four $\mathrm{CpS}$ types are initiated in the conceptualizer.

From the examples given in section 4.3.1 it will be clear that the 'Analytic Strategy' involves a conceptual analysis of the originally intended concept. Subsequently, the information about the concept's component properties is processed into a new preverbal message. The construction of a new preverbal 
message is obviously needed since the linguistic structure of an analytic strategy is completely different from that set up for the original message. As usual, the preverbal message will be influenced by the speaker's knowledge of the preceding discourse, the spatio-temporal environment and the world. In this particular case, the speaker's 'contextual' knowledge will determine which properties should be mentioned and in what order.

Once a new preverbal message has been set up for this $\mathrm{CpS}$ the formulator is called into operation again. New lexical items are activated and morphologically and phonologically encoded. In fact then, the use of analytic strategies requires the complete speech production process to be repeated. It will be obvious that this puts heavy demands on the processing effort to be invested by the speaker. Certainly when many of the referent's properties are mentioned, which implies that many new lexical items have to be accessed and encoded, the spcaker's task is greatly increased.

The process underlying the use of holistic strategies seems to be somewhat less complicated. It mainly comprises the selection of a different concept which is sufficiently similar to the original one to convey the speaker's intended meaning. Presumably, there is no need to set up a completely new preverbal message in the case of a holistic strategy, although the speaker may have to make some adjustments to the original speech plan to make sure the new word fits in grammatically and semantically. The larger part of the preverbal message can probably be retained, however, and this suggests that the 'Holistic Strategy' is less complicated, and therefore takes less effort, than the 'Analytic Strategy'.

Linguistic strategies were said to be based on the speaker's linguistic knowledge of the L1, the L2, possible Ln's, and the correspondences between these languages. The process in the case of transfer strategies is fairly straightforward. An L2 speaker who replaces an L2 word by the corresponding L1 word ignores (or changes) the indication in the preverbal message conceming the language of encoding and exploits the fact that one and the same concept may activate $\mathrm{L} 1$ as well as $\mathrm{L} 2$ lexical items. Thus, the process requires only a minor change to be made in the preverbal message, which suggests that it takes very little effort. In some cases, however, transfer strategies involve additional linguistic information needed to adapt $L 1$ words phonologically and/or morphologically to the L2. Consequently, in these cases the speaker will need to expend somewhat more processing effort.

The other linguistic strategy. 'Morphological Creativity', also requires access to additional linguistic knowledge. As we have seen, the speaker who adopts this CpS type creates a new word (new to him) by applying his knowledge of L2 morphological rules to an existing L2 word. This suggests that in the case of 'Morphological Creativity' the concept does activate the appropriate lexical item, and accesses the required lemma information, but fails to access the corresponding morpho phonological information. Since the solution of this problem requires the activation of additional 
morpho-phonological knowledge, which is not contained in the lexical item itself, the production of "morphological creations" also seems to require more effort than the use of an L1 word without any morphological or phonological adaptation to the L2.

It is worth noting that conceptual strategies may lead to new encoding problems. Particularly in the case of analytic strategies it is possible that not all of the information specified in the preverbal message is adequately represented in the mental lexicon. Or, to put it more simply, the (L2) speaker may not know all the words needed to give a description. In that case the speaker may decide to resort to another $\mathrm{CpS}$ and may again opt for a conceptual or a linguistic one. Thus, in example (24) the subject who had adopted an analytic strategy to convey the item 'reel of cotton', was confronted with another problem, viz. 'thread'. He solved this linguistically first, by transferring the Dutch word 'draad' to English, pronouncing it as /dred/. Apparently, this solution did not satisfy him, for he tackled the problem once more. This time he approached the problem conceptually, and came up with his final choice "rope":

(24) uh, it's a wooden thing you can put on, uh 1 some, uh dread, on 1 uh, rope (reel of cotton; 202t1)

New encoding problems may also present themselves to the speaker who has chosen to use a holistic conceptual strategy. If this speaker does not know the word for the related concept either, he will be forced to adopt another CpS to solve this new encoding problem (unless, of course, he prefers to revise his message or ask the interlocutor to solve the problem for him). In example (25) the subject first opted for a holistic strategy, viz. "drill" for 'hammer drill', and subsequently employed a transfer strategy to compensate for the word 'drill':

(25) bore (hammer drill, Du: boor, 304t3)

Conceptual strategies, then, may give rise to new encoding problems, and thus may have $\mathrm{CpS}$ embedded within them. In this study embedded $\mathrm{CpS}$ will be referred to as subordinate CpS. It will be clear that the existence of subordinate $\mathrm{CpS}$ requires the communication process to be cyclic. Each conceptual strategy may give rise to new encoding problems, hence to new $\mathrm{CpS}$.

Linguistic strategies as a rule do not cause new encoding problems. The reason for this is that the processes which underly them do not require the activation of other $\mathrm{L} 2$ lexical items, while the activation of $\mathrm{L} 1$ lexical items in the case of transfer strategies does not usually cause any problems to L2 speakers. ${ }^{6}$ This does not mean that linguistic strategies are always successful in conveying the speaker's intended meaning. They are clearly not. 
Unsuccessful linguistic strategies, however, tend to be followed by other CpS. They do not contain subordinate CpS.

The speaker who has encoded a $\mathrm{CpS}$ will send the resulting intemal speech plan to the monitoring system in the conceptualizer via his own speech comprehension system. This allows him to estimate whether the CpS is likely to convey his original communicative intention. If it is, it will be articulated. If it is not, it may be changed, or another CpS may be added. To evaluate the comprehensibility of $\mathrm{CpS}$, the speaker needs to have access to the contextual knowledge store that feeds into the conceptualizer (see figure 4.1). This point will be further developed in section 4.5.2.

\subsection{Communication: general principles and constraints}

In the previous section $\mathrm{CpS}$ use was embedded into Levelt's model of speech production. This revealed that the use of $\mathrm{CpS}$ does not alter the communication process itself: using CpS can be seen as another way of encoding the originally intended message. Consequently, it seems reasonable to assume that $\mathrm{CpS}$ use will be subject to the same principles and the same constraints that govem communication in general. The next three subsections will deal with Grice's cooperative principle (section 4.5.1), the role of mutual knowledge (section 4.5.2) and two of the constraints that affect communication (section 4.5.3). The contents of these three sections will form the basis of the explanation of $\mathrm{CpS}$ use to be given in chapter 8 .

\subsection{The cooperative principle}

According to Grice (1975) effective communication is govemed by the cooperative principle. ${ }^{7}$ This principle requires speech participants "to make their conversation such as is required, at the stage at which it occurs, by the accepted purpose or direction of the talk exchange in which they are engaged" (p.45). This general principle covers four major conversational maxims, which relate to the quantity, the quality, the relation and the manner of communication. The first of these maxims charges the speaker to be appropriately informative, that is, neither too detailed, nor too vague. The second maxim charges him to give information which is true and of which he is sure. The third maxim charges him to be relevant and the fourth maxim, finally, charges him to be perspicuous, that is clear and brief.

Grice introduced the cooperative principle and the maxims to explain the notion of conversational implicature. He argues that speakers can convey information without formulating it explicitly, because speech participants assume each other to be cooperative. To illustrate this he gives thefollowing example: 
A: I am out of petrol

B: There is a garage round the comer

Assuming that B is cooperative, A will interpret B's mentioning the garage as if it is relevant. Consequently, he will infer from it that the garage is open, or at least that it may be open, and has (or may have) petrol to sell (Grice, 1975:51).

Grice observes that not all of his maxims are equally important ('quantity', for instance, is less important than 'quality') and that they are not always adhered to. In some cases maxims clash, so that the speaker is forced to make a choice. Thus, it may not always be possible to be fully informative and perspicuous (or brief) or to be fully informative and only give information of which one is absolutely sure. In other cases maxims may be broken deliberately to create certain effects. A speaker may, for instance, flout the maxim of quality, as in the ironical "he really is an intelligent chap", said of someone who just failed an exam for the fifth time.

The studies of referential communication reported in chapter 3 support Grice's claim that speech participants are cooperative. In particular, they illustrate the operation of the maxims of quantity and manner. As we have seen, the speakers generally made their references to abstract figures sufficiently informative, but not more informative than necessary. Thus, while making their references clear, they also attempted to keep them as brief as possible. This is shown most clearly in the gradual shortening of repeated references to the same figures (Krauss \& Weinheimer, 1964; Clark \& Wilkes-Gibbs, 1986; Bongaerts et al., 1987). Having started with a fairly lengthy description, the subjects usually ended up with a name. So, obviously, the speakers refrained from expressing information which their listeners would be able to infer from shared knowledge, in this case the preceding discourse.

The maxims of quantity and manner seem to serve the same purpose. They are both directed at the production of intelligible utterances (sufficiently informative and clear), with a minimal expenditure of effort (not too informative and brief). Since the maxim of relation (be relevant) also seems to be directed at minimizing the speech participants' efforts in the communication process, it may be concluded that observation of the cooperative principle implies the speakers' adherence to the principle of economy (or least effort). A similar view of communication is adopted by Clark \& Wilkes-Gibbs (1986), who maintain that speakers not only work together in conversation, in that they repair, expand and replace utterances until mutual understanding is reached, but that they also try to minimize their joint efforts in doing so.

Leech (1983) discusses the principle of economy as one of four principles of 'Textual Rhetoric'. "Being quick and easy", he says, may be advantageous to the speaker as well as the listener, since "If one can shorten the text while keeping the message unimpaired, this reduces the amount of time and effort 
involved both in encoding and decoding" (p.67). The phrase 'while keeping the message unimpaired' is of considerable importance in this quotation. It shows that 'to be quick and easy' is not always recommendable. Speakers who maximize the principle of economy at the expense of the intelligibility of their messages are obviously putting the cart before the horse. As Leech points out, this means that "in practice, a balance has to be struck between saving time and effort, and maintaining intelligibility" (p.67).

Grice's cooperative principle and the economy principle seem to apply to CpS use too. Speakers who are confronted with lexical problems will attempt to solve these by giving their listeners sufficient information to infer their intended meanings. This information will generally be true and relevant, and will be presented in a clear way so as to reduce the effort the listeners have to put into the inferencing process. As in ordinary communication, the principle of economy cannot be maximized in all cases, since this might lead to unintelligible $\mathrm{CpS}$. Consequently, we may predict that speakers will maintain a balance between a) reaching their communicative goals (=effect) and b) the amount of effort they (and their interlocutors) spend on this (= effort). More specifically, it can be expected that speakers who are confronted with lexical problems will try to achieve their communicative goals, i.e. make themselves understood, by adopting those $\mathrm{CpS}$ which require minimal effort, both from themselves to encode, and from their listeners to decode.

\subsubsection{The role of mutual knowledge}

In the preceding section it was noted that the speakers in Krauss \& Weinheimer, 1964; Clark \& Wilkes-Gibbs, 1986 and Bongaerts et al., 1987 were able to reduce their references to figures they had referred to before by exploiting mutual knowledge (or shared knowledge). This suggests mutual knowledge plays an important role in communication (Clark \& Marshall, 1981; Clark \& Carlson, 1982, Clark, 1985, but see Sperber \& Wilson, 1986). ${ }^{9}$ In the present section, the notion of mutual knowledge will be discussed in somewhat more detail. More particularly, the section will deal with the relationship between mutual knowledge and the principle of economy.

Clark \& Marshall (1981:43) specify four sources from which mutual knowledge may arise. Firstly, they say, it may be based on community membership. For example, (educated) Dutch people generally know that there were two World Wars, that the Olympic Games are held every four years and that books can be borrowed from libraries. Secondly, mutual knowledge may be based on physical copresence. If two people have both witnessed the same car accident, and have seen each other witness it, they will both assume each other to know about the accident. Thirdly, mutual knowledge may result from 
linguistic copresence. Two people who have not actually witnessed a particular car accident, but who have talked about it together, e.g. after having read about it in the local newspaper, will from then on also assume each other to know about the accident. And fourthly, mutual knowledge may be 'inferred from' physical and/or linguistic copresence and/or community membership. When talking about a car accident one may infer that a reference to "the injured" refers to the people injured in the accident since it is mutually known in most communities that accidents often cause people to be injured.

In Levelt's model of verbal communication, discussed in sections 4.1 and 4.2 , the role of mutual knowledge was accounted for by the relationship between the conceptualizer and the knowledge store containing the discourse model, situational knowledge and the encyclopedia. As Levelt points out in chapter 4 of his book the speaker takes shared world knowledge, shared situational knowledge and shared discourse knowledge into account when planning his discourse. Presumably, he derives the addressee's knowledge on these matters from the three components mentioned in the (contextual) knowledge store.

The importance of mutual knowledge can be illustrated by means of the following imaginary conversation which takes place between Ann and Bob while Ann is in bed with the flu:

Ann: I finished my book

Bob: okay, I'll get you another one

Ann's utterance is meant and interpreted by Bob as a request to go to the library and get her another book. Ann assumes that Bob will be able to arrive at this interpretation because she knows that he knows - or assumes that he knows a) that she likes reading books when she is ill (a very specific type of world knowledge, based on membership of a very small community), b) that books can be borrowed from libraries (world knowledge), and c) that Ann is ill (situational knowledge) and therefore cannot be expected to go to the library herself (world knowledge). Bob's answer is meant as and interpreted by Ann as a compliance on Bob's part to go to the library and borrow another book for her. Bob assumes that Ann will infer that "one" refers to a book here, because he knows that she knows that that is what they are talking about (discourse knowledge). As this example shows, many inferences need to be made before a message is properly understood. The role of mutual knowledge for this purpose is unmistakably very large indeed.

By exploiting mutual knowledge the speaker will considerably reduce the effort needed to communicate with his listener. In fact, it can be maintained that the principle of economy cannot be observed unless the speaker exploits mutual 
knowledge. If, for instance, a speaker did not take the listener's knowledge into account, he might either give too much information or too little. If he were to give more information than required, he might in this way make it easier for the listener to understand him, but he would clearly augment his own task. If, however, he were to give less information than required, he would, although reducing his own efforts, increase those to be invested by his listener, and he might not even succeed in communicating his message at all. In either case communication would not be very efficient.

Mutual knowledge plays a role in the selection of $\mathrm{CpS}$ too. As in ordinary communication, the speaker will reduce his and his interlocutor's processing efforts by drawing on linguistic and/or conceptual knowledge they share. More importantly, however, one would not expect the speaker to make use of either linguistic or conceptual knowledge unless he assumes this knowledge is shared. The reason for this is straightforward: the speaker who exploits knowledge that is not shared is unlikely to be understood and thus may fail to reach his communicative goal. ${ }^{10}$

\subsubsection{Constraints on communication}

Communication may be constrained by various factors. Two of these have been discussed in chapter 3, viz. the speaker's age (and related to this, his cognitive maturity) and social status. Here two other factors will be dealt with, which seem to affect CpS use in particular. They are lack of linguistic knowledge and lack of time.

It has already been shown in section 4.2 that lack of linguistic knowledge may keep the speaker from reaching his communicative goal. If he cannot solve his lexical problems by adopting alternative encoding procedures, the communication process may break down, after which a new or reduced message must be generated. It is worth noting that lack of linguistic knowledge on the part of the listener has a similar effect. If the listener cannot decode the message because he does not know the words that are used, the intended communicative goal will not be reached either (unless the speaker is prepared to repair his message).

Lack of time, either on the part of the speaker or on the part of the listener, may make it impossible to complete the intended message, or to make the message sufficiently informative to be comprehensible. Again, this means that the speaker runs the risk of not reaching his communicative goal. In addition, lack of time may make it impossible for the speaker to devote due attention to all (sub)plans and (sub)procedures which make up the communication process. As a result, time constraints are likely to increase the error-rate in communication (Levelt, 1976:56). 
From the literature on problem solving it is known that problem solvers who are confronted with problems beyond their power (e.g. because they have insufficient time, are too tired, or simply not intelligent enough) may decide to lower their aspiration levels. They replace the original goal by one which they consider 'good enough'. This behaviour is referred to as satisficing (Simon, 1957:205). It enables humans to maintain the balance "between the time (and effort) required to meet needs and the total time (and effort) available" (Simon, 1957:272).

Satisficing plays a role in communication too. The speaker who is confronted with a linguistic knowledge constraint or a time constraint will generally adapt his communicative intention to one that is within his reach. Thus, if the speaker foresees that a particular message will take too much time, or too much effort, he may decide to adapt it even if, strictly speaking, it were within his limits. In this way he maintains the balance between effect and effort, which, as we have seen, is characteristic of efficient communication.

As to the use of $\mathrm{CpS}$ it will be clear that lack of linguistic knowledge is a most relevant factor, because the decision to use a particular $\mathrm{CpS}$ will depend on the speaker's ability to encode it. Time is an important factor because the use of some $\mathrm{CpS}$ types makes heavy processing demands, which cannot be met under certain time constraints. Moreover, the time needed to think of an alternative encoding procedure may be so long that the speaker risks losing his tum (Beattie, 1980). The speaker who estimates that the use of a particular CpS will be very complicated from a linguistic point of view, and/or very time-consuming, may decide it is not worth the effort and therefore lower his communicative goal.

In this respect it is worth noting that the extent to which a speaker is inclined to satisfice may depend on his personality. After all, it is generally known that some people are prepared to spend much more effort than others to reach their goals. Obviously, individual differences like this may affect $\mathrm{CpS}$ use too.

\subsection{Conclusion}

In this chapter the use of CpS was embedded within a model of speech production (Levelt, 1989). It was shown that the communication process was somewhat more complicated in the case of lexical problems, but not really different from communication without lexical problems. This supported our view that the study of $\mathrm{CpS}$ should not be isolated from the study of communication.

Subsequently, a new taxonomy of $\mathrm{CpS}$ was proposed. One advantage of this taxonomy is that it is much more parsimonious than the taxonomies which have been used to date. It comprises only two archistrategies, each of which can be 
subdivided into two CpS types. A second, and more important advantage is its compatibility with Levelt's model of communication. The distinctions between the four CpS types reflect differences in the conceptual and linguistic processes underlying them, and can therefore be considered to have psychological plausibility.

Finally, some principles and constraints that govem communication were discussed. It was predicted that the cooperative principle and the principle of economy, the notion of mutual knowledge and constraining factors like lack of linguistic knowledge and lack of time also affect the use of $\mathrm{CpS}$. In chapter 8 it will be seen whether the results of the Nijmegen project can indeed be explained by these factors.

\section{Notes to chapter 4}

1. Note that this is a direct result of the code model being based on Shannon \& Weaver 's (1949) model of speech transmission, which is naturally uni-directional (Herbert Schriefers, personal communication).

2. Lexical access is part of the formulating procedure, which consists of grammatical and phonological encoding (cf. figure 4.1). It is usually automatic.

3. Kerkman (1984) notes that for bilingual speakers the organization of the mental lexicon may depend on a speaker's proficiency in the two languages. His data indicate that in the case of very advanced L2 leamers (Dutch university teachers of English) there are separate lexical representations for $\mathrm{L} 1$ and $\mathrm{L} 2$ words, while differentiation also takes place in the semantic network. For less advanced L2 learners Kerkman reports evidence in favour of a single integrated semantic network. Lexical representations in this case are separate for non-cognates, but not for cognates.

Whether and to what extent proficiency-related differences in the organization of the mental lexicon affect $\mathrm{L} 2$ leamers' use of $\mathrm{CPS}_{\mathrm{S}}$ are interesting questions. At the moment, however, we know of no research which could provide sensible answers to them.

4. Some $\mathrm{CpS}$ require the speaker to adjust his original preverbal message, e.g. when the intended concept is paraphrased or replaced by a related one. This implies that the distinction between (1) and (3) is not clear-cut, but then neither is the distinction between 'Reduction Strategies' and 'Compensatory Strategies' (cf. section 2.2.2).

5. The taxonomy presented here was the final outcome of many discussions between Eric Kellerman, Theo Bongaerts and myself. Earliet versions of it have appeared in Bialystok \& Kellerman (1987) and Kellerman et al. (1987). The present - and as far as I am concemed final - version is the one which appeared in Poulisse (1987).

6. Note that if the activation of a particular $\mathrm{L} 1$ lexical item did cause a problem, the speaker would probably refrain from using a transfer strategy in this case.

7. The cooperative principle is not the only conversational principle observed in communication. Grice (1975) refers to "other maxims (aesthetic, social or moral in 
character), such as 'Be polite"' (p.47). An elaborate discussion of the principle of politeness and other principles such as the irony principle, the interest principle and the Pollyana principle (pleasant topics of conversation are preferred to unpleasant ones) is given in Leech (1983).

8. Leech (1983) makes a distinction between Interpersonal Rhetoric and Textual Rhetoric. Interpersonal Rhetoric relates to discourse and is said to be subject to such principles as the cooperative principle and the politeness principle. Textual Rhetoric concerns message transmission and is controlled by the processibility principle, the clarity principle, the economy principle and the expressivity principle.

9. Sperber \& Wilson (1986) reject the notion of mutual knowledge as a psychologically implausible one, because of what has come to be known as the mutual knowledge paradox (Clark \& Marshall, 1981). A speaker $S$ can never be sure that a hearer $H$ knows $X$, and that $H$ knows that $S$ knows $X$, and that $H$ knows that $S$ knows that $H$ knows $X$, and so on ad infinitum. For this reason they introduce the notion of mutual manifestness, and suggest that "A fact is manifest to an individual at a given time if and only if he is capable of representing it mentally and accepting its representation as true or probably true" (p.39).

Since the notion of mutual manifestness is less clear and less well-known than the notion of mutual knowledge, the latter notion will be used in this thesis. It should be clear, however, that mutual knowledge is a probabilistic notion and that speakers exploit what they assume to be mutually known rather than what is mutually known.

10. Note that in some cases where understanding is considered relatively unimportant, speakers do use $C_{p} S$ that are constructed on the basis of knowledge that is not shared, particularly when such $\mathrm{CpS}$ require litule effort (cf. chapter 8 ). 


\section{Experimental Design}

As explained in chapter 1, the three main objectives of this research project are 1) to gain insight into the relationship between a person's L2 proficiency level and his use of CpS; 2) to study the relationship between CpS use in L1 and L2; and 3) to establish the relative effectiveness of the various CpS types. In this chapter the methods followed to obtain the answer to the first two research questions are outlined. Sections 5.1 and 5.2 contain a description of the subjects' proficiency levels and an account of the procedures followed to select them. In section 5.3 the considerations which led to the final choice of experimental tasks will be presented, after which the tasks, including the instructions, will be discussed in detail. Reasons for collecting retrospective data after only two of the four experimental tasks will be discussed in section 5.4, while a typical test-session will be described in section 5.5. The chapter will finish with a brief note on the processing of the data. For the methods used to establish the effectiveness of $\mathrm{CpS}$, the reader is referred to chapter 10.

\subsection{Subjects}

In order to be able to study the effect of L2 proficiency on CpS use in detail, it was decided to collect data from subjects at three different proficiency levels. Each of the three groups consisted of 15 subjects. It was felt that 15 was a number which would satisfy statistical requirements without posing too many practical problems with respect to handling the data. In view of previous claims that the use of some CpS types is task-specific (see chapter 3), it seemed preferable to collect data on a variety of tasks from a fairly small number of subjects rather than to have just one task carried out by a large number of subjects.

The three groups were chosen so as to cover as wide a range of proficiency as possible. There were some restrictions though. To make sure that the CpS produced by the subjects in each of the three groups could be compared, all subjects needed to perform the same tasks. Since these tasks had to be difficult enough to elicit CpS from the most proficient subjects, the proficiency level of the elementary subjects could not be set too low. They had to have enough language at their disposal to be able to complete the tasks successfully.

From the experiences gained in earlier studies of $\mathrm{CpS}$ involving Dutch learners of English (Poulisse, 1981; Elsen et al., 1982) we knew that 3-VWO pupils ${ }^{1}$ could be expected to meet our demands. Their knowledge of English generally enables them to get their messages across, albeit with many grammatical errors. Besides, their proficiency level should be high enough to allow them to use $\mathrm{CpS}$ effectively. This is all the more important in view of the 
suggestion made by Bialystok \& Frohlich (1980) that a certain minimum level of proficiency is required for effective $\mathrm{CmS}$ use.

To allow group-wise comparisons, the proficiency levels of the two other groups had to be sufficiently distinct from the lowest level as well as from each other. For this reason 15 second-year university students of English constituted the most proficient group. The intermediate group consisted of 15 5-VWO pupils. Table 5.1 gives some general information on each group's proficiency level and age.

Table 5.1 Information on the proficiency levels and the ages of the subjects in the three experimental groups

\begin{tabular}{lllll}
\hline & status & proficiency level & years of study & age \\
\hline group 1 & 2nd-year students & advanced & 7 or more & $19-25$ \\
group 2 & 5-VWO pupils & intermediate & 4 or 5 & $16-18$ \\
group 3 & 3-VWO pupils & low & 2 & $14-15$ \\
\hline
\end{tabular}

The 3-VWO pupils who took part in the experiment were in their third year at school, which means that at the time the experimentation took place (autumn 1984) they had been learning English for two years and three months. The 5-VWO pupils were in their fifth year and had been leaming English for at least four years and three months (for ease of reference the three months will not be mentioned in the remainder of the discussion). All second-year students had attended classes in English for at least six years at secondary school (again VWO), and were now studying English language and literature full time at the university.

\subsection{Selecting subjects}

In order to ensure as much homogeneity as possible in each of our three proficiency groups, the selection of subjects was based on a number of criteria. For VWO pupils they were 'years of tuition in English', 'school-report marks', 'teacher judgements' and 'score on a general language proficiency test'. For second-year students the criteria were 'contact with the English language', 'results on first-year exams', and again 'score on a general language proficiency test'.

\subsubsection{Years of tuition in English}

The Dutch school system is such that pupils who fail to meet a certain standard in a number of subjects at the end of the school-year are not allowed to go on 
with the next year's courses. They have to take all subjects, including the ones they had no problems with, a second time. Moreover, it is possible to do a 5 year HAVO $^{2}$ course first and then switch to VWO and continue in the fifth year. Thus, not all 5-VWO pupils have had four years of tuition in English. Quite a few have had five or even more. Ideally, all 3-VWO and 5-VWO pupils who participated in the experiments should have had two and four years' tuition in English respectively. This was no problem in the case of 3-VWO pupils, but it proved to be impossible to select 15 suitable 5-VWO pupils (from a population of 40 ) without discarding all other criteria. Therefore, the criterion was set at two years for 3-VWO pupils and four or five years for 5-VWO pupils.

Second-year university students of English generally have a more varied background, and at their level a two months' stay in America or contacts with an English-speaking friend may outweigh an extra year's tuition in English. It was therefore decided to exclude students who had had extensive contacts with native speakers of English. Conversely, little attention was paid to the number of years in which tuition in English had been received.

\subsubsection{School-report marks and exam marks}

The second criterion was formed by school-report marks for English for VWO pupils and exam marks for second-year students. In The Netherlands marks range from 1 (lowest) to 10 (highest). The borderline between fail and pass lies between 5 and 6 . Generally, the school-report mark that is given is the average of all school-marks during one term. The VWO pupils who were selected for the experiment all had school-report marks of 6 or 7 for English. That is to say that their achievements had been satisfactory but no more than that.

For students the results on four first-year exams were combined into a total score. The exams were 'pronunciation', 'fluency and listening comprehension', 'translation' and 'phonology'. The maximum score to be obtained was 40 . The students who were finally selected all had a combined exam score between 22.1 and 29.0.

\subsubsection{Teacher judgements}

In addition to the school-report marks teacher judgements were collected for the VWO pupils. The judgements were given on a five-point scale. The teachers were asked to indicate for each pupil whether his general proficiency was 'far below avcrage' (1), 'somewhat below average' (2), 'average' (3), 'somewhat above average' (4) or 'far above average' (5). One teacher, who had been teaching his class for two months only, did not provide any information on this point because he felt incapable of judging his pupils reliably. Of the pupils for whom a teacher judgement was available, only those were included in the experiment who had been given a score of 3 or 4 . 


\subsubsection{Scores on a general language proficiency test}

The last selection criterion was formed by the subjects' scores on a general language proficiency test. Various possibilities were considered in this respect. Since our research focusses on CpS use in the oral production of language, the most obvious choice would be an oral language proficiency test. However, oral proficiency tests such as the F.S.I. interview have to be administered individually. Selecting $\mathbf{4 5}$ subjects from a population that is at least twice as large would have involved the organization of 90 interviews. This was considered much too timeconsuming, in particular since the reliability of such interviews is not very high if the interviewers are not trained, or when they test so infrequently or independently that they evolve their own scoring system (cf. Jones, 1975; Wilds, 1975; Lowe, 1983). The only way to obtain reliable scores on an interview would be to have a number of judges rate the subjects' performance independently. This was considered much too cumbersome (and much too expensive) for the mere purpose of selecting homogeneous groups of subjects. It was therefore decided not to have an oral language proficiency test.

The second possibility was to have a written standardized test of general language proficiency. One advantage of such a test is that its reliability has already been established elsewhere. A second advantage is that standardized tests are usually well-known, which would enable us to report our subjects' proficiency level on an intemationally recognized scale. A search through available tests led to the selection of the Michigan Test of English Language Proficiency. This test consists of three components testing grammar, vocabulary and text comprehension. The time needed to complete the test is 75 minutes, and although this was too long for our purposes - the test had to be taken within one fifty-minute school period - it was decided to explore its possibilities a little further.

A pretest was administered to 27 3-VWO pupils and 29 5-VWO pupils of the Pius X College in Almelo to find out if the test could be reliably divided into two halves. Unfortunately, the results of the pretest proved that this was not the case. The pupils who did the odd-numbered items of the Michigan test performed considerably better than those who did the even-numbered items $(73.5 \%$ correct vs $57.4 \%$ correct for 3 -VWO pupils and $87.3 \%$ correct vs $67.8 \%$ correct for 5 -VWO pupils). This, and particularly the fact that 5-VWO pupils scored lower on the even-numbered items than 3-VWO pupils did on the odd-numbered items (67.8\% vs $73.5 \%$ ), led us to conclude that the application of half of the Michigan Test would not give us a reliable picture of our subjects' proficiency level.

Pretesting the complete Michigan Test on a small number of advanced learners of English was not very successful either. Five second- and third-year university students of English all scored more than $97 \%$ correct. $^{3}$ Apparently the test has no discriminative power at this level, due to a ceiling effect. It was therefore decided not to use the Michigan test for selection purposes. 
Considering the large variation in proficiency level between our three groups of subjects, and in view of the experiences with the Michigan Test, it was expected that any one language proficiency test to be taken by all three groups would suffer from ceiling and/or floor effects. For this reason it was decided to proceed from the assumption that the number of years during which tuition in English had been received should in reality distinguish among our three levels of proficiency. To ensure homogeneity within each of the three groups three separate cloze tests were developed, each adapted to the particular group level for which it was intended.

Cloze tests are integrative tests of general language proficiency. They are based on the theory that language is redundant and that knowledge of a language can be expressed in terms of the ability to understand messages with reduced redundancy (cf. Spolsky, 1973). In a cloze test the redundancy has been reduced by deleting every $n$th word (where $n$ is a number between 5 and 10). The subject has to fill in the missing words. His score is obtained by counting the number of correct words. What is taken to be correct depends on the scoring method. The two methods used most commonly are the exact word method (only the original word is considered correct) and the acceptable word method (any word that fits the context lexically and grammatically is correct). In general, cloze tests are considered to be very reliable and valid tests of general language proficiency (cf. e.g. Oller, 1979; see also Van Els et al. 1984:327ff. for a useful discussion of cloze tests). 4

Several cloze tests were constructed for 3-VWO and 5-VWO levels. They were pretested on various groups of 3 and 5-VWO pupils at the Ludgercollege in Doetinchem and the Jeroen Bosch College in 's-Hertogenbosch. For the second-year students several tests were selected from Garman \& Hughes (1983). They were pretested on various groups of students at teacher training colleges in Nijmegen on the assumption that their level of English proficiency is reasonably comparable to that of university students of English.

The final choice of cloze tests was determined by their reliability in the pretests. Since the variation in proficiency level among the subjects within one group was assumed to be fairly small, we accepted a reliability of .70 (= KR 20).

The cloze tests were then presented to 463 -VWO and 555 -VWO pupils of the Elshof College in Nijmegen, and to 32 second-year students of English at Nijmegen University. As can be seen in table 5.2, the reliability of the cloze tests, when marked with the exact word method, was somewhat lower in the actual tests than in the pretest, particularly at 3-VWO level. This is due to the fact that there was much less variation among the pupils of the Elshof College than among the pupils of the two different schools who took part in the pretest $\left(s^{2}=14.7\right.$ vs $\left.s^{2}=36.9\right)$. Marking the same tests with the acceptable word method proved to increase the reliability considerably. This is consistent with Oller's (1972) finding that for non-native speakers the acceptable word method 
yields higher correlations with other tests than the exact word method. It was therefore decided to base the selection of subjects on the scores obtained on the acceptable word method version of the cloze tests.

Table 5.2 The reliability of the cloze tests in the pretest compared to its reliability in the actual test

\begin{tabular}{lcccccc}
\hline & $\begin{array}{l}\text { N of } \\
\text { items }\end{array}$ & Ss & $\begin{array}{c}\text { reliability pretest } \\
\text { (exact) }\end{array}$ & Ss & \multicolumn{2}{r}{$\begin{array}{c}\text { reliability actual test } \\
\text { (exact) }\end{array}$} \\
(acceptable)
\end{tabular}

For 3.VWO pupils the criterion was set at a score between 27 and 37 (out of 48), for 5 -VWO pupils at a score between 58 and 72 (out of 81), and for second year students at a score between 50 and 67 (out of 80).

With the help of the four criteria, 'years of tuition in English', 'school-report/exam marks', 'teacher judgements' and 'scores on a cloze test', three fairly homogeneous groups of 15 subjects each were selected. The subjects were equally divided among both sexes, the ratio always being 7 to 8 . All subjects who participated in the experiment were volunteers. They were paid Fl.18,- for the complete experimentation, which lasted approximately 3 hours.

In general we tried to ensure the homogeneity of the three groups by excluding the best as well as the poorest subjects from our experiments. It will be clear, however, that when one has to recruit 15 subjects from a total population ranging from 32 to 44 (not everybody who took the cloze test was willing to participate in the experiment), one cannot but relax one's criteria. It is for this reason that we had to allow cloze test scores as divergent as $\mathbf{5 0}$ and $\mathbf{6 7 .}$

Similarly, we could not avoid including subjects who had had 5 years of English in our intermediate group, nor could we, in spite of all precautions, rule out differences in proficiency level between members of any one group. However, our assumption is that these differences do not affect the results of the three groups differently. Moreover, it is assumed that the differences between the groups are large enough to allow group comparisons with respect to the relationship between proficiency level and $\mathrm{CpS}$ use.

\subsection{Tasks used in the experiment}

One of the most important conclusions drawn from the literature on $\mathrm{CmS}$ and $\mathrm{CpS}$ to date is that the use of $\mathrm{CpS}$ is to a large extent task-specific (see chapter 
3). This made it necessary to elicit $\mathrm{CpS}$ in a variety of tasks, one of which at least should resemble a realistic communicative situation, so that a more generalizable picture of $\mathrm{CpS}$ use could be obtained. In our project, it was decided to have three tasks ranging from strictly controlled to fairly natural. In addition, it was necessary to have a fourth task which would enable us to compare strategic behaviour in L1 and L2.

Controlled tasks, as their name indicates, are tasks in which disturbing factors are controlled as much as possible. Generally, in the case of $\mathrm{CpS}$ research, this means that the speaker is not given any feedback, that the intended meaning is imposed by the task, and that the use of avoidance strategies is not allowed.

Natural tasks should, ideally, be indistinguishable from natural speech situations. It will immediately be clear that perfectly natural language can never be elicited in an experimental situation (cf. Labov's, 1972, discussion of the Observer's Paradox, and Tarone's, 1979, discussion of this same phenomenon with respect to the study of interlanguage). One way to achieve a fair degree of naturalness is to select familiar topics, or preferably, to allow the subject to determine the topic of speech. It stands to reason that in a natural task there are no restrictions on the amount and sort of feedback whatsoever. Such a task used in a study of $\mathrm{CpS}$ implies that the subject is free to solve or avoid problems, or solve them in cooperation with his interlocutor.

\subsubsection{The concrete picture description task (task I)}

The most controlled task, from now on to be referred to as task I, was a concrete picture description task similar to those used by Elsen et al. (1982) and Paribakht (1982; see also chapter 3). It consisted of 40 coloured photographs of objects which had been selected from a collection of 100 items on the basis of two pretests, one involving two groups of 20 third-year university students of English (each group judged 50 items), and one involving 22 3-VWO pupils, who judged all the items. The native language of all subjects involved in the pretests was Dutch.

In these pretests the subjects were asked to write down the Dutch word for the object they saw (on slides) if they recognized the picture, and to add the English word for it whenever they could. Only those items which were recognized by at least 39 of the subjects, but for which none of them knew the English word (with one or two exceptions) were included as test items. It was assumed that if third-year students did not know the English names for these items, they would certainly be problematic to leamers of a less high proficiency. Besides these 20 'difficult' items, 20 'easy' items were selected as fillers to encourage the subjects. All the easy items had been recognized (and named) by all of the subjects in the pretests. Two examples, one difficult and one easy, were selected in a similar way. Thus, the final test consisted of the following items: 


\section{Test items}

$\begin{array}{llll}\text { rolling pin } & \text { beermat } & \text { stilts } & \text { spirit level } \\ \text { bib } & \text { reel } & \text { humming-top } & \text { coat-hanger } \\ \text { measuring tape } & \text { abacus } & \text { three-way adapter } & \text { dustpan } \\ \text { clapper } & \text { flyswat } & \text { watch-strap } & \text { shoehom } \\ \text { teat } & \text { coal-scuttle } & \text { starfish } & \text { spout }\end{array}$

\section{fillers}

roses

pipe

telephone

book socks

ball

hat

pencil

dog

television

car

banana

bicycle

bottle

knife

cup

door

glass

apple

key

examples

newspaper (easy) colander (difficult)

The photographs were presented in one of four different random orders. The subjects were asked to look at them one by one and to make clear in English what object they saw, either by naming it, or in any other way. They were asked to do this in such a way that an Englishman who would later listen to the recordings of the session, would be able to identify the object (for an English translation of this and all other instructions see appendix II).

\subsubsection{The oral interview (task $N$ )}

We opted for an oral interview as the most natural task in our project. Although we felt obliged to make some concessions to the requirements of naturalness to guarantee the use of $\mathrm{CpS}$, we assumed the interview would be an adequate method for eliciting spontaneous data.

Each subject had a twenty-minute interview with a native speaker of English. The native speaker was a 29-year-old woman from Ireland. She was married to a Dutchman and had lived in the Netherlands for six months. Her knowledge of Dutch was very limited. Before experimentation began, she received instructions on the required intervicw techniques and was trained in a number of practice sessions. In these sessions it was emphasized that the subjects should be talked into lexical problems as much as possible, and particularly that they should not be helped too quickly. The advantage of this type of training was that the interviewer rapidly developed a persistent questioning technique which forced the subjects to use $\mathrm{CpS}$. The disadvantage of it was that repeated questions for more details such as "what sort of flowers do you grow in your garden?" or "and what would you put in your Chili?", occasionally made the interviews less natural than they could have been. On the whole the interviewer succeeded in creating a relaxed atmosphere though. 
The topics which were discussed in the interviews were partly determined beforchand. It was expected that familiar topics like school, home and holidays, since they would place subjects in realistic communicative situations where they were "in the know" while the interviewer was not, would be more motivating for the subjects to talk about than traditional exam topics like nuclear energy and capital punishment. A number of specific topics like gardening and cooking were included because they require the use of particular domains of language with which the subjects were expected to be unfamiliar and which would consequently force them to use many $\mathrm{CpS}$.

Other topics just came up spontaneously during the interviews and as long as the subjects showed an interest in talking about them, they were pursued. In general the strategy was to prefer lively conversations to predetermined "question and answer games". Illustrative extracts of interviews are given in chapters 7 and 8 . The interview will be referred to as task IV.

\subsubsection{The story retell task (task III)}

Finding a task which was in between controlled and natural tasks was not easy. In fact, what we wanted was a task in which we could control for variables like 'content' and 'feedback', but which, unlike task I, would not be devoid of context. The following tasks were considered:

\section{a. Telling a picture story}

A picture story task, as used by Váradi (1973) and Tarone (1977), to mention just two well-known studies, presents the subject with a series of pictures around which he has to construct a story. This type of task is quite demanding from a creative point of view, and it was expected that the length and the content of the stories produced by the subjects would depend on their creative skills, as well as on their competence in the L2. As a result, it would not only be difficult to compare the stories, but it would also be impossible to distinguish the linguistic from the creative factor.

\section{b. Giving instructions}

Instruction-giving tasks, such as the ones used by Brown \& Yule (1983), where people had to instruct each other how to put a mincer or a plug together, or by Hallmann, Ras, Swinkels \& Verhulst (1979), where learners of English instructed native speakers to put a puzzle together, were not considered to be suitable either. Apart from the fact that such tasks involve two subjects at a time, for which reason the number of subjects ought to be doubled, their outcome probably depends largely on the subjects' world knowledge and puzzling skills. Someone without "do-it-yourself" experience may find a Brown \& Yule-type task much more complicated than someone used to doing odd jobs. Again, linguistic and other cognitive skills cannot be properly distinguished. 


\section{c. Giving route directions}

Ratner \& Rice (1963) and some of the contributions in Jarvella \& Klein (1982) report experiments in which subjects give route directions, either with the help of a map, or on the street itself. The disadvantage of this task too is that two people are involved, which is awkward from an organizational point of view, but also makes it impossible to control for feedback. A second disadvantage is that the domain of language to be used is rather limited. Even if reference points like hospitals, libraries, roundabouts etc. are included on the map in an attempt to increase the number of lexical problems, it will be very easy to avoid mentioning these by using such phrases as: "take the first street on the right, the third on the left and then go straight ahead".

Considering the practical and organizational problems inherent to these tasks and the difficulty in controlling for cognitive factors, all three possibilities were discarded. The task which was finally decided on was a story retell task. It will be referred to as task III. There are a number of reasons which make a story retell task extremely suitable for the present purpose. Like task I it is controlled in that the contents of the story, and hence the problematic items, can be largely determined by the experimenter. Feedback too can be controlled, but in this case without affecting the naturalness of the task. After all, stories are naturally monologues. The naturalness also benefits from the fact that in a story retell task it is the message rather than the exact words that has to be conveyed. People seem to remember the meaning of a text, or, as Sachs (1967) puts it: "... the original form of the sentence is stored only for the short time necessary for comprehension to occur. When a semantic interpretation has been made, the meaning is stored." (p.437; cf. also Bransford, Barclay \& Franks, 1972; and Clark \& Clark, 1977). This focus on the meaning gives the subject more room to manoeuvre. It makes it easier to substitute related lexical items for the ones originally occurring in the story, or to have the interlocutor infer the intended meaning from the information contained in the context. The main advantage of the story retell task's middle position between the two extremes of strictly controlled and "as natural as possible" is that it forms a bridge for comparison between task I on the one hand and task IV on the other hand.

The story retell task which we constructed consisted of five ten-line stories. Three of these were selected from Hill (1977), one was an unfamiliar version of a well-known joke and one was written for the occasion. The stories from Hill (1977) were adapted for the present purpose by increasing the number of expected lexical difficulties. Familiar words like 'doctor' were replaced by words like 'representative' which were expected to be more difficult. The subjects were asked to listen to recordings of these stories read in Dutch by an experienced reader. After each story they were asked to retell it in English. Pictures had been drawn to accompany the stories to make sure that the subjects would not omit too many essential details (cf. appendix III for both stories and 
pictures). The subjects could look at these pictures while listening to the stories and while retelling them. The first of the five stories was presented as a practice story and later discarded from the analyses.

\subsubsection{The abstract figure description task (task II)}

In addition to the three tasks discussed above there was a need for one other task which should allow comparisons of strategic behaviour in L1 and L2. The main issue here is whether or not subjects transfer their $\mathrm{L} 1$ strategic competence to the L2. Will they adhere to their preferred strategy as expressed in the L1, in spite of linguistic problems, or will they opt for another strategy? If subjects do indeed resort to other strategies it may be possible to establish a hierarchy of preferred strategies.

For this purpose we chose the abstract figure description task, which had been used in various experiments on referential communication in the L 1 by Krauss and his associates (see chapter 3). As we have seen, the figures to be referred to in this task are novel graphic designs which do not have conventional names. Hence, they are not only problematic to L2 learners, but also to native speakers having to refer to them in their L1 (see appendix I for the figures used).

In order to be able to compare the $\mathrm{L} 1$ and $\mathrm{L} 2$ versions each subject had to carry out the task three times, twice in Dutch, followed by once in English. As in task I the subjects were instructed to make clear what figure they saw, but this time they were to do this in such a way that a native speaker who would later listen to the recordings of their tasks would be able to put the figures in the described order. The first version of the test was preceded by three examples. In the other two versions these were left out. The order of the figures in the three versions was different each time.

The method described above was suggested by Erik Schils (personal communication) for the following reason. ${ }^{5}$ Assuming that the figures are inherently conceptually difficult when they are dealt with the first time, but not the second time, due to a learning effect, and assuming that there are additional linguistic difficulties when describing these figures in the L2, but not in the L1, neither of the two possible orders which counterbalancing of this task would permit in case the task was carried out once in Dutch and once in English, would allow us to compare the results. For, if there were one Dutch version followed by one English version, we would be comparing two versions of which the first was conceptually difficult and linguistically relatively easy, ${ }^{6}$ while the second was conceptually easy and linguistically difficult. However, if the order were reversed, the English version preceding the Dutch version, then the first (English) version would be both conceptually and linguistically difficult, while the second (Dutch) version would no longer be problematic at all. Schematically, the two possibilities can be represented as follows, where $+C$ means conceptually difficult and $+\mathrm{L}$ means linguistically difficult. 


$\begin{array}{llll}\text { Dutch: } & + \text { C, }- \text { L } & \text { English: } & -\mathrm{C},+\mathrm{L} \\ \text { English: } & +\mathrm{C},+\mathrm{L} & \text { Dutch: } & -\mathrm{C},-\mathrm{L}\end{array}$

As neither of the possibilities allows comparison of the two versions (there are always two variables which differ), counterbalancing is an absolute necessity. However, counterbalancing should not be applied if there are differential effects; that is to say, if the leaming effect from task A to task B is different from that from task B to task A (cf. Van Vliet, 1973). Although the number of subjects in the present research is much too small to determine whether there are such differential effects, we strongly suspected them to be there (see Kellerman et al., in press). A subject who has to carry out the Dutch version first will probably use his preferred strategy and feel obliged to attempt to use this again in the English version. A subject who has had to struggle through the English version first, however, may well be inclined to transfer his imperfect L2 solution to the $L 1$. In that case there is no optimal $L 1$ version which could serve as a base-line against which to compare the $\mathrm{L} 2$ version.

In addition to the methodological reasons there was the danger that the requirement to do such a difficult task in English straightaway would discourage the subjects, in particular the younger ones. For this reason too, we decided to follow Erik Schils' suggestion to have a Dutch version in which the conceptual problem is solved, followed by a second Dutch version which is neither conceptually nor linguistically difficult and therefore comparable to the third English version, which is again only linguistically difficult. In scheme:

Time 1

Dutch: + C, - L
Time 2

Dutch: - C, - L
Time 3

English: - C, + L

A practical disadvantage of this methodological ingenuity might have been that subjects would find such repetition irksome. Fatigue and/or boredom might have undesirable effects on the data. However, pretests had convincingly demonstrated that this was not the case. ${ }^{7}$

\subsection{Retrospective tasks}

In order to facilitate the identification of $\mathrm{CpS}$ in tasks III and IV retrospective comments were collected from the subjects immediately after they had performed these tasks. Ideally, such comments should have been collected on all tasks. However, for practical reasons this was impossible. The time needed to collect retrospective data is approximately twice as long as that needed to collect the primary data. One will understand that with four tasks, which were expected to last $15,30,15$ and 20 minutes respectively, this would have led to 
an unreasonably large experimentation time. One direct consequence of this is that more than two test sessions would be needed. Considering that two thirds of our subjects could only be tested after schooltime, this would have extended the time of experimentation to over three months. In this timespan the subjects' knowledge of English would very likely have increased. Another disadvantage of having three sessions is that it increases the chances of dropouts. As it was essential that each subject performed all tasks this was considered rather risky, and it was decided to have two test-sessions only.

The final reason why it was decided not to collect retrospective data on all tasks is that there is a danger that the knowledge that one is required to retrospect affects task performance. If the subjects had been asked to provide retrospective data after each task it would have been obvious to them, once they had done this twice, that they would be required to do it again later. This could have affected the primary data.

Once it had become clear that it would not be wise to collect retrospective data on all four tasks, it had to be decided on which tasks they should be collected. In view of the fact that the identification of $\mathrm{CpS}$ was expected to be more difficult in those tasks in which the problems had not been determined beforehand (task IV) or could be more easily avoided (tasks III and IV), i.e. in the more natural tasks, it was decided to collect retrospective data on tasks III and IV, but not on tasks I and II. A more detailed account of the use of retrospective data and of the reasons for collecting themwill be given in chapter 6.

\subsection{The experimentation}

All tasks were carried out in the same room at the university of Nijmegen. Care was taken to place the equipment as inconspicuously as possible so that the room would not look frightfully experimental. Figure 5.1 illustrates the setting. In order not to disturb the interview the experimenter sat at a different table during that time. There were two cassette recorders. One was needed to play the stories for the story retell task, the other was used to record the subject's data. All primary data were additionally collected on video. This would not only enable us to study the use of gestures, but would also help the identification of CpS (cf. also chapter 6). The extra audio-recording was needed for the purpose of transcription.

The subjects were tested individually in two sessions of approximately one-and-a-half hours each. The order of the tasks was the same for all subjects. For practical reasons, it was decided to have one retrospective session each time. As tasks II and IV were considered to be the most difficult, they were placed in the second session, the expectation being that by that time the subjects 


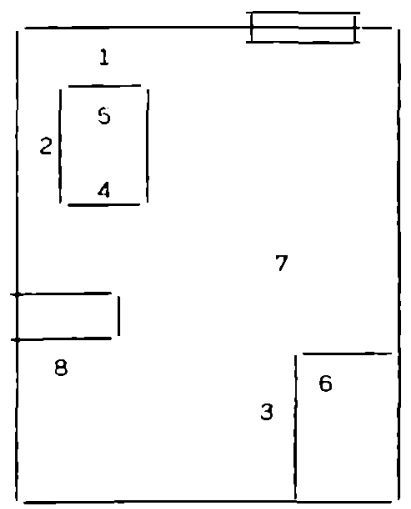

1. subject

2. experimenter (tasks I, II, III) interviewer (task IV)

3. experimenter in task IV

4. small cassette recorder

5. microphene

6. cassette recorder

7. video-camera

8. video-screen

Figure 5.1 A picture of the room in which the experiments took place

would be more at ease and therefore less likely to be put off by the difficulty of the tasks. Thus, the order of the tasks in all cases was I (concrete picture description) and III (story retell) plus retrospection in the first session, and II (abstract figure description) and IV (interview) plus retrospection in the second session.

Upon entering the room the subjects were offered a cup of coffee or tea, and were given some general instructions to read. These emphasized the importance of a good understanding of all task instructions. They urged the subjects not to talk about the experiments to their classmates and to strictly keep their appointments. Finally, they reminded the subjects that they would not be paid unless they attended both sessions. After the general instructions the experimenter asked for some additional personal information from the subjects conceming their date of birth and their contacts with English.

They were then given the task I instructions to read, after which they could ask questions. They were given a second opportunity to ask questions after the examples. They then carried out task I. After task I there was a short break in which the experimenter made some encouraging remarks. Then the instructions for task III were given, again with the possibility of asking questions before and after the example story. The stories were played and retold one by one. The subjects were informed that they could have small breaks in between if they felt like it, but hardly anyone wanted to have them. During both tasks the experimenter made written notes of problems she perceived. After task III the subjects were given the instructions for the retrospective session on task III. These required the subjects to watch the video-tape of their performance and to tell the experimenter everything they remembered thinking while doing the task. A more detailed description of the procedure followed to collect the retrospective data will be given in chapter 6 .

In the second session the subjects did task II, followed by task IV. Before the interviewer was called in the experimenter asked the younger subjects whether they had ever spoken to a native speaker of English before, and how 
they felt about it. As some of them seemed to be quite nervous, she tried to put them at ease, saying that the interviewer was very kind and understanding and would not mind repeating things if they were not clear. Then the interviewer was called in. The interviews lasted twenty minutes of which the first five minutes have not been analysed since they served as a warming up. By that time most of the subjects felt at ease and were happily talking away. On the whole the interviewer managed very well in creating a relaxed atmosphere. After the interview the interviewer left the room and the experimenter and the subject went through a retrospective session on the interview in the same way as they had done on task III in the first session. Before leaving, most of the subjects said that they had enjoyed the experiments. Although some of the tasks had been very difficult for them, they were often surprised at their own achievements.

The experimenter generally conducted four sessions a day. Due to the subjects' superb cooperation she was able to collect all the data within six weeks.

\subsection{Processing of the data}

The total amount of data to be analysed took up 34 hours, the average time needed to do the four tasks being 45 minutes per subject. All data were transcribed from the audio-tapes, using a Sanyo memoscriber. The transcription was orthographic. Only where Dutch or Ln words were used as strategies was the transcription phonemic, because these strategies cannot be properly classified without phonemic information. Furthermore, special care was taken to mark pauses, repetitions, rising intonation, laughs and coughs, as these might be significant in the identification of CpS use (see chapter 6). A full description of the method of transcription, together with an illustrative fragment, is given in appendix IV.

All transcriptions were stored on computer ${ }^{8}$ and subsequently checked by a research assistant, who also corrected typing errors and other inconsistencies. The transcription of the data and the subsequent correction took five months.

\section{Notes to chapter 5}

1. VWO is the Dutch type of secondary school education which prepares pupils for entrance into a university. A VWO education lasts six years, from the age of twelve until the age of eighteen. English is an obligatory subject which is taught throughout the six years for two or three fifty-minute periods per week.

2. HAVO is a Dutch type of secondary school education, just below the level of VWO. 
3. This shows the high standard of English as a foreign language achieved at Dutch universities. Note that in the TOEFL test too, the Dutch do extremely well. De Jong (1988) reports percentile ranks on the total TOEFL population of $95 \%$ for native speakers, $91 \%$ for the Dutch, $87 \%$ for the Swedish, and 50\% for the world. Dutch 4-HAVO pupils, whose level of proficiency is somewhere in between that of 3-VWO and 5-VWO pupils have a percentile rank of $48 \%$.

4. Recently, the use of cloze tests has been criticized (see Klein-Braley, 1985) and at the moment new tests exploiting the theory of reduced redundancy are being developed. So far, results with the C-test, a lind of cloze test where the second half of every other word is left out, look very promising (cf. the collection of articles in Klein-Braley \& Raat, 1985). Unfortunately, this test was not yet available at the time when our subjects had to be selected. At that time there seemed to be no better altemative than the cloze test.

5. Note that for methodological reasons discussed in chapter 3 it was impossible to adopt a 'between subjects' design.

6. Linguistically easy here means that there are no problems resulting from inadequate knowledge of the language.

7. Besides, when the subjects who participated in the actual experimentation were asked afterwards whether they had found this task difficult or boring 36 of them answered they had found it difficult. Only 2 said the repetition had made it boring, while 26 said that the repetition had been quite helpful. It was also repeatedly said that the task was too difficult to be boring, and that having to do three different orders had given it sufficient variety to keep up the interest.

8. The data of tasks I, II and III were transcribed on paper and later stored on computer. The task IV data were simultaneously transcribed and computerized. This was a much faster procedure, which initially could not be followed, however, because of insufficient computer facilities. 


\section{The Identification of Compensatory Strategies ${ }^{1}$}

The four tasks described in the previous chapter yielded a wealth of L2 leamer data. The next step, obviously, was to identify those utterances in the corpus which had resulted from $\mathrm{CpS}$ use. In early research the identification of $\mathrm{CmS}$ had relied heavily on the researchers' intuitions. As a result, many errors which were, in fact, manifestations of the learner's interlanguage system were interpreted as CmS (cf., for example, Tarone et al., 1976). Conversely, correct forms, which might well be $\mathrm{CmS}$, were often disregarded (cf. Corder's notion of covert errors, 1973b:272ff.).

Since we considered it essential for the validity of $\mathrm{CpS}$ research to distinguish strategic from non-strategic behaviour, rigorous criteria have been adopted in the present study to determine clear cases of $\mathrm{CpS}$ use. These criteria were based on the working definition discussed in chapter 2 . They will be specified in section 6.1. In the same section it will be argued that these criteria necessitated the combination of two identification methods to locate the $\mathrm{CpS}$ in tasks III and IV. One of these methods is based on an analysis of problem indicators in the data, the other on retrospective comments provided by the subjects immediately after task performance. Both methods will be motivated and described in detail in sections 6.2 and 6.3 , respectively. The results of the two identification methods will be compared in section 6.4. This will reveal that the use of retrospective data contributed much to the reliability of the identification procedure adopted in the Nijmegen project, and thus to the validity of this study. The last section will summarize the main conclusions.

\subsection{The criteria and the identification procedure adopted in the Nijmegen project}

In chapter 2, $\mathrm{CpS}$ were defined (for working purposes) as "strategies which a language user employs in order to achieve his intended meaning on becoming aware of problems arising during the planning phase of an utterance due to (his own) linguistic shortcomings". As we have seen, the most important criterion adopted in this definition is 'problematicity'. The speaker who adopts a CpS has to be aware of there being a problem. Two additional criteria that can be derived from the working definition are a) that the problem must be linguistic in nature, which in the present study means it must be a lexical problem, and b) that the speaker must aim at the solution of this lexical problem, that is to say, that he must attempt to achieve his originally intended meaning. 
The application of these criteria requires that for each utterance which is considered as a CPS three questions be answered:

1. was the speaker aware of a problem?

2. was this problem lexical in nature?

3. what was the speaker's originally intended meaning?

In general, it is not too difficult to answer these questions with respect to the data collected in tasks I and II. After all, the principal lexical problems in these tasks had been determined beforehand, so that in general the subjects' intended meanings were known. Besides, temporal variables and hesitation phenomena have been shown to point to problems during the planning process (cf. the discussion in section 6.2.1). Thus, pauses, repetitions and false starts, but also rising intonations, sighs, laughs and comments like "oh dear", "what's it called again?", function as problem indicators on the basis of which one can identify the CpS in these tasks with a reasonable degree of certainty.

The data from tasks III and IV are more problematic, however. In task III it is not always clear whether the problems are the result of lexical shortcomings, or whether the subject had simply forgotten some of the details of the story. In task IV the subjects were relatively free to determine the topic of the interview. This enabled them to avoid or hide problems whenever they felt like it. Therefore, problem indicators in the data no longer suffice to decide whether a $\mathrm{CpS}$ has been used. In particular, this is the case with very proficient $L 2$ leamers, who foresee possible problems at a relatively early stage in the planning of an utterance. Since their L2 resources are fairly large, they are able to develop an alternative speech plan in good time. As a result, it is extremely hard to find evidence for their $\mathrm{CpS}$ use in the form of hesitations, restructurings, and the like (cf. Færch \& Kasper, 1983c; see also Raupach, 1984, for a discussion of advanced learners' planning behaviour).

In order to arrive at a reliable identification of the more obscure $\mathrm{CpS}$ in tasks III and IV it was decided to use a combination of two identification procedures. Firstly, two independent judges would identify $\mathrm{CpS}$ on the basis of problem indicators in the data themselves. Secondly, the researcher would make use of retrospective data, i.e. of the comments which the subjects themselves had given on their performance immediately after having completed the task. Eventually, the criterion for a clear case in tasks III and IV was set up as "identified by both of the judges on the basis of problem indicators and/or by the researcher on the basis of the retrospective comments". There was one exception to this 'rule': irrespective of the judges' decisions, utterances were not identified as $\mathrm{CpS}$ if the retrospective comments clearly suggested that they did not qualify as such. ${ }^{2}$ 


\subsection{Identification on the basis of problem indicators in the data}

Problem indicators in the data were used for the identification of $\mathrm{CpS}$ in all four tasks. They were the only source of information for the identification in tasks I and II, while in tasks III and IV they were used in combination with retrospective comments. Considering the large role of problem indicators in the identification procedure, their use will be discussed in some more detail in section 6.2.1. Section 6.2 .2 will be devoted to a description of the method followed by the two independent judges who identified the CpS in tasks III and IV on the basis of the video-recordings. Finally, there will be a discussion of the degree of correspondence between the two judges' decisions in section 6.2.3.

\subsubsection{The use of problem indicators}

Problem indicators, or strategy markers, have played an important part in the identification stage of most studies of $\mathrm{CmS}$. It was not until 1983, however, when two articles appeared which addressed the problem of $\mathrm{CmS}$ identification, that their importance was acknowledged explicitly (Færch \& Kasper, 1983c; Raupach, 1983). Færch \& Kasper (1983c) distinguish three kinds of problem indicators: implicit signals of uncertainty, such as filled and unfilled pauses, repeats, false starts, corrections, drawls, rising intonation, laughs and sighs; explicit signals of uncertainty, which usually take the form of so-called gambits ("what's it called", "you know"); and direct appeals for assistance, e.g "what is Kunst?" (p.230).

Since the use of the two latter kinds of problem indicators for the purpose of $\mathrm{CmS}$ identification is fairly straightforward, only implicit signals of uncertainty will be commented on here. Of these, hesitation phenomena are the most prominent. Researchers' use of them as (lexical) problem indicators is based on studies of L1 use such as Maclay \& Osgood (1959), Goldman-Eisler (1964; 1968) and Levin, Silverman \& Ford (1967). Maclay \& Osgood (1959) noted that pauses and repeats tend to precede lexical words (nouns, verbs, adjectives and adverbs) rather than function words. This led them to the conclusion that these hesitation phenomena "presumably serve the same function - providing time for the selection among diverse lexical alternatives" (p.39). Apparently, complex selection processes, which involve many alternatives, require more time than simple ones.

Similar conclusions were reached by Goldman-Eisler $(1964 ; 1968)$ and Levin et al. (1967). In their studies it was found that complex speech (interpretations and explanations) was more hesitant than simple speech (picture descriptions). Goldman-Eisler also observed that speech (either complex or simple) became less hesitant with repeated trials. These findings 
were interpreted as evidence that "the hesitations in speech inversely mirror the automaticity of the cognitive process" (Levin et al. 1967:564). Considering that the use of CpS complicates the speech production process, and is, by (our) definition, non-automatic, it is very likely that it manifests itself in the form of hesitation phenomena.

As to the other implicit problem indicators mentioned above, a brief discussion will have to suffice. A rising intonation, which has the effect of turning an utterance into a question, can be interpreted as a sign of uncertainty (Kasper, 1981; 387ff. and 425ff.). Laughs can, among other things, be indications of embarrassment or ignorance, they can be signals that the speaker is merely guessing and knows that what he produces is not correct, and they can be used to fill pauses (Palmberg, 1982). In all cases they may be indicative of $\mathrm{CmS}$ use. The same point has been made by Stedje (1983), who treats laughs as dissociation markers. They indicate that "the speaker is aware of his errors ... (and) dissociates himself from his own product" (p.208). Other dissociation markers discussed by Stedje are sighs, expressions of anger, disgust or hopelessness, and 'audible quotation marks'. All of these, she says, may be "interlinked with a preceding, more or less failed strategy" (sic, p.208).

There is one other class of problem indicators which could facilitate the identification of $\mathrm{CpS}$ (or $\mathrm{CmS}$ ). It consists of non-verbal signals such as raising the eyebrows, questioning looks (which might be interpreted as appeals for assistance) and facial expressions displaying sadness, anger and/or disgust (Ekman \& Friesen, 1969). ${ }^{3}$ Other indications of lexical encoding problems are the increased use of gestures (Butterworth \& Beattie, 1978) and gaze aversion (e.g. looking at the ceiling, cf. Beattie, 1980). Since there have been only a few studies of $\mathrm{CmS}$ in which the data were video-recorded, non-verbal problem indicators have rarely been used in the identification of $\mathrm{CmS}$.

Although problem indicators definitely constitute a valuable source of information for the researcher who is to identify $\mathrm{CmS}$ use, they do not suffice in all circumstances. In section 6.1 we have already seen that problem indicators need not relate to lexical problems and that the speech of advanced learners rarely contains many problem indicators. An additional difficulty, noted by Raupach (1983) and Wiese (1981; 1984), is that most hesitation phenomena also occur in non-problematic L1 speech. Although these researchers do at the same time point out that the distribution of hesitation phenomena in the L1 differs from that in the L2, their observations clearly indicate that hesitation phenomena, and other performance features for that matter, should be interpreted with care. It is for this reason that Færch \& Kasper (1983c) suggest that "no performance feature can itself be taken as unambiguous evidence for strategic planning - what indicates a communicative problem is the increased frequency and the co-occurrence of performance 
features, making it likely that the subsequent utterance is the result of a communication strategy" (p.224).

\subsubsection{Instructions}

In the Nijmegen project two research assistants were employed to examine the video-recordings of tasks III and IV and to identify the $\mathrm{CpS}$ in these two tasks on the basis of the problem indicators which they observed. They will be referred to here as judge 1 and judge 2 . Before the two judges started their jobs they received a set of written instructions. These specified the three criteria mentioned in section 6.1 and the problem indicators discussed in the previous section. It was emphasized that $\mathrm{CpS}$ use should not be equated with errors, since some utterances resulting from $\mathrm{CpS}$ use might well be correct (by chance), while many errors are not caused by lexical problems at all, but are simply manifestations of the leamer's interlanguage system. In particular, the judges were wamed that the use of Dutch words or constructions, or the literal translation of Dutch expressions without there being any problem indicators were not to be identified as CpS.

To help the judges make the distinction between 'Reduction Strategies', which we initially intended to exclude from this study, and $\mathrm{CpS}$, they were given the following guideline: utterances could be identified as CpS if the speaker said something that was relevant or related to the originally intended message, but also when expressions like "thing" or "something of that kind" were used in its stead. It will be noted that this guideline causes almost all so-called reduction strategies, except those where the intended message is given up altogether, to be included as $\mathrm{CpS}$. In view of the fact that there is no clear dividing-line between 'Reduction Strategies' and $\mathrm{CpS}$ (cf. chapter 4) this seemed to be the most practical approach.

Finally, the instructions described the procedure to be followed by the judges. They were asked to read the transcripts before watching the video-recordings and mark possible cases of $\mathrm{CpS}$ use. This would enable them to focus their attention on the most relevant parts of the recordings. If, after having seen the video-recordings, they felt sure that a $\mathrm{CpS}$ had been used, they were to underline the relevant utterance in the transcript.

Both judges participated in two two-hour practice sessions to get used to the procedure. During these sessions they compared their results and discussed the differences with each other as well as the researcher. After these sessions the two judges proceeded independently. When they had finished, the outcomes of their identifications were compared by the researcher, who marked all utterances which had been underlined by both of them as clear cases of CpS use (the only exceptions being those cases which had to be rejected on the basis of the subjects' retrospective comments, cf. section 6.3.3). 


\subsubsection{The correspondence between the two judges}

To establish the reliability of the identification method described above, the judges' decisions with respect to the data of 12 subjects, 4 of each proficiency level, were compared (this amounts to approximately six hours of data). In this subset judge 1 identified 541 utterances as CpS, while judge 2 identified 324 CpS. There were 269 utterances which were identified by both judge 1 and judge 2 . This means that of the $541 \mathrm{CpS}$ identified by judge 1 only $49.7 \%$ were identified as such by judge 2 . Of the $324 \mathrm{CpS}$ identified by judge $283.0 \%$ were also identified by judge $1{ }^{4}$

These figures reveal that the degree of correspondence between the two judges is not very high. Judge 1 identified many more $\mathrm{CpS}$ than judge 2. A possible reason for this is that judge 1 was much better acquainted with $\mathrm{CpS}$ research than judge 2 , who was relatively new in the field. It is also possible though that the two judges entertained different ideas as to what constitutes $\mathrm{CpS}$ use. In spite of the instructions they may have operated according to their own criteria once they got involved in the job.

To find out which of these explanations was most likely to be correct we asked judge 2 to go through part of the data again. The subset she reconsidered consisted of 3 subjects' performances on task III and 3 different subjects' performances on task IV. For each task there was one subject of each proficiency level in this subset. The first time judge 2 dealt with these data she had identified $79 \mathrm{CpS}$. The second time, which was about four months later. she identified $122 \mathrm{CpS}$, viz. 77 of the $79 \mathrm{CpS}$ identified the first time and 45 new ones. The number of CpS identified by judge 1 in this subset was 134, but 42 of these CpS had not been identified by judge 2 in either the first or the second session.

The re-identification by judge 2 shows, first of all, that the relatively small number of $\mathrm{CpS}$ identified by her in the first session is probably due to her inexperience, since after four months' work on the project as a research assistant, she identified many more CpS. Sccondly, and perhaps even more importantly, it shows that an identification method which is exclusively based on problem indicators in the data is not very reliable. The identification by judge 1 not only differed considerably from the first, but also from the second identification by judge 2 .

The lack of correspondence between the two judges' identifications constituted all the more reason to restrict the analyses to those cases which had been marked as $\mathrm{CpS}$ by both of them. Even if this means that a number of $\mathrm{CpS}$ which actually occurred are not included in the analyses, those utterances which are included most probably are real instances of $\mathrm{CpS}$ use. ${ }^{5}$ Moreover, it turned out that many of the CpS in tasks III and IV that would have been missed if this had been the only identification method, could be identified on the basis of the subjects' retrospective comments. 


\subsection{Identification on the basis of retrospective comments}

In 1973 Corder called for the use of intuitive data in second language acquisition research (Corder, 1973a). Since then there have been sporadic attempts to incorporate introspective techniques into the research methodology (cf. Kellerman, 1974; Cohen \& Robbins, 1976; Schlue, 1977; Tarone, 1977; Glahn, 1980). However, it is only recently that such techniques have been applied systematically (cf. the contributions in Færch \& Kasper, 1987a). One reason for this is that the use of introspective data, including retrospective data, is generally considered to be controversial (see e.g. Nisbett \& Wilson, 1977). In section 6.3 .1 it will be argued why retrospective data could be used reliably in the case of the Nijmegen project. In connection with this the problem of researcher bias will be discussed in more detail in section 6.3.2. And finally, the importance of retrospective data will be illustrated in section 6.3.3.

\subsubsection{The reliability of retrospective data}

In their survey of the lilerature on introspective reports Ericsson \& Simon (1984) maintain that there are two main points of objection to the use of retrospective data:

1. Retrospective data are not reliable; they are incomplete, inaccurate and affected by researcher bias.

2. The knowledge that one will be required to retrospect influences the performance of the task.

In their discussion of these points of criticism Ericsson \& Simon argue that retrospective data can be considered as a reliable source of information provided they are collected under certain conditions. They suggest the following:

1) The data should be collected immediately after task performance, when memory is still fresh;

2) The subjects should be provided with contextual information to activate their memories;

3) All the information asked for must be directly retrievable, i.e. must have been hecded during task performance, so that the subjects are not induced to generate responses based on inferencing and generalizations;

4) For the same reason the information asked for should relate to specific problems, or a specific situation;

5) No leading questions should be asked to minimize the effects of "researcher bias"; 
6) The subjects should not be informed that they will be asked for retrospective comments until after task performance, so as not to affect their performance on the task.

The procedure adopted in the Nijmegen project largely satisfies these six conditions. A detailed description of it will serve to illustrate this. In each of the two test sessions the subject was asked to perform two tasks. The first time he carried out tasks I and III and the second time tasks II and IV. Immediately after having finished task III, or task IV (condition 1), the subject, who had previously not received any instructions in this respect (condition 6), was asked to listen to and watch the video-recordings of his own task performance. He was instructed to stop the tape, using a remote control, whenever he wanted to comment on his performance. The video-recordings served as contextual information (condition 2). Pretests had revealed that when subjects recognized a particular situation, they usually remembered how they set about it. Only in case the subjects did not spontaneously comment at points where pauses and other performance characteristics strongly suggested that a $\mathrm{CpS}$ had been used did the experimenter stop the tape. Sometimes this in itself was enough to trigger a comment. In other cases it was necessary to ask the subject a question. These questions always related to a specific problem (condition 4) and special care was taken that they did not suggest any "suitable" answer (condition 5) or force the subject to base his answer on more than the information directly available to him from his own memory (condition 3).

In order to familiarize the subject with this procedure each retrospective session was preceded by a five-minute practice session. For this purpose the recordings of the practice story and the first five minutes of the interview were used respectively. Most subjects were responsive in the practice session and commented spontaneously on their problems. Those who did not were urged to take the initiative more often. It was again emphasized that all the information they could provide was relevant, and they were assured that they should not worry about having had too many problems, nor about the time (and the tape!) they were taking. All the retrospective data were recorded on audio-tape.

\subsubsection{The influence of 'researcher bias'}

In the previous section it was pointed out that one of the objections to the use of retrospective data is that they are subject to researcher bias. Since researcher bias may have a devastating effect on the validity of one's research some more detailed discussion of this issue seems in place.

To control the disturbing influence of researcher bias as much as possible the experimenter who conducted the retrospective sessions tried to refrain from asking leading questions. Although it is obvious that her probing was not 
always felicitous, there are three observations which suggest that she was successful in reducing the effect of researcher bias. One is that most of the comments which led to the identification of a CpS were spontaneously given by the subjects. In the subset of data used to establish the correspondence between the two judges' identifications (i.e. the data of 12 subjects on task III as well as task IV) there were only 118 cases (out of 446 ) in which the identification was based on comments prompted by the experimenter (see table 6.1).

Table 6.1 The number of self-and other-initiated comments that led to the identification of a CpS

\begin{tabular}{lccc}
\hline & Self-initiated & Other-initiated & $\begin{array}{c}\text { Total number of } \\
\text { relevant comments }\end{array}$ \\
\hline group 1 & 58 & 11 & 69 \\
group 2 & 111 & 64 & 175 \\
group 3 & 159 & 43 & 202 \\
\hline Total: & $328(=74 \%)$ & $118(=26 \%)$ & 446 \\
\hline
\end{tabular}

The second observation is that the subjects seem to be very 'honest': there is no evidence that they tried to hide their shortcomings in an attempt to keep up appearances. One of these 'honest' remarks was made by a 5-VWO pupil. She had answered "roses" when the experimenter asked her what flowers her father was growing in their garden, but in the retrospective session she admitted that she did not really know what they had. "I don't think we have roses, but yes, I've got to say something <laughs>", she said (in Dutch).

The last observation is that most subjects were very willing to provide retrospective data. In fact, there were 33 instances in the subset under discussion where the subjects spontaneously provided the experimenter with more detailed information. Usually these comments reveal the use of reduction strategies, which, unlike CpS, are directed at avoiding problems. The most illustrative example of this phenomenon was given by a 3-VWO pupil in one of the pretests (cf. example 1$)^{6}$

(1) I: could you explain to me how, how a, a sailing ve vessel can go on, I mean, how does it work?

S: you've got sails on your boat

I: that's right, that's the only thing I know <laughs>

S: ja, <laughs $>$ and the /wi/ the, the sails,

a) S: now I'm talking about sails, two sails

E: $\mathrm{mm}$ 
S: and later, it became, I found it so difficult to explain that I went on with one sail, when explaining

E: $\mathbf{m m}$

S: later I was just talking about the mast and one sail on this side

E: $\mathrm{mm}$

$S$ : and then I didn't mention the little one in front, because I thought it 'd be an endless job to tell such a person how to sail

E: ja

S: uh get the wind, and erm, into, blowing away

I : and in what ways can you adjust your sails? I mean I I

S: erm, the wind erm, from uh below, ffrom below, from behind

I : all right that's more likely, certainly

b) S: the, "de wind van schuin van achter" (= free wind) is the most easy way of sailing

E: $\mathbf{m m}$

S: you can uh, you can also, if there's cross wind you can also sail like this, but that's, again again a lot more difficult to explain

E: $\mathrm{mm}$

S: so I just started with the most easy way

E: yes

S: erm, when the wind, when the wind's going behind, you can go forw/e/rd, and you've got to sail so, they /ge/ dus, they get full of the sails

I : they get, fu

S: full sails, the wind is going full in the sails

I : uh so, you've got uh, uh, a wind which is

S: right, ff, which came from right behind you

It looks as if the subject in this example exploits the retrospective session to rehabilitate himself. He seems to realize that because of his having had to reduce the message he did not really do his job properly. He now wants to make it clear that even if he did a bad job, this is due to language problems and not because he does not know the field. His expertise certainly shows in the above example, where he gives details of how to sail. Presumably, one reason why the relrospective sessions tumed out to be so informative is that the subjects grasped the opportunity to dissociate themselves from their less than adequate performance.

\subsubsection{The usefulness of retrospective data}

Considering that the retrospective data were collected under conditions which largely satisfy Ericsson \& Simon's (1984) requirements, it can be assumed that they are maximally reliable. Let us now consider in what ways these retrospective data can contribute to the solution of the problems related to the 
identification of $\mathrm{CpS}$ in tasks III and IV. It has already been said that to identify a CpS one must know 1) whether there is a problem, 2) whether this problem is lexical in nature, and 3 ) what the originally intended meaning is (see section 6.1).

In task III the second question turns out to be particularly prominent. In spite of the accompanying pictures some subjects still had problems remembering all the details of the story. It is of course essential that such memory problems are distinguished from lexical problems. In example 2 the subject, a 3-VWO pupil, is retelling a story about a man who gets a job as a caretaker in an old people's home and who, on moving day, receives a bunch of flowers with a card saying "with our deepest sympathy". Of course the man is very upset about this, so he rings the florist and finds out that two bunches of flowers have been mixed up and that his flowers have been sent to a funeral with a card saying "congratulations on your new position".

(2) S: uh, a man 1 who 1 hadn't a job 1 uh, wanted to 1 have, a job 2 erm, to help 1 old people, in a house, where, /auld/, old people lives 2

a) S: "bejaardentehuis" (= old people's home) I didn't know either

E: $\mathrm{mm}$, do you remember what sort of job he wanted to have in that house?

S: yes, "concierge" (= caretaker) but I didn't know what that was either, so I thought, someone who helps there and so

... 2 uh 4 the day after 1 that he, got the job $2 \mathrm{erm}$, he got $2 \mathrm{uh}$, some flowers 2 erm 1 with 1 sstanding on 1 uh 1 erm crazy thing.

b) S: uh yes, I didn't know, I didn't remember exactly what it said

E: $\mathrm{mm}$, but it was something crazy?

S: uh yes <laughs> yes something something unusual in any case

E: yeah (with our deepest sympathy; 305เ3)

In the retrospective session it is made clear that the subject had indeed remembered that the story was about a caretaker. He clearly indicates that he had to make do with "someone who helps there" because he did not know the appropriate word, so this is a CpS. Later on, he explains that he did not remember exactly what the card said. Thus, his second problem is probably due to a memory lapse rather than a lexical shortcoming. Hence, "crazy thing" is not a CpS, at least not in the sense adopted in this project.

For the identification of $\mathrm{CpS}$ in task IV, the answers to questions 1 and 3 are also of crucial importance. Due to the fact that the contents of the interview are frequenuly determined by the subject himself, it is not always clear to an outsider whether there was a problem, and whether what the subject says is in fact what he had originally intended to say. In this respect too, retrospective data proved to be most helpful, and many $\mathrm{CpS}$ that would otherwise have gone unnoticed could be identified on the basis of the subjects' comments. Thus, 
there was a boy who said that his family always ate a lot at Christmas. It was not until the retrospective session that the researcher found out that what he had really wanted to say was that they ate "lekker" (= 'tasty things'), but, he added, "I didn't know how to say that".

The importance of the retrospective comments for the identification of $\mathrm{CpS}$ in the data of the most proficient group of subjects is clearly illustrated in the following example, which led to the identification of "organizations" as a CpS for 'verenigingen' (= societies/associations).

(3) S: and uh, I'm a member of two organiza, uh two organizations

S: is that correct, "verenigingen"? I don't know, uh it seems a big word, organizations

E: em, association 1 society, I don't know

S: yeah, uh yeah I don't really know a word for "vereniging", but something like a yes, organization seems to me such a such a big word for

E: yeah

S: for something like that

E: yeah (societies; 105t4)

The subject tries to make clear that he is a member of two societies. He hesitantly refers to these as "organizations", but comments that this word is really "too big" for his purposes.

Besides enabling the researcher to identify $\mathrm{CpS}$ which might otherwise have remained unidentified, retrospective data have frequently yielded confirmatory evidence with respect to $\mathrm{CpS}$ use already identified on the basis of hesitation phenomena and the like. In this way, the reliability of the identification method was increased. An example is given in (4), where a 5-VWO pupil is talking about her father's garden.

(4) S: $2 \mathrm{erm}$, there he erm $1 \mathrm{erm}$ he teels

a) S: that's not correct either <laughs>

E: no, you knew didn't you?

S: "verbouwen" (= to grow), yes I knew

E: yes

S: 2 erm 3 o jee 3 boons?

b) S: "sla" (= lettuce)!, salad isn't it?

$\mathrm{E}$ : and "bonen" (= beans)?

S: uh, bones?

E: beans

S: oh yes, beans, oh how stupid <laughs> 
I : what, what are they?

S: uh "bonen" (= beans)

I: at are they like?

S: "bonen" erm, little green <draws a bean in the air uh 2 yes

I: vegetables, ja?

S: yes vegetables

I : $\mathrm{mm}$

S: and erm 1 salade

c) S: <laughs>, that's from French <laughs>

I : $\mathbf{m m}$

S: $1 \mathrm{erm}$, also flowers, uh dahlias (Dutch pronunciation)

d) E: is dahlias also English?

S: no! 1 well I don't really know

E: no okay but I just wanted to know whether you knew 1 it probably is, because she understands you

S: oh, well yes but she knows some Dutch (dahlias; 206t4)

The comments in a) and b) undoubtedly confirm the first identification based on the pauses and hesitations preceding "teels" (= grows), and the rather desperate exclamation "o jee" and the rising intonation, accompanying "boons" (= beans).

On the other hand, there are also a few instances where the retrospective data kept the researcher from incorrectly marking an utterance as a $\mathrm{CpS}$. Example 5 shows that the subject, a second-year student, who admittedly did have problems expressing the word "plooirokje" (= pleated skirt), was quite sure of "plies" (pronounced /plaiz/) as a correct English translation for "plooien" (= pleats). "Plies" should therefore not be considered as a CpS.

(5) S: if he had uh, skirts with, plies
S: "plooirok" (= pleated skirt) I didn't know either
E: you did know "plooien" (= pleats)?
S: yes, and skirt, so, at least, plies is "plooien" (= pleats), isn't it? it's not? $<$ laughs> oh that
E: <laughs> pleats
S: what is that?
E: uh, pleats, are "plooien"
S: oh, mm (pleats; 10313)

Likewise, "dahlias" in example 4 comment d) above, would not have been marked as a CpS if the subject had answered yes instead of a definite "no!" to the experimenter's question whether "dahlias" is also an English word. Now, of course, "dahlias" is considered a CpS, certainly because the subject adds 
"well yes, but she knows some Dutch", thereby indicating why she assumed transfer from Dutch might be successful with this interlocutor.

Summarizing, it can be stated that, although retrospection is not the only source of information, it does play a very important role in the identification of CpS. First of all, $\mathrm{CpS}$ can be identified more reliably if the subjects' comments provide independent support for the identification of the other two judges. Secondly, retrospective comments help the researcher to identify $\mathrm{CpS}$ which would otherwise have remained unnoticed. And thirdly, they reveal utterances which were incorrectly identified as CpS.

\subsection{A quantitative comparison of two methods of identification}

Now that the two methods which were employed to identify CpS in tasks III and IV have been discussed, the results of these two methods will be compared. The purpose of this (quantitative) comparison is to lend further support to the conclusion drawn above that retrospective data play an important role in the identification of CpS.

The comparison again relates to the same subset of data used to establish the correspondence between the two judges' identifications (i.e. the data of 12 subjects on task III as well as task IV). The results are summarized in table 6.2.

Table 6.2 The number of CpS identified without $(-R)$ and with $(+R)$ the use of retrospective data

\begin{tabular}{lcc}
\hline & Method 1(-R) & Method 2(+R) \\
\hline group 1 & 28 & 69 \\
group 2 & 113 & 175 \\
group 3 & 128 & 202 \\
\hline Total: & 269 & 446 \\
\hline
\end{tabular}

As we have seen in section $6.2 .3,269 \mathrm{CpS}$ were identified with the first method. So, in these 269 cases the two judges agreed that an utterance met the requirements of our definition of a $\mathrm{CpS}$. The retrospective comments considered in the second method led to the identification of $446 \mathrm{CpS}$. Table 6.2 shows that the number of $\mathrm{CpS}$ is inversely related to proficiency level. Of course it is quite likely that the most proficient group used fewer $\mathrm{CpS}$. After all, they had fewer problems. It should be bome in mind, however, that this 
effect may have been reinforced by the fact that their $\mathrm{CpS}$ were more difficult to identify.

Table 6.3 A specification of the results of retrospection

\begin{tabular}{|c|c|c|c|c|}
\hline & \multicolumn{2}{|c|}{ Method $1 \mathrm{CpS}$} & \multirow{2}{*}{$\begin{array}{l}\text { New } \\
\text { CpS }\end{array}$} & \multirow{2}{*}{$\begin{array}{l}\text { Total number of } \\
\text { relevant comments }\end{array}$} \\
\hline & confirmed & rejected & & \\
\hline $\begin{array}{l}\text { group 1 } \\
\text { group 2 } \\
\text { group 3 }\end{array}$ & $\begin{array}{l}17(=24.3 \%) \\
74(=41.6 \%) \\
92(=44.4 \%)\end{array}$ & $\begin{array}{l}1(=1.4 \%) \\
3(=1.7 \%) \\
5(=2.4 \%)\end{array}$ & $\begin{array}{r}52(=74.3 \%) \\
101(=56.7 \%) \\
110(=53.1 \%)\end{array}$ & $\begin{array}{r}70 \\
178 \\
207\end{array}$ \\
\hline Total: & $183(=40.2 \%)$ & $9(=2.0 \%)$ & $263(=57.8 \%)$ & 455 \\
\hline
\end{tabular}

Table 6.3 presents a more detailed overview of the retrospective comments. All in all, the 12 subjects whose data were examined gave 455 retrospective comments. Nine of these led to the rejection of CpS identified by method 1 , and consequently these 9 cases will be discarded from further analysis. In 183 cases, however, the method 1 identification was confirmed, that is to say, there was perfect agreement among all three judges. This means that these utterances can be considered as the clearest cases of CpS. (Note that the remaining 77 CpS identified by method 1 were not commented on in the retrospective session). 263 comments related to $\mathrm{CpS}$ that had either been marked by only one of the method 1 judges or had not been marked by them at all. The addition of this last category to those CpS that had already been identified by means of method 1 , and were not rejected by method 2 , resulted in the total number of 523 clear cases of $\mathrm{CpS}$ reported in table 6.4. In other words, the use of retrospective data in addition to the use of performance characteristics functioning as problem indicators, made it possible to almost double the number of identified CpS.

Table 6.4 The results of methods 1 and 2 combined

\begin{tabular}{lccc}
\hline & $\begin{array}{c}\text { Method 1 (-R) } \\
\text { (excluding rejects) }\end{array}$ & $\begin{array}{l}\text { Method 2 (+ R) } \\
\text { (new CpS only) }\end{array}$ & $\begin{array}{c}\text { Total number of } \\
\text { 'clear cases' }\end{array}$ \\
\hline group 1 & 27 & 52 & 79 \\
group 2 & 110 & 101 & 211 \\
group 3 & 123 & 110 & 233 \\
\hline Total: & 260 & 263 & 523 \\
\hline
\end{tabular}


The increase in the number of identified $\mathrm{CpS}$ is enormous and raises the question whether the researcher who interpreted the retrospective comments did not read too much in the data. After all, the criterion used to identify 'clear cases' of CpS in tasks III and IV implies that retrospective evidence by itself is sufficient for an utterance to be considered as an instance of $\mathrm{CpS}$ use (cf. the introduction to this chapter). Since the retrospective comments were interpreted by one person only, a great deal depended on this one person. If, for instance, she was too liberal in her judgements of the retrospective data, she could easily have distorted the notion of 'clear case' by including too many utterances as $\mathrm{CpS}$.

To establish the reliability of the researcher's interpretation of the retrospective comments, we asked a research assistant (judge 2 in method 1) to re-interpret 638 comments. These comments were made with respect to the same subset of data on which the comparison between the two identification methods was based. The research assistant's interpretation of them corresponded with the researcher's in 545 cases $(=85 \%)$. In 76 cases the research assistant interpreted a comment as evidence that a $\mathrm{CpS}$ had been used, while the researcher did not $(=11.9 \%)$. There were only 17 cases $(=2.7 \%)$ where the researcher identified $\mathrm{CpS}$ on the basis of the retrospective comments which were not identified by the research assistant. Considering that the research assistant who re-interpreted the retrospective comments was quite reserved in her method 1 identification, in any case in comparison with the other research assistant, these figures indicate that the researcher was definitely not too liberal in her judgements conceming $\mathrm{CpS}$ use. If anything, she was too conservative, but this, it should be noted, is in line with the decision to restrict the study to clear cases of CpS.

Earlier in this section it has been pointed out that 77 (269 - (183 confirmed +9 rejected)) of the CpS identified in method 1 were not commented on in the retrospective session. So in these cases method 1 will have to suffice. Considering though that method 1 involved two independent judges, and that only those cases are considered as clear cases where there is agreement among these two, this is hardly problematic. It is even less problematic if we take into account the fact that in the majority of these cases CpS use was so evident that the subjects did not feel called upon to comment on them. And, apparently, the experimenter too deemed it superfluous to ask for further comments at the time.

In this respect, it is important to note that the experimenter, who of necessity conducted the retrospective sessions without significant preparation, had to be selective in her promptings. Too many obvious questions might have given the subject the impression of being underestimated, with possibly irritation and/or boredom as the results. As the subjects' cooperation was an essential condition for the success of the retrospective sessions, it was occasionally felt that some 
questions that might have led to the identification of a $\mathrm{CpS}$ had better not be asked, in order not to disturb the session or irritate the subject.

\subsection{Conclusion}

This chapter has dealt with the identification of $\mathrm{CpS}$. To begin with three criteria were specified which had to be met for an utterance to be regarded as a CpS. The speaker must be aware of a problem, which is linguistic, or rather lexical, in nature, and which he intends to solve.

Subsequently, two identification methods were discussed. It appeared that the first method, where the decision conceming CpS use is based on problem indicators in the data is not very reliable. Two independent judges differed considerably in their interpretation of the data. This underlined the necessity for rigorous criteria and justified the decision that utterances must be identified as CpS by both of the judges to be considered as 'clear cases'.

The second method, in which the identification was based on a third person's interpretation of retrospective data, proved to make up for the relative unreliability of the first method. It was shown that the use of retrospection a) increased the number of identifiable CpS by $49 \%$; b) confirmed the method 1 identification in $68 \%$ of the cases, which increased its reliability; and c) allowed the researcher to eliminate (the small number of) $\mathrm{CpS}$ incorrectly identified by method 1. Besides, the spontaneity with which the comments were given suggests that researcher bias did not play an important role. It can therefore be concluded that retrospective data should be considered a valuable resource in the identification of CpS.

\section{Notes to chapter 6}

1. Part of this chapter is a (slightly) revised version of Poulisse, Bongaerts \& Kellemen (1987).

2. By applying strict criteria as to what qualifies as a clear case, we may have biassed the collection of $\mathrm{CpS}$. It is for instance possible that certain types of $\mathrm{CpS}$ consistently fail to be identified by these methods and do not therefore meet the criteria for inclusion in the corpus. While this may be true, we felt it would be better to en on the side of conservatism.

3. Ekman \& Friesen (1969) discuss seven primary affects which can be associated with certain movements of the facial muscles. Difficulty, of course, is not an affect, but its presence may be deduced from a combination of sadness, anger and disgust.

4. Note that it is impossible to report a Pearson $\mathrm{r}$ value here since the number of cases where neither of the two judges identified a CpS is unknown (see Maclay \& Osgood, 1959, for a discussion of the same problem in a study which involved the identification of hesitations by two judges). 
5. Exactly the same procedure was adopted by Maclay \& Osgood (1959).

6. In these examples S stands for 'Subject', I stands for 'Interviewer' and E stands for 'Experimenter'. The retrospective data are distinguished from the actual test data by means of indentation. The most important parts of the examples have been printed in bold type to draw the reader's attention. Note that the retrospective comments were originally given in Dutch and are here presented in translated form. 


\section{The Classification of Compensatory Strategies}

To classify the utterances which had been identified as clear cases of $\mathrm{CpS}$ a dual coding system was employed. In the first place, this system reflects the distinctions made in the process-oriented taxonomy presented in chapter 4 and it enables us to distinguish between 'Analytic' and 'Holistic Conceptual Strategies' on the one hand, and the linguistic strategies of 'Morphological Creativity' and 'Transfer' on the other hand. In the second place, it comprises more detailed information on the structure of an utterance, on the use of non-verbal encodings, and - in the case of transfer strategies - on the amount of adaptation to the $\mathrm{L} 2$ that has taken place. This additional information in the coding system should make it possible to give a more detailed description of CpS use.

This chapter consists of two parts. The first part contains our reasons for using a dual coding system and describes the kind of information it captures. The second part deals with the procedure that was followed when the coding system was applied, and reports on its reliability and its applicability to the data.

\subsection{The coding system}

The process-oriented taxonomy presented in chapter 4 has two advantages over taxonomies which have been used in $\mathrm{CmS}$ research to date. The first of these is parsimony. There are only two "archistrategies", the 'Conceptual' and the 'Linguistic', and each of these is divided into just two further subtypes (cf. figure 7.1).

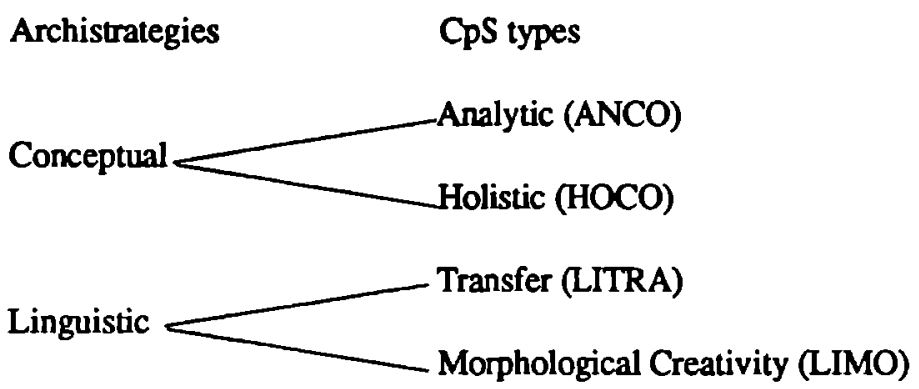

Figure 7.1 'Conceptual' and 'Linguistic' CpS types 
The second advantage of the process-oriented taxonomy is its psychological plausibility. The distinction between the two archistrategies can be directly related to the language user's decision to compensate for unknown lexical items by exploiting conceptual or linguistic knowledge sources. Besides, the distinction between the four $\mathrm{CpS}$ types listed in figure 7.1 reflects notable differences in the cognitive processes underlying the use of $\mathrm{CpS}$ of these types (cf. section 4.4).

It will be obvious that the new taxonomy reflects our interest in the processes underlying $\mathrm{CpS}$ use, and it is for this reason that the major analyses to be reported in chapter 8 will relate to the four CpS types distinguished in it. Still, some of the distinctions made in traditional taxonomies bring out differences in the encoding of $\mathrm{CpS}$ which are not without interest either. Even before the stage of classification was reached, it had become clear that there was a great deal of variation in the ways in which the subjects had encoded their CpS. In particular, there appeared to be differences in 1) the syntactic structure of analytic strategies; 2) the use of non-verbal behaviour, and 3) the amount of adaptation to the $\mathrm{L} 2$ in the case of transfer strategies. It was felt that these differences were worth investigating, not just because it would enhance the descriptive adequacy of the present study, but also because differences like these had played a role in previous research on CmS. Consequently, the only way to make sure that our results would be comparable to those of other studies - at least in some respects - was by including the encoding of CpS in our investigation.

The dual coding systern which was used to classify the clear cases of CpS in tasks I, III and IV combines information about the type of CpS which has been used and about the actual encoding of the $\mathrm{CpS}$. Initially, five $\mathrm{CpS}$ types were distinguished at the so-called process level. They were the 'Analytic Conceptual Strategy' (ANCO); the 'Holistic Conceptual Strategy' (HOCO); the combination of these two 'Conceptual Strategies' (HOCO + ANCO); the 'Linguistic Strategy of Transfer' (LITRA) and the 'Linguistic Strategy of Morphological Creativity' (LIMO). For reasons to be discussed below the distinction between ANCO and HOCO + ANCO could not be maintained, so that instances of the latter CpS type had to be treated as ANCO in the statistical analyses. Hence, only the four CpS types listed in figure 7.1 remained at process level.

For ANCO, a distinction was made at the encoding level between the use of transparent compound nouns ( $1 \mathrm{wc}$ ) and definition-like utterances (1def). In $\mathrm{CmS}$ research to date transparent compound nouns are usually referred to as 'Word Coinage'. Examples of this type of ANCO are:

(1) cooking erm apparatus (cooker; 108t4)

(2) a talk uh bird (parrot; 309t4) 
The definition-like type of ANCO has been referred to in the literature as 'Circumlocution', 'Description' or 'Paraphrase'. It can take various forms, as is illustrated by examples (3) to (9):

(3) he lives in the mountains (hermit; 113t4)

(4) not fluid (thick; 111t4)

(5) if you want to feed a baby, you use a fl uh a bottle, you p you screw this on top, so it can suck on it (teat; 102t1)

(6) this is used for killing erm 1 flies (flyswat; 109t1)

(7) a thing you kill flies with (flyswat; 204t1)

(8) erm, a device to uh to kill flies with (flyswat; 204t1)

(9) a toy for children, uh 3 which erm 3 which uh, goes round (humming-top; 309t1)

At the outset of the classification stage utterances like (3), (4), (5) and (6) were coded as ANCO, while utterances like (7), (8) and (9) were coded as HOCO + ANCO. This distinction proved to be untenable though. In some cases, like (7), the holistic element of the $\mathrm{CpS}$ shares so few semantic properties with the target item that the resulting utterance is only marginally different from an utterance like (6), which contains no holistic element at all. Since the distinction between (7) and (8) is equally marginal, it was felt that any line to be drawn between ANCO and HOCO + ANCO would be drawn arbitrarily. For this reason it was decided to discard the distinction and classify all utterances resembling examples (3) to (9) as ANCO.

HOCO was typically encoded by means of one superordinate, coordinate or subordinate word. A single code (1a) was used to mark this CpS type. It is an abbreviation of 'Approximation', the term that is used in traditional taxonomies to refer to this $\mathrm{CpS}$ type. In some instances HOCO was encoded by means of non-verbal behaviour. This will be discussed below.

The coding system marked three types of LITRA, which have also been distinguished in traditional taxonomies of CmS. They are 'Borrowing' (2ab), 'Foreignizing' (2af) and 'Literal Translation' (2alt). 'Borrowing' can be defined as the use of an $\mathrm{Ll}$ (or Ln) word without any phonological or morphological adaptation. Examples are:

(10) it asked for a shirt with erm 2 erm $2 \mathrm{t}, \mathrm{m}$ I don't know the word 2 plooitjes erin <laughs> (pleats; 110.3)

(11) I'd written 4 as uh, we say, voorwoord 1 before the the article (preface; 201t4)

'Foreignizing' can be defined as the use of an L1 (or Ln) word with phonological and/or morphological adaptation, as in examples (12) and (13):

(12) / petorsili/ (parsley, Dutch: peterselie; 209t4)

(13) cuffer (hairdresser, French: coiffeur, 314t3) 
'Literal Translation', finally, is the word by word translation of an L1 (or $\mathrm{Ln}$ ) word or phrase into the target language. Examples of this type of LITRA are:

(14) my elders (parents, Dutch: ouders; 303t4)

(15) setting your shoe (the Dutch equivalent of hanging your stockings up at Christmas Eve, Dutch: je schoen zetten; 311t4).

The last process-oriented $\mathrm{CpS}$ type, LIMO, was not further subdivided at the encoding level. All utterances of this CpS type were encoded $2 \mathrm{bd}$.

The coding system also distinguished between $\mathrm{CpS}$ that were encoded verbally and those that were (partly) encoded non-verbally. In traditional taxonomies the use of non-verbal behaviour is referred to as 'Mime', although 'Mime' is, strictly speaking, not the right word for it. ${ }^{1}$ The following are examples of non-verbal behaviour:

(10) S: and you uh, put the, the uh one thing in the in the in the aquarium and the other, you uh <sucks>

I: ja

$S:$ and then the water goes into the uh, the box (to suck; 210t4)

(17) S: an uh coat

I: $\mathrm{mm}$

S: with uh short uh 1 <indicates where the sleeve is cut off and laughs> (sleeves; 311t4)

(18) little green, uh 2 yes yes vegetables <indicates the shape and the size of a bean> (bean; 206t4)

(19) S: erm 1 I uh play an instrument erm

I: $\mathbf{m m}$

S: I don't know how you call it, in England erm, /vai $1 /$ ? uh / vaia $/ /$ <plays the violin> (violin; $312 t 4$ )

As the examples show, non-verbal behaviour can either replace speech (examples 16 and 17), or illustrate it (examples 18 and 19). If non-verbal behaviour occurred by itself, the intended concept was usually enacted (as in 16) or pointed at (as in 17). Since there is no explicit indication of a conceptual analysis in these cases (there is no listing of properties), they were encoded $1 \mathrm{mi}$ and trcated as $\mathrm{HOCO}$ at process level. ${ }^{2}$ In all cases where non-verbal behaviour coalesced with another $\mathrm{CpS}$ type it was encoded $+1 \mathrm{mi}$, but for the purpose of analyses at process level this information was ignored. Thus, in the statistical analyses to be reported in the next chapter, examples (18) and (19) were included as instances of ANCO and LITRA respectively. 
A summary of the encoding system is given in table 7.1.

Table 7.1 A summary of the coding system

process

ANCO

HOCO

LITRA

LIMO possible ways of encoding

\subsection{The applicability of the coding system}

The coding system described in the previous section was used to code all clear cases of CpS in tasks I, III and IV. For financial reasons all coding had to be done by the researcher. Although this is obviously not an ideal situation, it did not have any negative effects on the reliability of the classification process. The intracoder reliability - established by recoding the data of six subjects (two from each proficiency group) and expressed in the percentage of cases for which the first and the second coding were identical - was $97 \%$ for the four major CpS types at process level and $92 \%$ for the differences in the encoding of CpS. Recoding took place a year after the original coding had been completed. The total number of $\mathrm{CpS}$ which were reconsidered was 403 .

In order to determine the intercoder reliability the same subset of the data was recoded by a research assistant. There was $93 \%$ agreement among the two coders on the distinctions at process level. When the more detailed coding system was applied agreement amounted to $85 \%$.

The high percentages of agreement within and between the coders indicates that there were few problems with the applicability of the coding system. Still, it would be unjust to claim that there were no problems at all. We have already seen that the distinction between ANCO and combinations of HOCO and ANCO could not be maintained. Another problem was related to the possible interaction of conceptual and linguistic knowledge already mentioned in chapter 4 . This interaction may have played a role in utterances such as "clothes-maker" and "seastar". Obviously, it would be wrong to classify such cases as either 'Conceptual' or 'Linguistic', unless the retrospective comments should provide decisive evidence on this point. The researcher therefore marked ambiguous cases like these when coding the data (1lt), so that they could be excluded from the analyses if that should be desirable (see section 8.1.2). 
The following extract serves to illustrate the use of the coding system described in this chapter. Utterances resulting from $\mathrm{CpS}$ use are in bold print. The subject's intended meanings, recovered with the help of her retrospective comments, are given in the margin. They are followed by process-oriented classifications, to which specifications at the encoding level have been added (between brackets).

S: it (= the horse she rides on) is not my, uh my horse, but from the manege

I: from what?

S: from, the building, there

I: oh ja

S: where I am doing that

I: the club or the stables there

S: ja, uh 1 eerst it was uh of 1 uh a inan

I: $\mathrm{mm}$

S: the club, and, he can pay for the horses, and now, us club, has uh buy it

I: $\mathrm{mm}$

S: and now we have own horses ... uh 1 there are people who 1 makes the horse for the, who 1 uh help with the horse and, makes, uh, his, the house of the horse clean

I: $\mathrm{mm}$

S: and we must, uh do, the, saddle, where you can sit up uh, that we must do on the horse

I: put it up on top you mean?

S: ja

I: oh ja

S: yes, and, uh, that what he has on his head <pretends to put something over her own head and shoulders $>$ dus dat

I: $\mathbf{m m}$

S: with the, uh where you can uh may, hold the horse on

I: $\mathbf{m m}$

S: that we must do on it

I: $\mathbf{m m}$

S: and then we go in 1 uh 1 where we, go riding

I: $\mathrm{mm}$.... and can you go fast?

S: yes, erm, so, I think, seventy, kilometer 2 uh when you 1 pro hour

I: ja?

S: when you go very fast

I: ja, that is fast $1 \mathrm{~h}$ 'm 1 and do you have to wear

riding-school: LITRA

riding-school: ANCO

(1def)

at first: LITRA (2ab)

stable: ANCO (1def)

saddle: ANCO (1def)

harness: ANCO (1def $+1 \mathrm{mi})$

ring. ANCO (1def)

per: LITRA (2ab)

gallop: ANCO (1def) 
special clothes then?

S: uh yes, uh a trouser 1 and a cap

I: $\mathrm{mm}$

S: on your head, and 1 uh, and uh 2 pullover, is this? <points at her jumper>

I: ja

S: that's uh make, nn nothing, you can do, uh the thing you want to do, uh on, and then 1 uh large shoes

I: $\mathrm{mm}$

S: 2 uh for that the, hairs of the horse, don't uh, put in your feet

jumper. HOCO (1a + 1mi)

boots: ANCO (1def)

prick: HOCO (1a)

\subsection{Conclusion}

In this chapter a description has been given of the way in which the data were classified. Apart from the distinction between the four major CpS types introduced in chapter 4 (ANCO, HOCO, LITRA and LIMO), the coding system also captured information concerning the encoding of these $\mathrm{CpS}$ types. The assets of a dual coding system like this are twofold: on the one hand it has the advantages of a parsimonious and psychologically plausible taxonomy; on the other hand, it allows for a detailed description of the data at the encoding level.

The coding system that was described in this chapter did not pose many problems in terms of applicability. Classification was fast, easy and reliable in each of the three tasks in which it was used. Besides, there appeared to be no need for ad-hoc additions, certainly not at the process level. Considering the enormous variation in the data in terms of linguistic structure this can be taken as evidence that the distinctions between ANCO, HOCO, LITRA and LIMO are sufficiently general. In conclusion then, it can be said that in addition to being parsimonious and psychologically plausible, the taxonomy which was developed as part of the Nijmegen project has the advantage that it can be easily applied to a wide range of data.

\section{Notes to chapter 7}

1. Of the five categories of non-verbal behaviour distinguished by Ekman \& Friesen (1969) two can be used as $\mathrm{CpS}$ : emblems, which are defined as "those non-verbal acts which have a direct verbal translation, or dictionary definition usually consisting of a word or two, or perhaps a phrase" (p.63); and illustrators, that is, "movements which are directly tied to speech, serving to illustrate what is being said verbally" (p.68). Emblems can be coded arbitrarily or iconically (when the emblem resembles its significant visually). Some of the signs used in the sign alphabet language of the deaf are arbitrary emblems, viz. when the 
movements of the fingers do not look like the shapes of the letters they signify. Examples of iconic emblems are some of the other finger signs in which the fingers are placed into positions which closely resemble the alphabet letters they stand for, and the making or the shaking of a fist. Examples of illustrators which can function as $\mathrm{CpS}$ are pointing and drawing a picture of the referent.

2. The complete corpus contains 37 instances of $1 \mathrm{mi}$ (i.e. replacing non-verbal behaviour). In 12 cases $1 \mathrm{mi}$ took the form of enacting the intended concept. In 9 cases the intended referent was pointed at, and in 2 cases an emblem was used. The remaining cases of $1 \mathrm{mi}$ were realized in various other ways. 


\section{The Use of Compensatory Strategies in Tasks I, III and IV}

It will be remembered that one of the three major research questions addressed in the Nijmegen project concemed the relationship between L2 learners ' proficiency level and their use of CpS. In chapter 3 two hypotheses were formulated in connection with this research question. The first of these was that subjects of a lower L2 proficiency level would use more $\mathrm{CpS}$ than subjects of a higher L2 proficiency level. The second was that subjects of a lower L2 proficiency level would use more transfer strategies than more proficient subjects. These hypotheses were based on previous research (cf. chapter 3).

In this chapter the two hypotheses will be put to the test. First, a report will be given of the results of several quantitative analyses conceming the number and the type of CpS used by the three proficiency groups in tasks I, III and IV. The data elicited by means of task II have not been included in these analyses. They were primarily collected to answer the second research question, relating to the (potential) differences between $\mathrm{L} 1$ and $\mathrm{L} 2$ strategic behaviour, and will be dealt with separately in chapter 9 .

The second part of this chapter (sections 8.2.1 to 8.2.4) will contain a qualitative description of the data. The first three sections will relate to the use of $\mathrm{CpS}$ in tasks I, III and IV respectively, while the last section will be devoted to a discussion of individual differences in $\mathrm{CpS}$ use.

In section 8.3 the results of the quantitative and qualitative analyses will be discussed and explained in terms of the communication factors discussed in chapter 4 . Separate sections will be devoted to proficiency-related, task-related and person-related differences, and to the differences between super- and subordinate strategies. In the last section of this chapter there will be a summary of the main results.

\subsection{A quantitative analysis of the data ${ }^{1}$}

The first quantitative analysis to be reported here (in section 8.1.1) relates to the number of $\mathrm{CpS}$ used by each of the three proficiency groups in each of the three tasks. This will answer the question whether the number of $\mathrm{CpS}$ used is related to the subjects' proficiency level. Subsequently, the numbers will be broken down by $\mathrm{CpS}$ type to determine whether the type of $\mathrm{CpS}$ used is proficiency-related too. This question will be approached in three ways. In section 8.1.2 the frequencies with which each CpS type occurred will be presented. In section 8.1 .3 these frequencies will be converted into relative 
frequencies, after which they will be analysed by means of a two-way analysis of variance (ANOVA). And finally, the main findings will be visualized by means of correspondence analysis in section 8.1.4.

All analyses were carried out separately for super- and subordinate strategies. This was done to make sure that any differences relating to this distinction would show up.

\subsubsection{The number of compensatory strategies used}

All in all, the data of tasks I, III and IV contained 3203 clear cases of CpS. 2633 of these were superordinate $\mathrm{CpS}$ and 570 were subordinate $\mathrm{CpS}$. Table 8.1 shows how they were divided across proficiency groups and tasks.

Table 8.1 The number of super- and subordinate $\mathrm{CpS}$ per task $(\mathrm{I}=$ pictures, $\mathrm{II}=$ story retell and IV $=$ interview $)$ and per group ( $1=$ students, $2=5$-VWO pupils and $3=$ 3-VWO pupils)

\begin{tabular}{lrrrrrrrrr}
\hline & \multicolumn{2}{c}{$\begin{array}{c}\text { task I } \\
\text { super }\end{array}$} & \multicolumn{2}{c}{$\begin{array}{c}\text { task III } \\
\text { super }\end{array}$} & \multicolumn{2}{c}{$\begin{array}{c}\text { task IV } \\
\text { super }\end{array}$} & \multicolumn{2}{c}{$\begin{array}{c}\text { Ltal } \\
\text { super }\end{array}$} \\
\hline group 1 & 293 & 54 & 165 & 16 & 221 & 9 & 679 & 79 \\
group 2 & 302 & 176 & 298 & 32 & 321 & 23 & 921 & 231 \\
group 3 & 302 & 157 & 339 & 61 & 392 & 42 & 1033 & 260 \\
\hline total: & 897 & 387 & 802 & 109 & 934 & 74 & 2633 & 570 \\
\hline
\end{tabular}

The numbers of $\mathrm{CpS}$ elicited per subject in each of the tasks were collected in a 45 by 3 matrix and analysed as a two factor ANOVA with one between-Ss factor (proficiency groups 1,2 and 3) and one within-Ss factor (tasks). Of course, the task factor was not interesting per se, as possible differences would at most reflect their non-comparability. ${ }^{2}$ However, what was interesting, was the fact that 'tasks' interacted significantly with 'groups', both for the superordinate data, $F(4,84)=5.83, p<.001$ and for the subordinate data, $F(4,84)=6.70, p<.001$. Therefore, the group means were contrasted at the separate task-levels in two ways, viz. (1) university students vs VWO pupils and (2) 5-VWO pupils vs. 3-VWO pupils. ${ }^{3}$ The results of these contrasts are given in tables 8.2 (superordinate data) and 8.3 (subordinate data). 
Table 8.2 Group contrasts per task (superordinate data)

\begin{tabular}{lcrrrrr}
\hline Contrast: & task & SS & df & MS & F & p \\
\hline group 1 & I & 3.60 & 1 & 3.60 & 0.11 & .746 \\
$\quad$ vs & III & 1152.04 & 1 & 1152.04 & 33.61 & .000 \\
groups 2 + 3 & IV & 822.04 & 1 & 822.04 & 23.99 & .000 \\
\hline group 2 & I & 0.00 & 1 & 0.00 & 0.00 & 1.000 \\
$\quad$ vs & III & 56.80 & 1 & 58.80 & 1.72 & .193 \\
group 3 & IV & 172.80 & 1 & 172.80 & 5.04 & .026 \\
\hline & & & & & & \\
\hline
\end{tabular}

(') Ss. w. groups and tasks * Ss. w. groups pooled

Table 8.3 Group contrasts per task (subordinate data)

\begin{tabular}{lcrrrrrr}
\hline Contrast: & task & SS & df & MS & F & p \\
\hline group 1 & I & 547.60 & 1 & 547.60 & 49.56 & .000 \\
$\quad$ vS & III & 41.34 & 1 & 41.34 & 3.74 & .055 \\
groups 2+3 & IV & 23.51 & 1 & 23.51 & 2.13 & .147 \\
\hline group 2 & I & 10.80 & 1 & 10.80 & 0.98 & .325 \\
$\quad$ vs & III & 28.03 & 1 & 28.03 & 2.54 & .114 \\
group 3 & IV & 13.33 & 1 & 13.33 & 1.21 & .274 \\
\hline & Error (') & 1392.13 & 126 & 11.05 & & \\
\hline
\end{tabular}

(') Ss. w. groups and tasks * Ss. w. groups pooled

The comparison of university students (group 1) and VWO pupils (groups 2 and 3 ) in general confirms the prediction of an inverse relationship between the absolute number of $\mathrm{CpS}$ used by the subjects and their proficiency level. University students produce fewer superordinate $\mathrm{CpS}$ than VWO pupils, except in task I. This is not surprising though, since the number of supcrordinate $\mathrm{CpS}$ to be used in this task was largely predetermined by the number of problems included in it. Twenty pictures of 'difficult' objects generally resulted in the use of 20 superordinate CpS. University students also produce fewer subordinate $\mathrm{CpS}$ than VWO pupils, although the difference in the interview condition reflects only a tendency in the predicted direction. 
The differences between the two VWO groups are smaller. The global tendency only reaches significance for superordinate $\mathrm{CpS}$ in the interview.

\subsubsection{Analysis of compensatory strategy types: frequencies}

To gain some more insight in the use of the four different CpS types the number of super- and subordinate $\mathrm{CpS}$ was broken down by 'task', 'group' and 'CpS type' (cf. tables 8.4 and 8.5 respectively). It will be noted that the number of $\mathrm{CpS}$ included in tables 8.4 and 8.5 is somewhat smaller than that reported in table $8.1(D=50$ and $D=4$ respectively). This is due to the fact that not all CpS could be unequivocally interpreted as instances of a particular CpS type. For instance, an utterance like "clothes-maker" (for 'tailor') can be interpreted as an analytic strategy, a tailor being someone who makes clothes, or as a transfer strategy on the basis of Dutch 'kleermaker'. Because of their ambiguity, utterances like this were not included in the analyses.

Table 8.4 The number of superordinate $\mathrm{CpS}$ broken down by task, group and $\mathrm{CpS}$ type

\begin{tabular}{llrrrr}
\hline & & task I & task III & task IV & total \\
\hline \multirow{3}{*}{ group 1 } & ANCO & 279 & 94 & 93 & 466 \\
& HOCO & 2 & 59 & 77 & 138 \\
& LIMO & 1 & 3 & 1 & 5 \\
& LITRA & 6 & 4 & 43 & 53 \\
group 2 & ANCO & 296 & 173 & 161 & 630 \\
& HOCO & 0 & 85 & 86 & 171 \\
& LIMO & 0 & 6 & 3 & 9 \\
& LITRA & 2 & 24 & 67 & 93 \\
group 3 & ANCO & 291 & 215 & 201 & 707 \\
& HOCO & 3 & 78 & 101 & 182 \\
& LIMO & 1 & 5 & 1 & 7 \\
& LITRA & 3 & 32 & 87 & 122 \\
\hline Total: & & 884 & 778 & 921 & 2583 \\
\hline
\end{tabular}

Table 8.4 shows that most of the CpS used by the subjects were ANCO. The use of HOCO is clearly task-dependent. Whereas there are hardly any CpS of this type in task I, they occur quite often in tasks III and IV. The same goes for LITRA, which is quite frequent in task IV, but rare in task I. The use of LIMO is virtually negligible for all tasks and proficiency levels. 
Table 8.5 The number of subordinate $\mathrm{CpS}$ broken down by task, group and $\mathrm{CpS}$ type

\begin{tabular}{llrccr}
\hline & & task I & task III & task IV & total \\
\hline \multirow{4}{*}{ group 1 } & ANCO & 18 & 5 & 2 & 25 \\
& HOCO & 27 & 5 & 5 & 37 \\
& LIMO & 3 & 2 & 0 & 5 \\
& LITRA & 6 & 4 & 2 & 12 \\
& & & & & \\
group 2 & ANCO & 62 & 10 & 4 & 76 \\
& HOCO & 61 & 11 & 8 & 80 \\
& LIMO & 1 & 0 & 0 & 1 \\
& LITRA & 50 & 11 & 10 & 71 \\
& & & & & \\
group 3 & ANCO & 49 & 20 & 12 & 81 \\
& HOCO & 55 & 21 & 21 & 97 \\
& LIMO & 5 & 2 & 0 & 7 \\
& LITRA & 47 & 18 & 9 & 74 \\
\hline total: & & 384 & 109 & 73 & 566 \\
\hline
\end{tabular}

Table 8.5 gives the same information for subordinate $\mathrm{CpS}$. Compared to table 8.4, the differences in preferred $\mathrm{CpS}$ type are striking. ANCO is by no means predominant in the case of subordinate $\mathrm{CpS}$. It is outnumbered by HOCO while LITRA is also relatively frequent. Again there are hardly any instances of LIMO at subordinate level, so that we must conclude that this $\mathrm{CpS}$ type played a very minor role indeed. ${ }^{4}$

\subsubsection{Analysis of compensatory strategy types in terms of ANOVA}

For the statistical analyses the frequencies reported in tables 8.4 and 8.5 were converted into proportions. Like Paribakht $(1982 ; 1985)$ we felt this would give a more realistic picture of the effects of 'task' and 'proficiency level' on the subjects' preference for particular CpS types. Consider for instance the use of superordinate HOCO in task III (cf. table 8.4). If one were to go by frequencies alone, one would have to conclude that group 1 uses fewer $\mathrm{CpS}$ of this type than groups 2 and 3 ( 59 vs 85 vs 78). However, a comparison of the proportions would lead to a markedly different conclusion. Group 1 subjects solve their lexical problems in this task by means of HOCO in $36.8 \%$ of the cases ( 59 out of 160 ), group 2 in $29.5 \%$ of the cases ( 85 out of 288 ) and group 3 in 23.6\% (78 out of 330). Hence, one could conclude that, relatively, group 1 uses more HOCO in task III than groups 2 and 3. The same argument applies at the level of a single subject's frequencies pattem where a subject, using 12 instances of HOCO out of a total of $15 \mathrm{CpS}$, can be said to respond more 
holistic-conceptually than a person with 20 instances of this strategy out of a total of, for instance, $40 \mathrm{CpS}$.

In view of the above, every single subject's frequencies pattern on each of the tasks was converted into the corresponding relative frequencies pattern, yielding three such patterns per subject (i.e. one per task). Subsequently, for each of the four CpS types in tum, a 45 (Ss) by 3 (tasks) matrix was constructed with entries indicating the subject's relative use of the particular CpS type in each of the tasks. This was done separately for super- and subordinate $\mathrm{CpS}$, so that a total of 8 matrixes were created. The tables listed in appendix V contain the cell, row, column and grand means of the proportions in these matrixes. Each matrix was then analysed as a two-way ANOVA with one between-Ss factor ('proficiency level') and one within-Ss factor ('task'). Since we are dealing with proportions, an arcsine transformation was applied to the data before the ANOVA was run. The effect of this procedure, which has been recommended by Winer (1971), is to stabilize the within-cells variances. ${ }^{5}$

The first step in the analyses of the above-mentioned design is to determine whether the group and task factors interact in their possible effects on the dependent variables ANCO, HOCO, LIMO and LITRA. If they do not, this leads to a simplification of the subsequent analytical steps, since in that case only main effects for groups and tasks will need to be considered. In the case of interaction, however, separate group-wise analyses of task differences and task-wise analyses of group differences must be carried out. The results of the preliminary interaction tests, i.e. the obtained F-ratios and the corresponding significance values, are given in table 8.6.

Table 8.6 Preliminary interaction tests; $\mathrm{df}=(4,84)$; error term: tasks * subjects within groups

\begin{tabular}{lllll}
\hline & \multicolumn{2}{l}{ SUPERORDINATE } & \multicolumn{2}{l}{ SUBORDINATE } \\
\hline & F & p & F & p \\
\hline ANCO & 1.31 & .272 & 0.53 & .711 \\
HOCO & 2.46 & .051 & 0.62 & .649 \\
LIMO & 0.20 & .936 & 0.41 & .800 \\
LITRA & 2.27 & .069 & 0.96 & .433 \\
\hline
\end{tabular}

It appears that 'group' and 'task' hardly interact in their effects on the various dependent variables. Only for superordinate $\mathrm{HOCO}$ and LITRA do the interaction effects border on significance. With respect to the analyses of these two CpS types it is therefore necessary to proceed with caution and to concentrate on group-wise comparisons of tasks and task-wise comparisons of groups. For the remaining analyses only main effects will need to be considered. 
Table 8.7 Summary of tests of main or simple main effects and, where applicable, Newman-Keuls comparisons (superordinate data)

\begin{tabular}{|c|c|c|c|c|c|c|c|c|}
\hline source: & & Groups & $1-2$ & $1-3$ & Tasks & I-III & I-IV & III-IV \\
\hline error term: & & $\begin{array}{c}\text { Ss.w.Gr } \\
\left({ }^{\prime}\right)\end{array}$ & & & $\begin{array}{l}\text { tasks * } \\
\text { Ss.w.Gr }\end{array}$ & & & \\
\hline df: & & $(2,42)$ & & & $(2,84)$ & & & \\
\hline ANCO & $\begin{array}{c}\mathbf{F} \\
\mathbf{p} \\
\text { MSerr }\end{array}$ & $\begin{array}{l}2.91 \\
.066 \\
.084\end{array}$ & - & - & $\begin{array}{r}425.31 \\
.000 \\
.049\end{array}$ & $\gg$ & $\gg$ & $\gg$ \\
\hline $\begin{array}{l}\text { HOCO } \\
\text { Task I }\end{array}$ & $\underset{\text { MSerr }}{\mathbf{p}}$ & $\begin{array}{l}0.21 \\
.812 \\
.047\end{array}$ & - & - & $\begin{array}{ll}- & 125.66 \\
\text { Gr.1 } & .000 \\
& .049\end{array}$ & $\ll$ & $\ll$ & - \\
\hline Task III & $\begin{array}{c}\text { F } \\
\text { p } \\
\text { MSerr }\end{array}$ & $\begin{array}{l}5.95 \\
.003 \\
.047\end{array}$ & - & $\gg$ & $\begin{array}{rr}-\quad & 90.66 \\
\text { Gr.2 } & .000 \\
& .045\end{array}$ & $\ll$ & $\ll$ & - \\
\hline Task IV & $\begin{array}{c}\mathbf{F} \\
\mathbf{p} \\
\text { MSerr }\end{array}$ & $\begin{array}{l}6.98 \\
.001 \\
.047\end{array}$ & $\gg>$ & $\gg>$ & $\begin{array}{rr}- & 67.55 \\
\text { Gr.3 } & .000 \\
& .045\end{array}$ & $\ll$ & $\ll$ & - \\
\hline LIMO & $\begin{array}{c}\mathbf{F} \\
\mathbf{p} \\
\text { MSerr }\end{array}$ & $\begin{array}{l}0.15 \\
.859 \\
.010\end{array}$ & - & - & $\begin{array}{l}6.46 \\
.002 \\
.012\end{array}$ & $\ll$ & - & $\gg$ \\
\hline $\begin{array}{l}\text { LITRA } \\
\text { Task I }\end{array}$ & $\begin{array}{c}\text { F } \\
\text { p } \\
\text { MSerr }\end{array}$ & $\begin{array}{l}0.25 \\
.776 \\
.067\end{array}$ & - & - & $\begin{array}{lc}- & 24.60 \\
\text { Gr.1 } & .000 \\
& .061\end{array}$ & - & $\ll$ & $\ll$ \\
\hline Task III & $\begin{array}{c}\mathbf{F} \\
\mathbf{p} \\
\text { MSerr }\end{array}$ & $\begin{array}{l}4.80 \\
.010 \\
.067\end{array}$ & $<$ & $\ll$ & $\begin{array}{lr}- & 20.22 \\
\text { Gr.2 } & .000 \\
& .061\end{array}$ & $\ll$ & $\ll$ & $\ll$ \\
\hline Task IV & $\begin{array}{c}\text { F } \\
\text { p } \\
\text { MSerr }\end{array}$ & $\begin{array}{l}1.48 \\
.230 \\
.067\end{array}$ & - & - & $\begin{array}{rr} & 31.53 \\
\text { Gr.3 } & .000 \\
& .061\end{array}$ & $\ll$ & $\ll$ & $\ll$ \\
\hline
\end{tabular}

(') The error term for groups in the test of simple main effects is Ss.w.Gr. pooled with tasks * Ss.w.Gr. 
The results of the eight ANOVAs are listed in tables 8.7 and 8.8, which relate to super- and subordinate CpS respectively. Where appropriate, simple, or level-wise effects are reported instead of main effects. All significant effects are followed by the results of Newman-Keuls range tests in the columns labelled 1-2, 1-3 and 2-3 (for groups) and 1-2, 1-4 and 3-4 (for tasks). In these columns the symbols,$-<$ and $>$ are used to indicate whether the comparison is non-significant, or significant in the indicated direction. The symbols are doubled when the comparison is significant at the .01 rather than the .05 level. The error terms and degrees of freedom used in the F-ratios are given at the top of the table. For groups, the error term in the test of simple main effects is Ss w Gr pooled with tasks * Ss w Gr (cf. Kirk, 1968:263-265). For tasks, the error term is the same for main effects and simple main effects.

From table 8.7 it appears that there are some significant proficiency-related differences in the selection of superordinate CpS. Group 1 uses more HOCO in tasks III and IV, and less LITRA in task III. None of the differences between groups 2 and 3 (3-VWO and 5-VWO pupils) are significant though.

Task effects are considerable in the case of superordinate CpS. For ANCO all Newman-Keuls comparisons are significant, the proportion of ANCO being maximal in task I, less in task III and least in task IV. HOCO is less frequent in task I than in tasks III and IV. This goes for all three proficiency groups. None of the differences between tasks III and IV with respect to this CpS type are significant though. LIMO occurs most often in task III. The difference is significant, both in comparison with task I and in comparison with task IV. This result should be considered with some scepticism, however, since the proportions for this $\mathrm{CpS}$ type were based on very low frequencies (cf. tables 8.4 and 8.5). Finally, the use of LITRA proved to be greatest in task IV and, with the exception of university students, greater in task III than in task I.

Table 8.8 reveals that for subordinate CpS there are hardly any proficiency level effects. The only difference that approaches significance is that between group 1 and groups 2 and 3 in the case of LITRA, which is used less often by university students.

Again, we find that there are a number of task effects, but here they are less strong than in the case of superordinate $\mathrm{CpS}$. The differences in the proportional use of ANCO are similar to those observed for superordinate CpS. ANCO occurs most often in task I, less often in task III and least often in task IV. Subordinate HOCO occurs more often in task I than in task IV. The same goes for subordinate LIMO, but for reasons mentioned above this result is rather dubious. These last two task effects, it should be noted, are inverted in comparison with those for superordinate $\mathrm{CpS}$. Finally, it appears that there are no significant task-related differences at all with respect to LITRA as a subordinate $\mathrm{CpS}$. 
Table 8.8 Summary of tests of main effects and, where applicable, Newman-Keuls comparisons (subordinate data)

\begin{tabular}{|c|c|c|c|c|c|c|c|c|c|}
\hline source: & & Groups & $1-2$ & $1-3$ & $2-3$ & Tasks & I-III & I-IV & IUI-IV \\
\hline error term: & & Ss.w.Gr & & & & $\begin{array}{l}\text { tasks * } \\
\text { Ss.w.G }\end{array}$ & & & \\
\hline df: & & $(2,42)$ & & & & $(2,84)$ & & & \\
\hline ANCO & $\begin{array}{c}\mathbf{F} \\
\mathbf{p} \\
\text { MSerr }\end{array}$ & $\begin{array}{l}1.00 \\
.375 \\
.469\end{array}$ & - & - & - & $\begin{array}{l}9.00 \\
.000 \\
.530\end{array}$ & $>$ & $\gg$ & $>$ \\
\hline HOCO & 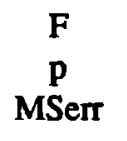 & $\begin{array}{l}1.80 \\
.178 \\
.701\end{array}$ & - & - & - & $\begin{array}{l}3.22 \\
.045 \\
.660\end{array}$ & - & $>$ & $>$ \\
\hline LMMO & $\begin{array}{c}\mathbf{F} \\
\mathrm{p} \\
\text { MSen }\end{array}$ & $\begin{array}{l}1.46 \\
.243 \\
.029\end{array}$ & - & - & - & $\begin{array}{l}3.06 \\
.052 \\
.028\end{array}$ & - & $>$ & - \\
\hline LITRA & $\begin{array}{c}\mathbf{F} \\
\mathbf{p} \\
\text { MSerr }\end{array}$ & $\begin{array}{l}3.22 \\
.050 \\
.740\end{array}$ & $<?$ & $<?$ & - & $\begin{array}{l}1.53 \\
.223 \\
.489\end{array}$ & - & - & - \\
\hline
\end{tabular}

Two general conclusions to be drawn from tables 8.7 and 8.8 are (a) that task effects are much larger than proficiency level effects; and (b) that many of the effects observed with superordinate $\mathrm{CpS}$ disappear with subordinate $\mathrm{CpS}$.

\subsubsection{A visualization of the results: correspondence analysis}

The different effects of the factors 'task' and 'proficiency level' can be visualized by means of an analytic technique called correspondence analysis (Benzécri, 1976). This technique, which can be applied by means of the ANACOR programme (Bettonvil, 1981), makes a multidimensional representation of 'row-categories' (here: nine task-proficiency level combinations) and 'column-categories' (here: four different $\mathrm{CpS}$ types). This is done in such a way that the distance between the two categories expresses the 'popularity' of a particular column-category with a particular row-category. Popularity, here, can be defined as the extent to which the observed frequency of a particular column-category exceeds its expected 
frequency. Thus, in the present study a $\mathrm{CpS}$ type is popular, and its distance to a task-proficiency level combination is small, if this CpS type was used more often in this particular task-proficiency level combination than one would expect on the assumption of independence. For a detailed account of correspondence analysis, and for a description of the arithmetic procedures employed in it, see Gifi (1981).

Figures 8.1 and 8.2 depict the ANACOR plots for super- and subordinate $\mathrm{CpS}$ in our study. The first plot reveals a distinct task-related pattern. Numbers 1,4 and 7 (task I), 2, 5 and 8 (task III) and 3,6 and 9 (task IV) clearly cluster together. The A, denoting ANCO, is right in the centre of the plot, thereby indicating its frequent occurrence in each of the three tasks. The positions of the other letters indicate that $\mathrm{HOCO}$ (B) is more or less equally popular in tasks III and IV, that LIMO (C) is relatively popular in task III, and that LITRA (D) is most popular in task IV.

If we now look at figure 8.2 we see that there is no such clear pattern in the case of subordinate CpS. The task-related clusters are not distinct and tend to overlap. The distances between numbers relating to any one of the tasks are often larger than those between numbers relating to different tasks. As in figure 8.1, it is not possible to discem any distinct proficiency level-related clusters either.

The two ANACOR plots visually support the findings reported earlier on the basis of ANOVA that 'task' is a more dominant factor than 'proficiency level' in determining the choice of CpS, and that any effects to be observed are stronger for superordinate than for subordinate CpS.

\subsection{A qualitative analysis of the data}

In the next sections the statistical analyses of the data will be supplemented by a qualitative description. First, the use of $\mathrm{CpS}$ in each of the three tasks will be illustrated (sections 8.2.1, 8.2.2 and 8.2.3). Much of the discussion will focus on differences in the realization of $\mathrm{CpS}$ types. In this way a more complete picture of the variation in the data will emerge. In section 8.2.4 some individual differences in the subjects' strategic behaviour will be discussed. This will be done on the basis of a detailed description of the data produced by two subjects one of whom can be characterized as a 'reflective', the other as an 'impulsive' person.

\subsection{The use of compensatory strategies in the picture description task (task I)}

As we have seen, almost all superordinate $\mathrm{CpS}$ in task I were analytic strategies. They generally took the form of definition-like descriptions in 

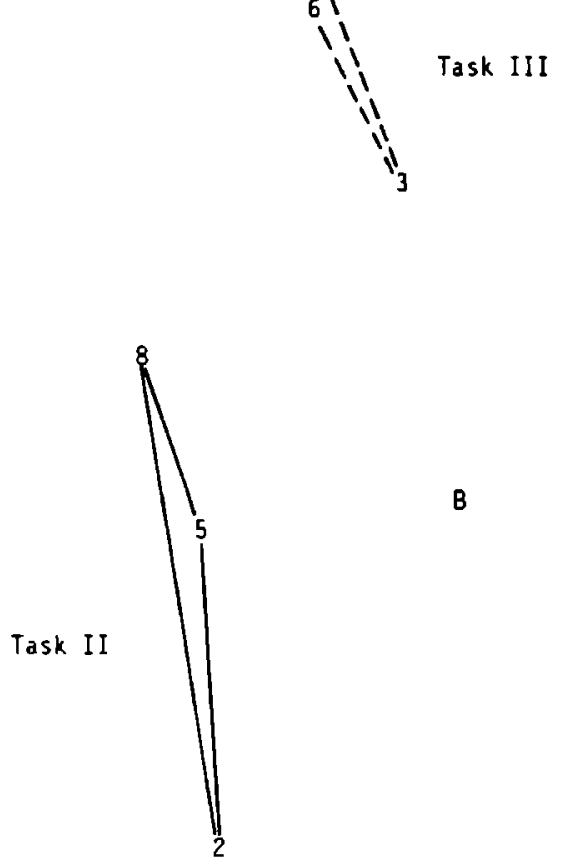

\section{A}

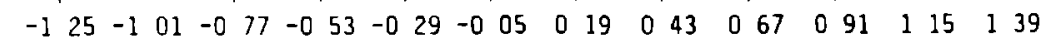

Figure 8.1 ANACOR plot for superordinate $\mathrm{CpS}(\mathrm{A}=\mathrm{ANCO}$; $\mathrm{B}=\mathrm{HOCO}$; $\mathrm{C}=\mathrm{LIMO}$; D=LITRA; $1=$ group 1 , task I; $2=$ group 1 , task III; $3=$ group 1 , task IV; $4=$ group 2 , task I; $5=$ group 2, task III; $6=$ group 2 , task IV; $7=$ group 3 , task I; $8=$ group 3, task III; $9=$ group 3 , task IV) 


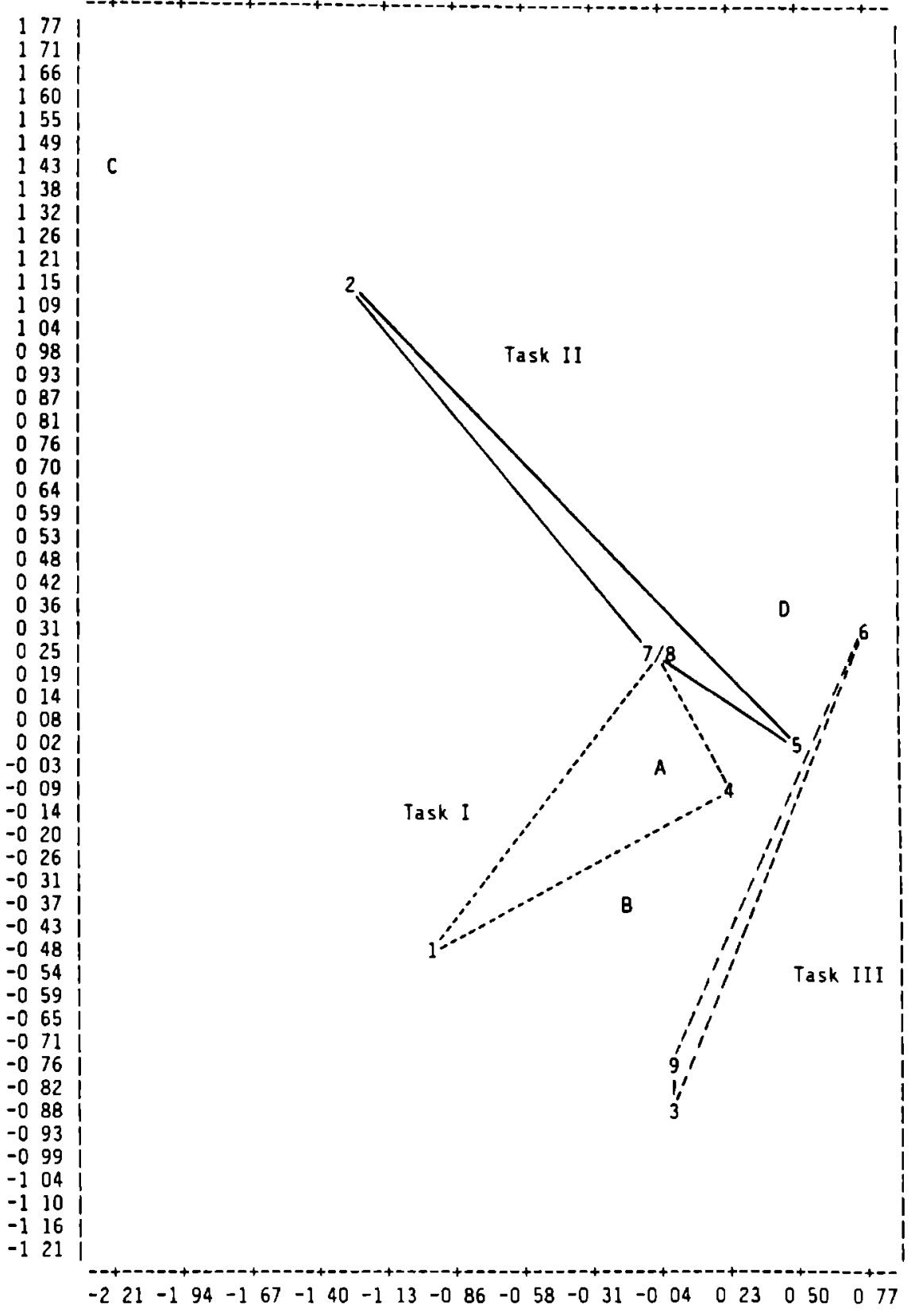

Figure 8.2 ANACOR plot for subordinate $\mathrm{CpS}(\mathrm{A}=\mathrm{ANCO}$; $\mathrm{B}=\mathrm{HOCO}$; $\mathrm{C}=\mathrm{LIMO}$; $\mathrm{D}=$ LITRA; $1=$ group 1 , task I; $2=$ group 1 , task III; $3=$ group 1 , task IV; $4=$ group 2 , task I; 5=group 2, task III; 6=group 2, task IV; $7=$ group 3, task I; 8=group 3, task III; $9=$ group 3 , task IV) 
which a number of the referents' most characteristic properties were mentioned. Consider the following examples, all taken from the data of the same 5-VWO pupil:

(1) erm 1 uh, a thing for, on a, bottle, for a baby, to 1 drink out (teat; 208t1)

(2) 2 oh, erm, a thing, which you can, lay down on, anything, so you can, see or it is erm 35 erm you can see it's, horizontal <French pronunciation> (spirit level; 208t1)

(3) erm, those are toys, for kids to play with, erm, you can put your, feet, on them, and then, walk on it (stilts; 208t1)

(4) erm 1 uh, a round, thing which you can put your, glass on, from Heineken (beermat; 208t1)

(5) erm, a thing of, wood 2 with, which you can erm 1 roll out $1 \mathrm{erm} 4$ if you uh 9 if you make erm, cookies or something like that, uh, you can 1 uh, roll it out 1 uh, with this thing (rolling pin; 208t1)

Clearly, these CpS are all based on conceptual knowledge. The subject estimates which properties are necessary for the intended concept to be communicated and mentions as many of these as she sees fit. She prefers to start her CpS with "erm, a thing ...". This tendency to start analytic strategies with a fixed formula was also observed for other subjects. It was particularly striking in the case of subject 106 , who started 16 out of the 20 analytic strategies she used as follows:

(6) erm, this is something you can, ket get coal in (coal-scuttle; 106t)

(7) erm, this is something baby babies use round wear around their necks, so that they won't, uh spoil /æn/ everything (bib; 106tl)

(8) erm this is something which helps you to, put on your shoes (shoehom; 106t1)

It is possible that in this way the subjects attempted to reduce the cognitive load posed by the organization of definitions. In some cases, however, in particular when they were longer, the formulas may also have served the subjects as a time-gaining device.

That all subjects used analytic strategies for nearly all the concepts they had to refer to in task I does not mean that there were no differences in their behaviour at all. Verouden (1987) made a detailed investigation of the number and the type of properties mentioned by the subjects for 17 of the referents in task I, and observed that there was considerable variation on these points. Most importantly, she found that the number of properties mentioned by the subjects was related to their proficiency levels. The least advanced pupils (group 3) mentioned fewer properties than either of the two other groups who did not differ with respect to each other (cf. table 8.9; Newman-Keuls range test, group 1 , group $2>$ group $3, p<.05$ ). 
Table 8.9 The average number of properties mentioned in task I per item and per group (adapted from Verouden, 1987)

properties per item

group 1

group 2

group 3
2.45

2.57

1.78

Verouden also reports huge individual differences in the number of properties mentioned by the subjects and notes that these occur even among subjects within one proficiency group. She cites the following examples to illustrate this:

(9) this is a thing erm, which is used erm, for babies, babies drink their milk erm 1 in a 2 in a little bottle and on the top of the bottle there is, this thing, and then uh it's very easily to suck uh 1 through this thing, it's sometime used sometimes used for, quieting, babies, and you just put this thing in the mouth and they're quiet 1 hopefully (teat; 101t1)

(10) erm 1 this is something uh, babies use, which they can 1 put in their mouth (teat; 106t1)

On the basis of Verouden's (1987) study it can be concluded that the Nijmegen data exhibit more proficiency-related differences than the analyses reported in section 8.1 revealed. However, these differences (in any case in task I) relate to the realization of $\mathrm{CpS}$, and not to the choice of particular $\mathrm{CpS}$ types.

Finally, it is worth pointing out that the subjects generally went to great lengths when performing task I. As will be shown in the following two sections the amount of detail provided in the analytic strategies in task I is usually much larger than in CpS of this type in tasks III and IV. Also, the number of subordinate $\mathrm{CpS}$ is considerably larger in task I than in the other tasks. An explanation for these last two findings will be offered in section 8.3.2.

\subsubsection{The use of compensatory strategies in the story retell task (task III)}

In task III there is more variation in the use of superordinate CpS. Although analytic strategies are most frequent still $(61 \%)$, holistic strategies are quite common (30\%) while transfer strategies are by no means exceptional (7\%; see appendix V, tables 1-4). The following extract illustrates the use of $\mathrm{CpS}$ in task III: 
it's a story which call, the representer <laughs> it's a man uh, uh, uh who has uh, discovered, uh 1 uh 1 ja, a thing you can put on your head and then your hair will grow, when you're bald, that's very nice, and uh, he tries to sell it, to uh, /so/ uh, to a lot of, em 1 hair-cutters <laughs>, erm 1 he does it uh, very, uh xxx clever, he's uh, bald, self, his himself, and uh, then, he puts on uh, uh <laughs> 3 'n pruik (= a wig) <whispers> 2 erm $6 \mathrm{erm}$, a thing which is made of uh, other man's hair or static hair, and you can put it on your head and then uh, it seems if you're not bald, and uh, then he, uh beweren (= claims), uh<whispers 4 he says to the, to to the hair- cutter that uh 2 that uh has come, because he has use his own uh 2 own, wat is uitvinding nou weer (= now what is invention?) <whispers 2 own uh thing which he /hæ/ had d discovered, uh, he, uh 2 he 1 he uh, earned a lot of money, uh until the day, of uh, the 2 meeting which is hold every year, in 1 outside of uh the houses, in the air, and the wind had uh, blew off, that thing 1 which he had on his hairs, and so 1 uhthey discovered that he was a liar <laughs $>$ (the representative; 204t3) representative: limo hair-restorer:anco (1def)

hairdressers: anco (1wc)

wig: anco (1def) artificial hair anco (1def) claims: hoco

invention:anco (1def)

outside: anco (1def) open air: hoco wig: anco (1def)

In this extract the subject uses 9 superordinate $\mathrm{CpS}$ and 1 subordinate $\mathrm{CpS}$. All $\mathrm{CpS}$ are in bold print, while the subordinate $\mathrm{CpS}$ has also been underlined. The codes given in the right hand margin show that 6 of the 9 superordinate $\mathrm{CpS}$ were analytic strategies. One, "representer", was classified as LIMO, and two were classified as HOCO (viz. "says" for 'claim' and "air" for 'open air'). The one subordinate CpS in this extract, "static hair" for 'artificial hair' (Dutch: kunsthaar), was interpreted as an analytic strategy, although one could also argue that "static" is a holistic strategy for 'artificial'.

The extract brings up a number of interesting points. Firstly, it will be noted that not all analytic strategies are realized in the same way. Whereas the first analytic strategy (for hair-restorer) is similar to those that were used in task I, the second one, "hair-cutters", is structurally different. Some of the other analytic strategies are much less specific than those in task I. In "uh thing which he $\mathrm{hx} /$ had d discovered" and "that thing 1 which he had on his hairs" only one property of the intended concepts is mentioned, while in "outside of the houses", a CpS for 'outside' pointed out by the subject in the retrospective session, it is difficult to detect any individual properties at all. Thus, it can be concluded that in task III the subjects did not only exhibit more variety in their choice of $\mathrm{CpS}$, but also in their realization of these $\mathrm{CpS}$. In particular, they 
varied the structure of analytic strategies and tended to use less informative ones.

The second point to be made with respect to the above extract is that the subjects reduce the amount of information they provide, i.e. the number of properties they mention, when they refer to a particular concept for the second time. The two analytic strategies for 'wig' constitute a good example. The first time the subject explains what a wig is made of, what you do with it, and what the purpose of wearing a wig is. The second time the information is brought down to "that thing which he had on his hairs". Of course, this reduction in the amount of information given is well-known from discourse studies. Elaborate noun phrases are generally substituted by much simpler noun phrases or pronouns once reference has been established.

The subjects also used less specific $\mathrm{CpS}$ when the referent was not particularly relevant to the story as a whole. For instance, in the story of the courtcase, in which it does not really matter whether the bicycle- manufacturer presents the judge with a hammer drill, an ordinary drill, or just any tool, only one of the subjects specified that the drill was of a special kind (cf. appendix III for the stories used). Conversely, in the story of the rabbit buying a pleated skirt, 23 of the 45 subjects used subordinate CpS to convey the fact that the skirt was pleated. 6 In addition, 6 of the subjects attempted to express the concept 'pleats' but gave up, while 4 other subjects indicated that the skirt was of a special kind. The amount of detail provided in the story of the rabbit is probably due to the fact that the punch line of this story hinges on the skirt being pleated, which makes it hard to iron. This makes the pleats into a relevant detail which cannot simply be left out.

Clearly then, the amount of detail given in task III was, at least partly, determined by the amount of detail required. The subjects gave less information once reference to a particular concept had been established, and they did not put a great deal of effort into expressing details that were not really relevant.

\subsubsection{The use of compensatory strategies in the interview (task IV)}

In task IV the variation in CpS use is even greater than in task III. Of the superordinate CpS $50 \%$ are analytic, $30 \%$ are holistic and $20 \%$ are transfer strategies (see appendix $\mathrm{V}$, tables 1-4). In particular the large proportion of transfer strategies is striking. In this respect it should be remembered that task IV was the only task in which the subjects communicated with an interlocutor who was physically present and, more importantly, who participated actively in the conversation. This made the subjects' task easier in some respects, since the interlocutor often contributed to the solution of lexical problems by trying to guess the right words or by suggesting altemative ways to describe the 
extract in which a 5-VWO pupil is telling the interviewer about a bicycle tour he once made to Antwerp:

S: and, it's a one straight uh, road, to uh Antwerp, so we uh

I: is it not boring then?

S: we uh, were riding very fast, on our, we had a race uh, how do you call that uh 2 asporting uh bicycle

I: $\mathrm{mm}$

S: and erm, with ten uh <laughs> 1 so and erm, doesn't matter erm, so we went to Antwerp, and, the uh 1 parts of the uh road 1 which are uh, for uh bicycles, uh I don't know the word for that but erm 1

I: just the cycle-paths? ja

$S:$ ja cycle-paths they were not quite equal, there are some uh 1 if you uh 1 left the uh cycle-

I: ja paths, wh to cross a street

S: there was a little uh $1 \mathrm{erm} 1$ you /sks/, a little erm <laughs> 1 erm some sort of an, erm 3 which are erm 3

I: which slowed you down or something? is that what you mean?

S: ja it's you uh, /rai/ uh, ride on it and then you have erm 1 your wheel is uh very erm 1 uh na uh it doesn't matter <laughs>

I: is it, this thing is, put purposely in the road, to, to stop people going too fast or?

S: no that, not that

I: oh

S: no it's a quite erm 1 it's very simple but, I can't remember the word

I: ja it doesn't matter

$S$ : but a matter of fact, it was quite uh, uncomfortable to $\mathrm{dr}$ to ride over it

I: $\mathrm{mm}$

$S$ : and then they have uh, roads there with erm, stones in it

I: oh the old, cobble stones is it?

S: I guess so, that that's the word, erm ... (203t4)

racer: hoco

sports-bicycle:

$11 \mathrm{t}^{8}$

cycle-paths: anco

(1def)

kerbs: anco (1def) cobbled roads:

anco (1def)

cobbles: hoco (1a)

In this extract the interviewer gives the word 'cycle-paths' and she correctly guesses that "roads with stones in it" are 'cobbled roads'. But when the subject tries to explain that the cycle-paths had kerbs, so that they were bumpy, the 
interviewer does not understand him. She thinks he is trying to refer to 'speed ramps' and, being cooperative, she suggests various ways to describe this. When none of these prove to be very helpful, they decide to leave the problem unsolved and get on with the conversation.

The possibility of obtaining immediate feedback enabled the subjects to check the comprehensibility of their $\mathrm{CpS}$ and to repair them, or add another $\mathrm{CpS}$ if necessary. For analytic strategies this led to the subjects starting off with just one property and adding other properties only if the interlocutor indicated she had not yet understood what was meant. Examples (11) and (12) illustrate this:

(11) S: and uh ja we have uh, two beds, above which other

I: oh ja

S: you know that?

I: ja

S: stapelbed (bunk bed; 304t4)

(12) S: ... those uh, books about uh life on a farm you know, we call it ja streekromans, I don't know what you call it in English

I: h'm about life on a farm?

S: ja about uh, for, uh with they play mostly in the nine, in the end of the uh, nineteenth century

I: oh

S: on uh when, what life was then, about (regional novel; 114t4)

As can be seen, in (11) it was sufficient to mention one property only. The Dutch word 'stapelbed' seems to be superfluous. It is not necessary to convey meaning and might be interpreted as an attempt to inform the interlocutor about the Dutch word. In (12), however, more properties were needed, and given. So again, we see that the subjects adapt the amount of information they give to the amount of information required.

Similarly, many of the transfer strategies which occurred in task IV were followed by other $\mathrm{CpS}$ if the interlocutor indicated she had not understood them. There are 60 cases like (13) and (14) where a transfer strategy was used as the first $\mathrm{CpS}$ within a series of $\mathrm{CpS}$ referring to the same concept:

(13) S: yeah, ja my father is uh, having a lot of uh plants

I: $\mathrm{mm}$

S: in uh, ja in a cash

I: in what?

$S:$ in uh a glassen uh, ja sort of house

I: oh ja, glasshouse (greenhouse; 301t4)

(14) I: <laughs> ja, what is she studying in Antwerp?

S: erm, ja 1 I don't know how to say it in English, it's uh, tolk, I don't know

I: it's what sorry?

S: tolk ja, a man or woman 
I: talk

S: uh which uh, who, translate, uh, when you're talking English and there's a Russian man

I: oh ja

S: she understands you and, then she translate it in Russian for the man

I: hoh, translatior, translator I should say

S: ja, ja (interpreter; 204t4)

In other cases a second $\mathrm{CpS}$ was not considered necessary, so that many transfer strategies in task IV occurred by themselves. There are 114 instances like (15) and (16):

(15) I: and have you fish too?

S: yes, one aquarium <Dutch pronunciation>

I: $\mathbf{m m}$

S: one big fi uh, no big fish nee, much fish (aquarium; 302t4)

(16) S: erm you understand narcissen?

I: $\mathrm{mm}$

S: and uh roses

I: oh nice ja (daffodils; 206t4)

As in task III, the subjects did not go into details which they considered to be irrelevant. This is illustrated by examples (17) and (18) where holistic strategies were used which did not really convey the subjects' intended meanings:

(17) S: and so the 1 uh a man 1 I knows, a man uh who $1 \mathrm{~s}$ it's uh, an uncle of me ... (acquaintance; 310t4)

(18) S: we had to wait for the bus for uh th, uh half an hour (three quarters of an hour, 203t4)

In both cases it was the retrospective information which revealed what the subjects had really wanted to say, and hence that $\mathrm{CpS}$ had been used. The subjects who used these $\mathrm{CpS}$ apparently preferred maintaining the fluency of the conversation to communicating the two intended concepts.

In the remainder of this section I will briefly comment on two further aspects in which CpS use in task IV differs from that in other tasks. Both aspects concern the realization of $\mathrm{CpS}$.

Firstly, there are some task-related differences in the encoding of LITRA. As table 8.10 shows, approximately $70 \%$ of the superordinate transfer strategies that occurred in tasks I and III were foreignizings (cf. chapter 7). That is, the words transferred from the $\mathrm{Ll}(\mathrm{Ln})$ were phonologically and/or morphologically adapted to the $\mathrm{L} 2$. The other superordinate transfer strategies 
were either borrowings or literal translations. In task IV only $46 \%$ of the 197 superordinate transfer strategies were foreignizings, while $37 \%$ were borrowings and $17 \%$ were literal translations. So, the proportion of 'Borrowing' is much larger in task IV than in tasks I and III. For subordinate $\mathrm{CpS}$ there were no such task-related differences, there being a general preference for 'Foreignizing' (70-80\%).

Table 8.10 Different realizations of LITRA in tasks I, III and IV (superordinate CpS only)

\begin{tabular}{llll}
\hline & Lask I & task III & task IV \\
\hline Foreignizing & $7=67 \%$ & $43=71 \%$ & $91=46 \%$ \\
Borrowing & $1=8 \%$ & $9=15 \%$ & $73=37 \%$ \\
Literal Translation & $3=25 \%$ & $8=14 \%$ & $33=17 \%$ \\
\hline Total: & 11 & 60 & 197 \\
\hline
\end{tabular}

Upon close examination of the borrowings in task IV it appeared that 27 of them were used at the beginning of a series of $\mathrm{CpS}$ (as in example 14), while 10 occurred at the end of such a series, presumably as a last resort (cf. examples 19 and 20). The remaining 36 borrowings occurred by themselves as in examples (15) and (16).

(19) S: ... I know uh, a certain man, erm, he uh also lives in Indonesia

I: $\mathbf{m m}$

S: and he lives in the mountains, he's, a sort of, erm, uh how do you call it, an erm 1 uh, djee <laughs $>2 \mathrm{em} 2$ well anyway he lives in the mountains

I: ja

S: 'n kluizenaar I don't know the word I'm sorry, but erm

I: by himself, is it a hermit or something?

S: yes a hermit, that's what I was looking for <laughs> thank you

I: ja (hermit; 113t4)

(20) S: ... we eat uh 1 erm <laughs $>$ round uh, meat, with uh little, cords on it

I: oh, and what else?

S: we noem it uh, we call it uh rollade, in Netherlands (rolled meat; 31144)

Borrowings were also used in connection with concepts that were perceived by the subjects as typically Dutch, such as 'Sinterklaas' (Santa Claus), 'HTS' (a Dutch type of higher education) and 'boerekool' (a Dutch dish). This use of 'Borrowing' for language- or culture-specific concepts has also been noted by Færch \& Kasper (1986). 
The other phenomenon that distinguishes task IV from the other tasks is the use of non-verbal means to encode (part of) the $\mathrm{CpS}$. Strategic non-verbal behaviour occurred 35 times in task I, 4 times in task III and 115 times in task IV. Of course it is not surprising that non-verbal encoding was more frequent in task IV than in tasks I and III. After all, task IV was the only task in which someone was actually present to see it. ${ }^{10}$

In chapter 7 it has already been indicated that non-verbal encoding can take various forms. The most common form in the Nijmegen data was the use of gestures to indicate the shape, the size or some other characteristic of the intended concept (see example 21), but pointing to, or touching the intended concept, or the enacting of it also occurred (see examples 22 to 24):

(21) S: well uh, w erm we now we are, erm, uh ja, I don't know how to say that, golfs, golven

I: no, I don'l know that

S: ja it's uh, on the sea 1 waves, waves <indicates the shape and the movement of a wave with his hand (wave; 210t4)

(22) S: and, uh, kast, ja uh, hoe zeg je dat <whispers>

I: what's that?

S: ja, it's a thing like that <points at the cupboard> (cupboard; 305t4)

(23) S: ... and erm, I've a great uh box uh with uh beams

I: beams?

S: erm 1 those uh 1 little <touches the beads in her earrings>

I: oh the beads ja (beads; 213t4)

(24) S: ... and erm 1 uh she he (= a bird) begun to uh, to fluiten to fff to Muiten so <whistles> ja he <laughs> (whistle; 306t4)

To conclude, one can say that the discussion of the use of CpS in task IV brought up three major points. Firstly, it was observed that the subject and the interlocutor both worked towards reaching an adequate, if not always correct, solution for the lexical problems they encountered. Secondly, the task IV data confirmed the observation made in connection with task III that the subjects were not more specific than necessary. In particular, it was suggested that the possibility of obtaining immediate feedback led to the use of less specific CpS which were repaired or supplemented by other CpS only if they were not understood. And thirdly, there appeared to be some task-related variation in the realization of $\mathrm{CpS}$.

\subsubsection{Individual differences}

So far, most of the evidence presented in this chapter supported the idea that $\mathrm{CpS}$ use is predominantly task-related. One should be careful, though, not to infer from this that 'task' is the only influential factor. Individual factors play a role too. 
An example of this has already been given in section 8.2.1 where the number of properties contained in the references in task I was shown to vary considerably over subjects. The subjects also differed in other respects such as the amount of time they needed to carry out the tasks, the number of lexical problems they attempted to solve, and the use of certain CpS types, particularly LITRA.

In this section part of the data of two subjects will be discussed in detail to bring out some of the individual differences in the subjects' strategic behaviour. The subjects were chosen out of an initial group of 12 subjects who, in comparison with other subjects, had been either extremely fast or rather slow on the first Dutch version of task II (the abstract figure description task). It was assumed that this group of 12 subjects would include at least two kinds of problem solvers which one might characterize as 'impulsive' and 'reflective' (cf. Brown, 1973; 1987: 84ff. for a discussion of these and other cognitive styles).

The first subject (308) whose data will be discussed here strikes one as a highly reflective person. Consider some of her task I data:

(25) erm 2 with, uh, this, thing, uh babies can drink, erm their milk 2 erm, or something else (teat; 308t1)

(26) erm, 11 erm 6 you can see, with 1 uh, this, thing, if, nou, nee dat kan je niet zo zeggen 8 nou ja, toch (no you cannot say that in this way 8 well I suppose you can, after all) if uh 1 something is 1 nou, nou ja, straight ik weet niet of dat goed is maar ja (I don't know whether that is correct) but yes (spirit-level; 308tl)

(27) erm 5 you can walk on 1 uh, with, uh, these things, uh, children, uh, often play with it (stilts; 308t1)

(28) erm 2 on, this, thing they, put erm, glasses, in restaurants or 1 cafés? 1 (beermat; $308 \mathrm{t} 1$ )

(29) erm 12 you can 1 uh roll, things with this, ik weet 't niet (I don't know) (rolling-pin; 308t1)

(30) 5 you can ring a clock with this (clapper; 308t1)

(31) S: 1 erm 6 hier kan ik niks over zeggen (I can't say anything about this)

E: ja, proberen! (yes, try!)

S: erm 4 you can put, erm, dirt on it <laughs> weet ik veel (how should I know) (duspan; 308t1)

As these examples show, 308 prefers to think before she starts speaking. Almost all of her descriptions are preceded by a long pause. Once she has started, she usually proceeds without too many problems, although she does speak rather hesitantly. The number of mistakes produced by this subject is remarkably low, certainly in comparison with her class-mates. The only grammatical error occurs when she refers to 'stilts' as "it". The fact that she takes so much time to plan, and probably monitor her speech, may explain the absence of many errors. In spite of her grammatical accuracy, however, the subject is extremely 
unsure of herself. She frequently indicates that she does not know whether what she said is correct, or expresses her doubts by a rising intonation (cf. cafés?). It is probably these same feelings of insecurity that initially keep her from describing a dustpan. Apparently, this subject prefers giving up to making a mistake.

The following extract is taken from her interview:

I: ... where d'you live?

S: here, in Nijmegen <laughs>

I: in the city?

S: uh, no not erm, in the city erm 1 erm 8

I: further outside

suburb: anco (1def)

S: ja

I: is it a nice area?

S: yes it's a nice area it's beautiful

I: is it, why?

S: erm, you have erm 1 the wood

I: oh

S: erm 3 nja <laughs>

I: it's an old part is it?

S: what do you say?

I: it's an old part of Nijmegen?

S: yes

I: $\mathrm{mm}$

S: oh no no wait erm 1 in the middle of the city is the old part but uh 2 where we live is erm 2 erm only 1 ten years old or so

I: oh, so it's a new part?

S: yes a new part

I: $\mathrm{mm}$, and where do you live there?

S: 1 erm 2 uh 2

I: is it in a street with other houses or?

S: oh yes erm 1 uh, it's uh on a street with other houses and uh, we live on erm $1 \mathrm{erm}$ 4 <laughs>

I: try

S: yes I know the word but I can't erm 4 freeway

I: oh ja, ja

S: uh 2 oh <laughs $>$ and uh 2 erm 4

I: what kind of a house is it? (308t4)

The first thing that strikes one when reading this extract is that nearly all of the subject's answers are very short. There are only two turns which exceed the one-line limit she seems to have set herself. The first of these is to clear up a misunderstanding about the meaning of city. The second is for the greater part a repetition of the interviewer's question: "it's on a street with other houses". There are numerous other instances in which the subject repeated the 
interviewer's question (I: in the city? S: no not in the city; I: is it a nice area? S: yes it's a nice area; I: so, it's a new part? S: yes a new part). Obviously, this is a very safe way of keeping the communication going without making mistakes. At the same time it gives the subject time to plan the rest of her answer. Not that she was very successful in this respect: the rest of the subject's answer generally consists of uhs and erms, with silent pauses in between, and an occasional laugh marking the subject's uncertainty. Usually, this was enough to oblige the interviewer to take the next tum.

As in task I, the subject's language is hesitant, but grammatically correct. Lexically, however, it is poor. The only uncommon word she uses is "freeway", and even of this word she does not seem to be sure. Other infrequent words are avoided. The only CpS in this extract, pointed out by the subject in the retrospective session, was "not erm, in the city" for 'suburb'. The complete interview contains only 11 clear cases of $\mathrm{CpS}$, which is far below the average number of $29 \mathrm{CpS}$ used by 3-VWO pupils in task IV.

Let us now tum to subject 301, who can be characterized as an impulsive person. Unlike 308, this subject does not seem to bother about grammatical correctness. She speaks fast with few, short, pauses and is not afraid to use CpS when necessary. The following examples are taken from her task I data:

(32) erm, an uh 1 a thing where you where uh, you can uh 1 measure something (measuring-tape; $301 \mathrm{t} 1$ )

(33) erm 1 a thing where uh, where you can uh, erm, dead some uh, insects (flyswat; 301t1)

(34) a band from the, uh watch (watch-strap; 301t1)

(35) $2 \mathrm{erm}$, an uh a spoon for uh /jes/for your uh shoes (shoehom; 301t1)

(36) uh a thing for, uh little ch/ai/dren for uh, for uh dinner (bib; 301t1)

(37) a thing for uh $3 \mathrm{~mm}$, for coals uh, ja <laughs> to uh do in (coalscuttle; 301t1)

(38) erm 1 a thing uh, what you can find on the, strand, on the beach, em 1 in the form of a, a star (starfish; 301t1)

(39) erm, a thing where uh, what can help you with uh telling, uh things (abacus; 30111)

(40) uh 1 uh the thing where uh coffee and tea uh can come out, from uh, a pot (spout; 301t1)

As with subject 308 , the descriptions which this subject gives are not very long. She generally mentions just one or two of the referents' properties. Apart from this there are few similarities, though. The pauses which occur at the beginning of the description tend to be short rather than long. Usually, there is another brief pause just after the first phrase, but on the whole the subject proceeds fast. She frequently transfers words from Dutch: "a band" (Du: horlogebandje), a "spoon for shoes" (Du: schoenlepel = spoon), "coals" (Du: kolen), "strand" (Du: strand = beach), "telling" (Du: tellen = to count). Some of these words 
happened to be correct, e.g. "coals", but were considered $\mathrm{CpS}$ because they met all the criteria specified in the working definition. Others, such as "band", "strand" and "telling" were obviously used without the subject being aware of a lexical problem and for this reason were discarded as CpS. Apart from these lexical deviations, the subject makes a large number of grammatical mistakes. Thus, she uses "a thing where" instead of 'with which', "a band from the watch" instead of 'of the watch', "a thing for coals, to do in" instead of 'a thing to put coals in', and "a thing what" instead of 'a thing which'.

Subject 301 's behaviour in the interview task is quite different from 308's too. Here is an illustrative extract in which she explains two card games:

I: do you ever play games at home in the evenings?

S: uh nou, not always, sometimes in holidays, we uh play uh mono, monopoly

I: ja monopoly: litra

S: do you know? or, uh ja, some other dings, things

I: card-games?

S: ja sometimes with my grandma, she likes that

I: what do you play?

$S:$ erm 1 ja, jokeren

I: how's that?

S: ja

I: how does that go?

S: ja you must have uh some, thirteen cards, and then you must have uh forty points

I: and how do you get the points?

S: ja you uh, ja, you can get some uh, cards from the table, what another one has uh jumped in there 1 ja that's uh, difficult to say but

I: no I play games similar to that but I we don't erm, have to get forty points

S: ah

I: so I don't know how you how you must get the forty points

S: na ja, uh, kij uh you, uh, ja, you uh put some wh, uh cards here

I: $\mathbf{m m}$

S: and I /mai/ pack him, or another card

I: $\mathrm{mm}$

S: I'm may take him

I: $\mathrm{mm}$

S: I can ook take an uh, an other card $2 \mathrm{erm}$, ja who's turning on his back 1 that I can't see uh

I: oh ja

explain: hoco (1a)

"jokeren": litra

S: ja

I: ja

off the pile: anco (1def) 
S: ja but that's uh, ja, not so very nice but my grandmother liked it, but Canasta, do you know that?

I: I know the name but I don't know how to play it

$S$ : oh, now that's very uh nice ook, l've learn it on a holiday from uh other peoples

I: oh

S: ja

I: and, do you have to use a board, to keep score? no?

$S$ : joa that's uh ja, ja, ja you can uh, take it in your mind but 1 that's too much

I: ja

S: $\mathbf{m m}$

I: I don't know that

S: no ja that's, too difficult to say but, uh, now it is very nice ja

I: try and tell me, or would you rather not?

S: uh, ja, na you must have uh 1 ja you, you take some cards and then you uh, ja you /tre:/ try to uh, erm have some cards on uh, bijvoorbeeld one two uh of nee two three and four, or five six and seven of zo, ja?

I: ja

S: ja and you can put that on the table, so and dan uh the points you have made, they are/tai/die are uh, ja, when you are the most have the most most points, you have win

I: $\mathbf{m m}$

S: but you can make uh Canasta, that's, then you have seven the same cards

I: in a row?

S: uh, oh wait, no I've tell it wrong, uh you must have uh, seven seven seven, or two two two

I: okay

S: three uh different cards, ja? and then when you have, uh bijvoorbeeld seven uh, cards from uh, two

I: $\mathrm{mm}$

S: then you have an uh Canasta

I: but you can't have seven cards, you play with, how many decks?

S: uh two, nee two, uh two play, two play uh cards

I: ja

S: ja, so you have uh, uh eight, uh eight, twos have you

I: ja ja

S: so and uh when you have seven then you have, five honderd /pau/ points or something, ja I don't know exactly but

I: and can two play this game?

S: ja or more

remember: anco (1def) 
I: $\mathbf{m m}$

S: but two that's uh, not so nice with more is going better

I: ja

S: ja (301t4)

Clearly, this subject is much more talkative than 308 . When asked, she goes into lengthy and detailed explanations of the two games, which is certainly not easy for her. Still, she carries on enthusiastically, which makes her speech look fluent. The conversation is spontaneous: the subject and the interviewer seem to be on an equal footing and there is a genuine exchange of information, which is brought out poignantly when the subject says "oh wait, no I've tell it wrong". In other parts of this interview the subject and the interviewer changed roles and the subject started asking questions. This happened in very few of the other interviews.

It will be noted though that, in spite of being fluent and natural, the interview unmistakably involves a non-native speaker. The extract is full of errors, both grammatical and lexical. It is also interspersed with little Dutch words such as "ook" (also), "ja" (yes), "bijvoorbeeld" (for example), "of nee" (or no) and "of zo" (or something like that). Since these words are probably used unconsciously, they can be explained as 'slips' (Færch \& Kasper, 1983c:211). They occur particularly often when the subject is most involved in her explanations. On other occasions she secms to use the first English word that comes to her mind, as if she cannot be bothered to retrieve the right one or use a CpS for it. Examples of this are "points" (the score), "jumped" (thrown in) and "pack" for which she later uses the more appropriate word "take". In yet other cases she uses the Dutch words "monopoly"11 (with an English pronunciation) and "jokeren". These last two cases were identified as CpS and classified as transfer strategies.

The comparison of subjects 308 and 301 reveals a number of individual differences. Subject 308, who makes the impression of being highly reflective, shows great concem for grammatical accuracy. She is inclined to avoid lexical problems and uses few $\mathrm{CpS}$ to solve them. In particular she refrains from using transfer strategies as much as possible. Conversely, subject 301, who seems to be quite an impulsive person, focusses predominantly on the contents of her message. She uses $\mathrm{CpS}$ whenever the communicative situation demands that she should solve her lexical problems and many of these are transfer strategies. All in all, subject 301's speech makes a much more fluent impression than subject 308 's, although it is undoubtedly much more faulty.

The subjects whose data have been discussed here represent two extremes. There were other subjects who tried to be correct and aimed at reaching full understanding at the same time. Subject 312 is a good example of this. Her 
speech is hesitant, grammatically correct as well as quite informative. There were also subjects who behaved quite differently over the three tasks. Subject 101, for instance, who was exceptionally explicit in task I (cf. section 8.2.1), behaved 'normally' in tasks III and IV. Similarly, subject 108, who appeared to be what one might call a 'reflective' or 'monitoring' person in task I, was very fluent in task IV in which she did not hesitate to use CpS at all. These examples suggest that the subjects' behaviour is only partly determined by their cognitive styles, and that partly, also, the subjects adapted their behaviour to the task at hand. ${ }^{12}$

\subsection{Discussion}

The quantitative analyses of the data reported in section 8.1 led to the following conclusions:

a) the number of $\mathrm{CpS}$ used is inversely related to the subject's proficiency level;

b) the type of $\mathrm{CpS}$ used is largely determined by the task;

c) there are some proficiency-related differences in the type of $\mathrm{CpS}$ used;

d) many of the effects observed for superordinate $\mathrm{CpS}$ disappear in the case of subordinate $\mathrm{CpS}$.

In addition, the qualitative discussion of the data in section 8.2 revealed:

e) that there are some proficiency-related differences in the realization of CpS, notably with respect to the number of properties mentioned in the analytic strategies used to refer to concrete objects in task I;

f) that there are many task-related differences in the realization of $\mathrm{CpS}$, notably in the length of analytic strategies, the encoding of transfer strategies and the use of non-verbal means of encoding;

g) that there are individual differences in the use of $\mathrm{CpS}$ depending at least partly on the learner's cognitive style.

In this section an attempt will be made to account for these findings. The discussion will be divided into four parts. Section 8.3.1 will deal with proficiency-related effects, while in section 8.3.2 an explanation will be offered for the large role played by the factor 'task'. Both the effects on the choice of CpS types and on the realization of $\mathrm{CpS}$ will be dealt with. In section 8.3.3 an attempt will be made to account for the reduced effects of both 'task' and 'proficiency level' in the case of subordinate $\mathrm{CpS}$. And finally, some comments will be made on the importance of individual differences in $\mathrm{CpS}$ use. 


\subsubsection{Proficiency-level effects}

The most obvious proficiency-level effect observed in the Nijmegen project concerned the inverse relationship between the absolute number of $\mathrm{CpS}$ used and the subject's proficiency level. The less proficient subjects (VWO pupils) produced a higher number of $\mathrm{CpS}$ than those who were more proficient (university students). This result, which is clearly not very spectacular, can be explained as a direct consequence of the VWO pupils' more limited command of the $L 2$ vocabulary. They encounter more lexical problems and therefore need to resort to $\mathrm{CpS}$ more often. The lack of many significant differences in the number of CpS used by 3-VWO and 5-VWO pupils is noteworthy. Despite differences in proficiency these two groups resorted to $\mathrm{CpS}$ equally often. A possible explanation for this is that the 5-VWO pupils may have set their communicative goals higher than the 3-VWO pupils. If they tried to produce more language, as well as more informative language, their need to use CpS may have increased as a result of this. Considering that in task I 5-VWO pupils mentioned significantly more of the referents' properties than 3-VWO pupils such an explanation is quite plausible.

There were also some proficiency-related effects with respect to the type of $\mathrm{CpS}$ used. They concerned the greater use of superordinate HOCO by university students in tasks III and IV, and the larger use of LITRA by VWO pupils in task III for superordinate $\mathrm{CpS}$ and in all tasks for subordinate $\mathrm{CpS}$. The most plausible explanation for the differences in the use of HOCO is that leamers of a lower proficiency level do not have a sufficiently large L2 vocabulary at their disposal to come up with suitable approximations. The larger use of LITRA by low proficiency subjects confirms the hypothesis formulated in section 2.2 on the basis of the research described there. Because of their more limited command of the L2 the less proficient subjects have to resort to the $\mathrm{L} 1$ more often. In view of this it is remarkable that there are not more proficiency-related differences in the use of LITRA in task IV (the interview). In this task all three proficiency groups used superordinate LITRA in approximately $20 \%$ of the cases where they resorted to CpS use. One would have expected high-proficiency subjects to use less LITRA in this task, since, at their level, there should be no need to make use of the L1. A possible explanation for this finding is that the task effects to be discussed in the next section were so powerful that they overruled some of the proficiency-related effects that might have occurred.

With respect to the realization of $\mathrm{CpS}$ there were remarkably few proficiency-related differences. The only difference observed at this level related to the number of properties mentioned in the subjects' references to concrete objects in task I (Verouden, 1987). In other respects, however, the realization of $\mathrm{CpS}$ was not proficiency-related. Proportionally, the encoding of LITRA as 'Foreignizing', 'Borrowing' or 'Literal Translation' did not differ 
between the three proficiency groups, nor were there any striking differences in the relative use of non-verbal means.

A possible explanation for the lack of more proficiency-related differences is that the subjects' proficiency levels were relatively high. It is conceivable that all of the subjects had already attained the minimum proficiency level required for efficient $\mathrm{CpS}$ use, and that therefore they were all able to use those $\mathrm{CpS}$ which they considered to be most appropriate. This explanation has become the more plausible, since there now is some evidence that subjects who have been leaming English for six months only use considerably more transfer strategies in the story retell task than the subjects who participated in the Nijmegen project (Van den Broek, 1988). ${ }^{13}$ This suggests that $\mathrm{CpS}$ use is much more strongly affected by the speaker's proficiency-level, until a certain minimum level of proficiency has been reached (cf. also Bialystok. 1983:115 for a discussion of the 'threshold paradigm'). ${ }^{14}$

\subsubsection{Task effects}

One of the major conclusions arrived at in sections 8.1 and 8.2 is that CpS use is largely task-related. Whereas in task I (picture description) the subjects predominantly used long, informative, but time-consuming analytic strategies, they also used a substantial number of short, often less informative, holistic strategies and transfer strategies in task III and particularly in task IV. It should be noted, however, that what seem to be task effects may in reality be item effects. It may, for instance, be easier to list properties for the concrete objects in task I than for some of the rather abstract concepts occurring in tasks III and IV.

To unravel any possible confusion between task and item effects the CpS used to refer to concrete objects in task IV were compared to those used in task I. The comparison included $884 \mathrm{CpS}$ in task I and $214 \mathrm{CpS}$ in task IV. All task IV CpS related to concrete objects of which clear photos could be taken. In this way the comparability of the items in tasks I and IV could be guaranteed. The results of the comparison are given in table 8.11.

Table 8.11 A comparison of the CpS types used for concrete objects in tasks I and IV and for all concepts in task IV (superordinate CpS only)

\begin{tabular}{|c|c|c|c|c|c|c|}
\hline \multicolumn{3}{|c|}{ task I } & \multicolumn{2}{|c|}{$\begin{array}{c}\text { task IV } \\
\text { (concrete objects) }\end{array}$} & \multicolumn{2}{|c|}{$\begin{array}{c}\text { task IV } \\
\text { (all concepts) }\end{array}$} \\
\hline ANCO & 866 & $98.0 \%$ & 91 & $42.5 \%$ & 455 & $49.4 \%$ \\
\hline HOCO & 5 & $0.6 \%$ & 58 & $27.1 \%$ & 264 & $28.7 \%$ \\
\hline LIMO & 2 & $0.2 \%$ & - & - & 5 & $0.5 \%$ \\
\hline LITRA & 11 & $1.3 \%$ & 65 & $30.4 \%$ & 197 & $21.4 \%$ \\
\hline Total: & 884 & & 214 & & 921 & \\
\hline
\end{tabular}


From table 8.11 it immediately follows that the distribution of $\mathrm{CpS}$ types in task IV is markedly different from that in task I even if one considers CpS for concrete objects only. Thus, it can be concluded that 'task' is an important factor determining $\mathrm{CpS}$ use. However, a comparison of the $\mathrm{CpS}$ used for concrete objects in task IV with those used for all concepts in task IV reveals that the proportion of LITRA is larger in the case of concrete objects. This suggests that in addition to the observed task effects there are certain item effects.

For the explanation of the task-related variation in $\mathrm{CpS}$ use it is useful to retum to chapter 4 where several communication factors were discussed which were expected to affect $\mathrm{CpS}$ use too.

Two of the factors considered in chapter 4 were Grice's cooperative principle and the economy principle which is entailed by it. Together these principles require speakers to produce intelligible messages on the one hand, and to minimize both their own and their listeners' processing effort on the other hand. With respect to CpS use the principles predict that speakers who are confronted with lexical problems will try to solve these problems, and thus achieve their communicative goals, by adopting those $\mathrm{CpS}$ which require minimal effort. However, it was also predicted that speakers will lower their communicative goals when they consider the amount of effort to be expended disproportionate to its expected effect. In this way speakers can maintain the balance between 'effort' and 'effect'.

In this thesis CpS which enable speakers to achieve their communicative goals will be referred to as effective $\mathrm{CpS}$. Whether a $\mathrm{CpS}$ is effective or not largely depends on mutual knowledge. Firstly, $\mathrm{CpS}$ are generally effective if the conceptual or linguistic knowledge on which they are based is mutually known. Thus, the CpS in examples (41) and (42) are effective provided the speaker and the listener both know that humming-tops are toys which tum round and make music when you push on them (example 41) and share knowledge of the Latin-based word 'aquarium' (example 42):

(41) 14 a toy $\mathrm{f}$ for $\mathrm{k}$ uh for small tsj children when they push on it 1 uh, the body starts, circling round very fast and is going to make music or all kinds of noises <coughs $>$ from within (humming-top; 111t1)

(42) I: and have you fish too?

S: yes, one aquarium <Dutch pronunciation $>$ (aquarium; 302t4)

CpS may also be effective, however, when they are used in contexts which are so informative that they enable the listener to interpret them correctly imespective of what one might call their 'internal effectiveness'. In these cases, the speaker and the listener presumably exploit their mutual knowledge of the linguistic and/or physical context. Thus, the CpS "animal" in example (43) is 
probably effective if the speaker and the listener are both looking at a picture on which there are no other animals besides a rabbit:

(43) one day 1 erm 1 his his door was opened by erm 2 erm $6<$ laughs $>12$ uh $2 \mathrm{erm}$ $39 \mathrm{gghh}$, there was /iz/ there was, he <laughs> erm 9 one day, the door 1 of erm $1 \mathrm{erm}$, the /sevar/ house is opened by an animal (rabbit; 21313)

In chapter 10 it will be demonstrated that analytic strategies in which many of the intended referents' properties are mentioned are generally effective under all circumstances. Conversely, holistic strategies are only effective when they are embedded within an informative context, while transfer strategies may be effective either when they are embedded in an informative context or when they are based on shared linguistic knowledge.

It is more difficult to determine which $\mathrm{CpS}$ require most effort (cf. McCawley, 1978; Gazdar \& Good, 1982). Like McCawley (1978:246) we will assume that expressions (and $\mathrm{CpS}$ ) which are "more complex in surface syntactic structure, as well as containing more phonological material" involve more processing effort. Thus, lengthy analytic strategies which list many of the referents' properties will be considered more effort-demanding than holistic strategies and linguistic CpS since these are usually short and structurally simple. That the production of analytic strategies takes more effort than the production of holistic strategies and transfer strategies is also suggested by Levelt's model of communication (chapter 4). For analytic strategies the speaker has to construct an entirely new preverbal message which implies that the conceptualizer is involved a second, and perhaps even a third or fourth time. Presumably then, the use of ANCO complicates the communication process and increases the effort to be invested in it. Levelt's model also suggests that the use of HOCO might be more effort-demanding than the use of LITRA. This is because holistic strategies require the speaker to select an alternative concept which shares a sufficient number of the originally intended concept's criterial properties. In the case of transfer strategies the process requires just a minor change to be made in the preverbal message: only the specification conceming the language of encoding is altered.

It seems then that there is only one $\mathrm{CpS}$ type,LITRA, which can be effective and requires little effort, but this $\mathrm{CpS}$, it has been said, is only effective if there is shared linguistic knowledge or if it is embedded in a context from which shared knowledge can be derived. Analytic strategies, as we have seen, are generally effective, but require relatively much effort, while holistic strategies, which require less effort, tend to be effective only if there is a supportive context. Consequently, the speaker who finds himself in a situation where transfer strategies are unlikely to be effective will have to choose between being effective and expending little effort. This choice will first of all depend on the speaker's goals, and the importance he attaches to reaching them. To a large 
extent, however, it will also be based on the available amount of time. The less time there is, the less effort the speaker will be able to expend.

Let us now consider in what ways tasks I, III and IV differed from each other, how this may have affected the operation of the cooperative principle and the economy principle, and how this, in tum, may explain the variation in the use of $\mathrm{CpS}$ in these tasks.

Firstly, there were differences in the task demands. The instructions for task I, the picture description task, required the subjects to solve all lexical problems (posed by the photographs). In tasks III and IV, however, it was possible to leave some problems unresolved and yet successfully complete the task as a whole. Thus, the tasks differed in the extent to which they allowed the subjects to 'satisfice' (i.e lower their aspiration levels). Particularly in task IV, the interview, the subjects could decide to risk misunderstanding on the part of the interlocutor if they judged a message to be of little relevance. Conversely, task I required all $\mathrm{CpS}$ to be effective.

Secondly, the tasks differed in complexity. In task I, the speaker merely had to refer to a familiar concept, and in most cases could do so by adopting one and the same syntactic structure. Task III was much more complex. It imposed a memory problem, and, in addition, required the subjects to pay attention to the syntactic structure of the sentences as well as the structure of the story as a whole. Task IV, finally, was most complex, since it required the subjects to plan both what they would say and how they would say it. Moreover, they had to pay attention to the contributions made by the interlocutor and adapt their own contributions accordingly. As a result of the greater complexity of tasks III and IV, these tasks can be expected to pose greater processing demands.

The differences in the complexity of the three tasks were further enhanced by the fact that the tasks differed in the extent to which time constituted a constraint. In task I there were no time constraints at all. The subjects could spend as much time on their references to the concrete objects on the photographs as they wanted. Strictly speaking, there were no time constraints in tasks III and IV either. However, after having carried out task III, some subjects reported that they had abstained from using elaborate $\mathrm{CpS}$ for recurring problems because they felt it was awkward to keep repeating the same lengthy utterances. ${ }^{15}$ In task IV conversational nules may have presented a time constraint. As Beattie (1980) reports, pauses longer than 5 or 6 seconds may cause the speaker to lose his tum. Thus, whereas in task I the subjects could spend as much time on their $\mathrm{CpS}$ as they thought fit, discourse constraints probably kept them from doing so in tasks III and IV. This then, is the third aspect in which the tasks differed.

Fourthly, the tasks differed in the opportunity they provided to make use of the context. In task I this opportunity was practically nil. The problems were not embedded within a context, since the photographs were presented in 
isolation. But in tasks III and IV the stories and the interview did provide contextual information. As a consequence, the speakers had to make sure that the CpS in task I were 'intrinsically effective', while in tasks III and IV they could rely on the context to contribute to the interpretation of $\mathrm{CpS}$ that might otherwise be unintelligible.

And finally, there was no interlocutor present in tasks I and III, while in task IV there was. The possibility of obtaining immediate feedback in task IV enabled the subjects to check whether a $\mathrm{CpS}$ had been sufficiently well understood. This means that it was not necessary for them to be absolutely sure of the effectiveness of their CpS. If a certain CpS turned out to be incomprehensible the subjects still had the chance to use another one.

Considering that analytic strategies are generally effective, certainly when many properties are mentioned, but also very time-consuming, it is not surprising that this $\mathrm{CpS}$ type abounds in task $\mathrm{I}$, which required effective $\mathrm{CpS}$, but did not impose any time constraints. The use of ANCO in this task may have been further increased by the fact that there was no interlocutor present. Not being able to obtain feedback, the subjects may have 'overcompensated' to make sure that their $\mathrm{CpS}$ were understood (cf. Krauss \& Weinheimer, 1966, for a similar effect of the absence of feedback).

The large number of subordinate CpS used in task $I$ is obviously related to the large number of analytic strategies in this task, since analytic strategies frequently give rise to new lexical problems. Moreover, the need to use effective $\mathrm{CpS}$ and the lack of time constraints have probably also contributed to the subjects' inclination to use many subordinate $\mathrm{CpS}$ in task I.

Since HOCO is a CpS that tends to be less effective, unless there is supportive contextual information, while LITRA is only effective if there is shared linguistic knowledge or a supportive context, these CpS types are less appropriate in task I. In tasks III and IV, however, they could be used successfully because these tasks do not demand all $\mathrm{CpS}$ to be perfectly comprehensible.

A second explanation for the large use of HOCO and LITRA in task IV is that this task allows the speakers to check whether comprehension has occurred. By using a holistic strategy or a transfer strategy that turned out to be effective the subjects could save themselves a great deal of processing effort. Of course, the use of ineffective holistic strategies and transfer strategies would be a waste of (little) effort, but such CpS can still be repaired, so that in any case the subjects would not run the risk of not reaching their communicative goals. As a matter of fact, many of the holistic strategies and transfer strategies used in task IV tumed out to be comprehensible. Only 3\% of the holistic strategies and $36 \%$ of the transfer strategies used elicited either a comprehension check or a request for clarification. This too may have induced the subjects to use such $\mathrm{CpS}$ more often. 
Another possible reason for the increased use of HOCO and LITRA in tasks III and IV is that these $\mathrm{CpS}$ types require relatively little processing effort. This makes them into easy, if not always effective, solutions in situations where time is limited, and particularly in complex tasks, where there is little attention to spare. The time constraint and the cognitive complexity of the task may also explain the large number of transfer strategies realized as 'Borrowing' in task IV. 'Borrowing', which probably requires the least processing effort of all $\mathrm{CpS}$, may have been used as a last resort $\mathrm{CpS}$ by all subjects when they felt pressed for time and/or were unable to attend to more suitable $\mathrm{CpS}$.

It seems then, that most of the task-related variation in $\mathrm{CpS}$ use can be explained in terms of the combined operation of the cooperative principle and the principle of economy. If necessary, the subjects expended much effort on the use of effective CpS (task I), but in those cases where the context made it less important for the CpS themselves to be effective, or where the solution of lexical problems was not particularly relevant or too much time- and effort-consuming (tasks III and IV), they frequently opted for CpS that might be less effective, but demanded less processing effort.

\subsubsection{Differences between super- and subordinate compensatory strategies}

Both task and proficiency effects proved to be stronger for superordinate than for subordinate $\mathrm{CpS}$. For task effects in particular the differences were striking. As figures 8.1 and 8.2 showed, the distribution of subordinate CpS was considerably less task-related than the distribution of superordinate CpS.

The differences between super- and subordinate $\mathrm{CpS}$ can be explained if one considers the fact that subordinate $\mathrm{CpS}$ are, by definition, always embedded within the context of a superordinate CpS. This particular position of subordinate $\mathrm{CpS}$ has certain consequences. Firstly, it suggests that there is relatively little need for subordinate $\mathrm{CpS}$ to be 'intrinsically effective'. After all, the linguistic context of the superordinate $\mathrm{CpS}$ provides some information too, for which reason subordinate $\mathrm{CpS}$ may be effective in any case. Secondly, it means that subordinate $\mathrm{CpS}$ must not be too complex, since the superordinate strategy itself has already complicated the communication process, so that there is little processing capacity to spare. As a consequence, the speaker will be inclined to opt for least effort $\mathrm{CpS}$ rather than effective ones (unless, of course, the two can be combined). This may explain why HOCO and LITRA, which typically demand little effort, but are not necessarily effective, occurred frequently as subordinate $\mathrm{CpS}$ in all three tasks, including task $I$. 


\subsubsection{Individual differences}

In section 8.2.4 a number of individual differences in the subjects' use of CpS were discussed. It appeared that a learner's cognitive style affected their L2 performance, including his use of $\mathrm{CpS}$. One subject, who could be characterized as a reflective person with great concern for grammatical correctness, used relatively few CpS and seemed to avoid the use of LITRA in particular. Another subject, who was much more impulsive, seemed to focus on the comprehensibility of her messages rather than their correctness, and she appeared to be using all CpS types frequently and without hesitation.

It is worth emphasizing here that the presence of individual differences in $\mathrm{CpS}$ use is of considerable importance. It goes to show that 'task' is not the only factor to determine $\mathrm{CpS}$ use and consequently that not all of the variation in CpS use can be accounted for by task-related factors. In particular, it should be noted that the choice between a CpS that is most likely to be effective and one that requires minimal effort may be strongly influenced by the subject's cognitive style (and/or his personality). Some subjects may simply be inclined to take more risks than others (Corder, 1978), while the urge to satisfice may also be a person-related matter. Since the subjects who participated in the Nijmegen project were selected on the basis of their L2 proficiency (see chapter 5), and not on the basis of other leamer-characteristics, it was not possible. however, to examine the relationship between CpS use and cognitive style or personality systematically.

A further complicating factor in this respect is that the subjects did not always behave consistently. Some subjects who appeared to be reflective and grammar-minded in task I could be characterized as impulsive persons in task IV, in which they seemed to be concemed about nothing except the communication of their messages. These differences are probably due to the different demands posed by tasks I and IV. It will be obvious that communication is much more important in an oral interview than in a picture description task. Moreover, the interview situation left the subjects little time to consider the grammatical correctness of their utterances and, almost naturally, caused them to focus on their fluency. It seems then, that the most important conclusion to be drawn from the individual differences discussed in this chapter is that a comprehensive account of $\mathrm{CpS}$ use will need to take both the 'task' factor and the leamer's cognitive style and personality into consideration.

\subsection{Conclusion}

Not surprisingly, the results of the Nijmegen project, presented in sections 8.1 and 8.2, confirmed the first hypothesis formulated in section 2.2 that leamers 
at a lower L2 proficiency level use more CpS than leamers at a higher $\mathrm{L} 2$ proficiency level. The second hypothesis, that leamers at a lower L2 proficiency level use (proportionally) more strategies which are based on their L1 than leamers at a higher L2 proficiency level, was only partly confirmed, however. Whereas for subordinate $\mathrm{CpS}$ the most proficient group of subjects did indeed use less LITRA than the two other groups, for superordinate CpS this was the case in task III (the story retell task) only. In tasks I and IV all three proficiency groups used LITRA equally often.

Task-related factors proved to be much more dominant with respect to the choice of $\mathrm{CpS}$. The subjects predominantly used elaborate analytic strategies in task I, while in task III, and particularly in task IV, they also used many short holistic strategies and transfer strategies. However, most of these task-related differences only occurred with superordinate $\mathrm{CpS}$. For subordinate $\mathrm{CpS}$ the distribution of $\mathrm{CpS}$ types was more or less even across the three tasks.

The task-related variation in the use of $\mathrm{CpS}$ was discussed in terms of the cooperative principle and the principle of economy, the degree of mutual knowledge and the presence or absence of a time constraint. The cooperative principle and the principle of economy entailed in it induced the subjects to use effective CpS when necessary (task I) and to use CpS that require minimal processing effort when possible (tasks III and IV). It was argued that what is necessary depends largely on the task demands and the context, while what is possible depends on the knowledge shared with the interlocutor and the amount of time available.

It was more difficult to account for the lack of more substantial proficiency-related differences. Two possible explanations were offered, one being that the 'proficiency level' factor is overruled by the more powerful 'task' factor, the other that the subjects who participated in the Nijmegen project were fairly advanced and had passed the stage at which differences in proficiency level manifest themselves in considerable differences in $\mathrm{CpS}$ use.

Finally, it was observed that there were individual differences in CpS use too. One subject, who focussed on grammatical accuracy, used few $\mathrm{CpS}$, and in particular seemed to avoid the use of LITRA, while another subject did not seem at all inhibited in her use of $\mathrm{CpS}$. Although learner-related factors other than 'proficiency level' could not be studied systematically in this project, these findings suggest that 'task', however important it may be, is not the only factor which affects $\mathrm{CpS}$ use.

\section{Notes to chapter 8}

1. Most of this section will also be published in Language Learning as a joint article by Poulisse \& Schils. 
2. That the number of superordinate $\mathrm{CpS}$ is largely the same in each of the three tasks is a fortunate coincidence which increases the immediate comparability of the results. The number of subordinate strategies, however, seems to be task-dependent, there being many more subordinate $\mathrm{CpS}$ in task I than in tasks III and IV.

3. These being a priori orthogonal contrasts, the maximum number of comparisons to be made is $k-1$, that is, the number of means -1 . Here, $k-1=2$, since there are three groups of subjects (Ferguson, 1981:294ff.).

4. In our oral data there are very few instances of LIMO (34, which amounts to a mere 1\%). It should be noted, however, that Zimmermann (1987) in a study of written data elicited from advanced German leamers of English by means of a translation task, quotes many errors which he classifies as form-oriented appraximations. Many of these errors closely resemble what we have called morphological 'creations' (e.g. "illucitation" for 'illustration'/'illumination' and "incitement" for 'incentive').

5. Some doubts cen be raiced with respect to the use of ANOVA for these dats, since very often the assumptions of a normal distribution and homoscedasticity are not met (Erik Schils, personal communication). For this reason it was decided to assess the 'robustness' of ANOVA in these respects by means of a 'twin-analysis' using randomization tests to determine the F-ratio's significance level (Edgington, 1987). The results of this test - which does not require either normality or homoscedasticity - were strikingly similar to those of ANOVA with the usual application of F-tables. This strongly suggests that there is no need to doubt the validity of ANOVA in this study, for which reason it was decided to present the results in terms of the more familiar ANOVA.

6. One subject (206), who experienced excessive difficulty in expressing the concept 'pleated skirt', refused to abandon the information about the pleats, because it would take away the gist of the story. After numerous pauses, some of which lasted up to 50 seconds, she finally put an end to this painful experience and altered the story into one about a rabbit inquiring after a "short dress" which it eventually says is "hard to make longer".

7. In other respects the presence of the interlocutor made the task more difficult Communication was less predictable, and solutions to lexical problems had to be given 'on-line'.

8. 1lt means that this subordinate CpS for 'sports-bicycle' could be classified either as a conceptual or as a linguistic strategy (cf. chapter 7).

9. There do not seem to be any proficiency-related differences in the realization of LITRA. In task IV, which is the only task with a reasonably large number of relevant cases, groups 1 , 2 and 3 use 14, 25 and 34 borrowings, respectively. For group 1 this amounts to 32.5\%, for group 2 to $37.3 \%$ and for group 3 to $39.1 \%$ of the total number of superordinate transfer strategies they used. Foreignizings are used 19 times by group $1(=44.2 \%), 34$ times by group $2(=50.7 \%)$ and 38 times by group $3(=56.7 \%)$. For 'Literal Translation' the numbers are 10 for group 1 (=23.2\%), 8 for group $2(=11.9 \%)$ and 15 for group $3(=17.2 \%)$.

10. Again, the use of non-verbal means in task IV does not appear to be related to the subjects' proficiency levels. Group 1 resorts to non- verbal means in $9.6 \%$ of the $\mathrm{CpS}$ used in this task, group 2 in $10.2 \%$ and group 3 in $13.4 \%$. 
11. The Dutch play their own version of monopoly which has Dutch cities and Dutch street names. Consequently, many Dutch people do not realize that the game is played in other countries as well.

12. A similar point was made by Brown (1987:85), who assumed that "differing contexts will evoke differing styles in one individual". See also Selinker \& Douglas (1985), who observe that speakers' linguistic behaviour, including their use of $\mathrm{CpS}$, differs in technical and nontechnical discourse domains.

13. The subjects in Van den Broek's (1988) study were first form pupils attending the same secondary school as the 5-VWO and 3-VWO pupils who participated in the Nijmegen project.

14. The increased use of transfer strategies by less proficient L2 leamers is by no means universal, though. In a study investigating the creation of an artificial pidgin, Van den Berg (1988) found that two Dutch leamers of Bahasa Indonesia, who knew only 172 words of this language and no grammar at all, solved virtually all of their lexical problems by means of (analytic) conceptual strategies. Although the subjects had agreed not to use Dutch, it must be assumed that the linguistic distance between Dutch and Bahasa Indonesia also kept them from using Dutch as a source of lexical transfer.

15. Apart from the fact that it was awkward and time-consuming to repeat the same lengthy $C p S$ again and again, it would not have served any purpose either. Once reference has been established, there is obviously no more need for elaborate references, as can be illustrated by the shortening of noun phrases in ongoing discourse. 


\section{A Comparison of Referential Strategies in $\mathrm{L} 1$ and $\mathrm{L}^{1}$}

In chapter 1 it was pointed out that the use of $\mathrm{CpS}$ is not restricted to $\mathrm{L} 2$ leamers. Although native speakers of a language may not resort to $\mathrm{CpS}$ as frequently as non-native speakers, there is no doubt that they make use of the same strategies, e.g. when they cannot immediately retrieve the right word, or when they explain the meaning of unknown words to children or foreigners (see chapter 1 for more examples).

In this chapter $\mathrm{L} 1$ and $\mathrm{L} 2$ referential behaviour will be compared. The aim of this comparison is to find out what, if anything, is specific to CpS use in the L2. It has already been shown in chapter 3 that there are a number of studies which suggest that there are few differences between the use of referential strategies in L1 and L2. Both Bongaerts et al. (1987) and Kellerman et al. (in press) report that native and non-native speakers of a language behave similarly when referring to abstract figures: they make use of the same set of strategies and exhibit a similar preference for holistic, or analogical, descriptions. The study to be reported here is modelled on the study by Kellerman et al. (in press), but includes subjects of different proficiency levels: some of these are much less advanced than the university students in Kellerman et al.'s study. This should make it possible to gain more insight into the effect of linguistic difficulties on $\mathrm{L} 2$ referential behaviour.

In what follows the set-up of the present study will be described and the use of an abstract figure description task will be motivated (section 9.1). Subsequently, there will be a recapitulation of the hypotheses which were formulated in chapter 3 . In addition to these hypotheses, which concem the subjects' choice of referential strategies, three hypotheses will be discussed which concem certain quantitative aspects of $L 1$ and $L 2$ referential behaviour (section 9.2). In section 9.3 the procedure which was followed to tum the protocols into analysable data will be described, while in section 9.4 the most important results of the analyses will be presented. In the last section there will be a discussion of the main findings, which will be followed by a brief general conclusion.

\subsection{Method}

The relationship between CpS use in $\mathrm{L} 1$ and $\mathrm{L} 2$ will be investigated in a comparison of the subjects' use of referential strategies in the L1 and L2 versions of task II. This task required the subjects to refer to 12 abstract figures, first in Dutch (twice) and then in English. The figures, which were taken from 
Krauss \& Weinheimer (1964), are given in appendix I. A more detailed description of task II has been given in chapter 5 .

The main reason for using an abstract figure description task is that abstract figures like those in appendix I do not have conventional names, which means that they cause identical referential problems to both L1 and L2 speakers. As Kellerman et al. (in press) showed, this allows one to collect comparable L1 and L2 data from the same group of subjects. This is an important advantage from a methodological point of view, since it means that in the comparison of L1 and L2 data one can rule out the effects of potentially interfering factors other than the language factor itself (see the discussion of Paribakht 1982; 1985; and Tarone \& Yule, 1983, in chapter 3).

A second reason for the use of task II is that the referential problems posed by abstract figures are in important ways similar to the problems for which the subjects used $\mathrm{CpS}$ in the other three tasks of the Nijmegen project. Whether referring to concrete objects or abstract figures, the subjects need to establish reference without being able to use the referents' names. This warrants the validity of the present study's conclusions with respect to the phenomenon we have defined as $\mathrm{CpS}$ in chapter 2.

Yet a third reason is that the strategies used to refer to abstract figures bear a close resemblance to 'Conceptual $\mathrm{CpS}$ ' (see chapter 4 ). The speaker who has referential problems either relates the referent to one that is similar to it or reminiscent of it (as in the case of a holistic conceptual strategy), or he mentions some of its properties or parts (as in the case of an analytic conceptual strategy). Again, this suggests that the results of the present comparison of $\mathrm{L} 1$ and $\mathrm{L} 2$ referential strategies bear on the relationship between L1 and L2 CpS use too.

\subsection{Hypotheses}

In chapter 3 three hypotheses were formulated with respect to the use of referential strategies by $L 1$ and $L 2$ speakers. They were:

1. Subjects referring to abstract figures will adopt the same referential strategies in L1 and L2, unless limited knowledge of the L2 makes it impossible for them to do so.

2. Subjects referring to abstract figures will prefer descriptions from a 'holistic' perspective to descriptions from a 'partitive' or 'linear' perspective.

3. Subjects who are unable to describe abstract figures from their preferred perspectives because of lexical difficulties will replace 'holistic' perspectives with 'partitive' or 'linear' perspectives and 'partitive' perspectives with 'linear' ones, but not vice versa. 
The first of these hypotheses rests on the assumption that $\mathrm{L} 2$ speakers will make use of the strategic competence they have developed while acquiring the L1 (unless L2 lexical problems prevent them from doing so). That strategic competence is transferable was suggested by Bongaerts et al. (1987) and Kellerman et al. (in press), who compared L2 speakers' referential behaviour to that of native speakers. In the present study we will investigate whether L2 speakers also use the same referential strategies if their knowledge of the L2 is limited. If they do not, we may, of course, still conclude that strategic competence is transferable, provided the least proficient L2 leamers are less successful in adopting the same strategies than the most proficient L2 leamers. This is because in this case we can be sure that it is the leamers' reduced command of the $\mathrm{L} 2$ which causes them to use different strategies. Only if L2 learners at different $L 2$ proficiency levels fail to adopt the same referential strategies in L1 and L2 (and fail to do so to the same extent), must we conclude that $\mathrm{L} 1$ strategic competence cannot be transferred to $\mathrm{L} 2$ situations.

The second hypothesis is also based on the studies by Bongaerts et al. (1987) and Kellerman et al. (in press). In addition, preference for descriptions from a 'holistic' perspective was reported by Krauss \& Weinheimer (1964) and Clark \& Wilkes-Gibbs (1986).

The third hypothesis, finally, goes back to Kellerman et al.'s (in press) claim that referential strategies are hierarchically ordered with respect to each other, such that not only within, but also across languages, 'holistic' perspectives are preferred to 'partitive' perspectives, which in turn are preferred to 'linear' perspectives. This hierarchical ordering of strategies is based on Kellerman et al.'s observation that subjects who are faced with lexical difficulties seldom replace descriptions from a 'partitive' or 'linear' perspective with descriptions from a 'holistic' perspective. Their explanation for this finding is that it is highly unlikely that subjects who fail to come up with a suitable analogy in the L1 version of an abstract figure description task will be able to think of one when they are confronted with lexical difficulties in the L2 version. Hence, they have no other option but to resort to a description from a less preferred ('partitive' or 'linear') perspective.

In addition to the three hypotheses discussed above, three hypotheses relating to a few more quantitative aspects of referential behaviour in $\mathrm{L} 1$ and $\mathrm{L} 2$ will be tested in this chapter. The first of these relates to the amount of time needed to carry out the two language versions of task II. In view of the fact that L2 speakers' language is typically more hesitant than that of L1 speakers, particularly when the L2 speakers are not very proficient, it can be hypothesized that:

4a. The subjects will need less time for the Dutch version of task II than for the English version; and

4b. The more proficient subjects will need less time for the English version of task II than the less proficient subjects. 
When Bongaerts et al. (1987) tested hypothesis $4 \mathrm{~b}$, they found that it was "essentially supported" (p.179). It is not clear, however, whether similar differences should be expected with respect to the number of words used. Bongaerts et al. (1987) hypothesized that the most proficient subjects would need fewer words than those who were less proficient, because their larger and more varied $L 2$ vocabulary would enable them to describe the figures in a more precise and compact manner. They found no evidence to support this hypothesis, however. Although their most proficient subjects did indeed need fewest words, the second most proficient group needed most words, while the least proficient group needed fewer words than either the second or the third most proficient groups.

These findings led Kellerman et al. (in press) to suggest that the relationship between the length of the subjects' 22 protocols (presumably including both time and number of words) and their proficiency level may be characterized by a U-shape, with the most and the least proficient subjects producing shorter descriptions than the intermediate subjects. They speculated that the most proficient subjects would exhibit native-like performance, hence produce relatively short descriptions, while in the case of minimally proficient $L 2$ speakers short descriptions might be mediated by frequent recourse to the $\mathrm{L} 1$. In the present study this assumption will be tested as hypothesis 5 .

5. In the English version of task II L2 speakers at an intermediate level of proficiency ( 5 -VWO pupils in this study) will produce longer descriptions than either more or less proficient L2 speakers.

Finally, it should be noted that no proficiency-related, or rather, group-related, differences are to be expected within the Dutch version of the task, since it can be assumed that the cognitive load of the task is the same for the three groups (see Bongaerts et al., 1987; Glucksberg et al., 1975, where it is claimed that children in their teens demonstrate adult competence levels in tasks like this). Thus, the sixth hypothesis to be tested here is:

6. There will be no group-related differences in the time or the number of words needed to carry out the Dutch version of task II.

The evidence that bears on these six hypotheses will be presented in section 9.4. First, some details conceming the scoring procedure will need to be outlined. This will be done in the next section. 


\subsection{Some procedural information}

To score the subjects' descriptions of the abstract figures the procedure outlined in Kellerman et al. (in press) was adopted. This procedure distinguishes three types of referential strategy, which manifest themselves as Descriptions from a Holistic Perspective, Descriptions from a Partitive Perspective, and Descriptions from a Linear Perspective. For ease of reference these strategy types will be referred to as 'Holistic', 'Partitive' and 'Linear Strategies'. A holistic strategy is adopted when a figure is seen as a whole rather than in terms of its constituent parts. Usually this takes the form of an analogy set up between the figure to be described and a real-world object, but the figure can also be related to a conventional geometrical shape. The following examples illustrate both types:

(1) erm, one is a sort of, saucer $1 \mathrm{erm}$, with four 2 sharp 1 erm 1 sort of star, rays, under it $(1082 ; 1)$

(2) number eleven uh 2 is a narrow triangle, uh 2 out of which uh little pieces are, cut, and it uh 1 it has rather sharp ends, ten, to be precise (105t2; a)

Very often analogies were hedged by phrases such as "it looks like" or "it's a sort of" as is the case in example (1). The examples also show that the subjects often added more specific information after the initial analogy had been set up.

A partitive strategy is adopted when a figure is viewed not as a whole, but as consisting of two or more parts. Again, this could be in the form of analogies to real-world objects or geometrical shapes, or even a combination of the two. Examples (3), (4) and (5) illustrate this:

(3) uh figure, nine, uh, is at, at the top uh, a rugby uh ball, and, on the 1 under, side 1 it uh, it likes 2 uh 3 it likes uh 10 it likes, at uh that part of the boat, that uh, uh, that, is under water $(3092 ;$ i)

(4) and, the eighth one, erm are, two triangles, which 2 which are under each other, and uh 2 and uh 1 on the 2 on the underst, triangle there are 1 two, two lines (2150; g)

(5) em 3 uh, figure uh one, uh, is a 2 uh figure that like, nee, that 3 uh 9 uh that likes of uh $3 \mathrm{erm} 3$ that likes $0 \mathrm{erm} 16 \mathrm{erm} 2 \mathrm{ja}$ uh figure one, th that likes uh 3 on the uh other nee, under, uh side 1 of erm 2 uh $3 \mathrm{erm}$, a circle 1 and, uh 3 and, at the top uh, it likes uh 2 uh, of an, uh 3 uh 1 nee and inside it likes uh 1 of an uh heart $(309 \mathrm{t} 2 ;$ d)

Finally, a subject who adopts a linear strategy breaks the figure up into its ultimate components (e.g. lines, angles, spatial relations) and describes it in terms of these. The 'Linear Strategy' is similar to the 'Partitive Strategy' in that both are 'segmental' (cf. Clark \& Wilkes- Gibbs, 1986, for the use of this term). 
The major difference between the two strategy types is that in the case of a partitive strategy the components are two- or three-dimensional and constitute analogies in themselves, whereas in the case of a linear strategy they are typically one-dimensional and do not give a conceptual interpretation of the figure as such. Rather, one could say that the 'Linear Strategy' takes the listener through the figure as it were, by giving a meticulous route description Consider the following example:

(6) erm uh, this one is, erm the top line is, uh 1 bent, erm 5 erm 2 and the, on both sides $1 \mathrm{~mm} 1$ there's a line downstairs erm 3 that is erm 3 in the middle it's, uh, in the middle of a figjure, figure, downstairs it's bent uh, to the inside, both, and then uh, at the bottom, there's a, line from 1 uh, up, uh from down 2 up, and, there's a line up from the, left to the right $(1032, \mathrm{e})$

It should be noted that the subjects did not always use just one strategy to describe the figures. They sometimes combined several ones as if they wanted to make sure native speakers would be able to recognize the figures from their descriptions. Example ( 7 ) illustrates the use of a holistic strategy followed by a linear one. Example (8) is even more complicated. Apart from the initial analogy to part of a heart and a comment that the figure as a whole is asymmetrical, the description contains partitive elements (one of the two holes of the heart looks like the half of an egg, while the other one does not look like anything), as well as some linear information (there is a little line under it, one tenth of a centimetre).

(7) then the next, it looks like 1 uh, the mouth of a, bird, from the, left under to, the middle, upstairs, there is a, round line, and 1 in the right upstairs, there is $2 \mathrm{erm}$, a little round, uh 1 hole 1 then, from the 2 under, from 1 left under, from the left, under, to the middle under, there is, also a round line, in the middle under, there is 2 uh 1 something like, a bar 3 then 2 uh, a thin bar, the $1 \mathrm{erm}$, in the ri right, under 2 there is 2 also a little bar, but, the lines are coming together 1 uh 2 with, uh 1 uh 3 with uh 2 in, but not in a sharp point (30412; h)

(8) three $2 \mathrm{erm}$ this, picture, looks like erm 3 the erm 1 side 1 sh erm 6 the side that uh is under 1 versie, vier four 1 looks like uh, the uh, piece of 23 part of a heart 2 they are they are two erm $5 \mathrm{erm} 3$ the picture is not $\mathrm{k}$ not erm 2 uh 6 uh uh 3 the left and the right side of the picture are not the same, and erm 2 they're there are, two erm 3 uh holes in it uh 2 one 1 hole, looks like 1 the half of an egg and the other looks like erm 7 the, head, no no, erm looks like uh 1 no uh that uh, doesn't look like anything but erm, there is uh 3 a little line 2 under, under it, of erm, one tenth of a centimetre (203t2; b)

A full analysis of the data would have provided information about a) the number of strategies, b) the type of strategies and c) the order of the strategies in each description. Since we were primarily interested in the subjects' preferred means of reference, we decided to reduce the working load by adopting the procedure 
followed by Clark \& Wilkes-Gibbs (1986) and restrict the analyses to the strategies with which the subjects initiated their descriptions.

In all, there were 1080 protocols (45 subjects $\times 12$ figures $\times 2$ language versions). Four of these were incomplete and were, therefore, discarded from the analyses. The remaining 1076 protocols were scored independently by Theo Bongaerts and myself. The scoring was identical in 1027 cases (over 95\%). The 49 cases on which different opinions were held initially, were discussed until complete agreement was reached.

For the sake of consistency, certain criteria were followed rather strictly when scoring the protocols. If, for instance, analogies were followed by more specific information, as in the English version of example (9), they were scored as holistic strategies, but if the same information was encoded in the form illustrated by its Dutch counterpart, where the figure is explicitly divided into a top and a bottom part, the utterance was considered to be partitive:

(9) Dutch: zes uh, is 'n stukje van de cirkel aan de bovenkant, en aan de onderkant uh, vier uh 1 spitse dingen d'r aan, die zijn niet allemaal even lang $(303 \mathrm{t} ; 1)$

(six uh, is a small piece of the circle at the top, and at the bottom uh, four uh 1 pointed things on it, these are not all equally long)

English: erm, a piece of a circle, erm 1 with, erm 2 four, erm 2 phew 6 erm 6 with four uh, sharp pins uh 1 uh, under uh, the, piece of the circle $(3032,1)$

It is important that coding conventions such as these should be taken into account when comparing an individual's Dutch and English protocols, since they suggest differences in strategy use which are in fact mainly differences in the realization of the strategies.

\subsection{Results}

The data were analysed in three ways. First, a general comparison was made of the distribution of strategy types in the Dutch and English versions of task II. For reasons specified in chapter 5, only the data from the second Dutch version were considered. The results of the comparison are given in section 9.4.1. Second, each subject's L1 descriptions were compared to their L2 counterparts to obtain an exact picture of the effect that having to perform in the $\mathrm{L} 2$ has on a subject's use of referential strategies. This analysis is discussed in section 9.4.2. And third, an analysis was carried out of the times and the number of words each of the three proficiency groups needed to refer to the figures in the two language versions. The results of this more quantitative analysis will be reported in section 9.4.3. 
To establish the relationship between the use of $\mathrm{CpS}$ in $\mathrm{L} 1$ and $\mathrm{L} 2$ a comparison was made of the subjects' referential behaviour in the Dutch and English versions of task $\Pi$. Table 9.1 contains a general survey of the strategies that were used.

Table 9.1 Distribution of holistic, partitive and linear strategies in Dutch and English

\begin{tabular}{lccccccc}
\hline & \multicolumn{2}{c}{ Holistic } & \multicolumn{2}{c}{ Partitive } & \multicolumn{2}{c}{ Linear } \\
& D & E & D & E & D & E \\
\hline group 1 & 134 & 137 & 21 & 21 & 25 & 22 \\
group 2 & 124 & 119 & 33 & 34 & 22 & 25 \\
group 3 & 117 & 116 & 43 & 32 & 20 & 31 \\
\hline Total: & 375 & 372 & 97 & 87 & 67 & 78 \\
\hline
\end{tabular}

As table 9.1 shows, the distribution of the three strategy types is largely the same for the Dutch and English versions of task II. This is a first indication that the use of referential strategies is similar in L1 and L2. A second indication is that in the English version the subjects did not resort to any strategy types that they had not also used in the Dutch version. In other words, reduced linguistic competence did not lead to the use of L2-specific strategies.

Table 9.1 also indicates that holistic strategies were the most favoured. Almost $70 \%$ of the descriptions were started from this perspective, in both the Dutch and the English versions. Descriptions from partitive or linear perspectives were far less popular. Of these two strategy types, partitive strategies were more frequent, but the difference is largely reduced in the English version as a result of an increased number of linear strategies at the expense of partitive strategies used by group 3 .

The general preference for descriptions from a holistic perspective was not without exceptions. In the case of figures $b$ and $g$, for instance, only $38 \%$ and $39 \%$ of the strategies were holistic. Apparently, these figures could not easily be associated with real-world objects and did not call up suitable analogies.

Apart from such figure-related differences in the choice of referential strategies, one can also discem certain individual differences. Subject 102, for instance, started all descriptions from a holistic perspective, both in Dutch and in English. In contrast, subject 103 set out from a linear perspective for 7 of the 12 figures in the Dutch version, and for 8 of the 12 figures in the English 
version. These deviations from the rule go to show that other factors besides the language which is being used or the speaker's proficiency level in that language may determine a speaker's choice of referential strategies.

\subsubsection{Identical strategies versus shifts}

Subsequently, a more detailed analysis of the data was undertaken in which each description given in Dutch was compared to its English counterpart. This analysis should yield more specific information about the extent to which subjects maintained their preferred strategies. The results of this comparison are summarized in table 9.2. The table relates to 536 pairs of descriptions, since there were 4 incomplete sets which had to be discarded from further analysis.

Table 9.2 A comparison of the strategies used in the Dutch and English versions of task II. Rows indicate the strategies used in Dutch, columns the strategies used in English.

\begin{tabular}{lrccc}
\hline & Holistic & Partitive & Linear & Dutch \\
\hline Holistic & 336 & 16 & 21 & 373 \\
Partitive & 27 & 60 & 10 & 97 \\
Linear & 9 & 10 & 47 & 66 \\
\hline English & 372 & 86 & 78 & 536 \\
\hline
\end{tabular}

From table 9.2 it can be deduced that the subjects started their descriptions from identical perspectives in 443 cases $(336+60+47=443)$, i.e. $82.6 \%$. In quite a few of these cases the subjects used CpS to maintain their preferred strategies in spite of lexical difficulty. This happened particularly often in the case of holistic strategies which in 66 cases were rendered in English by means of either a conceptual (64 instances) or a linguistic CpS ( 2 instances). Two examples of this are given below. Both exhibit the use of analytic conceptual strategies.

(10) Dutch: nummer een 1 is 'n trechter (1120; e)

(number one 1 is a funnel)

English: 3 figure number five 18 is like the 3 apparatus 1 you use for 2 pouring liquids 1 from 4 big bottles, into small bottles (1120; e)

(11) Dutch: vijf dat is 'n uh, knots (115t2; a)

(five that is an uh, club)

English: eleven is uh, erm 2 a thing uh medieval uh, knights, uh used to uh, $\mathrm{s}$ smash each uh each other's brains in $(115 \mathrm{t} 2 ; \mathrm{a})$ 
In other cases subjects managed to maintain holistic stratcgies in spite of lexical problems by substituting one analogy for another, so that the same strategy type was used, but realized in a different way. There are at least 15 instances of this. ${ }^{2}$ They are illustrated by example (12):

(12) Dutch: en, figuur vijf lijkt op 'n, uh 'n pikhouweel met 1 uh de punt nogal, kromgebogen scherpe punt, die naar, links wijst $(21212 ; \mathrm{h})$

(and, figure five looks like a, erm a pickaxe with $1 \mathrm{erm}$ the point rather, bent sharp point, which points left)

English: erm 1 eight, erm 3 it looks like, erm 7 a woodpecker <laughs> uh, a sharp 1 uh 2 with erm, the sharp side, erm $2 \mathrm{~m}$, it's a little, nee, ja $4 \mathrm{erm}$, with the sharp side to the left, erm, on the left side (212t2; h)

The large number of cases in which subjects used the same strategies to refer to a figure in Dutch and English again suggests that the type of referential strategy used is not language-specific. The fact that the subjects made extensive use of $\mathrm{CpS}$ to maintain their preferred strategies makes the evidence all the stronger. Apparently, the subjects felt that maintaining a preferred strategy was worth a great deal of effort. Alternatively, one may conclude it takes less effort to maintain a holistic strategy by means of a $\mathrm{CpS}$ than to adopt a new strategy.

Let us now tum to those cases where the subjects did not use the same strategies in the two language versions. There were 93 cases like this $(536-443=93)$. As in Kellerman et al. (in press), they will be referred to as shifts. It has already been noted in section 9.3 that some of these shifts may be the artificial result of too strict an application of the scoring system. This was illustrated by example (9). Of course, such cases (of which there were 36) do not really represent shifting behaviour, and for this reason they do not constitute evidence against our position that the use of referential strategies is largely the same in $\mathrm{L} 1$ and $\mathrm{L} 2$.

The same goes for shifts that were caused by 'second thoughts'. In 25 cases the subjects evidently changed their minds as to what they considered the most appropriate way of describing a particular figure. It will be recalled from chapter 5 that in order to reduce the risk of this happening the subjects were asked to describe the figures twice in Dutch before they started on the English descriptions. It was assumed that the subjects would have decided on a preferred way of describing a particular figure in the second Dutch version, and it was taken for granted that these descriptions would represent the subjects' ideal conceptualization of the figures. Consequently, it was expected that the subjects would attempt to describe the figures from the same 'ideal' perspective in English, unless lexical problems made it impossible for them to do so. 
Although this assumption generally proved to be correct, a number of the (second) Dutch protocols show signs of the subjects changing their minds about the best description. In these cases the subjects would often start their English description from the perspective that had appeared as a 'second thought' in the Dutch description. Consider the following examples: ${ }^{3}$

(13) Dutch: erm, 't achtste, is 'n uh 2 ja d'r zit 'n uitsteeksel aan naar beneden, en, daar boven zit ' $n$ uh 1 zitten allemaal punten $1 \mathrm{erm}$, een twee drie vier vijf zes <whispers> zes punten 2 ' $t$ lijkt wel 'n beetje op ' $n$ uh hu hu hu $v$ vossekop of zo, wollkop (3070; a)

(erm, the eighth, is an uh 2 yes there is a projection on it downwards, and, above that is an uh 1 are a lot of point $1 \mathrm{erm}$, one two three four five six <whispers> six points 2 it looks a bit like an uh huhu hu f fox's head or so, wolf's head) English: five 1 is like the head of an animal, a fox $(30712$; a)

(14) Dutch: erm figuurtje zes 2 is, rond, van boven, uh naar beneden toe, en, daar komen spitse, uh, ja figuurtjes uit 'n soort, 'n soort ster maar dan, voor de helft $(1060 ; 1)$

(erm figure six 2 is, round, from the top, uh downwards, uh there come sharp, uh, yes small figures out of a sort, a sort of star, but then, half)

English: erm figure three looks like 1 a star, but then only for the half, but, which 1 also ha has uh lines which, which end in, sharp points $(1062 ; 1)$

It will be obvious that shifts caused by second thoughts cannot be attributed to differences between the use of referential strategies in L1 and L.2. After all, the change in strategy choice first manifests itself in the Dutch protocol (i.e. in the L1).

When cases like the above are discarded, only 32 real shifts remain. Table 9.3 shows the number of shifts for each proficiency level group and indicates which strategies were substituted for the original ones.

Table 9.3 The distribution of shifts. H-P stands for an $\mathrm{L} 1$ holistic strategy replaced by an L2 partitive strategy, H-L stands for an L1 holistic strategy replaced by an L2 linear strategy, and so on.

\begin{tabular}{lccccccc}
\hline & H-P & H-L & P-L & P-H & L-H & L-P & Total \\
\hline group 1 & - & 4 & - & 1 & - & 1 & 6 \\
group 2 & 1 & 6 & 1 & 1 & - & 1 & 10 \\
group 3 & 4 & 5 & 3 & 3 & 1 & - & 16 \\
\hline Total: & 5 & 15 & 4 & 5 & 1 & 2 & 32 \\
\hline
\end{tabular}

The first point to be made with respect to table 9.3 is that the number of shifts, although small, seems to be related to the subjects' proficiency level. The least 
proficient subjects shift most. This suggests that differences in the use of $\mathrm{Ll}$ and $\mathrm{L} 2$ referential strategies, if they occur at all, are at least partly caused by lexical difficulty. The second point concems the direction of the shifts. There are 24 shifts (in columns 1,2 and 3) which follow the hierarchy described in Kellerman et al. (in press). Most of them are shifts from holistic to linear strategies, as in examples (15) and (16):

(15) Dutch: en de tweede is, 't lijkt op 'n kruik 1 en erm 2 aan de zijkanten, uh zitten er twee, erm 2 twee steel, twee steeltjes naar boven $(103 \mathrm{t} 2 ; \mathrm{j})$

(and the second is, it looks like a hot-water bottle 1 and erm 2 at the sides, uh there are two, erm 2 two hand, two small handles upwards)

English: erm, and the seventh is, erm 3 a sort of, $\mathrm{mm} 7 \mathrm{~mm} 6$ at the uh, at the at the top it's flat, then the, uh, two ben, uh two lines, erm, they're, a bit bending, they go down, and then uh, at both sides 1 uh 2 there are two 1 erm 1 two things that go up $2 \mathrm{~m}(1032 ; \mathrm{j})$

(16) Dutch: effe kijken, erm vierde, de 't uh lijkt op 'n hellebaard (305t2; h)

(let's have a look, erm fourth, the it uh looks like a halberd)

English: 2 poeh <laughs> 3 it has, oh, it has two, uh lines that 2 uh five 2 that goes down, effe kijken hoor, it goes down, and they are uh in the middle, of the thing $(305 t 2 ; h)$

The 8 other shifts go against the hierarchy. In 6 of these cases there are certain indications that the subjects were unable to realize the L1 strategy in the L2, which presumably forced them to come up with an analogy that they had not thought of initially. Examples (17) and (18)

illustrate this:

(17) Dutch: erm negen is 'n 2 ja twee driehoekjes op elkaar, uh, 't eerste driehoekje heeft ' $n$ uh, de bovenkant is boven, of de $v$ ja vlakke kant is boven 1 en uh, bij ' $t$ de onderste is de of vlakke kant onder, en er steken twee dingen uit, en uh die steken naar beneden $(3010 ; \mathrm{g})$

(erm nine is an 2 yes two small triangles on top of each other, uh, the first small triangle has an uh, the top is at the top, or the $f$ yes flat side is at the top 1 and uh, at it the bottom one is the or flat side under, and there are two things sticking out, and uh they stick downwards)

English: seven is, uh 4 uh, effe kijken (let's see), a butterfly with two, uh, things out of it $2(301 \mathrm{t} 2 ; \mathrm{g})$

(18) Dutch: en 't twaalfde 1 is 'n boog van onderen 'n smal boogje, met, in 't midden 1 twee 1 bredere boogjes die, naar elkaar toe lopen (312t2; d)

(and the twelfth 1 is a bow at the bottom a narrow little bow, with, in the middle 1 two 1 broader little bows which, run towards each other)

English: erm, the fourth is erm 3 it seems like a a heart <laughs> $(31212$; d)

It is not entirely clear what caused the 2 remaining shifts. In one of them (106t2; f) a new analogy is mentioned after which the original Dutch description is 
repeated. In the other one (207t2; b) an L1 linear strategy is replaced by a much simpler partitive one. In any case one may conclude from the analysis of shifts that most of them do indeed follow the hierarchy described in Kellerman et al. (in press). In those cases in which the hierarchy was contradicted this was probably also caused by lexical difficulty.

\subsubsection{Time and number of words}

The final analysis to be reported here concems the times and the number of words needed to carry out the $\mathrm{L} 1$ and $\mathrm{L} 2$ versions of the task. The results of the time count are shown in table 9.4.

Table 9.4 Average time (in seconds) per figure broken down by 'group' in each of the two task versions. The interaction between 'group' and 'language' is significant $(F(2,42)=7.44, p<.00)$

Dutch version

English version

\begin{tabular}{lll}
\hline group 1 & 17.78 & 26.74 \\
group 2 & 21.63 & 52.59 \\
group 3 & 19.23 & 43.55 \\
\hline
\end{tabular}

As table 9.4 shows, all three proficiency groups needed more time for the English version than for the Dutch one. The differences are significant in all cases $(F=4.70 ; p<.05$ for group $1 ; F=56.07, p<.001$ for group 2 and $F=34.59$, p<.001 for group 3). Tests of simple contrasts revealed that within the English language version there is also a significant proficiency level effect. University students (group 1) needed significantly less time for the English version than the secondary school pupils (groups 2 and 3; p<.001), who did not differ with respect to each other. There were no significant differences between the three groups as far as the Dutch version is concemed.

The results of the word count are displayed in table 9.5.

Table 9.5 Average number of words per figure broken down by 'group' in each of the two task versions. There is no interaction between 'group' and 'language' $(F(2,42)=$ $1.93, p=.16$ )

Dutch version

English version

\begin{tabular}{lll}
\hline group 1 & 31.80 & 34.77 \\
group 2 & 41.81 & 43.47 \\
group 3 & 40.85 & 37.33 \\
\hline
\end{tabular}


An analysis of variance revealed that in terms of words used the subjects did not perform differently in the Dutch and English task versions $(F=.07 ; p=$ .80 ). The differences between the three proficiency groups proved not to be significant cither $(F=.73 ; p=.49)$.

\subsection{Discussion and conclusion}

The major conclusion to be drawn from the results discussed in section 9.4 is that $\mathrm{L} 1$ and $\mathrm{L} 2$ referential behaviour are largely similar. This revealed itself in three ways. Firstly, and probably most importantly, the subjects made use of the same set of referential strategies to initiate their references in L1 and L2. Thus, lexical problems did not require the use of any additional L2-specific strategies. Secondly, the distribution of strategy use was very much the same for $\mathrm{L} 1$ and L2, which indicates that the general preference for holistic strategies is not just an L1-phenomenon. And thirdly, the subjects generally maintained their preferred strategy. If necessary, they used a CpS to do this. Descriptions from a different perspective were only opted for as a last resort.

The striking similarity between L1 and L2 descriptions confirms hypothesis 1 that subjects referring to abstract figures will attempt to adopt the same referential strategies in L1 and L2. It suggests that the subjects applied their L1 strategic competence to the new L2 situation. Their ability to do so has certain implications for $\mathrm{CpS}$ use as well. Considering that $\mathrm{CpS}$ are used to solve lexical problems similar to the referential problems in the abstract figure description task, it can be assumed that for CpS too the subjects will exploit their L1 strategic knowledge. Consequently, one may expect the use of $\mathrm{CpS}$ to be largely similar in $\mathrm{L} 1$ and $\mathrm{L} 2$ too.

This does not mean though that there are no differences between $\mathrm{L} 1$ and $\mathrm{L} 2$ CpS use at all. There may well be some as a result of reduced lexical competence in the L2, which may make it impossible for the subjects to put their strategic knowledge to use in L2 situations. However, in the present study of referential strategies in L1 and L2 there are very few instances of this. The number of real shifts is remarkably small for subjects of all three proficiency levels. One reason for this is that the subjects aptly employed $\mathrm{CpS}$ to solve their lexical problems. Another reason is that the subjects in the Nijmegen project did not need to adopt different strategies in the L2 version simply because they were all reasonably advanced. It will be recalled that a similar ceiling effect explanation was suggested in chapter 8 to account for the lack of more substantial proficiency-related differences in $\mathrm{CpS}$ use. If it applied there, and research with less proficient subjects suggests it does (cf. Van den Brock, 1988), it may well have played a role in these data too. 
The second finding to be discussed here concems the preference for holistic strategies. This confirms hypothesis 2 , which was based on the results of previous research (Krauss \& Weinheimer, 1964; Clark \& Wilkes- Gibbs, 1986; Bongaerts et al., 1987; Kellerman et al., in press). Clark \& Wilkes-Gibbs (1986) have argued that the preference for descriptions from a holistic perspective is in accordance with their assumption that speech partners will try to minimize collaborative effort. Holistic strategies are much shorter than partitive or linear strategies, which presumably makes them less demanding from an encoding point of view. Besides, they seem to be much easier to understand (cf. Heider, 1971; Kahler, 1975), which suggests that the processing load on the part of the listener is also relatively small.

In this respect it is worth noting that Clark \& Clark (1977) refer to a study by Santa \& Ranken (1972) which established that nonsense shapes are easier to recall and to recognize if they have labels. Clark \& Clark (1977) also mention a study by $\mathrm{H}$. Ellis (1968) in which this effect was proved to be stronger if the labels made sense of a nonsense figure, as for instance when a figure that roughly resembled a star was labelled as a star. Again, this suggests that holistic strategies, which label figures, are easier to process than linear strategies, which merely describe figures.

The preference for holistic strategies is also in accordance with the Gestalt theory of perception, which holds that people attempt to perceive figures as structured wholes. Their success in this depends on whether the figures are good or bad Gestalts, which again depends on certain principles, e.g. whether the figures are closed and/or symmetrical, and the number of curves they have. Examples of good Gestalts are circles and squares. Good Gestalts typically have names, so that they can easily be referred to. The figures in task II did not have names of course, but the subjects' attempts to name them all the same suggests they did conceive of them as good Gestaits (figures $b$ and $g$ excepted).

In section 9.4.2 it was noted that the number of shifts in the data is extremely small, certainly if one discards those cases in which the coding system was applied rather strictly or which resulted from 'second thoughts'. Of the 32 shifts that did occur 24 followed the hierarchy in Kellerman et al. (in press) and thus provided evidence for hypothesis 3 . In 8 cases the hierarchy was contradicted. Close analysis of these cases revealed that 6 of them were probably caused by lexical problems and contained new analogies in the English versions. It is conceivable that these new analogies were used for reasons of economy. The subjects may have felt the amount of effort needed to construct a comprehensible partitive or linear strategy in English was unreasonably large.

Finally, the quantitative analyses of the data revealed that subjects took more time to describe the figures in their L2 (English) than in their L1 (Dutch), and that the most proficient subjects needed less time for the English version than 
the less proficient ones. This is in accordance with hypotheses $4 \mathrm{a}$ and $4 \mathrm{~b}$. The fact that the English versions did not contain more words than the Dutch ones goes to show that the larger amount of time necded for the English versions is the result of longer pauses and not of more complicated descriptions.

There was no evidence in the data under discussion to confirm hypothesis 5 , which predicted that there would be U-shaped relationships between the times and the number of words used in the English protocols and the subjects' L2 proficiency level. Although group 2 did use more time and more words than the two other groups, the only significant difference was that in the time used by group 1 versus groups 2 and 3. The differences between groups 2 and 3 did not reach significance for either 'time' or 'number of words'. Still, it is worth bearing in mind that a $U$-shaped relationship might have been found if subjects at a lower proficiency level had been included in this study.

In the Dutch version none of the differences between the three groups in the times or the number of words used were significant, which is in accordance with hypothesis 6 . This finding is of considerable importance, since it confirms the correctness of one of the assumptions on which the use of an abstract figure description task was based, namely that from a cognitive point of view the task is equally difficult for all three groups. At the same time, it goes to show that the individual differences in the subjects' strategic behaviour (in this and all other tasks used in the Nijmegen project) are not group-related. This point may be even more important still, since it suggests that the three groups do not differ in other respects besides their L2 proficiency level.

The comparative study described in this chapter has provided further evidence for our position that $L 2$ speakers are able to exploit the strategic skills which they have developed as L1 speakers. It has been shown that L2 speakers who are confronted with referential problems attempt to solve these problems in the same way as they do in their L1. Regardless of the language in which they are operating, the subjects refer to abstract figures by using either a holistic, a partitive or a linear strategy. Moreover, they exhibit a clear preference for holistic strategies in the $\mathrm{L} 1$ as well as in the L2. This last finding, it seems, can bc attributed to an equal effect of the principle of economy in L1 and L2 situations.

The similarities between the subjects' use of referential strategies in the L1 and the L2 strongly suggest that the use of CpS too is independent of the subjects operating in the $\mathrm{L} 1$ or the $\mathrm{L} 2$. Two possible exceptions are (1) that $\mathrm{L} 1$ speakers do not use linguistic $\mathrm{CpS}$ to the same extent or in the same way as L2 speakers; and (2) that L2 speakers who are confronted with serious lexical difficulties need to resort to less preferred $\mathrm{CpS}$ types. However, further research will need to be done before a final conclusion can be reached with respect to these two points. 


\section{Notes to chapter 9}

1. Part of this chapter is based on a joint publication by Bongaerts \& Poulisse (in press).

2. In $\mathbf{1 5}$ other cases it is not clear whether a subject exchanged one holistic strategy for another because he foresaw problems in realizing the first strategy in English, or because he simply considered the first strategy to constitute a poor analogy which, he feared, might not lead to correct identification of the shape (cf. Bongaerts \& Poulisse, in press).

3. In Kellerman et al. (in press) cases like these are referred to as mirrors. Strictly speaking, however, only (13) is a mirror, since the Dutch and English protocols contain the same information in reversed order. (12), on the other hand, is not a mirror, since the English protocol leaves out all of the linear description given in the Dutch protocol. 


\section{The Effectiveness of Compensatory Strategies}

One of the Nijmegen project's research questions concerned the relative effectiveness of various $\mathrm{CpS}$ types. This research question was included for its possible pedagogical impacts. When the project proposal was written it was expected that "the results of such research might lead to the development of teaching methods directed at teaching leamers to use those $\mathrm{CpS}$ types which are most effective with respect to a particular communicative goal" (translated from Bongaerts \& Kellerman, 1983:3). As far as can be ascertained there were, at the time, only two studies which had dealt with this question. One of these was conducted by Ervin (1979), and the other one by Bialystok \& Froblich (1980, also described in Bialystok, 1983). In these studies the effectiveness of CpS was expressed in terms of native speaker judgements of their comprehensibility. Essentially, this means that effectiveness was equated with comprehensibility. This interpretation of effectiveness has also been adopted in the Nijmegen project. However, it was felt that a more objective measurement than a judgement task was needed to reliably establish the effectiveness of $\mathrm{CpS}$ types.

This chapter will start off with a description of the two above-mentioned studies by Ervin and Bialystok \& Frohlich. After this, two pilot studies conducted by students at Nijmegen University will be discussed (Verouden, 1985; Verkuijlen, 1987). The experience gained in these studies largely determined the shape of the main effectiveness experiment, which will be the topic of section 10.3. Section 10.4 summarizes the results. For a discussion of their pedagogical implications the reader is referred to chapter 11.

\subsection{Research to date}

Ervin's (1979) investigation of the comprehensibility of CmS was based on the oral narrations of three picture stories by 14 American students of Russian (see also chapter 3). The students were enrolled in intermediate level college Russian courses. A pilot study was used to select 32 of the stories' key elements for further investigation. The students' renditions of these 32 items were presented to a panel of 12 judges, who were asked to indicate the comprehensibility of each of these renditions on a five-point scale. The scale ranged from (1) 'item was left out' to (5) 'would have been well understood by a native speaker of Russian, even though the subject's grammar or vocabulary might still have been faulty' (Ervin, 1979:331). The panel was composed of three groups of 4 judges each. Group 1 consisted of 4 non-teaching native speakers of Russian, who knew little or no English. Group 2 consisted of 4 native speakers of Russian who taught Russian in the U.S.A. and who 
spoke English well. And group 3 consisted of 4 native speakers of English who taught Russian in American schools.

Ervin's study was directed at establishing the comprehensibility of the students' renderings of each individual item. It did not go into the comprehensibility of different types of $\mathrm{CmS}$, although Ervin suggests this as a topic for further research. Still, Ervin's research brought up an important point which may have certain implications for the study of the effectiveness of CpS types. He observed that the three groups of judges evaluated the data differently. Group 1 judges tended to be lenient, while group 2 judges tended to be severe in their ratings of the 11 best students. Group 3 judges showed a tendency to be lenient with the 3 lowest proficiency subjects. These differences between the three groups of judges, even if they are not very large, illustrate the subjectivity of a judgement task. Different groups of judges may evaluate things differently.

The study by Bialystok \& Frohlich (1980, see also Bialystok, 1983) did go into the effectiveness of specific CpS types. The CpS in this study were elicited from 44 English speaking leamers of French (14 adults and 30 grade 12 students) who performed either a picture reconstruction task or a picture description task. A more detailed description of the experimental set-up of this study has been given in chapter 3 .

The effectiveness of $\mathrm{CpS}$ types was determined as follows. First, the transcripts of the leamers' $\mathrm{CpS}$ for 8 target items were written on separate cards. These cards, each containing one CpS for one item, were then presented to 17 native speakers of French who were asked to rank- order them per item in terms of "their effectiveness in conveying the meaning of the particular item" (p.21). The CpS elicited from the adults and the students were rank-ordered separately by 10 and 7 judges respectively. For both adults and students functional descriptions were judged to be most effective, while language switches were judged to be least effective. These findings converge with the frequency distribution of these CpS types, which leads Bialystok (1983) to suggest that subjects are sensitive to the most appropriate means of expression for particular items. Another important point, made by Bialystok \& Frohlich (1980), is that not all functional descriptions were equally effective. Much depended on the sort and the amount of information contained in the description, that is, on the way in which the $\mathrm{CpS}$ was encoded.

Since the rank-orderings were given for each item separately, a second measurement was needed to compare across items. For this purpose the CpS that had received the highest mean rankings for each item were evaluated by two native speakers of French, who assigned a score to them ranging from ( 0 ) 'absolutely incomprehensible' to (5) 'perfectly comprehensible'. It appeared that there was little variation in the scores assigned to the CpS elicited from the adults, who were the most proficient. That is, the CpS that had been ranked 
highest were all considered to be approximately equally effective. This was not so in the case of $\mathrm{CpS}$ elicited from students. For instance, the most effective $\mathrm{CpS}$ used by this group for the item 'chaussette' received a combined score of only 2.

To find out whether more proficient leamers use more effective CpS Bialystok (1983) correlated the mean ranks assigned to a subject's CpS with this particular subject's results on a cloze test (used to estimate his general L2 proficiency level). The correlation was significant for both adults and students, indicating that the $\mathrm{CpS}$ which had been ranked by the judges as most effective were produced by the most proficient subjects. However, Bialystok quite rightly points out that adults and students do not differ so much in the types of $\mathrm{CpS}$ they use, but in their realization of these CpS. Again, this suggests that the effectiveness of a $\mathrm{CpS}$ depends to a large extent on the way in which it has been encoded. From the few differences in CpS type selection that did emerge, Bialystok concludes that a minimal level of proficiency may be required before one can make use of the full range of possible $\mathrm{CpS}$.

\subsection{Some pilot studies}

There are a number of points on which Bialystok \& Fröhlich's study might be improved. Firstly, there were only two judges in the second rating part of the experiment. Considering Ervin's finding that different groups of subjects may evaluate things differently, it would be wise to increase the number of judges and determine the inter-judge reliability (as was done by Bialystok \& Froblich for the 17 judges who participated in the rank-ordering part of the effectiveness experiment).

Secondly, the judges in Bialystok \& Fröhlich's study knew some English and it is possible that this interfered with their judgements (Bialystok \& Fröhlich, 1980:21). To rule out any potential effects of knowing the L2 learners' $L 1$, the judges should preferably not have any knowledge of this language at all.

Thirdly, Bialystok \& Fröhlich did not correct the $\mathrm{CpS}$ for grammatical inaccuracies and the like (p.21). Consequently, it is difficult to determine whether the judges in their study evaluated the effectiveness of particular CpS types, as they were supposed to do, or the grammatical correctness of the utterances presented to them. This problem can be solved if researchers edit the $\mathrm{CpS}$ whose effectiveness they want to establish by removing all surface errors.

Fourthly, only the highest-ranked $\mathrm{CpS}$ were included in the rating test. As a result, most of the $\mathrm{CpS}$ evaluated by the judges were descriptions (mainly of functions). To obtain a more complete picture a rating test should cover the full range of $\mathrm{CpS}$. 
Verouden (1985) conducted a rating experiment similar to the one used by Bialystok \& Frohlich, but with the improvements mentioned above. She composed a list of $144 \mathrm{CpS}$ which had been used by the subjects in the Nijmegen project to compensate for 24 items in the story retell task. Each CpS was preceded by the intended English word, and followed by a seven-point scale on which (1) meant 'totally incomprehensible' and ( 7 ) meant 'perfectly comprehensible'. The list consisted of one example of six different CpS types for each item. Both items and CpS types had been arranged in a pseudo-randomized order. The CpS types included in this study were 'Description', 'Circumlocution', 'Approximation', 'Word Coinage', 'Foreignizing' and 'Borrowing'. These CpS types were adopted from traditional taxonomies, since this pilot study was carried out before the development of the new taxonomy was completed. For an explanation of the terminology see chapter 2 . $^{2}$

The list of CpS was presented to 9 adult native speakers of English. They were asked to evaluate the comprehensibility of each $\mathrm{CpS}$ on the seven-point scale. To make it possible to establish the intra-judge reliability the task was repeated by the same informants after one month.

The mean evaluations per CpS type reported by Verouden are given in table 10.1. A test of a posteriori contrasts by means of the Student-Newman-Keuls procedure (MS error = denominator of the quasi F-ratio) indicates that 'Description' is more comprehensible than 'Circumlocution', 'Approximation' and 'Word Coinage', which are in tum more comprehensible than 'Foreignizing' and 'Borrowing' ( $\mathrm{p}=.05$ ). In terms of the process-oriented taxonomy used in the Nijmegen project this means that conceptual strategies are considered more comprehensible than linguistic strategies.

Table 10.1 Mean evaluations per CpS type (adapted from: Verouden, 1985)

\begin{tabular}{lc}
\hline CpS type & mean evaluation \\
\hline description (ANCO: 1def) & 5.28 \\
circumlocution (ANCO: 1def) & 3.60 \\
approximation (HOCO: 1a) & 3.88 \\
word coinage (ANCO: 1wc) & 3.60 \\
foreignizing (LITRA: $2 \mathrm{a}$ ) & 1.98 \\
borrowing (LITRA: 2ab) & 1.36 \\
\hline
\end{tabular}

Not all instances of a certain CpS type are considered equally comprehensible, though. Verouden notes that the evaluation of a particular CpS depends largely on the realization of this $\mathrm{CpS}$ and on the item for which it was used. To illustrate this she draws attention to the comparatively high evaluations of transparent word coinages such as "haircutter" (6.33) for 'hairdresser' and "bike-maker" (6.22) for 'bicycle-manufacturer'. 
Both the inter- and the intra-judge reliability proved to be reasonably high. Pearson correlation coefficients varied from .51 to .80 (between judges) and from .73 to .85 (within judges). All correlation coefficients were highly significant $(\mathrm{p}<.001)$. The validity of this study is questionable, though. As Verouden points out in her conclusion, it is possible that by removing the CpS from their contexts she reduced their comprehensibility. This suggests that another study should be undertaken in which $\mathrm{CpS}$ are evaluated within their original context.

The second pilot study to be discussed here was carried out by Verkuijlen (1987). ${ }^{3}$ His main purpose was to set up an experiment that would directly measure whether a $\mathrm{CpS}$ had been understood. Such an experiment, it was hoped, would be more objective than one which relied on native speakers' judgements or intuitions of the comprehensibility of $\mathrm{CpS}$. At the same time this pilot study was meant to establish the influence of the context on the effectiveness of CpS and to compare the results of 'subjective' and 'objective' experimental tasks.

Verkuijlen (1987) developed a task in which (edited) $\mathrm{CpS}$ for 19 different items were embedded within the context of the four stories used in the story-retell task. There were four task versions, each consisting of the same four stories (in different randomized orders), but with instances of different $\mathrm{CpS}$ types used for each item. The $\mathrm{CpS}$ types involved in this experiment were HOCO, HOCO + ANCO, ANCO and LITRA. To improve the comparability of the CpS used for each item Verkuijlen saw to it that the holistic and the analytic parts of the three 'Conceptual Strategies' were the same. In some cases this required the invention of suitable examples. Thus, for the item 'pleated skirt' he selected the CPS "a skirt" and "a skirt with folds in it" from the Nijmegen corpus, and invented the CpS "something with folds in it". Verkuijlen also had to invent some of the transfer strategies. In 4 cases this proved to be impossible, because the item did not permit the construction of a plausible transfer strategy. In these cases the transfer strategies were replaced with holistic strategies. All $\mathrm{CpS}$ in the stories were underlined. The subjects were asked to guess the words which the $\mathrm{CpS}$ were meant to convey.

This task was administered to four groups of 10 advanced students of English at Nijmegen University. All of these students were native speakers of Dutch. It would, of course, have been preferable to have native speakers of English as subjects, but for financial reasons it was impossible to conduct this pilot study in an English-speaking country. Each group of subjects received a different task version, so that there were 10 scores for each instance of $\mathrm{CpS}$ use. Immediately after the subjects had completed the task, they were given a similar task, this time with the correct answers given, and they were asked to evaluate the comprehensibility of the corresponding $\mathrm{CpS}$ on a seven-point scale. In the remainder of this chapter the two parts of the experiment will be referred to as the guessing task and the judgement task. 
In addition, Verkuijlen composed a task consisting of the same $\mathrm{CpS}$ without context. Again, he made four versions of this task, so that for each item an instance of a different $\mathrm{CpS}$ type was used in each version. Four groups of 10 students of English at a teacher training college in Nijmegen participated in this experiment. Again, each group of subjects received a different task version. As before, they were asked to guess the words which the $\mathrm{CpS}$ were meant to convey. Subsequently, they were given a list of all $76 \mathrm{CpS}$, to which the intended English words had been added. This time they were asked to evaluate the comprehensibility of the $\mathrm{CpS}$ on a seven-point scale.

Table 10.2 gives the results of Verkuijlen's experiments. The guessing tasks resulted in scores ranging from 0 to 10 , depending on the number of subjects that had been able to guess the correct words. The judgement tasks yielded average ratings between 1 and 7 . The differences between the results of the tasks with and without context were tested (by the present author) by means of Student's $t$ tests for independent samples (Ferguson, 1981:177ff.). The results of these tests are given in the two right-most columns.

Table 10.2 The results of Verkuijlen's experiments. Significant $t$ values are marked * $(p<.05)$ or ( $p<.001$; one-tailed, $\mathrm{df}=17$ for HOCO, HOCO + ANCO and ANCO, df $=13$ for LITRA)

\begin{tabular}{lcccccc}
\hline & \multicolumn{2}{c}{ with context } & \multicolumn{2}{c}{ without context } & \multicolumn{2}{c}{ t values } \\
& score & rating & score & rating & score & rating \\
\hline HOCO & 5.81 & 3.18 & 0.05 & 2.26 & $7.25^{* *}$ & \multirow{2}{*}{$2.68^{* *}$} \\
HOCO + ANCO & 8.84 & 5.67 & 7.74 & 5.45 & 1.59 & 0.75 \\
ANCO & 7.89 & 4.97 & 5.68 & 4.60 & $2.27^{*}$ & 0.77 \\
LITRA & 9.33 & 2.47 & 6.93 & 2.52 & $2.84^{* *}$ & -0.13 \\
\hline
\end{tabular}

A comparison of the results leads to two conclusions. Firstly, it is easier to guess the intended word if the context of the $\mathrm{CpS}$ is given. Particularly in the case of HOCO the context adds considerably to the comprehensibility. Hence, a valid study of the effectiveness of $\mathrm{CpS}$ should take the context into account.

Secondly, there are some discrepancies between the results of the 'objective' guessing task and the 'subjective' judgement task. Transfer strategies which had been understood by all participants often received very low ratings. Conversely, some holistic strategies which were not understood were given relatively high ratings. This occurred particularly often in the experiments without context. Verkuijlen points out that some of the differences in the results of the two tasks can be ascribed to the fact that the subjects in his study were native speakers of Dutch. Naturally, they had no problems in understanding transfer strategies themselves, but they may well have considered them incomprehensible to native speakers of English. Consequently, further 
investigations of this kind will need to be done with native speakers of the target language as informants.

\subsection{The York study of effectiveness}

The two pilot studies were followed by what will be referred to as the York study of effectiveness. The purposes of this study were to further examine the effectiveness of various $\mathrm{CpS}$ types within a suitable context, and to obtain more detailed information about the effects that two different experimental tasks may have on the results.

\subsubsection{Method}

In view of the findings of the pilot studies Verkuijlen's first task, in which subjects had to interpret and evaluate $\mathrm{CpS}$ in context, was adopted as the major instrument to establish the effectiveness of CpS. Two additions were made though. To gain more insight into the effect of the context a pseudo-cloze task was devised which consisted of the same four stories without $\mathrm{CpS}$. The number of subjects who would be able to fill in the gaps was expected to give some indication of the contribution of the context. This information could aid the interpretation of the results on the main guessing task (i.e. the one including $\mathrm{CpS}$ ). If the context is so informative that it makes the $\mathrm{CpS}$ redundant, i.e. if it is possible to guess the missing words from the context alone, one cannot draw any conclusions about the intrinsic effectiveness of the $\mathrm{CpS}$ for these words. After all, the meaning of these $\mathrm{CpS}$ will be clear from the context, whether the $\mathrm{CpS}$ themselves are comprehensible in isolation or not. Only if the missing words cannot be guessed from the context, but can be guessed from the CpS used, is it safe to conclude that the CpS are intrinsically effective.

The second addition concerned the inclusion of certainty indications in the guessing part of Verkuijlen's experiment. After the subjects had tried to guess the words which the $\mathrm{CpS}$ were meant to convey, they were asked to indicate whether they thought their answers were 'right', 'possibly right' or 'pure guesswork'. It was hoped that these indications of the certainty with which the subjects had given their answers might explain potential discrepancies between the results of the guessing part and the judgement part of the York experiments. The instructions to the York experiments are given in appendix VI, as are the $\mathrm{CpS}$ that were included in them.

\subsubsection{Subjects}

The guessing task and the judgement task were carried out by four groups of subjects. The number of subjects per group varied from 25 to 35 . The 
pseudo-cloze task was completed by 60 subjects. All subjects were native speakers of English. None of them knew Dutch, but it was impossible to control for their knowledge of other foreign languages. Approximately half of the subjects were secondary school pupils at Archbishop Holgate's School in York. The other subjects were adults, attending a variety of evening classes at the Burnholme School of Adult Education, also in York. ${ }^{4}$

\subsubsection{Results of the guessing task and the pseudo-cloze task}

The answers given in the guessing task and the pseudo-cloze task were scored as correct if they were identical to or synonymous with the words originally occurring in the stories. The decision whether something was a synonym or not was left to a native speaker of English. When in doubt, a dictionary was consulted. Strictly speaking, one cannot say that the answers were either right or wrong. Some of the wrong answers were clearly much closer to the target than others. "Display", for instance, seems a better substitute for 'shopwindow' than "wardrobe" or "rack", yet all three answers were considered incorrect. Where relevant, this will be taken into account when discussing the results.

Table 10.3 gives the correctness scores (in percentages) per CpS type and per item. For a list of the $\mathrm{CpS}$ included in the experiment see appendix VI. The last column in table 10.3 gives the correctness scores in the pseudo-cloze task. In some cases the $\mathrm{CpS}$ contained potentially misleading information, so that it was more difficult to guess their meaning than it was to guess the missing word in the pseudo-cloze task. This explains why some of the pseudo-cloze scores are higher than the scores for the corresponding items in the guessing task (see e.g the scores for 'shopwindow' and 'dispute').

From the mean correctness scores at the bottom of the table it appears that combinations of holistic and analytic strategies most often result in correct answers, so that $\mathrm{HOCO}+\mathrm{ANCO}$ might be considered to be the most effective $\mathrm{CpS}$ type. Holistic strategies were least comprehensible, and therefore seem to be least effective. However, a closer investigation of the individual correctness scores shows that there is considerable variation among the $\mathrm{CpS}$ of any one CpS type. This is particularly true for holistic strategies and transfer strategies where the correctness scores range from 0.0 to 92.3 (standard deviation: 33.82) and from 2.9 to 100.0 (standard deviation: 32.68), respectively. There are five holistic strategies with extremely low scores. They are "man" (tailor), "animal" (rabbit), "spray" (hair-restorer), "shopkeepers" (chemists) and "tool" (drill). These are all instances of superordinate words which are, apparently, much too general to enable one to guess the intended word. More specific holistic strategies such as "tribunal" (courtcase), "hairstylists" (hairdressers), "hair" (wig) and "to flatten" (to iron) proved to be much more comprehensible. In some cases, however, general superordinates were comprehensible. The 
Table 10.3 The percentage of correct answers per $\mathrm{CpS}$ type and per item in the guessing task, the percentage of correct answers in the pseudo-cloze task

\begin{tabular}{lrrrrr}
\hline & HOCO & HOCO + ANCO & ANCO & LITRA & cloze \\
\hline tailor & 0.0 & 96.1 & 94.1 & 88.6 & 11.7 \\
rabbit & 0.0 & 56.0 & 57.7 & 2.9 & 0.0 \\
pleats & 52.9 & 88.6 & 88.0 & 92.3 & 41.7 \\
shopwindow & 26.9 & 44.1 & 20.0 & 36.0 & 45.0 \\
to iron & 76.0 & 92.3 & 67.6 & 8.6 & 1.7 \\
salesman & 50.0 & 91.2 & 71.4 & 64.0 & 30.7 \\
hair-restorer & 0.0 & 34.6 & 44.1 & 48.6 & 5.0 \\
hairdressers & 88.6 & 100.0 & 100.0 & 61.8 & 5.0 \\
chemists & 11.8 & 74.3 & 60.0 & 92.3 & 1.7 \\
wig & 92.3 & 97.0 & 82.8 & 100.0 & 95.0 \\
dispute & 52.9 & 62.8 & 88.0 & 96.1 & 90.0 \\
courtcase & 76.9 & 76.5 & 54.3 & 32.0 & 40.0 \\
lawyer & 68.0 & 100.0 & 100.0 & 80.0 & 65.0 \\
judge & 82.8 & 88.0 & 100.0 & 82.3 & 86.7 \\
drill & 0.0 & 88.6 & 76.0 & 11.5 & 0.0 \\
caretaker & 61.5 & 47.0 & 45.7 & 56.0 & 66.7 \\
applications & 72.0 & 100.0 & 20.6 & 42.8 & 31.7 \\
moved & 71.4 & 76.0 & 76.9 & 100.0 & 71.7 \\
funeral & 88.2 & 85.7 & 76.0 & 30.8 & 35.0 \\
\hline mean & 51.2 & 78.9 & 69.6 & 59.3 & \\
\hline
\end{tabular}

correctness scores for "man" (lawyer) and "man" (judge) are 68.0 and 82.8, respectively. This can be explained by the results of the pseudo-cloze task, which reveal similar correctness scores for these two items. Apparently then, in these cases it is not the CpS, but the context that enabled the subjects to guess the intended meaning.

The two least successful transfer strategies are "konijntje" (rabbit) and "to strike" (to iron). Considering that there are no linguistic correspondences at all between these words and the intended English words, it is not surprising that they were not very comprehensible. 5 Still, other transfer strategies, such as "geschil" (dispute) and "pruke" (wig), which are equally unrelated to their English counterparts, did result in high correctness scores. As before, these findings can be explained if one takes the results of the pseudo-cloze task into account. 'Dispute' and 'wig' can be guessed from the context, whereas 'rabbit' and 'to iron' cannot.

It should be noted that the context is not the only factor to determine the comprehensibility of transfer strategies. The task contains three cases where 
the context provides little information, but where the transfer strategies are nevertheless understood. These cases concern the $\mathrm{CpS}$ "clothes-maker" (tailor) ${ }^{6}$, "coiffeurs" (hairdressers) and "drogists" (chemists). Evidently, these transfer strategies are well-chosen. "Clothes-maker" is a literal translation from Dutch 'kleermaker', a transparent word whose meaning is easily understood. "Coiffeurs" is a word taken from French, but is also used in English, and "drogists" is related to the English 'druggists' which is synonymous with 'chemists'.

If we now consider the correctness scores for analytic strategies, we see that there is less variation here (standard deviation: 24.62). The same goes for combinations of holistic and analytic strategies (standard deviation: 20.61), whose correctness scores are generally similar to those of analytic strategies. The role of the context seems to be much smaller with respect to these CpS types, which is not surprising considering the fact that analytic strategies and combinations of holistic and analytic strategies generally contain much information and therefore, as it were, provide their own context. Some relatively low correctness scores do occur though, notably for the CpS "somewhere in/in the window of his shop" (shopwindow), "something/some spray to make your hair grow faster" (hair-restorer) and "someone/a guard who had to take care of a house" (caretaker). In the case of 'shopwindow' the rather low correctness score for the combination of holistic and analytic strategies is due to a large number of subjects (12 out of 34) who had answered "display", which was not considered as an exact enough synonym. However, this does not explain the even lower correctness score for the analytic strategy, since here only 5 out of 35 subjects had answered "display". A comparison of the two CpS shows that the analytic strategy misses some crucial information. "Somewhere" is much vaguer than "in the window" and therefore does not enable the subjects to come up with the correct answer "shopwindow". In the case of 'hair-restorer' both strategies frequently resulted in answers like "hairtonic", "hairspray" or "hairlotion" which were regarded as incorrect, while the two strategies for 'caretaker' often resulted in the wrong answers "housekeeper" or "security guard".

The only item which is much better conveyed by the combination of holistic and analytic strategies than by the analytic strategy is 'applications'. "Letters to get a job" always yielded the right answer, while "things to get a job" often led to the answer "interviews". Again, the latter CpS was not specific enough and clearly contained too little information to enable the subjects to guess the intended word.

\subsubsection{Two experimental tasks compared}

In section 10.2 it was said that Verkuijlen (1987) found some discrepancies between the results of the guessing task and the judgement task. In an attempt 
to account for such discrepancies the York study required the subjects to indicate how sure they were of their answers. It was assumed that a $\mathrm{CpS}$ which enabled one to give an answer that was certainly correct would be considered more comprehensible than one which led to an answer about the correctness of which there was some doubt.

Table 10.4 The mean correctness scores and the mean ratings per $\mathrm{CpS}$ type in the York study of effectiveness

$\%$ correct mean rating

\begin{tabular}{lll}
\hline HOCO & 51.2 & 4.60 \\
ANCO & 69.6 & 5.62 \\
HOCO + ANCO & 78.9 & 5.99 \\
LTRA & 59.3 & 4.52 \\
\hline
\end{tabular}

Table 10.4, which gives the mean correctness scores and the mean ratings per $\mathrm{CpS}$ type, reveals that there is no discrepancy between the results of the two experimental tasks in the present study. A detailed comparison of the correctness scores and the ratings per $\mathrm{CpS}$ revealed that in virtually all cases $\mathrm{CpS}$ that had been understood by most of the subjects were evaluated as highly comprehensible. This proved to be true for all $\mathrm{CpS}$, of all $\mathrm{CpS}$ types, including those probably understood only by virtue of the context. This finding made the certainty indications superfluous. They had been collected to account for a discrepancy which in the York study did not exist.

Although the guessing task and the judgement task yielded comparable results, it would be premature to conclude from this that the two experimental tasks are equally suitable, and that therefore there is no need for an objective measurement of the effectiveness of $\mathrm{CpS}$. The subjects who participated in the York study all did both the guessing task and the judgement task. There was no time lag in between the two tasks. For this reason it is possible that the subjects conceived of the two tasks as one, and tried to make their judgements accord with the answers they gave earlier. That is, they probably judged a $\mathrm{CpS}$ to be comprehensible if they had been able to give the right answer, and incomprehensible if they had not. It is not clear whether their judgements would have been the same if they had not participated in the guessing task first.

To find out whether guessing and judgement tasks do indeed yield the same results, an independent-subjects design should be used, in which one group of subjects performs the guessing task and a second group of equivalent subjects performs the judgement task. Unfortunately, however, within the Nijmegen project there was not enough time to continue our experimentation in this area. 


\subsection{Conclusion}

The conclusions to be drawn from the research reported in this chapter are not very straightforward. On the one hand, the results clearly suggest that there are differences in the effectiveness of combinations of holistic and analytic strategies, analytic strategies, transfer strategies and holistic strategies, the first being the most and the last being the least comprehensible.

On the other hand, it can be concluded that it is not very sensible to speak of effective or less effective $\mathrm{CpS}$ types. As the scores on the pseudo-cloze task indicated, the comprehensibility of a particular CpS depends to a large extent on the context in which it is used. An informative context makes the use of CpS redundant. In addition to the context, the realization of $\mathrm{CpS}$ proved to play a large role. It has been shown that holistic strategies are more effective if they are specific rather than general, and that analytic strategies and combinations of holistic and analytic strategies too need to be sufficiently specific to be understandable. And finally, it tumed out that even transfer strategies, which were always thought to be incomprehensible (Bialystok \& Froblich, 1980; Haastrup \& Phillipson, 1983), are effective when there are linguistic correspondences between the transferred word and the intended target language word.

\section{Notes to chapter 10}

1. For a discussion of similar divergencies in native and non-native speakers' ev aluations of L2 learners' speech see Ludwig (1982) and Eisenstein (1983). See also Spencer (1973) for differences in the grammaticality judgements made by linguists and non-linguists, Albrechtsen, Herriksen \& Fanch (1980) for different evaluations of L2 leamers' speech by 16 to 17-year-old and adult native speakers, and Carroll, Bever \& Pollack (1981) for differences in sentence similarity judgements between subjects who are put in conditions that promote either "subjective or objective self-awareness" (i.e. between judges who could see themselves in a mirror and judges who could not).

2. The distinction between 'Circumbocution' and 'Description' in this study is extremely vague and seems to be based on the quality of the compensatory utterance, that is, on the sort and the amount of information contained in it Or, as Verouden puts it: "circumlocutions are often less good descriptions" (Verouden, 1985:14, translation mine). While this may explain why 'Description' is considered a more effective CpS type then 'Circumlocution' in Verouden's study, it is of course inappropriate to distinguish between two CpS types on qualitative grounds when the quality, or comprehensibility, of CpS types is the object of one's investigation.

3. An attempt to set up an on-line (naming) experiment failed as a result of a multitude of practical problems (Bors, Duivelaar \& Reinders, 1985). The idea was to have native speakers of English listen to a number of tape-recorded $\mathrm{CpS}$ and ask them to guess which words the $\mathrm{CpS}$ were meant to convey. Effectiveness was to have been expressed in terms of the number of correct guesses and the times needed to produce them. 
4. Many thanks are due to Mrs Jane Lambert, Head of English at Archbishop Holgate's School, and particularly to Mr Andrew Rogerson, teacher at the same school and Director of the Bumholme School of Adult Education, for their liberal help in the organization of the tests.

5. Moreover, the fact that 'strike' is an existing English word may have confused the subjects.

6. Strictly speaking, "clothes-maker" should not have been used in this study as an example of 'Transfer', since it can also be classified as an analytic strategy (cf. section 4.3.3). 


\section{Conclusion}

The last chapter of this thesis will be devoted to a general discussion of the Nijmegen project and its implications. Firstly, there will be an evaluation of the experimental design (in section 11.1). This includes the choice of tasks and subjects, the method used to identify $\mathrm{CpS}$, and the taxonomy employed for their classification. In section 11.2 some of the theoretical assumptions which lay at the basis of the Nijmegen project will be reviewed in the light of the project's findings. In addition, the definition of CpS will be reconsidered. Section 11.3 contains a general discussion of the findings reported in chapters 8, 9 and 10, and attempts to bring out the relationship between them. Section 11.4 deals with the implications of the Nijmegen project for the study of second language use (section 11.4.1), and with its more practical implications for foreign language pedagogy (section 11.4.2). The last section (section 11.5) contains some suggestions for future research.

\subsection{Evaluation of the experimental design}

To increase the generalizability of the results, the Nijmegen project was designed so that each subject performed four different tasks. Three of these tasks (the picture description task, the story retell task and the oral interview) were developed to elicit data relevant to research question 1, conceming the relationship between the subjects' $\mathrm{CpS}$ use and their $\mathrm{L} 2$ proficiency level. The other task (the abstract figure description task) was included to answer research question 2 and enabled us to compare the subjects' use of referential strategies in the $\mathrm{L} 1$ and the $\mathrm{L} 2$. The decision to have several tasks tumed out to have been of crucial importance. As the results reported in chapter 8 showed, the use of $\mathrm{CpS}$ is largely task-specific. This was reflected in two ways: firstly, the distribution of CpS types differed between tasks I, III and IV; and secondly, the proficiency-related differences that were found (in the use of holistic strategies and transfer strategies) showed up in some of the tasks only. In effect, this means that if only one task had been used, the conclusions with respect to task-related variation would not have been drawn, while the conclusions concerning proficiency-related differences would most likely have been distorted.

The choice of tasks proved to be quite felicitous. Each task presented the subjects with a large number of lexical problems, so that many $\mathrm{CpS}$ were elicited. A fortunate coincidence in this respect was that the number of (superordinate) CpS used in tasks I, III and IV was virtually equal. This increased the comparability of the proportions on which the statistical analyses were based. A third advantage of the tasks used is that they differed in certain 
predetermined aspects, so that it was possible to pinpoint factors like 'task demands', 'time' and 'presence of the interlocutor', which contributed to the task-related variation in $\mathrm{CpS}$ use. Through a combination of these more specific task-related factors with general principles of communication it was possible to account for the observed variation in the use of $\mathrm{CpS}$.

The choice of subjects presented more problems. Although it was possible to select three groups of subjects for whom the tasks were sufficiently difficult to elicit CpS, but not too difficult to frustrate them, it was felt that the proficiency levels of these three groups may have been too high to capture all of the proficiency-related differences in $\mathrm{CpS}$ use. This feeling was strengthened when Van den Broek (1988) found that subjects who had been leaming English for only six months used a much larger proportion of transfer strategies in the story retell task Even though Van den Broek's study was small-scale and involved only one task, her findings suggest that in future studies it would be advisable to include at least one group of subjects whose proficiency level is much lower than that of the subjects in our study.

As to the procedure of CpS identification followed in the Nijmegen project, it can be said that in general it was satisfactory. The degree of correspondence between the two judges who identified $\mathrm{CpS}$ on the basis of problem markers (= method 1) was not particularly high, but this problem was reduced by including only those utterances in the corpus which had been marked as $\mathrm{CpS}$ by both of them. Moreover, the use of retrospective data (= method 2 ) proved to be invaluable and this also made up for some of the inadequacies of the first method.

Now that the value of retrospective data has been established, it will be clear that the reliability of the identification procedure can be improved by allowing judges to base their decisions conceming $\mathrm{CpS}$ use on all the data available. In other words, all judges should have access to both audible and visible problem indicators and to the subjects' retrospective comments.

Finally, some comments may be made with respect to the taxonomy which was developed as part of the Nijmegen project. Its most important advantage, as has been argued in chapter 4 , is its psychological plausibility. Firstly, the distinction between conceptual and linguistic strategies captures the fact that speakers (or writers) draw on two different knowledge sources to solve their lexical problems. And secondly, the distinctions between the 'Analytic' and 'Holistic' conceptual strategies and the linguistic strategies of 'Transfer' and 'Morphological Creativity' reflect differences in the processes underlying these strategies. One of the assets of the taxonomy's psychological plausibility is that the observed differences in CpS use could be accounted for in terms of factors that affect the processes underlying them. For instance, the relatively large use of holistic strategies and transfer strategies in task IV (the interview) could be ascribed (in part) to the fact that the task was more complex and imposed a time limit. As a result, the subjects could not always spend the 
processing effort required for the production of the more complex analytic strategies.

A practical advantage of the new taxonomy is that it can be applied fast and reliably, that is, with great consistency. Obviously, the success with which the taxonomy can be applied is closely related to its parsimony. Another practical advantage of the fact that only a small number of $\mathrm{CpS}$ types has been distinguished is that this considerably facilitated the statistical analyses and the subsequent interpretation of the results. ${ }^{1}$

The dual coding system which was described in chapter 7 was useful in that it allowed a more detailed description of the data. The most important advantage of this is that a comparison of the Nijmegen results with the results of previous studies is made much easier. Even so, it should be evident that in the long run a parsimonious and psychologically plausible taxonomy such as the one presented in chapter 4 is much to be preferred.

\subsection{Some theoretical considerations}

In the first chapter of this thesis two issues have been discussed which were fundamental to the Nijmegen project. The first of these concemed our treatment of CpS use as an aspect of language use, not leaming, while the second concerned our position that $\mathrm{CpS}$ use is not $\mathrm{L} 2$-specific. The decision to relate the study of CpS to studies of communication was a direct result of our having taken these two assumptions as starting-points. It was felt that a more general approach like this was needed to bring out the commonalities in L1 and L2 speakers' use of CpS.

In retrospect, it can be concluded that the study of communication has provided a useful framework for the study of CpS. Firstly, the notion of $\mathrm{CpS}$ could be clarified by embedding it in Levelt's (1989) model of communication. It was demonstrated at which point in the speech production process the need for $\mathrm{CpS}$ arises, and what altemative means of encoding a speaker can adopt when lexical problems threaten to disturb this process. As a result, the use of $\mathrm{CpS}$ as well as the use of 'Reduction Strategies' and 'Interactive Strategies' could be described in more tangible forms. At the same time Levelt's model could be used to explain the differences in the psychological processes underlying the use of 'Analytic' and 'Holistic' conceptual strategies and the linguistic strategies of 'Transfer' and 'Morphological Creativity'. In this way the psychological plausibility of the distinctions made in the taxonomy could be brought out.

Secondly, it tumed out that general principles of communication such as the 'cooperative principle' and the 'principle of economy' provided an adequate account of the observed task-related variation in $\mathrm{CpS}$ use. The explanatory value of these principles with respect to our data strengthens our claim that 
CpS should be studied as an aspect of communication, and hence, that the study of CpS use should be integrated into the study of communication.

To support our position that the use of $\mathrm{CpS}$ is not $\mathrm{L} 2$-specific, it was pointed out in chapter 1 that there are many similarities between the lexical strategies adopted by L2 leamers with a limited command of the L2 lexicon and the strategies adopted by teachers, experts, dictionary writers, aphasics, and native speakers who cannot retrieve, or are not allowed to use a particular word (as in quizzes). In addition, parallels were drawn between $\mathrm{CpS}$ use and the use of lexical innovations by children acquiring the $\mathrm{L} 1$, the mechanisms of lexical expansion developed in pidgins, and the lexical simplification strategies in motherese, foreigner talk and simplified readers.

Further evidence for the assumption that the use of $\mathrm{CpS}$ is not $\mathrm{L} 2$-specific was yielded by the task II data (the abstract figure description task). The comparison of the subjects' referential strategies in the $\mathrm{L} 1$ and $\mathrm{L} 2$ versions of this task showed them to be very similar, which suggests that L2 leamers can apply their L1 strategic competence in L2 situations. Consequently, it can be assumed that in the case of $\mathrm{CpS}$ use too L2 leamers will exploit their L1 strategic knowledge, so that similar $\mathrm{CpS}$ will be used in $\mathrm{L} 1$ and $\mathrm{L} 2$ situations.

In the second part of this section the working definition of $\mathrm{CpS}$, which has been presented in chapter 2 , will be reconsidered. It is repeated here for convenience's sake.

"Compensatory strategies are strategies which a language user employs in order to achieve his intended meaning on becoming aware of problems arising during the planning phase of an utterance due to his own linguistic shortcomings" (Poulisse et al., 1984:72)

It has already been pointed out in chapter 2 that this definition is general in some respects (language user, linguistic shortcomings), and specific in others (problems during the planning phase, due to the language user's own linguistic shortcomings). It will be evident that the definition should be changed on the latter points, so that it will also cover the solution of problems that arise at a later stage in the speech production process, as well as potential comprehension problems on the part of the interlocutor, for which the language user may want to compensate in advance.

In addition, it was felt that it would be appropriate if a definition of CpS did not only define $\mathrm{CpS}$ as a process, but would also specify the outcome of that process. After all, all research on $\mathrm{CpS}$ is of necessity based on the linguistic products resulting from $\mathrm{CpS}$ use. We therefore suggest the following definition:

Compensatory strategies are processes, operating on conceptual and linguistic knowledge representations, which are adopted by language users in the creation of 
alternative means of expression when linguistic shortcomings make it impossible for them to communicate their intended meanings in the preferred manner.

In this definition $\mathrm{CpS}$ are first and foremost defined as processes, viz. as processes which operate on conceptual and linguistic knowledge representations. The products which result from these processes are defined as alternative means of expression, and these may, of course, be either verbal or non-verbal.

To distinguish the use of compensatory strategies from the larger class of referential strategies, the definition specifies that the reason for $\mathrm{CpS}$ use resides in linguistic shortcomings. In this respect it is irrelevant whether language users compensate for their own linguistic shortcomings (as in the present study), their listeners' shortcomings (as in the case of native speakers communicating with L2 leamers, mothers communicating with children, experts with laymen or dictionary makers with potential consultants), or linguistic shortcomings which have been artificially imposed (as in the case of quizzes and language games). It is also irrelevant whether the shortcomings are permanent or temporary.

Like the working definition this new definition should be read from the language user's perspective, since it is the language user who determines whether or not an expression is the preferred manner of referring to a particular concept. Since the definition specifies that it is impossible for the language user to use the preferred means of expression, problematicity is presupposed in this definition too. However, problematicity by itself is not a definitional criterion. Firstly, the language user who is unable to encode his preferred means of expression, because his mental lexicon does not contain a fully specified lexical item for a particular concept included in the preverbal message, is not necessarily conscious of there being a problem. If an altemative way of encoding presents itself immediately, it is, in fact, highly unlikely that the speaker perceives any difficulty at all. And secondly, there are situations in which linguistic problems may accompany the use of referential strategies which are similar to, but not the same as CpS, e.g. when one is referring to abstract figures which have no conventional names, when one is looking for the best stylistic variant or when one is devising a new brand name. What is criterial to CpS use, therefore, is not so much 'problematicity', but rather the speaker's awareness of the existence of an alternative means of expression which he would have preferred to use if he had been able to do so.

The operationalization of this criterion requires the elicitation of retrospective data just as much as the criteria specified in the working definition did. Only in this way will it be possible to determine whether or not the language users considered their expressions the preferred manner of reference, and hence, whether or not they used CpS. 


\subsection{General discussion of the results}

The most striking result obtained in the Nijmegen project concerns the enormous differences in the subjects' use of $\mathrm{CpS}$ in tasks I, III and IV. In the picture description task (task I) virtually all $\mathrm{CpS}$ were analytic, while in the story retell task (task III) and particularly in the oral interview (task IV) holistic strategies and transfer strategies were also used relatively frequently. In chapter 8 these differences were explained in terms of the cooperative principle and the principle of economy. The combination of these principles predicts, first of all, that of two equally effective $\mathrm{CpS}$ (i.e. two $\mathrm{CpS}$ which are expected to be equally communicative) the speaker will use the one that requires least effort. And secondly, it predicts that the speakers will strive to maintain a balance between effort and effect. In practice, this means that the subjects will attempt to use effective $\mathrm{CpS}$, unless they consider the amount of effort to be expended on these $\mathrm{CpS}$ disproportionate to the expected effect.

How much effort the speaker is prepared to expend on a particular $\mathrm{CpS}$ - in other words, how much effort he considers proportionate to the expected effect - depends on his communicative goal and on the amount of time available to him. Thus, in task $\mathrm{I}$, where achievement of the communicative goal was important (the task demanded every single lexical problem to be solved) and where there was no time limit, the amount of effort the subjects were prepared to expend was relatively large. In tasks III and IV, however, it was much smaller, particularly in the case of lexical problems whose solution was not considered very relevant. This explains why analytic strategies, which are generally effective (see chapter 10), but require much effort (see chapter 4), were more popular in task I than in tasks III and IV. Similarly, it explains why holistic strategies and transfer strategies, which are only effective under certain conditions (see again chapter 10), but generally require relatively little effort (see chapter 4 ), occur more frequently in tasks III and IV.

As in task I, the subjects' referential strategies in task II were often quite extensive, since the subjects frequently added partitive or linear strategies to their initial holistic strategies (usually analogies in this task). Again, the most likely explanation for this is that task Il did not confront the subjects with a time constraint, so that there was no reason for them not to spend extra effort if they thought this would make their referential phrases more effective.

The 'York study of effectiveness' yielded results which substantiated the explanation given for the task-related variation in $\mathrm{CpS}$ use. Firstly, it was found that analytic strategies are intrinsically more effective than transfer strategies which, in turn, are intrinsically more effective than holistic strategies. As a consequence, these strategies are increasingly less appropriate for use in tasks which provide little contextual information. 
Secondly, the York study confirmed the (intuitively obvious) assumption that transfer strategies are generally effective if the $\mathrm{L} 1$ word is linguistically similar to the intended L2 word. This implies that such CpS are suitable for use in all tasks, since transfer strategies as a rule require little effort and are therefore not subject to time constraints. The absence of (superordinate) transfer strategies in task I can be explained as follows: with one exception, the $\mathrm{L} 1$ words referring to the concepts depicted in this task could not be easily transformed into English on the basis of linguistic correspondence rules, so that transfer strategies would hardly have been effective here. Note, however, that transfer strategies were used in task I to compensate for some of the subordinate problems, as they were in tasks III and IV.

Thirdly, the 'York study of effectiveness' brought out the fact that in some cases the use of an intrinsically effective $\mathrm{CpS}$ is made redundant by the information contained in the context. This is in accordance with the finding that holistic strategies, and transfer strategies involving $L 1$ words that bear no linguistic resemblances to the intended L2 words, were used in tasks III and IV to solve lexical problems which were embedded within the context of the ongoing discourse (i.e. the story or the interview).

To conclude this section, it seems useful to make a distinction between effectiveness and efficiency. $\mathrm{CpS}$ are effective if they enable the interlocutor to infer the intended meaning. They are efficient if they are effective, and if they take a minimum of processing effort, both from the speaker to produce them and from the listener to understand them. Thus, whereas several $\mathrm{CpS}$ may be equally effective, the one that is produced and understood with the least effort will be the most efficient one.

Efficient $\mathrm{CpS}$ use is obviously in accordance with the principle of economy. Hence, it would not be surprising if the subjects in the Nijmegen project, whose referential behaviour seems to have been guided by this principle, aimed at using efficient rather than effective $\mathrm{CpS}$.

\subsection{Implications of the Nijmegen project}

The Nijmegen project has shown that CpS use is subject to general principles of communication. The implications of this finding are straightforward. Future studies of $\mathrm{CpS}$ use should be integrated into the study of communication.

The project also has certain implications for the study of second language use. They will be discussed in section 11.4.1. In section 11.4.2 the pedagogical implications of the project's findings will be considered. They are, of course, closely related to the conclusions reached in chapters 9 and 10. 
The Nijmegen project has but few implications for second language acquisition research, which is not surprising in view of the fact that it was primarily a study of (second) language use. The subjects were tested only once, and there were no attempts to establish the learning effects of $\mathrm{CpS}$ use. Another reason why this study has little to say about the process of second language acquisition is that relatively few proficiency-related differences were found with respect to the choice of particular CpS types. The ones that were found concemed the greater use of superordinate holistic strategies by the most advanced leamers in the story retell task and the oral interview, and the greater use of transfer strategies by the less proficient subjects, particularly in the story retell task. The greater use of holistic strategies in the case of university students seems to take place at the expense of their use of transfer strategies, certainly when they are subordinate. Presumably, this is because advanced learners have a larger vocabulary store from which they can more easily draw suitable lexical alternatives. This conclusion is obviously not very spectacular though.

The implications with respect to the study of second language use are somewhat more interesting. It was found that the use of $\mathrm{CpS}$ varied considerably over the picture description task, the story retell task and the oral interview. In fact, the task factor was so important that in some cases it overruled proficiency-related differences and individual differences apparent in other tasks. This clearly underlines the necessity of studying second language use in a variety of situations.

The importance of the task factor has been demonstrated in many other studies of second language use (cf. Tarone, 1988, for a recent overview). Most of these, however, were not set up to investigate the task factor per se, so that it was often difficult to say what caused the task-related variation. Although the Nijmegen project was not set up to investigate the task factor either, it had the advantage that the tasks were deliberately chosen so as to vary in aspects like 'feedback' and 'possibility of avoiding problems' (or 'task demands'). This made it relatively easy to isolate the more specific task-factors that were responsible for the differences in CpS use. Like Tarone (1988:116/117), we would therefore like to conclude that the selection of tasks should receive considerably more attention in studies of second language use. In particular, researchers who are interested in the task factor should be aware of the aspects in which tasks differ from each other, and should exploit the possibility of manipulating these.

\subsubsection{Foreign language pedagogy}

In the past few years foreign language teachers have become increasingly interested in $\mathrm{CpS}$. Being aware of the fact that it is impossible to teach leamers 
all the linguistic means they may need in future, they have come to appreciate the value of $\mathrm{CpS}$ as an alternative means to cope with linguistic difficulty. They have therefore raised the question which role $\mathrm{CpS}$ should play in the foreign language classroom (e.g. Willems, 1987). More specifically, they would like to know how the use of CpS can be promoted, whether learners require instruction and practice in the use of $\mathrm{CpS}$, whether some $\mathrm{CpS}$ types are more useful than others, and what sort of exercises they should use.

Of the three research questions addressed in the Nijmegen project two are relevant to foreign language pedagogy. They are the questions concerning the relationship between CpS use in L1 and L2 (chapter 9) and the relative effectiveness of CpS types (chapter 10).

The comparison of the use of referential strategies in the two different language versions of task II indicated that subjects generally use the same strategies in L1 and L2. Only when lexical problems make it impossible for them to realize their preferred strategy in the L2, do they adopt a different strategy. These 'last resort strategies' are not specific to the L2, though. They are also used in the L1 and may therefore be considered part of the subjects' strategic competence.

Considering the similarities between lexical $\mathrm{CpS}$ and the referential strategies used in the abstract figure description task, it can be assumed that $\mathrm{CpS}$ use too is based on a common strategic component. Having acquired the ability to use $\mathrm{CpS}$ in the course of leaming their L1, L2 learners can be expected to make use of this ability in L2 situations too. For the foreign language classroom this implies that strictly speaking there is no need to teach subjects about different types of $\mathrm{CpS}$, how they can be constructed, and when they should be used. This conclusion is confirmed by the data collected in the Nijmegen project. Even though none of the subjects had received any instruction about $\mathrm{CpS}$ prior to the experimentation, they all managed to solve most of their lexical problems by using $\mathrm{CpS}$.

Still, one should be careful not to jump to the conclusion that instruction and exercises in the use of $\mathrm{CpS}$ can be banned from the classroom altogether. Færch \& Kasper (1986) report a study by Brodersen, Gibson and Svendsen (see Brodersen \& Gibson, 1982) in which subjects' communicative abilities were greatly improved after they had received instruction in $\mathrm{CpS}$ use. ${ }^{2}$ Even though only "those leamers who belonged to the middle level of proficiency in the class had made progress towards using more appropriate risk-taking strategies ... the general attitude in the class towards errors and towards risk-taking had changed, more learners accepting the need to make an attempt even if they did not have the right word" (Færch \& Kasper, 1986:190). The advantages of an attitudinal change like this are obvious. Leamers who are afraid to make mistakes will never be good communicators. Conversely, leamers who have experienced that $\mathrm{CpS}$ help them to communicate successfully in spite of their limited knowledge of the L2, will be more 
motivated to communicate. This, in tum, will not only provide them with more opportunities for learning the language, but may also increase their motivation to leam it.

Consequently, encouraging leamers to use $\mathrm{CpS}$ - and instructing them about $\mathrm{CpS}$ is one way of doing this - may well be useful, both from a communicative and from a learning point of view.

The study of effectiveness reported in chapter 10 was originally set up to establish which $\mathrm{CpS}$ types are most effective, the implication being that these $\mathrm{CpS}$ types should be taught in the foreign language classroom. Since it has just been argued that it is not really necessary to explicitly teach CpS, the implications of this study are somewhat more restricted than we had at first assumed. Still, the results may suggest which $\mathrm{CpS}$ types leamers should be encouraged to use.

The effectiveness study did not yield a straightforward answer to this question. Rather, it led to the conclusion that one cannot speak of more or less effective $\mathrm{CpS}$ types, since the effectiveness of a particular $\mathrm{CpS}$ depends largely on its realization and on the context in which it is used. This implies that from a communicative point of view it is not very realistic to stimulate the use of some CpS types and not others. After all, even $\mathrm{CpS}$ like transfer strategies, which were always thought to be ineffective, do in some cases enable speakers to get their meaning across.

Still, there are two reasons for encouraging the use of analytic strategies and combinations of holistic and analytic strategies. One is that these $\mathrm{CpS}$ are intrinsically most effective (provided, of course, that they are sufficiently informative). This means that they are generally successful, even when the context in which they are used provides little (or no) additional information. Consequently, the speaker who uses $\mathrm{CpS}$ of these two kinds is very likely to reach his communicative goals. Another reason why L2 leamers should be encouraged to use analytic strategies and combinations of holistic and analytic strategies is that such $\mathrm{CpS}$ require the use of the $\mathrm{L2}$, which makes them preferable from a didactic point of view.

How teachers should promote the use of $\mathrm{CpS}$ is a moot point. Færch \& Kasper (1986) and Willems (1987) have suggested the use of information gap activities which require learners to solve communicative problems caused by lexical shortcomings (see also Littlewood, 1981; and Pattison, 1987, for examples). Such activities may indeed be very useful, if only because they may convince learners that it is possible to achieve understanding even if one's L2 productions are not error-free.

At the same time it is important not to abandon vocabulary leaming (Færch \& Kasper, 1986:189). Particularly in the case of conceptual strategies, a basic command of the $\mathrm{L} 2$ vocabulary is indispensable. It has already been pointed out that effective CpS use may require a minimum level of proficiency 
(Bialystok, 1983). ${ }^{3}$ For efficient $\mathrm{CpS}$ use, this seems to be all the more true. The use of holistic strategies by the less proficient subjects in the Nijmegen project was relatively small, presumably because their limited L2 vocabulary made it impossible for them to encode them. As a result, less efficient strategies had to be used. Another example of less efficient $\mathrm{CpS}$ use due to an inadequate command of vocabulary is the use of many subordinate $\mathrm{CpS}$ embedded in analytic strategies. The encoding, but also the decoding of these strategies, was often very effort demanding, and not always effective.

In conclusion then, the implications of the Nijmegen project for foreign language pedagogy can be summarized as follows. First, teachers should encourage their leamers to use $\mathrm{CpS}$ in class, for instance by stimulating the use of such strategies in information gap activities. And second, teachers should not neglect the learning of vocabulary, since a greater command of the vocabulary (besides reducing the need to use $\mathrm{CpS}$ ) seems to be related to more efficient $\mathrm{CpS}$ use.

\subsection{Suggestions for further research}

The present study revealed a number of areas which call for future research. Most important in this respect is the need for further studies of the processes underlying $\mathrm{CpS}$ use. One would like to know more precisely how different types of $\mathrm{CpS}$ are integrated into the speech production process. In addition, it would be useful to investigate what causes a speaker to adopt a particular CpS. Is it, for instance, the case that speakers follow a certain selection order and that they first consider those $\mathrm{CpS}$ which require least effort and resort to the more demanding types only if the former do not pass the evaluation stage? One way of answering questions like these would be to examine the effect of increasing time constraints in tasks I and III. In this condition subjects are likely to use those $\mathrm{CpS}$ which they would reject if they had more time.

Further research is also required with respect to CpS adopted to overcome grammatical and phonological problems. The Nijmegen taxonomy was set up for lexical CpS only and it is not clear whether one should attempt to extend it to strategies compensating for other kinds of linguistic problems. Phonological problems in any case seem to be of a different order. They are generally solved by replacing the problematic phoneme (e.g./ /) with one that is unproblematic (e.g. /d/) and the distinction between conceptual and linguistic strategies is hardly relevant here. On the other hand, the distinction may be applicable to grammatical CpS. The substitution of "je vais aller" for ' $\mathrm{j}$ ' irai' can be conceived of as a conceptual strategy, while the use of an active structure to replace a passive one is classifiable as a linguistic strategy.

In view of the similarities between $\mathrm{L} 1$ and $\mathrm{L} 2 \mathrm{CpS}$ use, it would also be advisable to study the use of CPS by $\mathrm{L} 1$ speakers. In particular, it would be 
interesting to investigate the use of $\mathrm{CpS}$ by young children, since these are often confronted with linguistic gaps similar to those experienced by adult L2 learners. The establishment of a firm link between studies of $\mathrm{L} 1$ and $\mathrm{L} 2$ acquisition (or leaming) and communication is undoubtedly a prerequisite for the development of one general theory of language acquisition and use, and this should, of course, be our ultimate aim.

There are also a number of more practical areas in which further research may be desirable. Most obvious is the need for a study involving a group of less proficient subjects. Such a study may reveal proficiency-related differences which remained hidden in the Nijmegen project.

Studies including less proficient subjects may also shed light on the minimal proficiency level required for efficient $\mathrm{CpS}$ use. For this purpose it is important that the proficiency groups are selected with great care. Preferably, there should be several low proficiency groups whose proficiency levels vary only little with respect to each other. In this way it may be possible to pinpoint differences in CpS use to minor differences in the subjects' proficiency levels. Another possibility is to set up a longitudinal study, in which L2 learners are engaged in conversations or other communicative tasks from the very first stage of language learning. By observing their language use at daily/weekly intervals it should be possible to detect when they start using $\mathrm{CpS}$, and when they start doing so efficiently.

As far as the choice of subjects is concemed future research might also follow up on the studies by Tarone (1977), Palmberg (1979) and Haastrup \& Phillipson (1983), in which attempts were made to establish the effects of L2 leamers' $\mathrm{L} 1$ backgrounds and personalities on their use of CmS. 'L1 background' probably affects the leamers' use of transfer strategies, since these tend to be ineffective when their L1s are unrelated to the target language. The effect of 'personality' is obscure, but the results reported in chapter 8 do seem to suggest that individual differences in the leamers' cognitive styles, which are closely related to their personalities, affect their use of $\mathrm{CpS}$. Research in this area, however, should be set up much more carefully than has been customary until now. Firstly, the learners' personalities and/or their cognitive styles should be properly established. And secondly, other person-related factors like 'L2 proficiency level', 'L1 proficiency level' (or 'general linguistic ability'), 'age' and 'social status' should be controlled for, or included in the design as independent factors.

Finally, it would be useful to conduct further research with respect to the communicative situation. In particular, the role of the interlocutor should be investigated in more detail, since communication, and hence the solution of communicative problems, can be regarded as a joint responsibility of the speaker and the interlocutor (Clark \& Wilkes-Gibbs, 1986). Such an investigation might consist of a detailed analysis of the interlocutor's behaviour, but could also go into the effect of "interlocutor-related" aspects 
such as 'Ll background', 'knowledge of the target language', 'age', 'social status', 'personality' and so on.

Summing up, we may conclude that there are many aspects of $\mathrm{CpS}$ use which remain to be investigated. At the same time, we may express the hope that the experiences gained in the Nijmegen project will be profitable to future researchers of $\mathrm{CpS}$. The observed task-related variation in $\mathrm{CpS}$ use suggests that a combination of several elicitation methods should be used, while the lack of more substantial proficiency-related differences calls for studies with less proficient subjects. In addition, the use of retrospection in the identification procedure and the statistical analysis of proportions rather than numbers of $\mathrm{CpS}$ seem recommendable. Most important, however, is the need to adopt a psychologically plausible taxonomy of $\mathrm{CpS}$ such as the one developed for the Nijmegen project, since it is only in this way that one can direct one's attention to those factors which constrain the processes underlying $\mathrm{CpS}$ use. Eventually, this will put researchers in a much better position to explain and predict $\mathrm{CpS}$ use.

\section{Notes to chapter 11}

1. In this respect it must be remembered that separate ANOVAs were nun for each CpS type both at the super- and at the subordinate levels. With four $\mathrm{CpS}$ types distinguished, this amounted to 8 ANOVAs. If, however, we had distinguished twelve CpS types, as Farch \& Kasper (1980) did, the number of ANOVAs would have been 24, which would have made it very difficult to interpret them intelligibly. Moreover, a large number of different $\mathrm{CpS}$ types would probably have resulted in many (near-) empty cells, since none or only few instances of certain CpS types would have been used in each task. Statistically, this would have caused great problems, particularly since the ANOVAs in this study were based on proportions, which are highly susceptible to distortion via small numbers.

2. The instruction consisted of: "(1) play-back to the class of their own video-recordings, to discuss the effectiveness of different types of strategy; (2) direct teaching about communication strategies and about the interplay between the use of communication strategies and leaming; (3) role-playing activities, placing the learners in situations in which the use of strategies was inevitable; and (4) reducing the teacher 's willingness to assist and to accept Danish-based appeals" (Farch \& Kasper, 1986:189).

3. Van den Berg's (1988) data suggest that this minimum may be much lower than one has hitherto assumed. Although her subjects knew only 172 words of Bahasa Indonesia and no grammar, they were able to use (analytic conceptual) CpS effectively (see also chapter 8. note 14). 


\section{References}

Alatis, J. (ed.), (1968) Contrastive Linguistics and its Pedagogical Implications. Washington D.C.: Georgetown University Press.

Albrechtsen, D., Henriksen, B. \& Færch, C. (1980) Native speakers' reactions to learners' spoken interlanguage, Language Learning, 30, 365-396.

Alkire, A., Collum, M., Kaswan, J. \& Love, L. (1968) Information exchange and accuracy of verbal communication under social power conditions, Journal of Personality and Social Psychology, 9, 301-308.

Allen, E. (1984) Shared nomenclature: an analysis of students' communicative strategies in a foreign language, Foreign Language Annals, 17, 103-108.

Ammerlaan, T. (1984) A process-oriented approach to lexical strategies in referential communication. Unpublished M.A. thesis, Dept. of English, University of Nijmegen.

Appel, R. \& Muysken, P. (1987) Language Contact and Bilingualism. London: Amold.

Asher, J. (1969) The total physical response approach to second language learning, Modern Language Journal, 58, 24-32.

Bailey, N., Madden, C. \& Krashen, S. (1974) Is there a "natural sequence" in adult second language learning?, Language Learning, 24, 235-243.

Beattie, G. (1980) Encoding units in spontaneous speech: some implications for the dynamics of conversation. In H. Dechert \& M. Raupach (eds), Temporal Variables in Speech: Studies in Honour of Frieda Goldman-Eisler. The Hague: Mouton, 132-143.

Bentlage, A. (1985) The role of second language in dyadic referential communication. Unpublished M.A. thesis, Dept. of English, University of Nijmegen.

Benzécri, J. (1976) L'Analyse des Données, part 2: L'Analyse des Correspondences. Paris: Dunod.

Bettonvil, B. (1981) ANACOR, Correspondence Analysis of Contingency Tables. Leiden University: Dept. of Data Theory.

Bialystok, E. (1983) Some factors in the selection and implementation of communication strategies. In Færch \& Kasper (1983a), 100-118.

Bialystok, E. (1984) Strategies in interlanguage learning and performance. In Davies, Criper \& Howatt (1984), 37-48.

Bialystok, E. \& Fröhlich, M. (1980) Oral communication strategies for lexical difficulties, Interlanguage Studies Bulletin, 5.1, 3-30.

Bialystok, E. \& Kellerman, E. (1987) Process and parsimony: an analysis of leamers' communication strategies. In B. Das (ed.), Patterns of Classroom Interaction in South-East Asia. Singapore: RELC, 160-175.

Bialystok, E. \& Ryan, E. (1985) A metacognitive framework for the development of first and second language skills. In D. Forrest-Pressley, G. MacKinnon \& T. Waller (eds), Meta-cognition, Cognition, and Human Performance. New York: Academic Press, 207-252.

Bialystok, E. \& Sharwood Smith, M. (1985) Interlanguage is not a state of mind: an evaluation of the construct for second language acquisition, Applied Linguistics, 6, 101-117.

Blum-Kulka, S. \& Levenston, E. (1983) Universals of lexical simplification. In Færch \& Kasper (1983a), 119-139.

Bongaerts, T. \& Kellerman, E. (1983) Het gebruik van compensatiestrategieën door Nederlandse leerders van het Engels. Research proposal submitted to the University of Nijmegen.

Bongaerts, T., Kellerman, E. \& Bentlage, A. (1987) Perspective and proficiency in L2 referential communication, Studies in Second Language Acquisition, 9, 171-199.

Bongaerts, T. \& Poulisse, N. (in press) Communication strategies in L1 and L2: same or different? To appear in Applied Linguistics. 
Bors, L., Duijvelaar, G. \& Reinders, M. (1985) Een objectieve meting van de effectiviteit van compensatiestrategieën. Unpublished term paper, Dept. of Applied Linguistics, University of Nijmegen.

Bransford, J., Barclay, J. \& Franks, J. (1972) Sentence memory: a constructive versus an interpretive approach, Cognitive Psychology, 3, 193-209.

Brodersen, D. \& Gibson, K. (1982) Kommunikationsstrategier i folkeskolen, Sproglareren, 7, 26-36.

Brown, G. \& Yule, G. (1983) Teaching the Spoken Language. Cambridge: Cambridge University Press.

Brown, H. (1973) Affective variables in second language acquisition, Language Learning, 23, $231-244$.

Brown, H. (1987) Principles of Language Learning and Teaching, 2nd edition. Englewood Cliffs, N.J.: Prentice-Hall.

Brown, R. (1958) How shall a thing be called?, Psychological Review, 65, 14-21.

Butterworth, B. \& Beattie, G. (1978) Gesture and silence as indicators of planning in speech. In R. Candlin \& P. Smith (eds), Recent Advances in the Psychology of Language: Formal and Experimental Approaches. New York: Plenum Press, 347-360.

Brumfit, C. \& Johnson, K. (eds), (1979) The Communicative Approach to Language Teaching. Oxford: Oxford University Press.

Canale, M. \& Swain, M. (1980) Theoretical bases of communicative approaches to second language teaching and testing, Applied Linguistics, 1, 1-47.

Carroll, J. (1980) Naming and describing in social communication, Language and Speech, 23, 309-322.

Carroll, J., Bever, T. \& Pollack, C. (1981) The non-uniqueness of linguistic intuitions, Language, 57, 368-383.

Chomsky, N. (1959) A review of B.F. Skinner's Verbal Behaviour, Language, 35, 26-58. Reprinted in J. Fodor \& J. Katz (eds), (1964) The Structure of Language: Readings in the Philosophy of Language. Englewood Cliffs, N.J.: Prentice Hall, 547-578.

Chomsky, N. (1965) Aspects of the Theory of Syntax. Cambridge, Mass.: M.I.T. Press.

Clark, E. (1981) Lexical innovations: how children leam to create new words. In W. Deutsch (ed.), The Child's Construction of Language. London: Academic Press, 299-328.

Clark, E. (1983a) Meanings and concepts. In J. Flavell \& E. Markman (eds), Handbook of Child Psychology, vol. 3: Cognitive Development. New York: Wiley, 787-840.

Clark, E. (1983b) Convention and contrast in acquiring the lexicon. In T. Seiler \& W. Wannenmacher (eds), Concept Development and the Development of Word Meaning. Berlin: Springer Verlag, 67-89.

Clark, H. (1985) Language use and language users. In G. Lindzey \& E. Aronson (eds), The Handbook of Social Psychology, vol. 3, 3rd edition. New York: Harper and Row, 179-231.

Clark, H. \& Carlson, T. (1982) Speech acts and hearers' beliefs. In Smith (1982), 1-36.

Clark, H. \& Clark, E. (1977) Psychology and Language. New York: Harcourt Brace Jovanovich.

Clark, H. \& Marshall, C. (1981) Definite reference and mutual knowledge. In A. Joshi, B. Webber \& I. Sag (eds), Elements of Discourse Understanding. Cambridge: Cambridge University Press, 10-63.

Clark, H. \& Wilkes-Gibbs, D. (1986) Speaking as a collaborative process, Cognition, 22, 1-39.

Cohen, A. \& Robbins, M. (1976) Toward assessing interlanguage performance: the relationship between selected errors, leamers' characteristics and leamers' explanations, Language Learning, 26, 45-67. 
Cook, V. (1985) Chomsky's universal grammar and second language leaming, Applied Linguistics, 6, 2-18.

Cook, V. (1988) Chomsky's Universal Grammar. Oxford: Basil Blackwell.

Corder, S. (1967) The significance of leamers' errors, IRAL, 5, 161-170.

Corder, S. (1973a) The elicitation of interlanguage. In J. Svartvik (ed), Errata: Papers in Error Analysis. Lund: Gleerup, 36-47.

Corder, S. (1973b) Introducing Applied Linguistics. Harmondsworth: Penguin.

Corder, S. (1978) Strategies of communication. In M. Leiwo \& A. Räsänen (eds), Publications de l'Association Finlandaise de Linguistique Appliquée, 23, 7-12. Reprinted in Færch \& Kasper (1983a), 15-19.

Corder, S. (1981) Language continua and the interlanguage hypothesis. In S. Corder (ed.), Error Analysis and Interlanguage. Oxford: Oxford University Press, 87-94.

Corrales, O. (1985) The use of communication strategies in second language learning. Unpublished doctoral dissertation, University of Pittsburgh

Dạvies, A., Criper, C. \& Howatt, A. (eds), (1984) Interlanguage. Edinburgh: Edinburgh University Press.

Dechert, H. (1983) How a story is done in a second language. In Farch \& Kasper (1983a), 175-195.

Dechert, H., Möhle, D. \& Raupach, M. (eds), (1984) Second Language Productions. Tübingen: Narr.

Dechert, H. \& Raupach, M. (eds), (1980) Towards a Cross-Linguistic Assessment of Speech Production. Frankfurt: Lang.

Dell, G. (1986) A spreading-activation theory of retrieval in sentence production, Psychological Review, 93, 283-321.

De Jong, J. (1988) Some cross-national comparative data on tests of English as a foreign language. Unpublished internal report, Cito, Dutch National Institute for Educational Measurement, Amhem.

De Keyser, R. (1986) From learning to acquisition? Foreign language development in a U.S. classroom and during a semester abroad. Unpublished doctoral dissertation, Stanford University.

De Villiers, J. \& De Villiers, P. (1981) Methods for the study of language acquisition. In R. Vasta (ed.), Strategies and Techniques of Child Study. New York: Academic Press.

Di Pietro, R. (1979) Verbal strategies in the modern language classroom, Bulletin of the PMLA, 57, 3-10.

Di Pietro, R. (1982) The open-ended scenario: a new approach to conversation, TESOL Quarterly, 16, 449-464.

Dickson, W. (1982) Two decades of referential communication research: a review and meta-analysis. In C. Brainerd \& M. Pressley (eds), Verbal Processes in Children. New York: Springer, 1-33.

Dulay, H. \& Burt, M. (1972) Goofing: an indicator of children's second language leaming strategies, Language Learning, 22, 235-252.

Dulay, H. \& Burt, M. (1973) Should we teach children syntax?, Language Learning, 23, 245-258.

Dulay, H. \& Burt, M. (1974a) You can't learn without goofing. In J. Richards (ed.), Error Analysis. Perspectives on Second Language Acquisition. London: Longman, 95-123.

Dulay, H. \& Burt, M. (1974b) Natural sequences in child second language acquisition, Language Learning, 24, 37-53.

Edgington, E. (1987) Randomization Tests, 2nd edition. New York: Dekker.

Eisenstein, M. (1983) Native reactions to non-native speech: a review of empirical research, Studies in Second Language Acquisition, 5, 160-176.

Ekman, P. \& Friesen, W. (1969) The repertoire of nonverbal behavior: categories, origins, usage, and coding, Semiotica, 1, 49-98. 
Ellis, H. (1968) Transfer of stimulus predifferentiation to shape recognition and identification leaming: role of properties of verbal labels, Journal of Experimental Psychology, 78, 401-409.

Ellis, R. (1984) Communication strategies and the evaluation of communicative performance, ELT Journal, 38, 39-44.

Ellis, R. (1985) Understanding Second Language Acquisition. Oxford: Oxford University Press.

Elsen, A., De Kleine, M., De Vries, P. \& Weynen, G. (1982) Proficiency level and the use of compensatory strategies by learners of English as a foreign language. Unpublished term paper, Dept. of Applied Linguistics, University of Nijmegen.

Ericsson, K. \& Simon, H. (1984) Protocol Analysis: Verbal Reports as Data. Cambridge, Mass.: MIT Press.

Ervin, G. (1979) Communication strategies employed by American students of Russian, Modern Language Journal, 63, 329-334.

Frrch, C. (1984) Strategies in production and reception, the empirical evidence. In Davies, Criper \& Howatt (1984), 49-70.

Færch, C. \& Kasper, G. (1980) Processes and strategies in foreign language learning and communication, Interlanguage Studies Bulletin, 5.1, 47-118.

Farch, C. \& Kasper, G. (eds), (1983a) Strategies in Interlanguage Communication. London: Longman.

Færch, C. \& Kasper, G. (1983b) Plans and strategies in foreign language communication. In Farch \& Kasper (1983a), 20-60.

Færch, C. \& Kasper, G. (1983c) On identifying communication strategies in interlanguage production. In Færch \& Kasper (1983a), 210-238.

Færch, C. \& Kasper, G. (1984) Two ways of defining communication strategies, Language Learning, 34, 45-63.

Færch, C. \& Kasper, G. (1986) Strategic competence in foreign language teaching. In G. Kasper (ed.), Learning, Teaching and Communication in the Foreign Language Classroom. Arhus: University of Ârhus, 179-193.

Færch, C. \& Kasper, G. (eds), (1987a) Introspection in Second Language Research. Clevedon: Multilingual Matters.

Færch, C. \& Kasper, G. (1987b) From product to process - introspective methods in second language research. In Færch \& Kasper (1987a), 5-23.

Fakhri, A. (1984) The use of communicative strategies in narrative discourse: a case study of a leamer of Moroccan Arabic as a second language, Language Learning, 34, 15-38.

Ferguson, G. (1981) Statistical Analysis in Psychology and Education, 5th edition. New York: McGraw-Hill.

Galván, J. \& Campbell, R. (1979) An examination of the communication strategies of two children in the Culver City Spanish Immersion Program. In R. Andersen (ed.), The Acquisition and Use of Spanish and English as First and Second Languages. Washington, D.C.: TESOL, 133-150.

Garman, M. \& Hughes, A. (1983) English Cloze Exercises: With Answers and Explanations. Oxford: Basil Blackwell.

Gazdar, G. \& Good, D. (1982) On a notion of relevance. In Smith (1982), 88-100.

George, H. (1972) Common Errors in Language Learning. Rowley, Mass.: Newbury House.

Gifi, A. (1981) Non-linear Multivariate Analysis. Leiden University: Dept. of Data Theory.

Glahn, E. (1980) Introspection as a method of elicitation in interlanguage studies, Interlanguage Studies Bulletin, 5.1, 119-128.

Glahn, E. (1985) The metalinguistic phase in conversations between native speakers and learners. In E. Glahn \& A. Holmen (eds), Learner Discourse (= Anglica et Americana, 22), Copenhagen: University of Copenhagen, 24-42. 
Glucksberg, S. \& Cohen, J. (1968) Speaker processes in referential communication: message choice as a function of message adequacy. Proceedings of the Seventy-sixth Annual Convention, American Psychological Association.

Glucksberg, S. \& Krauss, R. (1967) What do people say after they have learned how to talk? Studies of the development of referential communication, Merrill-Palmer Quarterly, 13, 309-316.

Glucksberg, S., Krauss, R. \& Higgins, E. (1975) The development of referential communication skills. In F. Horowitz (ed.), Review of Child Development Research, 4. Chicago: Chicago University Press, 305-345.

Glucksberg, S., Krauss, R. \& Weisberg, R. (1966) Referential communication in nursery school children: method and some preliminary findings, Journal of Experimental Child Psychology, 3, 333-342.

Goldman-Eisler, F. (1964) Discussion and further comments. In E. Lenneberg (ed.), New Directions in the Study of Language. Cambridge, Mass.: M.I.T. Press, 109-130.

Goldman-Eisler, F. (1968) Psycholinguistics: Experiments in Spontaneous Speech. New York: Academic Press.

Grice, H. (1975) Logic and conversation. In P. Cole \& J. Morgan (eds), Syntax and Semantics, vol. 3. New York: Academic Press, 41-58.

Haastrup, K. \& Phillipson, R. (1983) Achievement strategies in learner/ native speaker interaction. In Farch \& Kasper (1983a), 140-158.

Hakuta, K. (1974) A preliminary report on the development of grammatical morphemes in a Japanese girl leaming English as a second language, Working Papers on Bilingualism, 3, 18-43.

Hallmann, A., Ras, P., Swinkels, M. \& Verhulst, H. (1979) Giving people a puzzle: the report of an experiment. Unpublished term paper, Dept. of English, University of Nijmegen.

Hatch, E. (ed.), (1978) Second Language Acquisition. Rowley, Mass.: Newbury House.

Hatch, E. (1983) Psycholinguistics: A Second Language Perspective. Rowley, Mass.: Newbury House.

Hatch, E. \& Long, M. (1980) Discourse analysis, what's that? In D. Larsen- Freeman (ed.), Discourse Analysis in Second Language Research. Rowley, Mass.: Newbury House, $1-40$.

Heider, E. (1971) Style and accuracy of verbal communications within and between social classes, Journal of Personality and Social Psychology, 18, 33-47.

Hill, L. (1977) Advanced Stories for Reproduction Tokyo: Oxford University Press.

Irujo, S. (1985) Do proficiency and setting affect lexical simplification strategies? Paper presented at the 19th TESOL Convention, New York, April 1985.

Jakobson, R. (1960) Linguistics and poetics. In T. Sebeok (ed.), Style in Language. Cambridge, Mass.: MIT Press, 350-377.

Jarujumpol, W. (1983) A study of lexical simplification: a foreign language communication strategy based on semantic competence in the mother tongue. Unpublished doctoral dissertation, Southern Illinois University at Carbondale.

Jarvella, R. \& Klein, W. (eds), (1982) Speech, Place and Action. New York: Wiley.

Johnston, R. \& Singleton, C. (1977) Social class and communication style: the ability of middle and working class five year olds to encode and decode abstract stimuli, British Journal of Psychology, 68, 237-244.

Jones, R. (1975) Testing language proficiency in the United States Government. In R. Jones \& B. Spolsky (eds), Testing Language Proficiency. Arlington, Virginia: Center for Applied Linguistics, 1-7.

Jordens, P. (1977) Rules, grammatical intuitions and strategies in foreign language learning, Interlanguage Studies Bulletin, 2.2, 5-76. 
Kähler, H. (1975) Beschreibungsmerkmalc als Determinanten der Dekodierungsleistungen von Personen unterschiedlicher sozialer Schichtzugehörigkeit, Zeitschrift für Sozialpsychologie, 6, 246- 258.

Kasper, G. (1981) Pragmatische Aspekte in der Interimsprache. Eine Untersuchung des Englischen fortgeschrittener deutscher Lerner. Tübingen: Narr.

Kellerman, E. (1974) Elicitation, lateralization and error analysis, York Papers in Linguistics, 4, 165-189.

Kellerman, E. (1977) Towards a characterisation of the strategy of transfer in second language learning, Interlanguage Studies Bulletin, 2.1, 58-145.

Kellerman, E. (1988) Referential communication in a second language: the role of compensatory strategies. Paper presented at the eighth Second Language Research Forum, Hawaii, March 1988.

Kellerman, E., Ammerlaan, T., Bongaerts, T. \& Poulisse, N. (in press) System and hierarchy in L2 compensatory strategies. To appear in R. Scarcella, E. Andersen \& S. Krashen (eds), Developing Communicative Competence. New York: Harper and Row.

Kellerman, E., Bongaerts, T. \& Poulisse, N. (1987) Strategy and system in L2 referential communication. In R. Ellis (ed.), Second Language Acquisition in Context. Englewood Cliffs, N.J.: Prentice Hall International, 100-112.

Kerkman, J. (1982) Taalpsychologisch onderzoek naar de organisatie van het tweetalig lexicon: cen overzicht, Gramma, 6, 199-214.

Kerkman, J. (1984) Woordherkenning in twee talen. In A. Thomassen, L. Noordman \& P. Eling (eds), Het Leesproces. Lisse: Swets \& Zeitlinger, 139-152.

Kirk, R. (1968) Experimental Design: Procedures for the Behavioral Sciences. Belmont, California: Brooks/Cole.

Klein-Braley, C. (1985) Reduced redundancy as an approach to language testing. In Klein-Braley \& Raatz (1985), 1-13.

Klein-Braley, C. \& Raatz, U. (eds), (1985) Fremdsprachen und Hochschule (= AKS-Rundbrief 13/14). Bochum: Ruhr-Universität.

Klosek, J. (1982) Second language communication strategies and grammatical accuracy. Unpublished doctoral dissertation, City University of New York.

Krauss, R. \& Glucksberg, S. (1969) The development of communication: competence as a function of age, Child Development, 40, 255-266.

Krauss, R. \& Glucksberg, S. (1977) Social and nonsocial speech, Scientific American, 236, 100-105.

Krauss, R. \& Rotter, G. (1968) Communication abilities of children as a function of status and age, Merrill-Palmer Quarterly, 14, 161-173.

Krauss, R. \& Weinheimer, S. (1964) Changes in reference phrases as a function of frequency of usage in social interaction: a preliminary study, Psychonomic Science, 1, 113-114.

Krauss, R. \& Weinheimer, S. (1966) Concurrent feedback, confirmation, and the encoding of referents in verbal communication, Journal of Personality and Social Psychology, 4, 343-346.

Krauss, R. \& Weinheimer, S. (1967) Effect of referent similarity and communication mode on verbal encoding, Journal of Verbal Learning and Verbal Behavior, 6, 359-363.

Labarca, A. \& Khanji, R. (1986) On communication strategies: focus on interaction, Studies in Second Language Acquisition, 8, 68-79.

Labov, W. (1972) Sociolinguistic Patterns. Philadelphia: University of Philadelphia Press.

Lantolf, J. \& Frawley, W. (1985) On communication strategies: a functional perspective, Rassegna Italiana di Linguistica Applicata, 17, 143- 157.

Larsen-Freeman, D. (1975) The acquisition of grammatical morphemes by adult ESL students, TESOL Quarterly, 9, 409-419.

Lê, T. \& McCausland, M. (1986) The child as a communicative strategist, Australian Review of Applied Linguistics, 9, 43-61. 
Leech, G. (1983) Principles of Pragmatics. London: Longman.

Levelt, W. (1976) Skill theory and language teaching. Studies in Second Language Acquisition, 1, 53-70.

Levelt, W. (1989) Speaking: From Intention to Articulation. Cambridge, Mass.: Bradford Books/MIT Press.

Levelt, W. \& Schriefers, H. (1987) Stages of lexical access. In G. Kempen (ed), Natural Language Generation. New Results in Artificial Intelligence, Psychology and Linguistics. Dordrecht: Martinus Nijhoff, 395-404.

Levin, H., Silverman, I. \& Ford, B. (1967) Hesitations in children's speech during explanation and description, Journal of Verbal Learning and Verbal Behavior, 6, 560-564.

Littlewood, W. (1981) Communicative Language Teaching. An Introduction. Cambridge: Cambridge University Press.

Littlewood, W. (1984) Foreign and Second Language Learning: Language Acquisition Research and its Implications for the Classroom. Cambridge: Cambridge University Press.

Lowe, P. (1983) The ILR oral interview: origins, applications, pitfalls, and implications, Die Unterrichtspraxis, 16, 230-244.

Ludwig, J. (1982) Native speaker judgements of second-language learners' efforts at communication: a review, Modern Language Journal, 66, 274-283.

Lyons, J. (1977) Semantics. Cambridge: Cambridge University Press.

Maclay, H. \& Osgood, C. (1959) Hesitation phenomena in spontaneous English speech, Word, 15, 19-44.

McCawley, J. (1978) Conversational implicature and the lexicon. In P. Cole (ed.), Syntax and Semantics, vol. 9: Pragmatics. New York: Academic Press, 245-259.

McLaughlin, B. (1987) Theories of Second Language Learning. London: Amold.

Möhle, D. (1984) A comparison of the second language speech production of different native speakers. In Dechert, Möhle \& Raupach (1984), 26- 50.

Mühlhäusler, P. (1986) Pidgin and Creole Linguistics. New York: Basil Blackwell.

Munby, J. (1978) Communicative Syllabus Design. Cambridge: Cambridge University Press.

Nayar, P. (1987) Communication strategies in ESL. Umpublished doctoral dissertation, University of South Carolina, Columbia.

Nisbett, R. \& Wilson, T. (1977) Telling more than we can know: verbal reports on mental processes, Psychological Review, 84, 231-259.

Oller, J. (1972) Scoring methods and difficulty levels for cloze tests of proficiency in English as a second language, Modern Language Journal, 56, 151-158.

Oller, J. (1979) Language Tests at School. London: Longman.

Olson, D. (1970) Language and thought: aspects of a cognitive theory of semantics, Psychological Review, 77, 257-273.

Palmberg, R. (1979) Investigating communication strategies. In R. Palmberg, (ed.), Perception and Production of English: Papers on Interlanguage, $(=A F T I L, 6)$. Abo: Ábo Akademi, 33-75.

Palmberg, R. (1982) Laughing matters - a look at some foreign language communication data, Scandinavian Working Papers on Bilingualism, 1, 12-18.

Palmberg, R. (1983) On the relationship between communication strategies and learning strategies. In J. Fisiak (ed.), Papers and Studies in Contrastive Linguistics, vol. 17. Poznan: Adam Mickiwicz University, 93-99.

Paribakht, T. (1982) The relationship between the use of communication strategies and aspects of target language proficiency: a study of Persian ESL students. Unpublished doctoral dissertation, University of Toronto. 
Paribakht, T. (1985) Strategic competence and language proficiency, Applied Linguistics, 6, $132-146$.

Pattison, P. (1987) Developing Communication Skills. A Practical Handbookfor Language Teachers, with Examples in English, French and German. Cambridge: Cambridge University Press.

Poulisse, N. (1981) Communication strategies: a comparative analysis. Unpublished term paper, Dept. of Applied Linguistics, University of Nijmegen.

Poulisse, N. (1987) Problems and solutions in the classification of communication strategies, Second Language Research, 3, 141-153.

Poulisse, N., Bongaerts, T. \& Kellerman, E. (1984) On the use of compensatory strategies in second language performance, Interlanguage Studies Bulletin, 8.1, 70-105.

Poulisse, N., Bongaerts, T. \& Kellerman, E. (1987) The use of retrospective verbal reports in the analysis of compensatory strategies. In Farch \& Kasper (1987a), 213-229.

Poulisse, N. \& Schils, E. (in press) The influence of task- and proficiency-related factors on the use of compensatory strategies: a quantitative analysis. To appear in Language Learning.

Ratner, T. \& Rice, F. (1963) The effect of the listener on the speaking interaction, The Psychological Record, 13, 265-268.

Raupach, M. (1983) Analysis and evaluation of communication strategies. In Færch \& Kasper (1983a), 199-209.

Raupach, M. (1984) Formulae in second language speech production. In Dechert, Möhle \& Raupach (1984), 114-137.

Reddy, M. (1979) The conduit metaphor - a case of frame conflict in our language about language. In A. Ortony (ed.), Metaphor and Thought. Cambridge: Cambridge University Press, 284-324.

Richards, J. (1971) A non-contrastive approach to error analysis, English Language Teaching, 25, 204-219.

Richards, J. (ed.), (1974) Error Analysis: Perspectives on Second Language Acquisition. London: Longman.

Rosansky, E. (1976) Methods and morphemes in second language acquisition research, Language Learning, 26, 409-425.

Sachs, J. (1967) Recognition memory for syntactic and semantic aspects of connected discourse, Perception and Psychophysics, 2, 437-442.

Santa, J. \& Ranken, H. (1972) Effects of verbal coding on recognition memory, Journal of Experimental Psychology, 93, 268-278.

Schlue, K. (1977) An inside view of interlanguage. In C. Henning (ed.), Proceedings of the Los Angeles Second Language Research Forum. Los Angeles: UCLA, 342-348.

Selinker, L. (1969) Language Transfer, General Linguistics, 9, 67-92.

Selinker, L. (1972) Interlanguage, IRAL, 10, 209-231.

Selinker, L. \& Douglas, D. (1985) Wrestling with 'context' in interlanguage theory, Applied Linguistics, 6, 190-210.

Shannon, C. \& Weaver, W. (1949) The Mathematical Theory of Communication. Urbana: University of Illinois Press.

Sharwood Smith, M. (1981) On the status of learning strategies in interlanguage performance. Unpublished manuscript, Dept. of English, University of Utrecht.

Shaw, A. (1977) Foreign language syllabus development: some recent approaches, Language Teaching \& Linguistics: Abstracts, 10, 217-233.

Simon, H. (1957) Models of Man. New York: Wiley.

Smith, N. (ed.), (1982) Mutual Knowledge. London: Academic Press.

Spencer, N. (1973) Differences between linguists and non-linguists in intuitions of grammaticality-acceptability, Journal of Psychological Research, 2, 83-98. 
Sperber, D. \& Wilson, D. (1986) Relevance: Communication and Cognition. Oxford: Basil Blackwell.

Spolsky, B. (1973) What does it mean to know a language; or how do you get someone to perform his competence? In J. Oller \& J. Richards (eds), Focus on the Learner: Pragmatic Perspectives for the Language Teacher. Rowley, Mass.: Newbury House, 164-176.

Stedje, A. (1983) Deception and dissociation markers as indicators of communicative strategies. In H. Ringbom (ad.), Psycholinguistics and Foreign Language Learning. Ảbo: Ábo Akademi, 201-211.

Stedje, A. (1985) In search of content words - on decision points in strategies, Scandinavian Working Papers on Bilingualism, 4, 136-152.

Tarone, E. (1977) Conscious communication strategies in interlanguage: a progress report. In H. Brown, C. Yorio \& R. Crymes (eds), On TESOL '77. Teaching and Learning English as a Second Language. Washington, D.C.: TESOL, 194-203.

Tarone, E. (1979) Interlanguage as chameleon, Language Learning, 29, 181-191.

Tarone, E. (1980) Communication strategies, foreigner talk, and repair in interlanguage, Language Learning, 30, 417-431.

Tarone, E. (1981) Some thoughts on the notion of communication strategy, TESOL Quarterly, 15, 285-295.

Tarone, E. (1988) Variation in Interlanguage. London: Amold.

Tarone, E., Cohen, A. \& Dumas, G. (1976) A closer look at some interlanguage terminology: a framework for communication strategies, Working Papers on Bilingualism, 9, 76-90. Reprinted in Farch \& Kasper (1983a), 4-14.

Tarone, E. \& Yule, G. (1983) Communication strategies in East-West interactions. Paper presented at the Conference on English as an International Language: Discourse Patterns Across Cultures, Honolulu, Hawaii, June 1983. In L. Smith (ed), Discourse Across Cultures. New York: Prentice Hall (1987), 49-65.

Tielen, A. \& Witteveen, G. (1987) Referential communication in first and second languages: a comparison. Unpublished M.A. thesis, Dept. of English, University of Nijmegen.

Trosborg, A. (1982) Communication strategies: relating theory and practice, Finlance, 2, 111-136.

Van den Berg, M. (1988) The creation of an artificial pidgin and its subsequent depidginization. Unpublished M.A. thesis, Dept. of English, University of Nijmegen.

Van den Broek, L. (1988) Compensatiestrategieën in verhaaltjes. Unpublished M.A. thesis, Dept. of Applied Linguistics, University of Nijmegen.

Van Els, T., Bongaerts, T., Extra, G., Van Os, C. \& Janssen-Van Dieten, A. (1984) Applied Linguistics and the Learning and Teaching of Foreign Languages. London: Amold.

Van Vliet, G. (1973) Het Psychologisch Experiment. Een Praktische en Theoretische Inleiding op de Experimentele Methode in de Gedragswetenschappen. Nijmegen: Berkhout Testmateriaal.

Váradi, T. (1973) Strategies of target language leamer communication: message adjustment. Paper presented at the VIConference of the Romanian-English Linguistics Project Timisoara, May 1973. Published in IRAL, 18, 59-71 (1980). Republished in Farch \& Kasper (1983a), 79-99.

Verkuijlen, P. (1987) Op zoek naar een instrument voor de objektieve meting van de effektiviteit van kompensatiestrategieën. Unpublished M.A. thesis, Dept. of Applied Linguistics, University of Nijmegen.

Verouden, G. (1985) Een schaalbeoordeling van de effectiviteit van compensatiestrategieën. Unpublished term paper, Dept. of Applied Linguistics, University of Nijmegen. 
Verouden, G. (1987) On the relationship between second language proficiency level and the use of semantic features in descriptions. Unpublished M.A. thesis, Dept. of English, University of Nijmegen

Wagner, J. (1983) Dann du tagen eineeeee - weisse Platte - An analysis of interlanguage communication in instructions. In Færch \& Kasper (1983a), 159-174.

Widdowson, H. (1978) Teaching Language as Communication. Oxford: Oxford University Press.

Wiese, R. (1981) Verzögerungsphänomene in Erst- und Zweitsprachenproduktionen. In W. Kühlwein \& A. Raasch (eds), Sprache: Lehren Lernen, Band II. Kongressberichte der 11. Jahrestagung der Gesellschaft fur Angewandte Linguistik GALe.V., Darmstadt, 1980. Tübingen: Nar, 181-185.

Wiese, R. (1984) Language production in foreign and native languages: same or different? In Dechert, Möhle \& Raupach (1984), 11-25.

Wilds, C. (1975) The oral interview test. In R. Jones \& B. Spolsky (eds), Testing Language Proficiency. Arlington, Va.: Center for Applied Linguistics, 29-44.

Wilkins, D. (1975) A communicative approach to syllabus construction in adult language learning. In A. Van Essen \& J. Menting (eds), The Context of Foreign Language Learning. Assen: Van Gorcum, 173-179.

Wilkins, D. (1976) Notional Syllabuses. Oxford: Oxford University Press.

Willems, G. (1987) Communication strategies and their significance in foreign language teaching, System, 15, 351-364.

Willich, C., Fischer, A. \& Schwanenberg, E. (1972) Sprachlicher Informationstransfer in und zwischen sozialdifferenten Populationen mit ausdruckshaltigen Fotos als Bezugsgegenständen, Zeitschrift für Sozialpsychologie, 3, 245-261.

Winer, B. (1971) Statistical Principles in Experimental Design, 2nd edition. New York: McGraw-Hill.

Zimmermann, R. (1987) Form-oriented and content-oriented lexical errors in L2 learners, IRAL, 25, 55-67. 
Appendix I. The abstract figures used in task II (from Krauss \& Weinheimer, 1964)

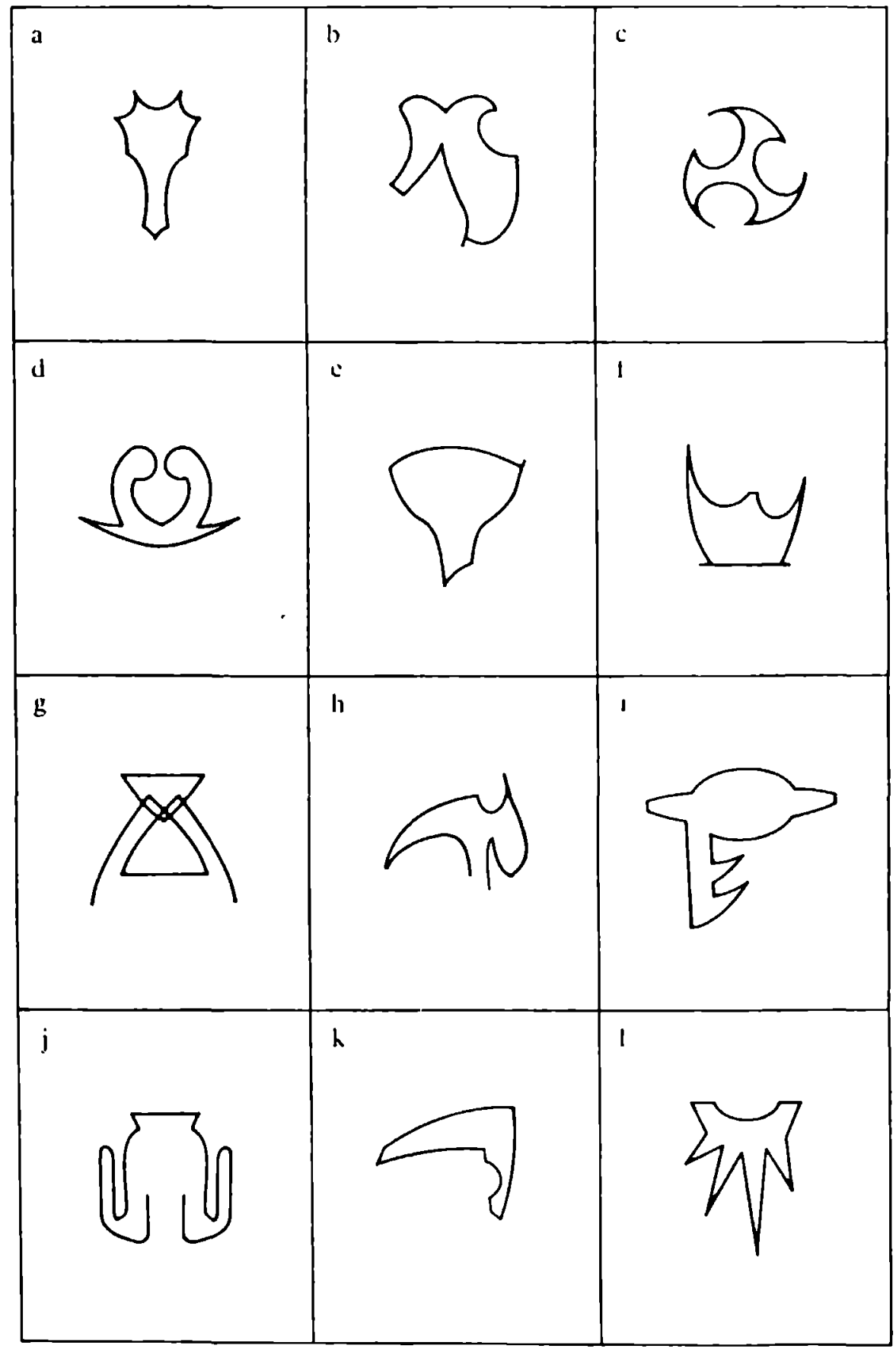




\section{Appendix II. Instructions to tasks I, II, III and IV (translated from Dutch)}

\section{Task I}

In a minute you will be shown 40 pictures of objects which you know and for which you also know the Dutch names. The idea is that you make clear which object you see. You have to do this in English, and in such a way that an Englishman or -woman who is to listen to and watch your recordings will understand which object you are talking about. This Englishman or -woman does not know any Dutch at all. If you see an object for which you know the English word, then you must say that word. If you do not know the English word you must try to find a different way of making clear what the object is.

Sometimes this will be rather difficult, but it does not really matter if you make mistakes, as long as it is clear to this Englishman or -woman what you mean.

As soon as you think you have been clear enough, you can continue with the next picture. You cannot ask me anything during this test, and I cannot say anything to you.

You will be given two examples first, to see if you still have any questions. You will also be given a code; mention this code before you start doing the test.

\section{Task II}

Part I In a minute you will be given a sheet of paper with 12 unusual figures. These figures have been arranged in a certain order. The idea is that you indicate the order of the figures, so that a Dutch person who is to listen to and watch your recordings, and who has the figures arranged in a different order, can put them in the order you have in front of you.

Whenever you think the Dutch person has heard enough to recognize a figure, you can continue with the next one.

You will be given three examples first. After these three examples you can ask questions if necessary. After this, the actual test starts. Then you can no longer ask me anything, and I can no longer say anything to you.

Do not forget to mention your code first. On the top left hand of your paper it says which version you have. Please mention this too before you start.

Part 2 You will have noticed that the task which you have just performed was not very easy. I would like to ask you to perform the same task again, with the same figures arranged in a different order. Later I will have another Dutch person listen to this and he or she will then have to determine the right order. You will not be given any examples this time. Try to be as clear as possible. You will notice that it will be easier this time.

Do not forget your code, and please mention which version you have.

Part 3 Finally, I would like to ask you just once morc to indicate the order of the unusual figures. Please do it in English this time, and in such a way that it can be recognized by an Englishman or -woman who does not speak or understand Dutch. It does not matter if you make mistakes, as long as you enable the Englishman or -woman to determine the right order.

You can work at your own pace again. Remember that I cannot say anything to you during the test.

Do not forget your code, and again mention which version you have. 


\section{Task III}

In a minute you will hear five short stories. These stories have been recorded on tape, and will be told to you in Dutch (only once). After each story the tape will be stopped. The idea is that you will then retell the story in English in as much detail as possible and in such a way that it is comprehensible to an Englishman or -woman who does not understand any Dutch.

There is a series of pictures to go with each of the stories. You can look at them both while you are listening to the stories and when you are retelling them. Make sure that all the information on the pictures is included in your English version of the stories.

The first story is meant to let you practise a little and to see if you still have questions. Do not worry about your English. Mistakes do not really matter, as long as you retell the story as precisely as possible. This task makes heavy demands on your memory. Try to concentrate as well as possible. If necessary we can have a shor break after each story.

Do not forget your code.

\section{Task IV}

In a minute you will be having a 20-minute conversation with Geraldine Hargrave. Geraldine is from Cork (Ireland). She used to work there in a library. A short while ago she manried a Dutchman. She now lives in Oosterhout near Nijmegen, but she still speaks hardly any Dutch.

Try to answer the questions she asks you as completely as possible: do not limit yourself to "yes/no" and "I don't know", but have a real conversation. It is alright if you interrupt Geraldine or ask her questions. It does not maner if there are mistakes in your English, as long as you talk as much as possible.

Please mention your code first. 


\section{Appendix III. The stories and the pictures used in task III*}

There once was a man who was going to visit a distant cousin with his wife. While they were waiting on the platform for their train the man saw a weighing-scale. It was one of those apparatuses which give cards on which one's future is printed as well as one's weight. The man decided to weigh himself so he stepped on the scales, put a penny in, and waited for the card to come out. Since he was not wearing his glasses he asked his wife to read the card out to him.

On the card was written, 'You are a special man, you have great courage, willpower and perseverance. You are to have a golden future'. After she had read this out, the man's wife umed the card over, looked at the back for a moment and sneered, 'Huh, and it's got your weight wrong too'. (practice story)

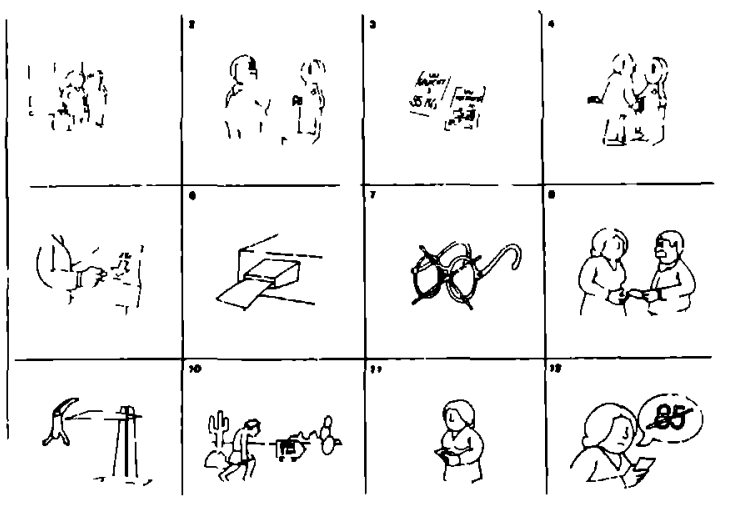

Once upon a time there was a tailor. One day, a rabbit entered his shop. 'Good morning', it said, 'Do you have pleated skirts?'. 'No', the tailor said, 'I don't have any'. 'Oh', said the rabbit and it left. The next moming, however, it again stepped into the shop. 'Good moming tailor, have you got any pleated skirts?'. 'No, I'm sorry, the tailor answered. 'Oh', the rabbit said, and again it left. The tailor began to feel somy for the rabbit and decided to add a pleated skirt to his collection of clothes. The next moming he had one hanging nicely on a clothes-hanger in the shopwindow, and when the rabbit came in and again asked for a pleated skirt, the tailor was pleased to say, 'Yes, now I do have one'. Then the rabbit just grinned and said, 'They're difficult to iron, aren't they?'.

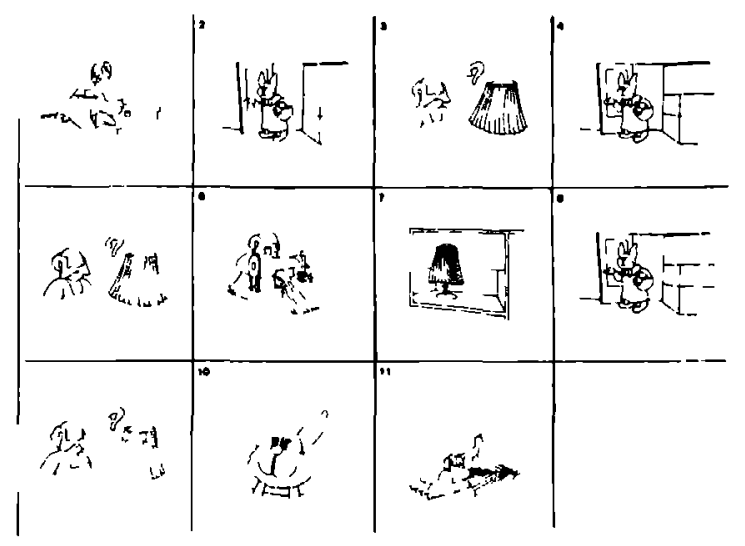


There once was a salesman in hair-restorers. Each day he set out to try and sell his product to hairdressers and chemists. Now, this salesman happened to be bald himself, but to improve his business he had bought himself a wig and he led all hairdressers and chemists to believe that he owed his beautiful head of hair to this new product. In this way he sold quite a lot, until, one day, the wind blew off his wig during the annual open-air demonstration. That put an embarrassing end to his profitable business.

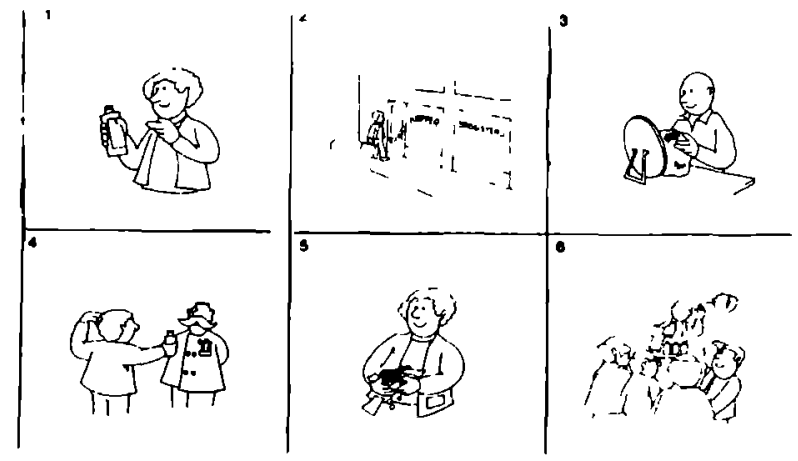

For a long time Mr. Jackson had wanted to get a permanent job as a caretaker in an old people's home. At last, after numerous applications, he got the job he wanted, and he and his wife moved to the official flat which they were now to live in. The next day a beautiful bunch of flowers was delivered to them, with a note which said, 'Deepest sympathy'. Naturally, Mr. Jackson was rather annoyed to receive such an extraordinary note, and he telephoned the shop which had sent the flowers to find out what this was supposed to mean. When the owner of the shop heard what had happened, he immediately apologized to Mr. Jackson for having made the mistake. But he added that he was more worried about the fact that the flowers which were meant for Mr. Jackson, were sent to a funeral. And they had a card which said, 'Congratulations on your new position'.

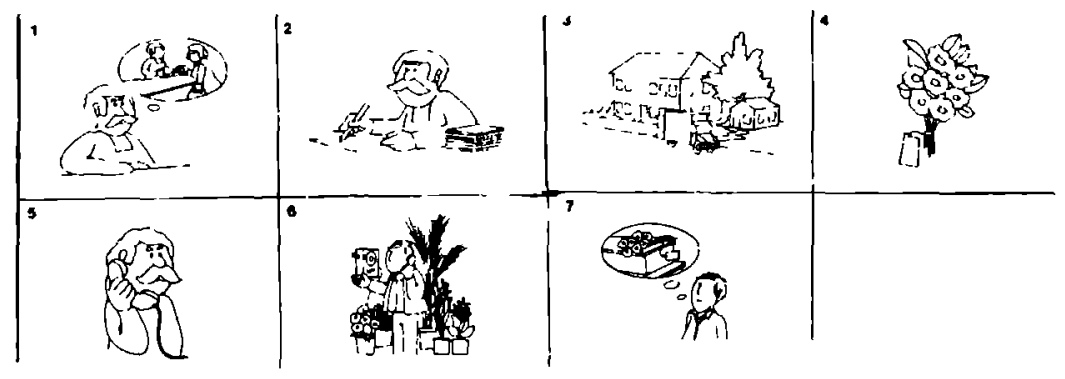

There once was an owner of a bicycle factory who had a serious dispute with his neighbour, an ironmonger. In the end this even led to a courtcase. Just before that took place the owner of the bicycle factory asked his lawyer which judge would be hearing the case. His lawyer told him 
and then asked if he happened to know the judge. The owner of the bicycle factory said, 'No, I don't, but I wanted to know his name so that I can send him a bicycle'. 'I beg your pardon', the lawyer called out indignantly. 'That would be sheer bribery and you would be sure to lose the case'.

Some weeks later the case was heard, and the owner of the bicycle factory won it. As he was leaving, he said to his lawyer, 'My present to the judge was quite successful, wasn't it?'. The lawyer was even more shocked than before and said, 'What! Did you really send him a bicycle?'. 'No, no', the owner of the bicycle factory said, 'I sent him a hammer drill and I put my opponent's name on the card which I sent with it'.

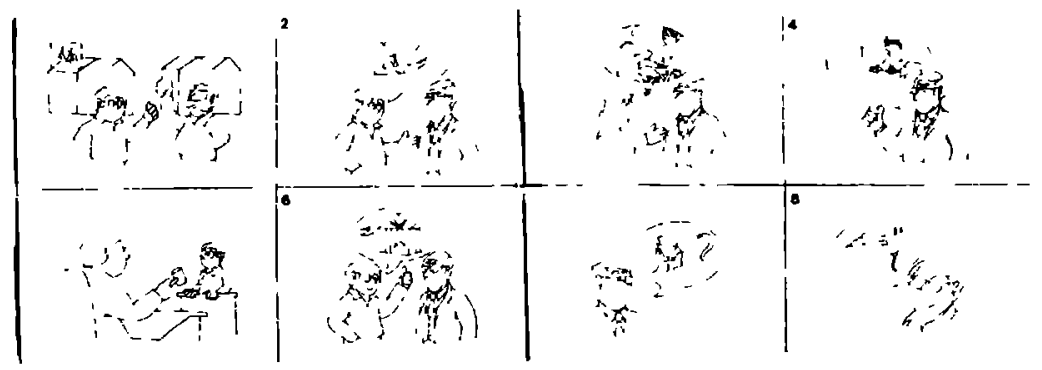

* These are translations of the stories which were originally presented in Dutch. The pictures are by André Fekkes of the Audio-Visual Service Centre at Nijmegen University. 


\section{Appendix IV. Method of transcription}

A separate file was created for the transcription of each subject's performance on each of the four tasks. The 00000 line at the top of each of these files gives information about the task, the subject and the date of recording. Tasks I, II, III and IV are marked by 1e, 2n for the Dutch and $2 e$ for the English version of task II, 3e and 4e, respectively. The subject's identity is marked by a three-digit code of which the first digit indicates his/her proficiency level. Thus, 101 refers to a second-year university student of English, 201 to a 5-VWO pupil and 301 to a 3-VWO pupil. The third figure in the 00000 line refers to the date of recording. The last figure refers to the number of the tape on which the data are stored. Since the original numbers are no longer in use, this figure can be ignored.

In the task I datafiles the following codes (which are abbreviations of Dutch words) have been used to indicate the objects to which the subjects referred:

$\begin{array}{llll}\text { klos } 00 & \text { reel } & \text { tel00 } & \text { abacus } \\ \text { brom00 } & \text { humming-top } & \text { tuit00 } & \text { spout } \\ \text { kleer00 } & \text { coathanger } & \text { stek00 } & \text { three-way adapter } \\ \text { cen00 } & \text { measuring tape } & \text { blik00 } & \text { dustpan } \\ \text { vlie00 } & \text { flyswat } & \text { klep00 } & \text { clapper } \\ \text { hor00 } & \text { watchstrap } & \text { deegrol00 } & \text { rolling pin } \\ \text { schoen00 } & \text { shoehom } & \text { bier00 } & \text { beermat } \\ \text { slab00 } & \text { bib } & \text { stel00 } & \text { stilts } \\ \text { ko00 } & \text { coal-scuttle } & \text { water00 } & \text { spirit level } \\ \text { zee00 } & \text { starfish } & \text { speen00 } & \text { teat }\end{array}$

They precede the actual references. Following each reference is an estimation of the number of seconds needed to produce it (in brackets).

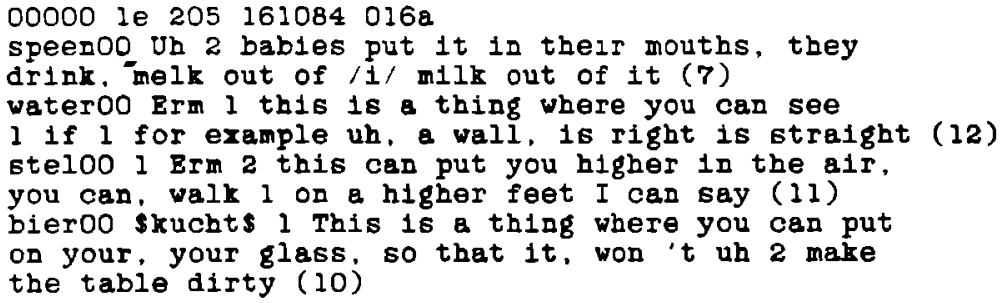

In task II, too, codes have been used to indicate which shape is being referred to. The codes, a00 to 100 , refer to the shapes in appendix I. Again, the references are followed by an indication of the time needed to produce them. Time indications have also been added to each of the stories retold as part of task $\mathrm{II}$.

The data have been transcribed orthographically unless the subject's pronunciation differed markedly from standard English or Dutch In these cases broad phonetic transcriptions have been used, which are marked by / /. Keyboard limitations led to the use of 3 for 3 and ae for $\boldsymbol{x}$. Utterances produced by the researcher or by the interviewer (in task IV) are marked by I. at the beginning of the relevant line(s). Contracted forms have been separated by means of spaces, so that they can be counted as two words. Thus, it's has been typed as it 's. 
Other transcription conventions that have been followed are:

\author{
- to mark pauses shorter than one second; \\ 123 or other numerals, to mark the approximate length of pauses longer than one second \\ (note that all numbers spoken by the subjects have been typed in full); \\ ? $\quad$ to mark a rising intonation; \\ $\$$ to mark relevant information on the subjects' and the interviewer's behaviour, e.g. \\ $\$$ lacht $\$=$ laughs, zucht $\$$ = sighs, $\$$ zacht $\$=$ softly; \\ uh to mark short filled pauses; \\ erm to mark long filled pauses; \\ cc repetition of consonants as in ccircus, to mark their being sustained; \\ $x x x$ to mark an incomprehensible word: \\ $\mathrm{XXX} \times \mathrm{XXX}$ to mark two (or more) incomprehensible words.
}

\title{
example
}

uh there was a tallor, and a rabblt, and 1 uh one day, there was a a rabbit, came in the shop and asked for erm 4 uh 3 uh 9 for a rokje \$zacht\$ 11 erm, In xxx/na/ 3 \$zucht\$

\$lacht\$ jee 1 bandploolrok \$zacht\$ 5 and asked for a clothe erm, it 's for women, erm. they have it round their walst. with erm 3 erm 2 with lines in it 3 and uh, the tallor said no, I don 't have that $1 \mathrm{ub}$, and the other day, the rabbit came again, and asked. heve you, a clothe \$lacht\$for women with uh lines in it?. no I don't have that. sald the tailor 1 and 1 the tallor uh thinks, he uh, the rabbit uh. will came again and, I vill make uh, for him. that kind of clothe, and uh he began to work, and in the morning. he had finished his work and it hanged in, his shop, and the rabbit came, erm in his shop and asked for lt, asked, for h1t, for 1t, and he sald, yes uh, I have it, and the rabbit smiled and said, erm $l$ uh. It 's not easy to make it uh 2 szuchts 3 mm 21 erm. ja. you do it after the wash, uh, with your clothes, uh, when you want to /w3r/ them 1 and. the, rabbit means that and he sald $u h$, $1 t$ isn't easy to do that, with, that kind of clothe (166) 


\section{Appendix V. The relative use of each $\mathrm{CpS}$ type per task and per group}

Table 1 Means for cells, rows, columns and grand mean for ANCO (superordinate data)

\begin{tabular}{lllll}
\hline & Lask I & task III & task IV & rows \\
\hline Group 1 & .970 & .583 & .425 & .659 \\
Group 2 & .993 & .608 & .542 & .714 \\
Group 3 & .977 & .645 & .523 & .715 \\
\hline columns & .980 & .612 & .497 & .696 \\
\hline
\end{tabular}

Table 2 Means for cells, rows, columns and grand mean for HOCO (superordinate data)

\begin{tabular}{lllll}
\hline & task I & task III & task IV & rows \\
\hline Group 1 & .007 & .367 & .380 & .251 \\
Group 2 & .000 & .290 & .272 & .187 \\
Group 3 & .010 & .238 & .258 & .168 \\
\hline columns & .005 & .298 & .303 & .202 \\
\hline
\end{tabular}

Table 3 Means for cells, rows, columns and grand mean for LIMO (superordinate data)

\begin{tabular}{lllll}
\hline & Lask I & task III & task IV & rows \\
\hline Group 1 & .003 & .023 & .003 & .010 \\
Group 2 & .000 & .019 & .007 & .009 \\
Group 3 & .003 & .015 & .002 & .007 \\
\hline columns & .002 & .019 & .004 & .008 \\
\hline
\end{tabular}

Table 4 Means for cells, rows, columns and grand mean for LITRA (superordinate data)

\begin{tabular}{lllll}
\hline & task I & task III & task IV & rows \\
\hline Group 1 & .020 & .027 & .193 & .080 \\
Group 2 & .006 & .083 & .179 & .090 \\
Group 3 & .010 & .102 & .218 & .110 \\
\hline columns & .012 & .071 & .196 & .093 \\
\hline
\end{tabular}


Table 5 Means for cells, rows, columns and grand mean for ANCO (subordinate data)

\begin{tabular}{lllll}
\hline & Lask I & task III & task IV & rows \\
\hline Group 1 & .378 & .193 & .055 & .209 \\
Group 2 & .348 & .236 & .136 & .240 \\
Group 3 & .327 & .298 & .193 & .273 \\
\hline columns & .351 & .242 & .128 & .241 \\
\hline
\end{tabular}

Table 6 Means for cells, rows, columns and grand mean for HOCO (subordinate data)

\begin{tabular}{lllll}
\hline & task I & task III & task IV & rows \\
\hline Group 1 & .384 & .191 & .156 & .243 \\
Group 2 & .393 & .380 & .229 & .334 \\
Group 3 & .363 & .361 & .322 & .349 \\
\hline columns & .380 & .311 & .234 & .309 \\
\hline
\end{tabular}

Table 7 Means for cells, rows, columns and grand mean for LIMO (subordinate data)

\begin{tabular}{lllll}
\hline & task I & task III & task IV & rows \\
\hline Group 1 & .032 & .027 & .000 & .020 \\
Group 2 & .007 & .000 & .000 & .002 \\
Group 3 & .023 & .021 & .000 & .014 \\
\hline columns & .021 & .016 & .000 & .012 \\
\hline
\end{tabular}

Table 8 Means for cells, rows, columns and grand mean for LITRA (subordinate data)

\begin{tabular}{lllll}
\hline & task I & task II & task IV & rows \\
\hline Group 1 & .139 & .189 & .056 & .128 \\
Group 2 & .252 & .251 & .302 & .268 \\
Group 3 & .288 & .320 & .151 & .253 \\
\hline columns & .226 & .254 & .170 & .216 \\
\hline
\end{tabular}




\section{Appendix VI. The York experiments (instructions, samples of the tasks, list of compensatory strategies)}

\section{Instructions to the guessing task}

When people speak a foreign language, they often nu into problems because they do not know all the right words. If this happens, they often try to get their messages actoss via altemative ways. These alternative ways are called compensatory strategies.

This test is meant to find out whether some of these strategies are easier to understand than others. The test consists of two parts. In the lirst part you will be asked to read four short stories. There are some compensatory strategies in these stories, which were told by Dutch learners of English. The compensatory strategies have been underlined, and they are numbered. You are asked to guess the word the learner intended. You can write this word down on the dotted line (with the same number) underneath the story. Your answer should consist of one word only.

After you have given each answer please indicate how certain you are that your answer is right. You can do this by putting a circle round one of the suggested ratings.

For instance, in the following lines two compensatory strategies occur:

\section{example}

I have a very nice bedroom which I share with my brother. There is one bureau ${ }^{1}$ in our bedroom, and there are two things in which we can put our clothes. ${ }^{2}$. There are many posters on the walls and I like being there to read or listen to my records.

\section{I think this answer is:}

1. .................... right / possibly right / pure guesswork

2. ................... right / possibly right / pure guesswork

The person who filled in the answer sheet thought that the first compensatory strategy stood for 'table'. He thought this answer was possibly right. He filled in 'wardrobe' for the second compensatory strategy, and this time he was sure his answer was right.

If you still have questions, please ask them now. If not, you can stan doing the test. Remember to put your name on each page. You will be given the second part of this test after you have finished this part. It is very important that you do not talk about the test in between the two parts.

\section{Instructions to the judgement task}

You have just guessed the words which the Dutch leamers tried to get across. You will now be presented with the same stories again. However, this time the words that the learners actually tried to get across are given undernealh the stories.

I would like you to indicate how easy it is to understand the compensatory strategies that were used. You can do this by assigning to each compensatory strategy a score between 1 and 7 , where 1 means 'absolutely impossible to understand' and 7 means 'perfectly easy to understand'. 


\section{- work fast}

- do not num back to an item after you have completed the story

- do not assign more than one score to an item

- please use the full scale

If you still have questions, please ask them now. Do not forget to put your name on the test sheet.

\section{Instructions to the cloze test}

You will be asked to read four short stories. As you will see, a few words have been left out of these stories. I would like you to guess the missing words in each case and to fill them in on the dotted lines underneath the stories. Your answer should consist of one word only.

After you have given each answer, please indicate how certain you are that your answer is right. You can do this by putting a circle round one of the suggested ratings.

\section{A sample of the guessing task}

$1 d \&$

name:

There once was an employee ${ }^{1}$ in some spray to make your hair grow faster ${ }^{2}$. Each day he set out to try and sell his product to ones who cut people's hair ${ }^{3}$ and drogists ${ }^{4}$. Now, this employee happened to be bald himself, but to improve his business he had bought himself some hair 5 and he led all the ones who cut people's hair and the drogists to believe that he owed his beautiful head of hair to this new product. In this way he sold quite a lot, until, one day, the wind blew off his hair during the annual open-air demonstration. That put an embarrassing end to his profitable business.

I think this answer is:

1..................... right / possibly right / pure guesswork

2. .................... right / possibly right / pure guesswork

3. ................... right / possibly right / pure guesswork

4. ..................... right / possibly right / pure guesswork

5. .................... right / possibly right / pure guesswork

\section{A sample of the judgement task}

$1 \mathrm{~d} \&$

name:

There once was an employee ${ }^{1}$ in some spray to make your hair grow faster ${ }^{2}$. Each day he set out to try and sell his product to ones who cut people's hair ${ }^{3}$ and drogists ${ }^{4}$. Now, this employee happened to be bald himself, but to improve his business he had bought himself some hair ${ }^{5}$ and 
he led all the ones who cut people's hair and the drogists to believe that he owed his beautiful head of hair to this new product. In this way he sold quite a lot, until, one day, the wind blew off his hair during the annual open-air demonstration. That put an embarrassing end to his profitable business.

1. salesman

2. hair-restorers

3. hairdressers

4. chemists

5. wig
1234567

125345567

$\begin{array}{llllllll}1 & 2 & 3 & 4 & 5 & 6 & 7\end{array}$

123345667

122345567

\section{A sample of the cloze test}

There once was a (1) ....... in (2) ....... Each day he set out to try and sell his product to (3) ....... and (4) ....... Now, this (1) happened to be bald himself, but to improve his business he had bought himself a (5) ....... and he led all the (3) and (4) to believe that he owed his beautiful head of hair to this new product. In this way he sold quite a lot, until, one day, the wind blew off his hair during the annual open-air demonstration. That put an embarrassing end to his profitable business.

I think this answer is:

1. ................... right / possibly right / pure guesswork

2. ................... right / possibly right / pure guesswork

3. .................... right / possibly right / pure guesswork

4. ................... right / possibly right / pure guesswork

5. ................... right / possibly right / pure guesswork

List of compensatory strategies used in the York experiments

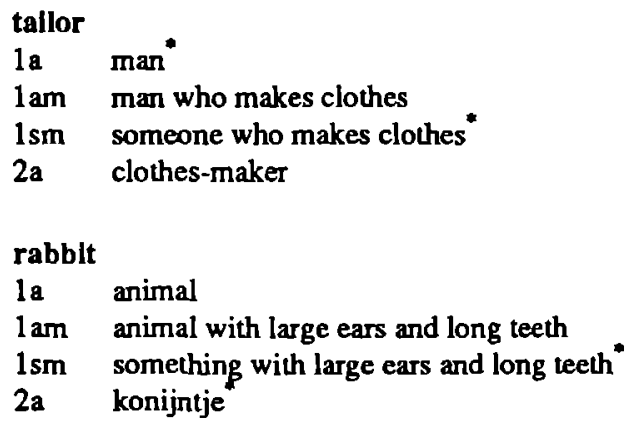


pleats

1 la lines

1 am folded lines

$1 \mathrm{sm}$ folded things

2a ploois

\section{shopwindow}

la window

lam window of his shop

$1 \mathrm{sm}$ somewhere in his shop

2a etalage

\section{iron}

1a flatten

1 am flatten after the washing to make beautiful

$1 \mathrm{sm}$ make beautiful after the washing

2a strike

\section{salesman}

1 e employee

lam employee who earned his money by selling

$1 \mathrm{sm}$ someone who earned his money by selling

2a vertegenwoordiger"

\section{halr-restorer}

1a spray

lam spray to make your hair grow faster

$1 \mathrm{sm}$ something to make your hair grow faster

2a hairgrow-middle

\section{hairdressers}

1a hairstylists

1 am hairstylists who cut people's hair*

$1 \mathrm{sm}$ ones who cut people's hair

2a coiffeurs

\section{chemists}

la shopkeepers"

1 am shopkeepers who sell shampoo and soap and perfume and things like that

$1 \mathrm{sm}$ people who sell shampoo and soap and perfume and things like that

2a drogists

$\begin{array}{ll}\text { wig } & \\ \text { la } & \text { hair } \\ \text { lam } & \text { hair which was not real } \\ \text { lsm } & \text { something which was not real } \\ \text { 2a } & \text { pruke }\end{array}$


carctaker

1 a guard

1 am guard who had to take care of a house

$1 \mathrm{sm}$ someone who had to take care of a house

2a concierge

\section{applications}

la letters

1 am letters to get a job

$1 \mathrm{sm}$ things to get a job

2a sollicitations

move

1a travelled

1 am travelled with their furniture and other things

$1 \mathrm{sm}$ got with their furniture and other things

2a rehoused

\section{funeral}

1 a ceremony"

$1 \mathrm{am}$ ceremony when someone is buried

$1 \mathrm{sm}$ situation when someone is buried

2a begrafenis*

dispute

1 a difficulty

lam difficulty because they didn't like each other *

1sm thing because they didn't like each other

2a geschil"

\section{courtcase}

1 a tribunal

1 am tribunal in which a judge was necessary

$1 \mathrm{sm}$ situation in which a judge was necessary

2a right-business

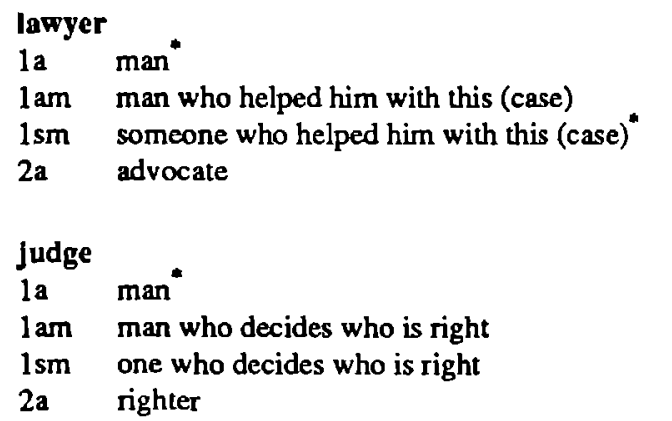


drIII

la tool

Iam tool with which you make holes in the wall

$1 \mathrm{sm}$ thing with which you make holes in the wall

$2 \mathrm{a}$ bore

* CpS marked with an asterisk were not used by the subjocts, but were made up for the purpose of this experiment. 


\section{Summary}

This thesis reports the results of an investigation into the use of lexical compensatory strategies (CpS) by Dutch learners of English. Thus, it deals with the strategies speakers use to solve lexical problems when communicating in a foreign language (L2). The following three research questions were addressed:

1. what is the relationship between the leamers' L2 proficiency and their use of $\mathrm{CpS}$ ?

2. what is the relationship between the use of CpS in L1 (first language) and L2?

3. what is the relative effectiveness of different CpS types?

The first four chapters of this thesis are largely theoretical. Chapter 1 describes the most important developments in second language acquisition research so as to account for the increasing interest in the study of $\mathrm{CpS}$. Subsequently, it is argued that $\mathrm{CpS}$ are strategies of language use which are applied by L1 and L2 speakers alike. This leads to the conclusion that research on $\mathrm{CpS}$ should not be isolated from research on (L1 and L2) communication.

Chapters 2 and 3 contain a survey of the most relevant literature. Chapter 2 comprises a summary of the discussion on definitions and deals with a number of practical and theoretical problems related to existing taxonomies of CpS use. Chapter 3 describes empirical studies of $\mathrm{CpS}$ and in addition discusses some research on the use of referential strategies in the $\mathrm{L} 1$.

In chapter 4 the use of $\mathrm{CpS}$ is integrated into a model of communication (Levelt, 1989). Subsequently, a distinction is made between conceptual and linguistic strategies. Within the class of conceptual strategies a subdivision is made between analytic and holistic strategies, while linguistic strategies are subdivided into morphological creativity and transfer. Each of these four CpS types can be described in terms of Levelt's model, which suggests the new taxonomy is psychologically plausible. Chapter 4 ends with a discussion of Grice's cooperative principle, the principle of economy and certain factors which affect communication. These principles and factors, it will be shown, also play an important role in the choice of $\mathrm{CpS}$.

Chapters 5,6 and 7 relate to the methods of data-collection and data-processing. Chapter 5 contains a motivation of the choice of our three subject groups, which consisted of 15 second-year university students of English, $155-V W O$ pupils and $153-V W O$ pupils respectively. In addition, the four tasks which were used to elicit $\mathrm{CpS}$ are discussed. They comprised the naming or describing of concrete objects (task I) and abstract figures (task II), a Dutch - English story retell task (task III) and an interview with a native speaker of English (task IV). 
Chapter 6 goes into the procedure which was followed to identify CpS. In all tasks CpS were located on the basis of problem indicators like pauses, a rising intonation and remarks like "what's it called again". To facilitate the identification of $\mathrm{CpS}$ in the story retell task and the oral interview, retrospective comments were collected from each of the subjects immediately after they had carried out these tasks. As a result, the reliability of the identification method was considerably increased.

The coding system which was used to classify the $\mathrm{CpS}$ contained in our data is discussed in chapter 7. Besides the four CpS types mentioned above, this system also captures information about the realization of $\mathrm{CpS}$.

Chapters 8,9 and 10 report the results of the project with respect to the three research questions specified above. In chapter 8 it appears that the number of $\mathrm{CpS}$ used by the subjects in tasks I, III and IV is related to their L2 proficiency level. As expected, the least proficient subjects use most CpS. The type of CpS used proved to be largely task-related, however. In task I the subjects predominantly used analytic strategies while in task III, and particularly in task IV, they also used many holistic strategies and transfer strategies.

The task-related variation in the use of $\mathrm{CpS}$ can be explained in terms of Grice's cooperative principle and the principle of economy. In general, the subjects attempted to use $\mathrm{CpS}$ that were both effective (in the context) and required minimal processing effort.

Chapter 9 compares the subjects' use of referential strategies in the Dutch and English versions of task II (the abstract figure description task). From this comparison it can be concluded that $\mathrm{L} 1$ and $\mathrm{L} 2$ referential behaviour are largely similar. Regardless of the language in which the subjects are operating they resort to holistic, partitive or linear strategies. In both language versions holistic strategies are most popular, which is not surprising considering that these strategies require least processing effort, both from the speaker and from the listener. Finally, it is found that the subjects generally attempt to maintain their preferred strategy (as expressed in the L1) in the L2. These findings suggest that $L 2$ speakers transfer their $L 1$ strategic skills to $L 2$ situations.

Chapter 10 deals with the effectiveness of different CpS types. Effectiveness has been established by means of a task which required native speakers of English to guess the meaning of $\mathrm{CpS}$. The results of this part of the Nijmegen project indicate that combinations of holistic and analytic strategies are most, and holistic strategies are least comprehensible. At the same time, however, it must be concluded that it is not really sensible to speak of more or less effective $\mathrm{CpS}$ types. It appears that the comprehensibility of a particular $\mathrm{CpS}$ depends largely on the context in which it is used.

In the eleventh and last chapter of this thesis the research project under consideration is evaluated. A general discussion of the results confirms the correctness of our initial assumptions that research on CpS use should be integrated into the study of communication and that there are no essential 
differences in L1 and L2 speakers' use of CpS. The practical implication of these conclusions for the foreign language classroom is that $\mathrm{CpS}$ use need not be taught, since $\mathrm{L} 2$ leamers are able to exploit the strategic competence which they developed as children leaming their L1. Still, it may well be useful to encourage $\mathrm{L} 2$ leamers to use $\mathrm{CpS}$, since this may improve their motivation to communicate in, and hence, to leam the L2. Chapter 11 finishes with some suggestions for further research. 


\section{Samenvatting}

Dit proefschrift rapporteert over een onderzock naar het gebruik van lexicale compensatiestrategieën $(\mathrm{CpS})$ door Nederlandse leerders van het Engels. Het handelt, met andere woorden, over de strategieën die gebruikt worden om woordproblemen in een vreemde taal (T2) op te lossen. Daarbij staan de volgende drie vragen centraal:

1. wat is de relatie tussen het gebruik van $\mathrm{CpS}$ en het $\mathrm{T} 2$ vaardighcidsniveau van de leerders?

2. is het gebruik van $\mathrm{CpS}$ in de $\mathrm{T} 2$ vergelijkbaar met het gebruik van dergelijke strategieën in de moedertaal (T1)?

3. wat is de relatieve doeltreffendheid van de verschillende CpS types?

De eerste vier hoofdstukken van het proefschrift zijn vooral theoretisch van aard. In hoofdstuk 1 worden de belangrijkste ontwikkelingen in het tweede-taalverwervingsonderzoek geschetst ter verklaring van de groeiende belangstelling voor de studie van CpS. Vervolgens wordt beargumenteerd dat CpS taalgebruiksstrategieën zijn die zowel door T1 als T2 sprekers benut worden. Hieruit wordt de conclusie getrokken dat onderzoek naar $\mathrm{CpS}$ niet los gezien kan worden van onderzoek naar (T1 én T2) communicatie.

In de twee daaropvolgende hoofdstukken wordt een overzicht gegeven van de meest relevante literatuur. Hoofdstuk 2 bevat een samenvatting van de discussie over definities van $\mathrm{CpS}$ en bespreekt een aantal praktische en theoretische problemen met betrekking tot enkele gangbare taxonomieën van $\mathrm{CpS}$. Hoofdstuk 3 beschrijft empirisch onderzoek naar $\mathrm{CpS}$ en gaat bovendien in op een aantal studies naar het gebruik van referentiële strategieën in de T1.

In hoofdstuk 4 wordt het gebruik van CpS toegelicht aan de hand van een communicatiemodel (Levelt, 1989). Vervolgens wordt een onderscheid gemaakt tussen conceptuele en linguistische strategieën, die op hun beurt weer worden onderscheiden in analytische en holistische strategieèn en morfologische creativiteit en transfer. Ieder van deze vier $\mathrm{CpS}$ types kan in termen van Levelts model beschreven worden, wat betekent dat men aan deze nieuwe taxonomie psychologische plausibiliteit toe mag schrijven. Hoofdstuk 4 besluit met een bespreking van Grice's cooperative principle, het principle of economy en enige factoren die van invloed zijn op communicatie. Naar zal blijken spelen deze principes en factoren ook een belangrijke rol bij het gebruik van $\mathrm{CpS}$.

De hoofdstukken 5, 6 en 7 hebben betrekking op de wijze van dataverzameling en -verwerking. In hoofdstuk 5 wordt de keuze van de proefpersonen, 15 tweedejaars studenten Engels, 15 5-VWO leerlingen en 15 3-VWO leerlingen, toegelicht. Daamaast worden de taken besproken. Deze 
behelsden het in het Engels benoemen of beschrijven van concrete voorwerpen (taak I) en abstracte figuren (taak II), het in het Engels navertellen van vier korte, in het Nederlands gestelde verhaaltjes (taak III) en het voeren van een 15-minuten-durend gesprek met een moedertaalspreekster van het Engels (taak IV).

Hoofdstuk 6 gaat in op de identificatieprocedure. In alle taken werden $\mathrm{CpS}$ gelocaliseerd aan de hand van probleemaanduidende verschijnselen zoals pauzes, vragende intonatie en opmerkingen zoals "hoe heet dat nou". Daamaast werd in de taken III en IV gebruik gemaakt van retrospectief commentaar van de proefpersonen. Op deze manier werd de betrouwbaarheid van de identificatieprocedure aanzienlijk vergroot.

Het codeersysteem dat gebruikt is om de geidentificeerde $\mathrm{CpS}$ te classificeren wordt besproken in hoofdstuk 7. Naast de al genoemde CpS types, bevat dit systeem ook informatie over de realisatie van deze $\mathrm{CpS}$ types.

In de hoofdstukken 8, 9 en 10 worden de resultaten gerapporteerd met betrekking tot de drie genoemde onderzoeksvragen. In hoofdstuk 8 blijkt allereerst dat het aantal CpS dat door de proefpersonen in de taken I, III en IV gebruikt wordt, afhankelijk is van hun T2-vaardigheidsniveau. Zoals verwacht gebruiken de minst gevorderde leerders de meeste $\mathrm{CpS}$. De keuze van bepaalde types CpS blijkt echter vooral afhankelijk te zijn van de taakstelling. In taak I gebruiken de proefpersonen overwegend analytische strategieën, terwijl ze in taak III, en vooral in taak IV, naast analytische strategieën ook veel holistische strategieèn en transferstrategieën gebruiken.

De taakafhankelijke variatie in CpS keuze kan verklaard worden in termen van Grice's cooperative principle en het principle of economy. Over het algemeen proberen de proefpersonen $\mathrm{CpS}$ te gebruiken die tegelijkertijd effectief zijn (binnen de context) en een minimale hoeveelheid inspanning vergen.

In hoofdstuk 9 wordt het gebruik van referentièle strategieèn in de Nederlandse en Engelse versies van taak II (het beschrijven van abstracte figuren) vergeleken. Deze vergelijking leidt tot de conclusie dat er grote overeenkomsten zijn tussen referentieel gedrag in de T1 en de T2. Zowel in het Nederlands als in het Engels maken de proefpersonen gebruik van holistische, partitieve en lineaire strategieën. In beide talen zijn holistische strategieën het meest populair, iets wat niet verwonderlijk is gezien het feit dat deze strategieèn zowel van de spreker als van de luisteraar de minste inspanning vragen. Tenslotte wordt gevonden dat de proefpersonen veelal proberen die strategie waaraan ze in de $\mathrm{T} 1$ de voorkeur geven ook in de $\mathrm{T} 2$ te gebruiken. Deze resultaten wijzen erop dat $\mathrm{T} 2$ sprekers in staat zijn de strategische vaardigheden die ze in de $\mathrm{T} 1$ ontwikkeld hebben over te dragen naar T2 situaties.

Hoofdstuk 10 behandelt de effectiviteit van de verschillende CpS types. Deze werd vastgesteld met behulp van een taak die moedertaalsprekers van het 
Engels liet raden naar de betekenis van een aantal CpS. De resultaten van dit deel van het onderzoek tonen aan dat combinaties van holistische en analytische strategieën het meest, en holistische strategieën het minst begrijpelijk zijn. Tegelijkertijd moest echter geconcludeerd worden dat het niet echt zinnig is om te spreken van meer of minder effectieve CpS types. De begrijpelijkheid van een bepaalde $\mathrm{CpS}$ bleek voor een groot deel afhankelijk te zijn van de context waarin deze gebruikt was.

In het elfde en laatste hoofdstuk van dit proefschrift wordt het hier gerapporteerde onderzoek geëvalueerd. Een algemene discussie van de resultaten bevestigt de juistheid van het uitgangspunt dat onderzoek naar CpS gerelateerd moet worden aan onderzoek naar communicatie. Ook de aanname dat T1 en T2 sprekers niet wezenlijk verschillen in hun gebruik van $\mathrm{CpS}$ houdt stand. De praktische implicatic van deze conclusies is dat docenten in de moderne vreemde talen hun leerlingen niet hoeven te onderrichten in het gebruik van $\mathrm{CpS}$, aangezien $\mathrm{T} 2$ leerders in staat zijn gebruik te maken van de strategische vaardigheden die zij zich als kinderen eigen gemaakt hebben bij het leren van hun moedertaal. Overigens neemt dit niet weg dat het nuttig kan zijn $\mathrm{T} 2$ leerders aan te moedigen $\mathrm{CpS}$ te gebruiken. Doordat ze met behulp van $\mathrm{CpS}$ veel gemakkelijker kunnen communiceren in de $\mathrm{T} 2$ zal hun motivatie om de T2 te leren naar alle waarschijnlijkheid toenemen. Hoofdstuk 11 besluit met enkele aanbevelingen voor verder onderzoek. 


\section{Curriculum Vitae}

Nanda Poulisse was bom in Kerkdriel on August 11, 1958. In 1976 she received her Gymnasium A diploma from the Jeroen Bosch College in 's-Hertogenbosch and began her studies in English Language and Literature at the University of Nijmegen. Specializing in Modem English Linguistics she graduated (cum laude) from this University in 1982, having spent the academic year 1980-1981 at the University of Edinburgh. After graduation she taught English for a year at the Pius X College in Almelo. In November 1983 she was appointed by the University of Nijmegen to carry out the research project on which this thesis is based. She is currently (and temporarily) working at the same University as a teacher/researcher in the Department of Applied Linguistics. 




\section{Stellingen}

behorende bij het proefschrift The Use of Compensatory Strategies by Dutch Learners of English, te verdedigen op 27 juni 1989 door W. M. Poulisse

1. Onderzoek naar het gcbruik van communicatiestrategieën heeft zich tot nu toe te zcer gcricht op tweede-taalleerders en heeft te weinig geprofiteerd van de bevindingen uit onderzoek naar het gebruik van soortgelijke strategieën in de cerste taal.

2. De effectiviteit van compensatiestrategieèn is afhankelijk van de context waarin deze gebruikt worden (dit proefschrift). Onderzoek naar de effectiviteit van verschillende compensatiestrategie-types is derhalve niet direct relevant voor het onderwijs in de moderne vreemde talen.

3. Zolang communicatie nog een menselijke aangelegenheid is, is iedere poging een communicatiemodel met voorspellende waarde te ontwikkelen gedoemd te mislukken.

4. Bij het maken van een keuze uit de door de Nederlandse Taalunie voorgestelde altematieve spellingregelingen voor werkwoordsvormen dient in overweging genomen te worden dat een spellingwijze waarbij de regel van gelijkvormigheid uitsluitend wordt toegepast op een deel van de regelmatige (zwakke) werkwoorden, waardoor vormen ontstaan als het gebeurd, naar analogie van het gebeurde en het is gebeurd (zie Geerts et al., 1988, Voorzetten 20. Rapport van de Werkgroep ad hoc Spelling: 165), erg moeilijk te hanteren zal zijn voor hen die het Nederlands als tweede en/of vreemde taal pogen te leren.

5. De toenemende tendentie om de rapportage van statistische analyses te beperken tot summiere aanduidingen van de waarde van een toetsingsgrootheid en de desbetreffende overschrijdingskans, ten detrimente van facetten van beschrijvende statistiek en onderzoeksopzet, degradcert deze rapportage tot een oncontrolcerbaar ritueel en berooft daarmee de statistiek van haar belangrijkste deugd: overtuigingskracht.

6. Een van de voordelen van grote gezinnen is dat de ouders zich minder intensief met de opvoeding van hun kinderen plegen te bemoeien. 
7. Het verenigingsleven zou er mee gebaat zijn als verenigingen onderling overeen zouden komen de duur van een lidmaatschap op minimaal een jaar, c.q. een seizoen, te stellen.

8. De huidige opstelling bij promoties aan de K.U. Nijmegen, waarin aan paranimfen elk zicht op de promovendus en de corona ontnomen wordt, maakt het deze niet alleen onmogelijk hun feitelijke functie - het bijstaan van de promovendus - naar behoren uit te oefenen, maar maakt het voor hen ook weinig aantrekkelijk deze functie te bekleden. 

